FILIPE FABIAN BUSCARIOLO

ESTUDO DE DIFERENTES TIPOS DE SOLO EM TÚNEL DE VENTO ATRAVÉS DE SIMULAÇÃO NUMÉRICA.

São Paulo

2009 
FILIPE FABIAN BUSCARIOLO

\section{ESTUDO DE DIFERENTES TIPOS DE SOLO EM TÚNEL DE VENTO ATRAVÉS DE SIMULAÇÃO NUMÉRICA.}

Dissertação apresentada à Escola Politécnica da Universidade de São Paulo para obtenção do Título de Mestre em Engenharia.

Área de Concentração:

Engenharia Mecânica

Orientador:

Prof. Dr. Antonio Luis de Campos

Mariani

São Paulo 


\section{FICHA CATALOGRÁFICA}

\section{Buscariolo, Filipe Fabian}

Estudo de diferentes tipos de solo em túnel de vento através de simulação numérica / F.F. Buscariolo. São Paulo, 2009 $125 \mathrm{p}$.

Dissertação (Mestrado) - Escola Politécnica da Universidade de São Paulo. Departamento de Engenharia Mecânica.

1. Túneis de vento (simulação computacional)

2. Aerodinâmica 3. Método dos elementos finitos I. Universidade de São Paulo. Escola Politécnica Departamento de Engenharia Mecânica II. t. 
A toda minha família, amigos e avó (in memorium) com muito carinho. 


\section{AGRADECIMENTOS}

Em primeiro lugar gostaria de agradecer aos meus pais, Vera e Celso e aos meus irmãos, Fábio e Fernanda, pela ajuda e apoio ao longo do curso. Além disso, minha namorada, Taluana, aos meus amigos mais próximos, principalmente Marcelo Massad por toda ajuda na impressão, e minha família por todo apoio.

Ao amigo e orientador Prof. Dr. Antonio Luis de Campos Mariani pela amizade, apoio, orientação e oportunidade de desenvolver este trabalho, em conjunto com outros colegas, tanto da Escola Politécnica quanto do IPT.

À GENERAL MOTORS DO BRASIL, especialmente a todo 0 departamento de Cálculo Estrutural - CAE da Engenharia do Produto, especialmente aos chefes, engenheiros Roberto Pereira Ramos, Eduardo Almeida e Attila Budavari, pela oportunidade de desenvolver um trabalho de pesquisa relacionado aos assuntos da empresa e pelo apoio que me possibilitou concluir o mestrado paralelamente às atividades da empresa. Aos amigos, engenheiros Leonardo José Della Volpe e Júlio César Lelis Alves, por toda experiência, ajuda e aprendizado na área de CFD e aerodinâmica, além de um agradecimento especial ao amigo, engenheiro Nelson Quim, por toda ajuda nas áreas de CFD, aerodinâmica, programação e experiências com o mestrado. Ao amigo, engenheiro Håkan Danielsson, da SAAB AUTOMOTIVE, por toda ajuda e conhecimento em túneis de vento. Ao engenheiro Frank Werner da OPEL por toda ajuda.

A todos que, direta ou indiretamente, colaboraram na execução deste trabalho. 


\section{SUMÁRIO}

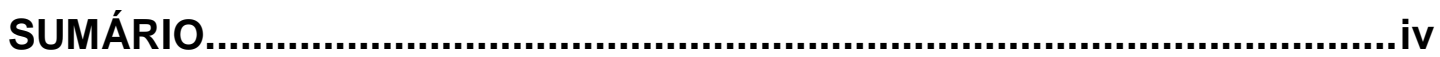

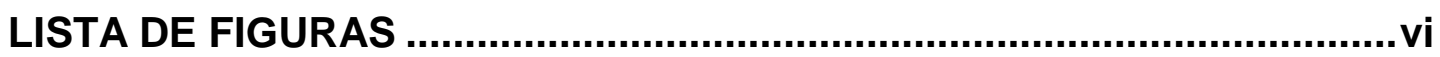

LISTA DE TABELAS .........................................................................ii

LISTA DE ABREVIATURAS E SIGLAS..................................................

LISTA DE SÍMBOLOS ........................................................................

SÍMBOLOS GREGOS.............................................................................

RESUMO

ABSTRACT

1. INTRODUÇÃO

2. OBJETIVOS

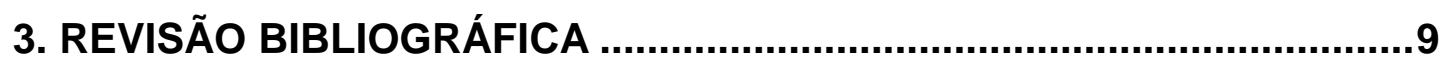

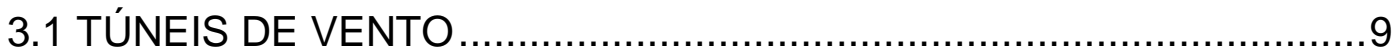

3.1.1 Tipos e classificações de túneis de vento .................................12

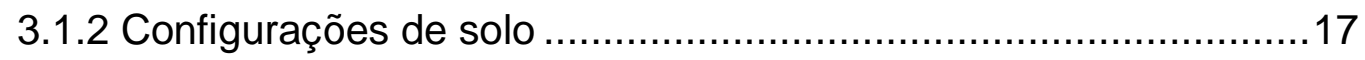

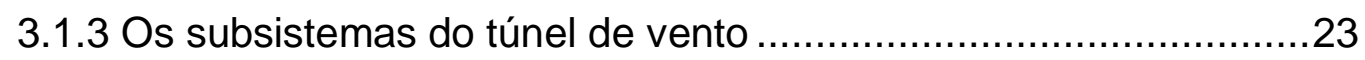

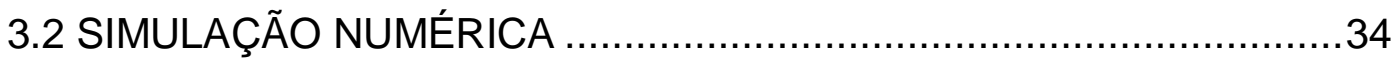

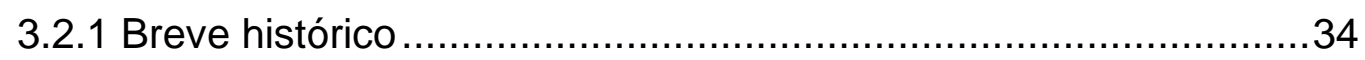

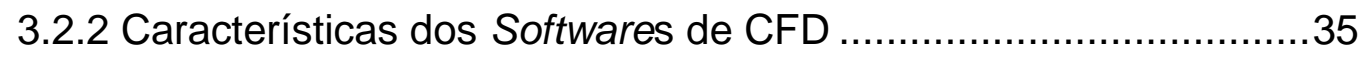

3.2.3 Trabalhos envolvendo simulação numérica de escoamentos ......36

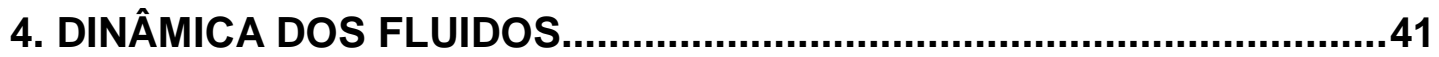

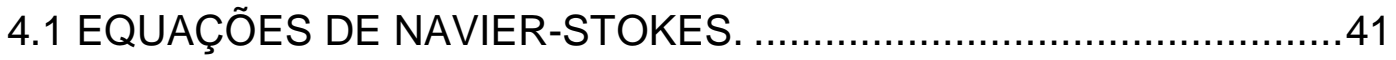

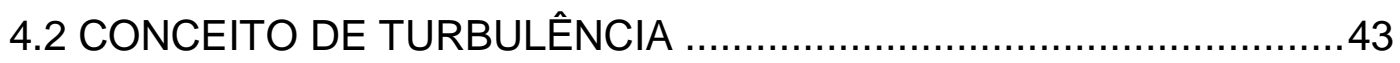

4.2.1 Equacionamento da turbulência............................................... 44

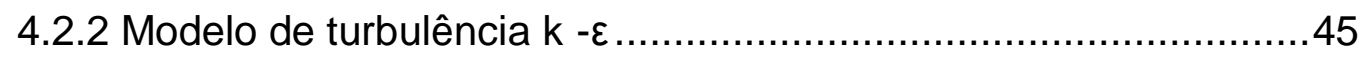

4.2.3 Condições de contorno do modelo de turbulência $k-\varepsilon \ldots \ldots \ldots \ldots \ldots \ldots . . . .47$

4.3 DESCRIÇÃO DA FUNÇÃO DE PAREDE.......................................48

5. MODELAGEM NUMÉRICA E ENSAIOS EXPERIMENTAIS DE

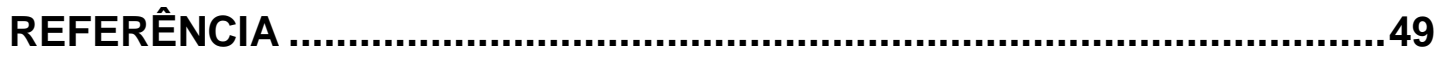

5.1 CARACTERIZAÇÃO DO TÚNEL DE VENTO ...................................49 
5.2 CARACTERIZAÇÃO DO VEÍCULO E ENSAIO EXPERIMENTAL DE PROTÓTIPO EM TÚNEL DE VENTO …...............................................50

5.3 OS MÉTODOS NUMÉRICOS E SUA APLICAÇÃO.............................52

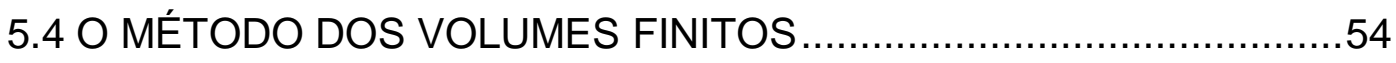

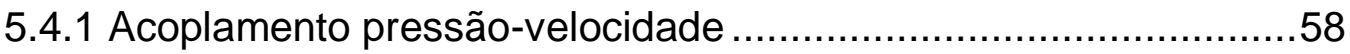

5.4.2 Determinação do Coeficiente de Arrasto ………………….........60

5.5 GERAÇÃO DE MALHA

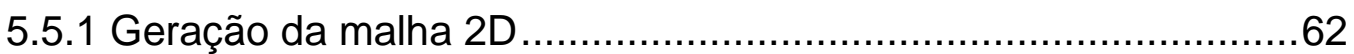

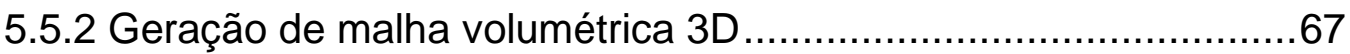

5.6 SIMULAÇÃO VIRTUAL DO PROTÓTIPO EM TÚNEL DE VENTO ....70

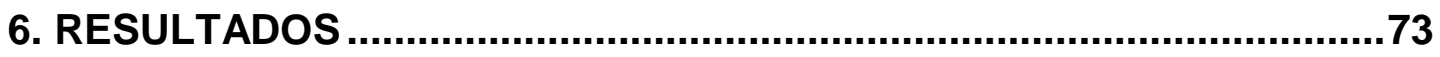

6.1 ESTUDO SOBRE DIMENSÕES DOS ELEMENTOS DE MALHA ......73

6.2 ESTUDO AERODINÂMICO DE UMA RODA ISOLADA .....................81

6.3 SIMULAÇÃO COM PISO FIXO NA SEÇÃO DE TESTES …...............86

6.4 SIMULAÇÃO COM PLATAFORMA ELEVADA NA SEÇÃO DE TESTES

6.5 SIMULAÇÃO COM ESTEIRA ROLANTE NA SEÇÃO DE TESTES ...95

7. CONCLUSÕES

7.1 ANÁLISE DE PARÂMETROS E CONDIÇÕES DE CONTORNO NA SIMULAÇÃO NUMÉRICA 101

7.2 ANÁLISE COMPARATIVA PARA ALTERNATIVAS DE PISO NA SEÇÃO DE TESTES 103

7.3 SUGESTÃO PARA NOVOS TRABALHOS. 109

8. REFERÊNCIAS BIBLIOGRÁFICAS 110 ANEXOS 116

ANEXO A - CONFIGURAÇÃO DO SOFTWARE FLUENT® 117 ANEXO B - SCRIPT PARA SIMULAÇÃO EM CLUSTER. 130 


\section{LISTA DE FIGURAS}

Figura 1.1 - Túnel de Vento do CTA em São José dos Campos (DEFESABR, 2008)

Figura 1.2 - Túnel de Vento de Camada Limite Atmosférica do IPT, localizado na Cidade Universitária (USP), em São Paulo (SACOMANO FILHO, 2008). 3

Figura 1.3 -Exemplo de linhas de corrente obtidas para o escoamento com a aplicação de uma análise virtual de CFD em um veículo de competição (FLUENT, 2003)

Figura 3.1 - Os estudos na aerodinâmica veicular: a) determinação de forças e momentos; b) sistema de arrefecimento veicular; c) fluxo de ar sobre o veículo; d) fluxo de ar interno à cabine do veículo.

Figura 3.2 - Alteração do coeficiente de arrasto para diferentes tipos de disposição do radiador (BUCHHEIM,1983.).

Figura 3.3 - Coeficiente de arrasto $(C d)$ de um carro sedan esporte com e sem aberturas frontais (RENN. E GILHAUS, 1986.)

Figura 3.4 - Túnel de vento de circuito aberto. (SACOMANO FILHO, 2008) 14 Figura 3.5 - Túnel de vento FKFS (Forschungsinstitut für Kraftfahrwesen und Fahrzeugmotoren Stuttgart), na Alemanha, de circuito aberto.(FKFS, 2009).

Figura 3.6 - Túnel de vento de circuito fechado. (SACOMANO FILHO, 2008)

Figura 3.7 - Túnel de vento DNW (Deutsch-Niederisch Windkanal) de circuito fechado, localizado na Holanda.(DNW, 2009).

Figura 3.8 - Figura ilustrativa dos componentes internos do túnel de vento de

circuito fechado para ensaio aerodinâmico em veículos automotivos. 16

Figura 3.9 - Figura ilustrativa dos tipos de solo em túneis automotivos. (A) Plataforma Elevada; (B) - Injeção de ar; (C) - Esteira rolante; (D) - Sucção distribuída (HUCHO, 1998)

Figura 3.10 - Esquema de uma plataforma elevada montada em um túnel de vento.(KATZ, 1995) 
Figura 3.11 - Detalhe do piso fixo de um túnel de vento com sucção. (A2WT, 2009)

Figura 3.12 - Exemplo de uma esteira rolante, localizada na seção de testes do túnel de vento automotivo Windshear, nos EUA. (WINDSHEAR, 2008).. 20 Figura 3.13 - Veículo montado sob sistema de esteira e cilindros rotativos. (QUIM, 2007)

Figura 3.14 - Sistema T-Belt, localizado no túnel de vento da Pininfarina. (PININFARINA, 2008)

Figura 3.15 - Detalhe do sistema de sucção na entrada da seção de testes do túnel de vento. (DNW, 2009)

Figura 3.16 - Figura ilustrativa dos principais subsistemas de um túnel de vento nas proximidades da seção de testes.

Figura 3.17 - Túnel de vento com alta contração da Universidade Purdue. (PURDUE, 2009)

Figura 3.18 - Detalhe da contração de um túnel de vento localizado na Universidade Purdue. (PURDUE, 2009).

Figura 3.19 - Detalhe da seção de teste de um túnel de vento da Honda F1 (HONDA WIND TUNNEL, 2008).

Figura 3.20 - Túnel de vento de seção de testes aberta. (MAIABARA, 2009)

Figura 3.21 - Túnel de vento de seção de testes fechada. (PURDUE, 2009)

Figura 3.22 - Efeito da fronteira lateral no campo de escoamento: a) efeito de contração em um túnel com seção de testes fechada, b) expansão em um túnel com seção de testes aberta. (HUCHO, 1998)

Figura 3.23 - Balança aerodinâmica do túnel de vento Windshear, localizado na Carolina do Norte, EUA.(WINDSHEAR, 2008) 30

Figura 3.24- Detalhe da tela de proteção de um túnel de vento.(PURDUE, 2009)

Figura 3.25 - Colméia retificadora na entrada do túnel de vento da NASA (NASA, 2008) 
Figura 3.26 - Ventilador do túnel de vento da General Motors, em Warren.(RELATÓRIO DE ENSAIO DA CAMINHONETE, 2007)

Figura 3.27 - Guias de ar, localizadas após o ventilador do túnel de vento Windshear, na Carolina do Norte, EUA.(WINDSHEAR, 2008).

Figura 3.28 - Linha de fluxo, em torno de um carro de Fórmula 1, calculadas por um programa de CFD. (FLUENT, 2003).

Figura 3.29 - a) Separação de fluxo e formação do vórtice de ferradura para rodas em condição estacionária Elofsson (2002) b) Deslocamento do ponto de estagnação e alteração da esteira de vórtices devido à rotação da roda Cogotti (1983). c) Redução do coeficiente de arrasto para roda em movimento Cogotti (1983)

Figura 4.1 - Condições de contornos aplicadas a um perfil de asa em simulação virtual de túnel de vento (QUIM 2007).

Figura 5.1 - Túnel de Vento da General Motors para testes aerodinâmicos em escala natural de veículos (HUCHO, 1998).

Figura 5.2- Perspectiva do veículo testado e posicionamento do sistema de coordenadas.

Figura 5.3 - Detalhes internos do motor do veículo.

Figura 5.4 - Volume de Controle para ilustrar a discretização das equações de transporte escalar (FLUENT, 2003).

Figura 5.5 - Algoritmo do Método de Solução Segregado.

Figura 5.6 - Etapas de geração de malha 2D pelo algoritmo "Advancing Front"

Figura 5.7 - Criação do novo elemento, escolha inicial.

Figura 5.8 - Exemplo de um elemento com ângulo de distorção "skew" de $22,6^{\circ}$.

Figura 5.9 - Malha superficial 2D no veículo.

Figura 5.10 - Detalhe da parte traseira do veículo, com malha superficial 2D.

Figura 5.11 - Vista superior da malha superficial 2D no veículo. 66

Figura 5.12 - Detalhe do cofre do motor, com detalhamento do motor e seus componentes. 66 
Figura 5.13 - Detalhe da parte inferior do veículo, com detalhamento de seus componentes.

Figura 5.14 - a) Tetraedro de baixa qualidade; b) Tetraedro de ótima qualidade.

Figura 5.15- Corte em y $=0 \mathrm{~m}$ mostrando a malha volumétrica gerada.

Figura 5.16- Corte em y $=0 \mathrm{~m}$, mostrando a malha volumétrica gerada....... 70

Figura 5.17 - Figura da seção de testes do túnel de vento com piso fixo e veículo colocado sobre ele.

Figura 6.1 - Dimensões dos elementos da malha superficial na grade do pára-choque adotadas no trabalho de Quim (2007).

Figura 6.2 - Dimensões de elementos para a malha superficial, na região traseira da caminhonete utilizada neste trabalho.

Figura 6.3 - Número de elementos volumétricos gerados em função da dimensão das células 2D.

Figura 6.4 - Tempo de processamento para a geração da malha volumétrica 3D em função da dimensão do elemento 2D .77

Figura 6.5 - Tempo de processamento da simulação pelo FLUENT® em função da dimensão do elemento 2D. 77

Figura 6.6 - Coeficientes de arrasto para ensaio experimental e simulações numéricas em função da dimensão do elemento 2D 78

Figura 6.7 - Valores de y+ na malha próxima à superfície do veículo em função das dimensões dos elementos 2D.

Figura 6.8 - Histograma de distribuição de quantidade de células em função do valor do Skewness.

Figura 6.9 - Vista lateral da roda com pneu 175/70R14 e indicação dos eixos adotados

Figura 6.10 - Vista superior da roda com pneu 175/70R14 e indicação dos eixos adotados

Figura 6.11 - Condições analisadas: a) roda fixa b) roda em rotação. 82

Figura 6.12 - Vista em perspectiva da roda com piso fixo e pneu 175/70R14; visualização dos vetores velocidade. 
Figura 6.13 - Vista em perspectiva da roda com piso móvel e pneu 175/70R14; visualização dos vetores velocidade.

Figura 6.14 - a) Estudo de Elofsson (2002) com roda parada b) Estudo de Cogotti (1983) com roda em movimento c) Linha de corrente sob roda estacionária com formação do vórtice ferradura. d) Linha de corrente sob roda em movimento resultando o desprendimento de vórtice na região superior.

Figura 6.15 - Linhas de corrente no em torno do veículo, na condição de piso fixo.

Figura 6.16 - Linhas de corrente em planos longitudinais em relação ao veículo com solo fixo

Figura 6.17 - Distribuição de velocidades no plano longitudinal passando pelo centro da roda.

Figura 6.18 - Distribuição de velocidades em um plano longitudinal passando pelo centro do veículo

Figura 6.19 - Distribuição de pressões no plano próximo à roda dianteira do veículo

Figura 6.20 - Distribuição de pressões em um plano longitudinal passando pelo centro do veículo

Figura 6.21 - Detalhe da zona turbulenta junto à roda traseira do veículo ... 90 Figura 6.22 - Esquema da seção de testes do túnel de vento com plataforma elevada e veículo sobre ela.

Figura 6.23 - Linhas de corrente em planos longitudinais em relação ao veículo com plataforma elevada

Figura 6.24 - Distribuição de velocidades no plano central da roda do veículo sobre uma plataforma elevada.

Figura 6.25 - Distribuição de velocidades em um plano longitudinal passando pelo centro do veículo sobre uma plataforma elevada

Figura 6.26 - Distribuição de pressões no plano próximo à roda dianteira do veículo sobre uma plataforma elevada 94

Figura 6.27 - Distribuição de pressões em um plano longitudinal passando pelo centro do veículo sobre uma plataforma elevada 
Figura 6.28 - Detalhe da zona turbulenta junto a roda traseira do veículo sobre uma plataforma elevada

Figura 6.29 - Esquema da seção de testes do túnel de vento com a representação da esteira rolante e veículo colocado sobre ela. 96

Figura 6.30 - Linhas de corrente em planos longitudinais em relação ao veículo com esteira rolante

Figura 6.31 - Distribuição de velocidades no plano central da roda do veículo com esteira rolante

Figura 6.32 - Distribuição de velocidades em um plano longitudinal passando pelo centro do veículo com esteira rolante 98

Figura 6.33 - Distribuição de pressões no plano próximo à roda do veículo com esteira rolante 99

Figura 6.34 - Distribuição de pressões em um plano longitudinal passando pelo centro do veículo com esteira rolante .99

Figura 6.35 - Detalhe da zona turbulenta junto a roda traseira do veículo com esteira rolante

Figura 7.1 - Gráfico comparativo do arrasto do veículo ensaiado, obtido em teste e simulação virtual. 104

Figura 7.2 - Gráfico comparativo do arrasto do veículo, obtido nos três tipo de solo ensaiados virtualmente.

Figura 7.3 - Campos de velocidade no plano central à roda dianteira. ....... 105

Figura 7.4 - Campos de pressão no plano central à roda dianteira.............. 106

Figura 7.5 - Campos de velocidade no plano central à roda traseira. .......... 107

Figura A.1 - Interface do software FLUENT®.

Figura A.2 - Função de escala, dada em milímetros, no menu Grid, do FLUENT®.

Figura A.3 - Função Define - Models do FLUENT®, onde o tipo de simulação será selecionada.

Figura A.4 - Menu Solver, onde os parâmetros são mantidos padrão do software, com solução do tipo Steady State no software FLUENT®.

Figura A.5 - Menu Viscous Model, onde os parâmetros de turbulência k- $\varepsilon$ serão configurados. 
Figura A.6 - Menu Materials, onde o ar é colocado como elemento fluido do sistema a ser resolvido.

Figura A.7 - Condições de contorno do túnel de vento.

Figura A.8 - Configuração das condições de contorno da simulação no software.

Figura A.9 - Configuração de condições de velocidade na entrada do túnel de vento

Figura A.10 - Configuração das condições na saída do túnel de vento

Figura A.11 - Configuração do software para cálculo do arrasto

Figura A.12 - Configuração do valores necessário para o cálculo. 126

Figura A.13 - Função para cálculo de área projetada, no próprio software FLUENT®.

Figura A.14 - Projeção do veículo ensaiado no mesmo plano da entrada da seção de teste do túnel de vento para cálculo de sua área frontal pelo software FLUENT®

Figura A.15 - Monitoramento dos diversos parâmetros quanto a sua convergência no FLUENT®.

Figura A.16 - Inicialização do fluxo de ar, pela entrada do túnel do FLUENT® 128

Figura A.17 - Gráfico da convergência da simulação. 129 


\section{LISTA DE TABELAS}

Tabela 4.1 - Equações de Navier-Stokes para um fluido Newtoniano e compressível (VERSTEEG E MALALASEKERA, 1995).

Tabela 4.2 - Equações de escoamento turbulento para fluido compressível (VERSTEEG E MALALASEKERA, 1995). 45

Tabela 4.3 - Coeficientes do modelo $k-\varepsilon$ de Turbulência................................... 46

Tabela 5.1 - Principais dimensões do veículo estudado 50

Tabela 5.2 - Parâmetros e configurações para ensaio experimental e simulação numérica 


\section{LISTA DE ABREVIATURAS E SIGLAS}

$\begin{array}{ll}\text { CAD } & \text { Computer Aided Design } \\ \text { CAE } & \text { Computer Aided Engineering } \\ \text { CFD } & \text { Computacional Fluid Dynamics } \\ \text { CTA } & \text { Centro Técnico Aeroespacial } \\ \text { CRFM } & \text { Condenser-Radiator-Fan Module } \\ \text { DNW } & \text { Deutsch-Niederisch Windkanal } \\ \text { F1 } & \text { Fórmula 1 } \\ \text { FKFS } & \text { Forschungsinstitut für Kraftfahrwesen und } \\ & \text { Fahrzeugmotoren Stuttgart } \\ \text { GM } & \text { General Motors } \\ \text { GMB } & \text { General Motors do Brasil } \\ \text { GMNA } & \text { General Motors of North America } \\ \text { HPC } & \text { High Performance Computing } \\ \text { MDF } & \text { Método das Diferenças Finitas } \\ \text { MEF } & \text { Método de Elementos Finitos } \\ \text { MRF } & \text { Multiple Reference Frame } \\ \text { MVF } & \text { Método dos Volumes Finitos } \\ \text { NASA } & \text { National Aeronautics and Space Agency } \\ \text { NS } & \text { Navier-Stokes } \\ \text { RANS } & \text { Reynolds Average Navier-Stokes } \\ \text { SIMPLE } & \text { Semi-Implicity Method for Pressure-Linked Equation } \\ \text { SUV } & \text { Sport Utility Vehicle } \\ \text { UG } & \text { Unigraphics } \\ \text { USP } & \text { Universidade de São Paulo } \\ \text { 2D } & \text { Três Dimensões } \\ \text { 3D } & \end{array}$




\section{LISTA DE SÍMBOLOS}

\begin{tabular}{|c|c|}
\hline$A$ & área \\
\hline$a_{i, j}$ & coeficientes lineares convectivos \\
\hline$C_{a}$ & constante \\
\hline$C_{d}$ & coeficiente de arrasto aerodinâmico \\
\hline$C_{1 \varepsilon}$ & coeficiente empírico do modelo $k$ - $\varepsilon$ de turbulência \\
\hline$C_{2 \varepsilon}$ & coeficiente empírico do modelo $k$ - $\varepsilon$ de turbulência \\
\hline$C_{\mu}$ & coeficiente empírico do modelo $k-\varepsilon$ de turbulência \\
\hline$D$ & diâmetro \\
\hline$d_{f}$ & função da razão da área pelo coeficiente $a_{i, j}$ \\
\hline$E$ & energia \\
\hline$E_{i j}$ & componentes da deformação cisalhante média \\
\hline$E_{w}$ & parâmetro de rugosidade da parede \\
\hline$e_{i j}$ & componente da deformação cisalhante \\
\hline$F$ & força \\
\hline I & intensidade de turbulência \\
\hline$J_{f}$ & função de fluxo de massa \\
\hline$k$ & energia cinética turbulenta \\
\hline$N_{s}$ & número de divisões \\
\hline$p$ & pressão \\
\hline $\bar{p}$ & pressão média \\
\hline$p^{\prime}$ & flutuação da pressão \\
\hline$R$ & raio \\
\hline $\operatorname{Re}$ & número de Reynolds \\
\hline$R e_{c r i t}$ & número de Reynolds crítico \\
\hline$S$ & fonte de energia \\
\hline$t$ & tempo \\
\hline$U$ & velocidade \\
\hline$U_{c}$ & velocidade característic \\
\hline
\end{tabular}




\begin{tabular}{|c|c|}
\hline \multicolumn{2}{|c|}{ coordenadas } \\
\hline$u^{\prime}$ & flutuação da velocidade na direção x \\
\hline $\bar{u}$ & velocidade média na direção x \\
\hline $\bar{u}_{r}$ & campo de velocidade relativa média \\
\hline$\overline{u_{r}^{\prime}}$ & flutuação do campo de velocidade relativa \\
\hline$u_{\tau}$ & velocidade de atrito na parede \\
\hline$u^{+}$ & velocidade na subcamada viscosa da parede \\
\hline$V$ & volume \\
\hline $\mathrm{V}_{\mathrm{c}}$ & volume de controle \\
\hline$\overline{\mathrm{V}}$ & velocidade média relativa do fluido ao longe \\
\hline$v$ & componente da velocidade na direção y \\
\hline $\bar{v}$ & velocidade média na direção y \\
\hline$v^{\prime}$ & flutuação da velocidade na direção y \\
\hline$w$ & componente da velocidade na direção z \\
\hline$w^{\prime}$ & flutuação da velocidade na direção z \\
\hline $\bar{w}$ & velocidade média na direção z \\
\hline $\mathrm{y}$ & medida de distância em relação à parede \\
\hline$y^{+}$ & coordenada na subcamada viscosa da parede \\
\hline
\end{tabular}




\section{SÍMBOLOS GREGOS}

\begin{tabular}{ll}
$\Delta p$ & variação de pressão \\
$\Delta s$ & variação do deslocamento \\
$\Delta t$ & variação do tempo \\
$\delta$ & distância entre os pontos nodais de um elemento triangular \\
$\delta_{m}$ & comprimento mínimo de um elemento triangular \\
$\varepsilon$ & energia cinética turbulenta \\
$\Phi$ & função de dissipação das tensões viscosas \\
$\phi$ & grandeza escalar \\
$\phi^{\prime}$ & flutuação da grandeza escalar \\
$\bar{\phi}$ & grandeza escalar média \\
$\Gamma$ & coeficiente de difusividade \\
$\Lambda_{s}$ & perímetro de uma superfície \\
$\mu$ & viscosidade dinâmica \\
$\mu_{t}$ & viscosidade turbulenta \\
$v$ & viscosidade cinemática \\
$\rho$ & densidade \\
$\tau_{i j}$ & componentes do tensor de tensões \\
$\tau_{w}$ & tensão de cisalhamento na parede \\
$v$ & velocidade superficial \\
\hline & dade angular \\
\hline &
\end{tabular}




\section{RESUMO}

O trabalho aqui apresentado visa estudar diferentes tipos de piso localizados na seção de testes de um túnel de vento e verificar a influência que ocorre em ensaios de automóveis analisando o escoamento entre o veículo e o solo, assim como avaliar alterações no coeficiente de arrasto, utilizando simulações numéricas computacionais. O coeficiente de arrasto de um veículo é uma propriedade aerodinâmica importante e, quanto menor for esse valor, melhor será seu rendimento, além de melhorar o consumo de combustível, item relevante hoje no projeto de novos automóveis. Partindo de um ensaio experimental de uma pequena caminhonete em túnel de vento com piso fixo, um modelo virtual igual é construído e analisado por CFD, nas mesmas condições de teste do ensaio real. A diferença de resultado entre 0 coeficiente de arrasto medido em túnel de vento e o cálculo por simulação é de $0,25 \%$, mostrando que o método de simulação possui grande confiabilidade. Posteriormente, outras duas simulações considerando dois outros tipos de solo: plataforma elevada e esteira rolante são analisadas e apresentaram diferenças de decréscimo valor de arrasto de 0,002 e 0,012 respectivamente, em relação a simulação com piso fixo, mostrando a influência de alterar o tipo do solo na seção de testes do túnel de vento. $O$ comportamento do escoamento de ar é visualizado através de imagens do campo de velocidades e de pressões, sendo caracterizadas a camada limite e regiões de estagnação. Complementarmente, são realizados dois estudos: o primeiro considerou apenas uma roda isolada em condição de piso fixo e com esteira rolante, na mesma seção de testes do túnel de vento, visando medir a influência de mudar tipos de solo, sem utilizar um veículo completo, economizando em processamento e preparação de modelo. O segundo estudo considerou 3 diferentes tamanhos de malha sendo eles 5, 10 e 20 mm e medir a influência disso no resultado do coeficiente de arrasto obtido.

Palavras-chave: Túneis de Vento (simulação computacional); Aerodinâmica; Método dos volumes finitos. 


\begin{abstract}
The work here presented aims to study different types of ground configurations, located at the test section of a wind tunnel and check their influence on the drag coefficient of one car, using only computer simulations. The drag coefficient of a vehicle is one of the most important aerodynamic proprieties, and as low as this drag value can be, the car performance will increase and the fuel consumption will decrease, item which has been persued in new vehicles. Starting from one real wind tunnel test of a small pick-up, with static test section ground, a virtual model was built and tested using CFD, following the same configuration of the real test. The difference between test and simulation results was $0.25 \%$, showing that the methodology here used is reliable. After that, two other types of ground were simulated: elevated plate and moving belt and the results show that drag value decreased 0.002 and 0.012 respectively, compared to the value obtained with static ground simulation.The flow behavior is demonstrated with colored images of the velocity and the pressure fields. As a complement for this work, two other cases were studied: the first one analyzed one isolated wheel in two different types of ground: static and moving belt, at the same wind tunnel test section, aiming to measure the influence of these types of ground, without the need of using a complete car, saving computational and modeling time. The second study shows the influence of mesh size, considering three cases: 5,10 and $20 \mathrm{~mm}$, in order to evaluate the influences of it on drag coefficient results provided by CFD.
\end{abstract}

Keywords: Wind Tunnel (computational simulation), Aerodynamics, Finite Element Method. 


\section{INTRODUÇÃO}

Estudos aerodinâmicos são de grande importância para 0 desenvolvimento de um veículo, em virtude de diversos fatores como sua geometria com linhas modernas, proporcionando uma aparência atrativa, combinada com economia de combustível, menor ruído e fatores ecológicos.

Historicamente, por volta de 1920 ocorreram os primeiros estudos de aerodinâmica aplicados a veículos. Neste período foram feitas as primeiras considerações de que os carros em movimento dissipavam significativa parcela de potência como resultado de sua resistência ao deslocamento contra o ar. Na década de 1930, as montadoras de automóveis começaram a se preocupar com estes efeitos da resistência aerodinâmica, quantificando-os em valores para a força e para o coeficiente de arrasto. Há, então, a intensificação de pesquisas para obter veículos cada vez mais aerodinâmicos. Esse desenvolvimento prossegue até os dias de hoje, com investimentos em estudos e busca de formas geométricas cada vez mais inovadoras, visando principalmente diminuir a citada resistência do veículo no seu deslocamento contra o ar.

No projeto de automóveis, a aerodinâmica é levada em consideração para atender diversos itens de desempenho que, podem ser avaliados a partir de ensaios em túnel de vento. Dentre os quesitos de projeto que são influenciados por aspectos aerodinâmicos, podem ser citados:

- consumo de combustível;

- valor da velocidade final;

- dirigibilidade e estabilidade em altas velocidades;

- arrefecimento de motores e de freios;

- redução do ruído provocado pelo vento;

- ventilação da cabine;

- condicionamento de ar;

- projeto de acessórios montados externamente. 
A questão do consumo de combustível pode ser destacada como uma das importantes preocupações da indústria automobilística. Veículos com formas aerodinâmicas otimizadas possuem menor arrasto e, conseqüentemente, o gasto de combustível é reduzido. Esta redução é apoiada, também, pelo aumento da consciência ecológica e preocupação com a preservação do meio ambiente, evidenciadas pelo surgimento de regulamentações e leis. No Brasil o Conselho Nacional do Meio Ambiente estabeleceu a resolução CONAMA n²299/2001, que impõe certas características aos novos veículos, como taxas controladas de emissões de gases, agredindo o meio ambiente em menor escala, comparados aos veículos antigos.

Uma maneira tradicional de realizar estudos aerodinâmicos é através de ensaios em túneis de vento. Nessas instalações, são possíveis testes para desenvolvimento de aspectos aerodinâmicos de diversos tipos de veículos, desde carros, aviões, trens, bicicletas, visando otimizar suas formas geométricas. Atualmente, as grandes empresas, principalmente automotivas e aeronáuticas, possuem túneis de vento próprios, onde realizam diferentes tipos de ensaio visando melhorar seus produtos e, algumas vezes, alugam estas instalações para outras empresas que não possuem estrutura própria, possibilitando este tipo de desenvolvimento. $\mathrm{Na}$ indústria automotiva, destaca-se o túnel da General Motors em Warren, Michigan, considerado um dos maiores do mundo, segundo Kelly e Schenkel, (1982). No Brasil existem alguns túneis, com destaque para o do CTA, em São José dos Campos e o Túnel de Vento de Camada Limite Atmosférica do Instituto de Pesquisas Tecnológicas do Estado de São Paulo - IPT, localizado no campus Butantã da Universidade de São Paulo, na capital paulista. 


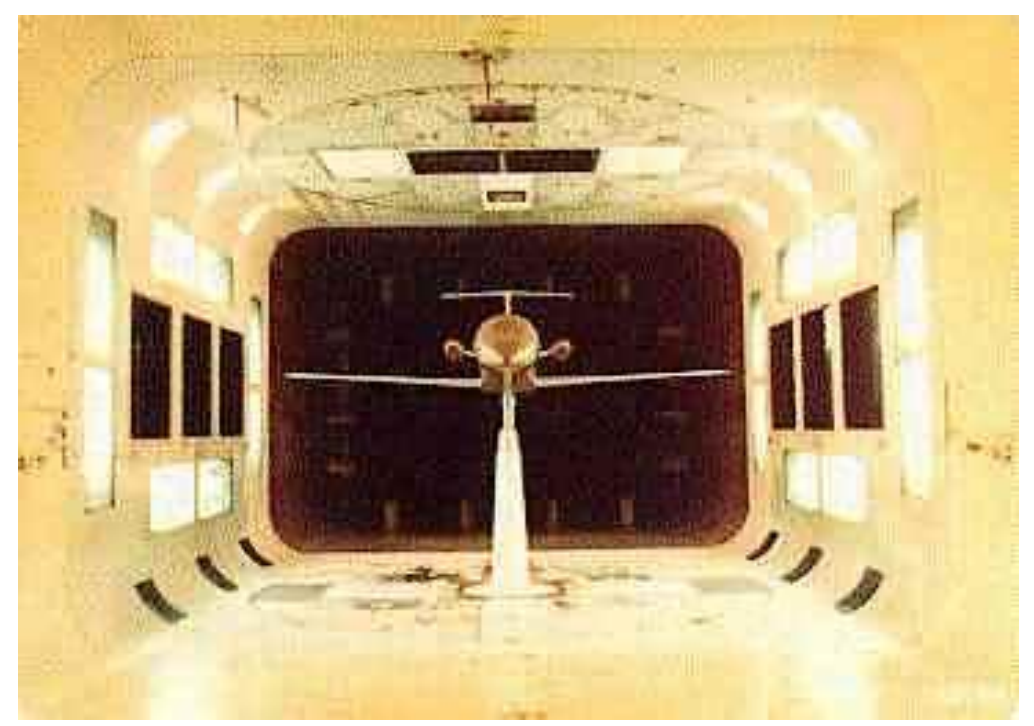

Figura 1.1 - Túnel de Vento do CTA em São José dos Campos (DEFESABR, 2008)

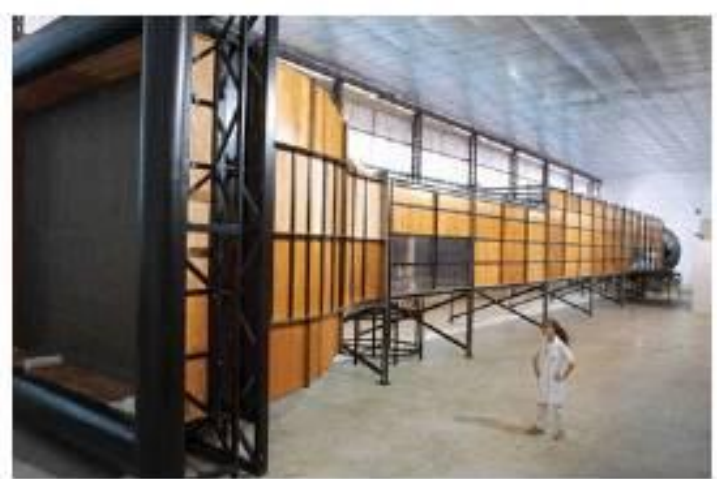

Figura 1.2 - Túnel de Vento de Camada Limite Atmosférica do IPT, localizado na Cidade Universitária (USP), em São Paulo (SACOMANO FILHO, 2008).

O foco do presente trabalho está na solução adotada para o solo do túnel de vento em sua seção de testes. Os túneis de vento podem ter diversas configurações quanto ao solo nesta seção: piso fixo, plataforma elevada, esteira rolante, piso com orifícios para sucção de camada limite, entre outras, que estabelecem diferentes situações para tratar o escoamento de ar na região da interação veículo-solo. As variações destas configurações propiciam uma melhor aproximação com a condição real de operação do veículo. Essa representação do solo do túnel, em se tratando de ensaio de veículos automotivos, é um dos aspectos mais importantes, pois o solo pode exercer influência no valor do arrasto, devido a variações no comportamento da camada limite do escoamento nesta região. Podem também ocorrer 
combinações de uma dada configuração de solo com um sistema de sucção da camada limite, contudo quanto mais complexa a solução escolhida, mais significativo será acréscimo no investimento para construção do túnel.

Neste trabalho são estudados três tipos de configuração de piso: solo estático ou fixo, plataforma elevada e esteira rolante, possibilitando comparar estas soluções.

A alternativa adotada no presente estudo para implementar a análise comparativa, é o uso de simulações numéricas que possibilitam testar diversas condições de solo em um mesmo túnel de vento, virtualmente representado, sem necessidade da construção de um modelo físico de cada solução.

Esta escolha está afinada com a tendência dirigida para o uso de ferramentas do tipo CAE - Computer Aided Engineering, que tem aumentando nos últimos anos devido a fatores relacionados à redução de custo e o menor tempo de resposta na analise de uma proposta. O aumento na utilização desse tipo de ferramenta é também motivado pela evolução nos códigos comerciais, que passaram a oferecer melhor interface com 0 usuário, ampliação das possibilidades de resolução de casos, incluindo problemas de mecânica dos fluidos complexos.

Os programas de computador do tipo CAE voltados para a resolução de problemas de dinâmica dos fluidos possuem uma denominação específica chamada de CFD - Computational Fluid Dynamics. Estes softwares são capazes de oferecer resultados com boa exatidão para diversos casos de escoamento de fluidos em sistemas fechados, escoamentos ao redor de corpos, assim como situações complexas envolvendo sistemas bifásicos e análises térmicas com troca de calor. Dentre os softwares comerciais podem ser citados o FLUENT®, CFX®, Star$\mathrm{CD} \AA$ 


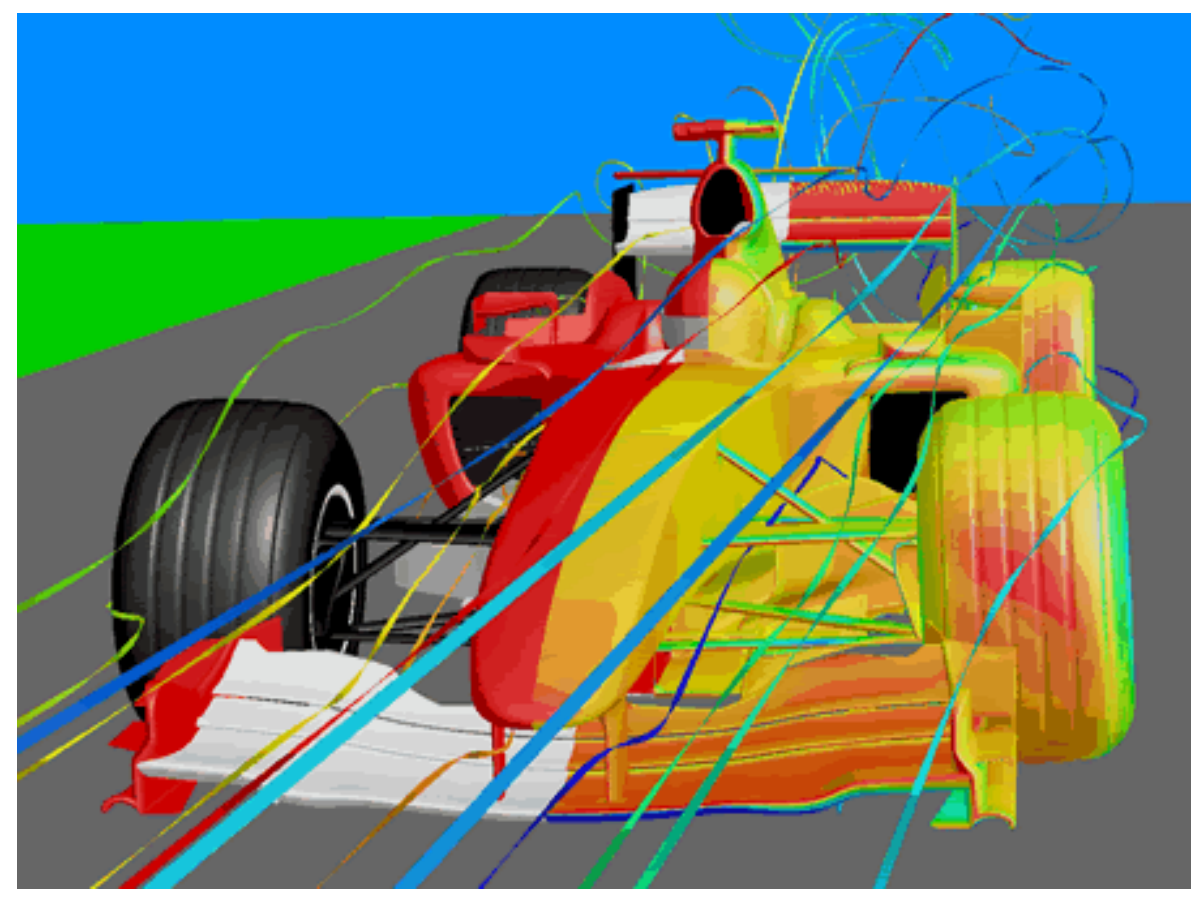

Figura 1.3 -Exemplo de linhas de corrente obtidas para o escoamento com a aplicação de uma análise virtual de CFD em um veículo de competição (FLUENT, 2003)

Motivações fortes para a utilização desse tipo de software são economizar com a redução da necessidade de ensaios experimentais, e facilitar a imposição das mesmas condições de contorno de um ensaio para outro, oferecendo alto grau de confiabilidade em resultados comparativos.

Outra motivação para o uso destas ferramentas é a facilidade em adotar variações nos parâmetros de escoamento ou modificações em geometrias estudadas, implementadas em um modelo virtual, sem existir a necessidade de fabricação de diferentes modelos físicos, e com capacidade de produzir resultados semelhantes àqueles obtidos em testes reais.

A indústria automobilística tem usado cada vez mais programas de computador desenvolvidos para aplicações de CFD. Um exemplo desta aplicação é predizer os efeitos da resistência aerodinâmica em veículos, no seu estágio inicial de projeto, reduzindo a necessidade de ensaios em túnel de vento, gerando economia.

As equipes de competição na Fórmula 1, também, tem usado essas ferramentas na comparação de alternativas para otimização aerodinâmica em seus veículos, adotando uma configuração base e determinando 
numericamente os valores de suas propriedades aerodinâmicas. Em seguida são feitas modificações nesse modelo, e a partir de novo processamento, é possível verificar as diferenças causadas em virtude das alterações.

A dissertação está organizada apresentando, inicialmente, um capítulo de introdução ao tema proposto, mostrando o túnel de vento e o conceito de simulação numérica. Na seqüência, um capítulo que contém os objetivos propostos neste trabalho e casos estudados. O capítulo seguinte mostra a revisão bibliográfica com trabalhos que precedem este estudo e utiliza conceito de simulação numérica, túnel de vento e aerodinâmica. As equações que descrevem escoamento são apresentadas em um capítulo, com o objetivo de indicar as equações resolvidas neste trabalho para obter os valores buscados. A metodologia é colocada na seqüência, contendo as condições de contorno e programas de computador utilizados neste estudo. Os resultados deste são apresentados no penúltimo capítulo. Finalizando, as conclusões dos estudos são dadas, sumarizando os resultados obtidos e sugerindo assuntos para futuros trabalhos. 


\section{OBJETIVOS}

O objetivo deste trabalho é estudar a influência no escoamento do ar na região de um corpo ensaiado em diferentes tipos de configurações para o solo da seção de teste de um túnel de vento. Para atingir este objetivo são analisados aspectos relacionados à interação do escoamento do ar com um veículo ou com parte dele. Estes aspectos são: o comportamento do escoamento avaliado a partir da visualização dos campos de velocidades e de pressões e dos valores obtidos para o coeficiente de arrasto total do veículo.

As condições de piso da seção de testes do túnel de vento são definidas para o estudo comparativo a partir das soluções mais empregadas em túneis de vento automotivo, visando representar a condição real de um veículo em movimento. Existem diversos tipos de alternativas de piso para uma seção de teste de túnel de vento, sendo as mais usuais o solo fixo e a esteira rolante, cada uma com suas características próprias.

O estudo é realizado através de simulações numéricas para três casos: o primeiro com o piso estático, com o veículo fixo no solo do túnel. O segundo caso considera o veículo também estático, mas fixo em uma plataforma acima do nível do solo do túnel. O terceiro considera o veículo colocado sobre uma esteira rolante, que substitui o solo da seção de testes do túnel. Neste último caso, o piso se movimentará, assim como as rodas do veículo, ao contrário dos casos anteriores.

Para os três casos, o veículo utilizado para realização das simulações é uma caminhonete de pequeno porte, representada por um modelo desenvolvido para aplicações em programas de elementos finitos, considerando seu motor e sistema de arrefecimento. Esta escolha é feita por possibilitar a validação dos procedimentos, hipóteses e condições de contorno adotadas para a simulação numérica a partir de resultados conhecidos para ensaios experimentais realizados em túnel real. 
A condição de referência para a validação é a adotada no primeiro caso, ou seja, piso estático. Todos os valores dimensionais da seção de testes do túnel de vento onde foi realizado o ensaio experimental foram adotados nas simulações numéricas.

As simulações numéricas são realizadas utilizando os programas UG® e HYPERMESH® para a modelagem do veículo e da seção de testes do túnel, T-GRID® na geração da malha volumétrica e FLUENT® para processamento numérico do escoamento em torno do veículo.

Como meta complementar, para avaliação do processamento computacional e análise comparativa do escoamento em torno de um corpo fixo e rotacionando, um primeiro estudo é realizado considerando apenas uma roda com pneu, isolada do veículo. Nesta análise, a roda é colocada no túnel de vento, buscando conhecer o comportamento aerodinâmico do corpo na condição estacionária, e comparando-se com a roda em movimento de rotação e solo em movimento, como se houvesse uma esteira ali presente. Deseja-se obter as diferenças que ocorrem nos padrões do escoamento na região da roda e no valor do coeficiente de arrasto. Esta análise justificou-se, pois o tempo de confecção de malha e o tempo de processamento computacional utilizado são menores que os exigidos para o estudo do veículo completo, embora a seção de testes utilizada seja a mesma, em ambos os casos.

Outra meta avaliada complementarmente neste trabalho é a influência de diferentes tamanhos de malha sobre o valor obtido para o coeficiente de arrasto do veículo inteiro e os respectivos tempos de processamento. Este refinamento está relacionado com o dimensionamento dos elementos de malha utilizados para discretizar a geometria do veículo. São utilizados três diferentes tamanhos e os resultados do coeficiente de arrasto obtidos nas simulações numéricas são comparados ao resultado obtido em ensaio experimental. Também é avaliado o tempo de processamento necessário para cada uma das dimensões adotadas. 


\section{REVISÃO BIBLIOGRÁFICA}

Neste capítulo, são apresentados conceitos básicos sobre túneis de vento, seus principais componentes, destacando-se os tipos de configurações de solo da seção de teste do túnel adotados neste estudo: piso fixo, plataforma elevada e piso móvel ou esteira rolante. A abordagem traz um, também, breve histórico sobre a evolução das simulações numéricas computacionais envolvendo mecânica dos fluidos, referências sobre métodos e programas de computador utilizados, e sobre aplicações de CFD.

\subsection{TÚNEIS DE VENTO}

Para estudos detalhados de aerodinâmica em veículos são utilizados túneis de vento, ou túneis aerodinâmicos. Estes podem ser definidos como aparatos que, com instrumentação adequada, permitem obter, através de ensaios, valores de parâmetros que resultam da interação entre 0 ar e o objeto a ser ensaiado. $\mathrm{O}$ ar movimentado através do túnel pode estar em diferentes velocidades e também pode haver controle de temperatura e de umidade.

Segundo Hucho (1998) os testes em túnel de vento permitem estabelecer condições de contorno bem controladas como, por exemplo, a velocidade na seção de teste e, em determinados tipos de túnel como, por exemplo, nos túneis de circuito fechado, estas condições independem dos parâmetros atmosféricos externos.

As principais grandezas obtidas por ensaios realizados em túnel de vento são:

- Forças resultantes aerodinâmicas e suas componentes: identificadas como arrasto, sustentação e de força lateral.

- Momentos resultantes: arfagem, rolagem e lateral. 
As forças obtidas em um ensaio experimental são geralmente medidas por meio de uma balança aerodinâmica, localizada abaixo do piso da seção de testes do túnel. Sensores podem ser instalados para monitorar regiões específicas do corpo ensaiado.

Com as grandezas obtidas, podem ser calculados os parâmetros relevantes como:

- Coeficiente de arrasto $(C d)$;

- Coeficiente de sustentação;

Katz (1995) indica que outros ensaios podem ser realizados em túneis de vento, tais como:

- Deposição de partículas;

- Conforto térmico de passageiros, como ventilação de cabine e sistema de ar condicionado;

- Aeroacústico e ruído gerado pelo vento;

- Desempenho térmico do sistema de arrefecimento do motor;

Katz (1995) e Hucho (1998) comentam que os valores dos resultados de ensaios podem contribuir para análise de:

- Redução de consumo de combustível;

- Estabilidade veicular em altas velocidades;

- Estabilidade veicular devido aos ventos cruzados;

- Distribuição térmica e fluxo de ar no interior do veículo;

- Nível sonoro de ruído devido ao efeito de desprendimento de vórtices; 


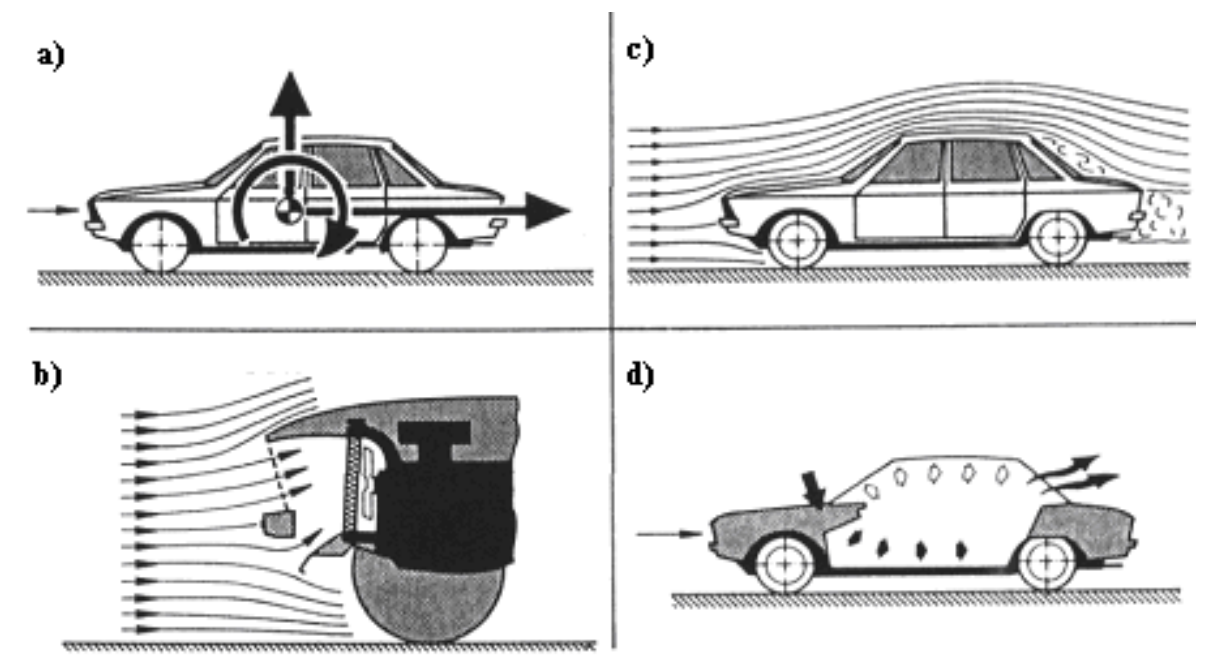

Figura 3.1 - Os estudos na aerodinâmica veicular: a) determinação de forças e momentos; b) sistema de arrefecimento veicular; c) fluxo de ar sobre o veículo; d) fluxo de ar interno à cabine do veículo.

O princípio de funcionamento de um túnel de vento supõe que o ar é soprado, por um ventilador até a seção de teste, onde se encontra o modelo, o qual pode ser em escala ou tamanho real. Na seção de testes as características do escoamento devem controladas, assim como o perfil de velocidades e o comportamento da camada limite devem assumir padrões conhecidos e previamente determinados. Neste trabalho a preocupação com o tipo de piso da seção de testes está relacionada com sua influência no comportamento do escoamento na região da camada limite e a influência que pode causar no arrasto de um veículo.

Pode-se exemplificar a realização de ensaios de veículos e seus componentes em túneis de vento através dos estudos realizados por Buchheim (1983) e Renn e Gilhaus (1986). Nestes, o coeficiente de arrasto calculado a partir das medidas experimentais realizadas em veículos é comparado em diferentes situações. No artigo de Buchheim (1983), o ar movimenta-se em rotas de percurso distintas em função da posição do radiador, e no texto de Renn e Gilhaus (1986) é avaliada a presença e a ausência de aberturas frontais em um veículo. Os resultados demonstrando variação no coeficiente de arrasto para diversas configurações de radiadores e a diminuição do arrasto, no caso de um veículo com entrada de ar fechada estão nas figuras 3.2 e 3.3 a seguir. 

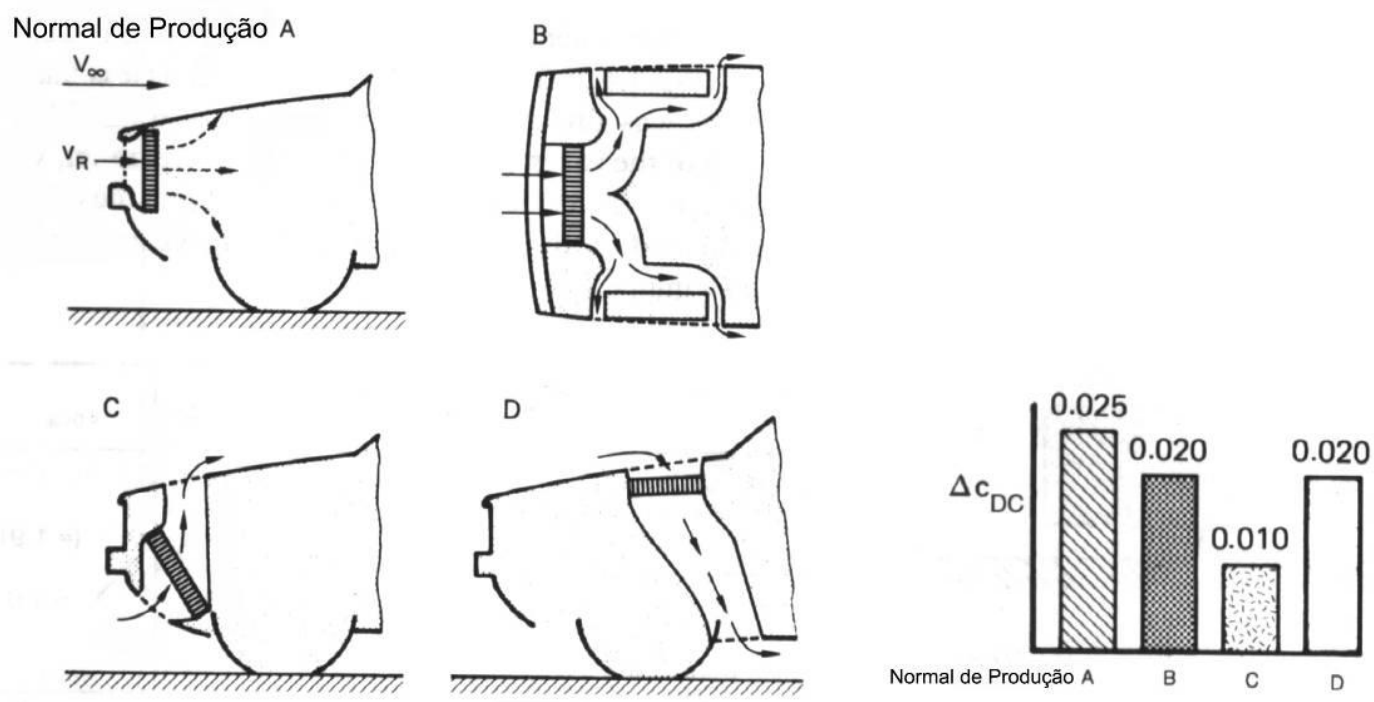

Figura 3.2 - Alteração do coeficiente de arrasto para diferentes tipos de disposição do radiador (BUCHHEIM,1983.).
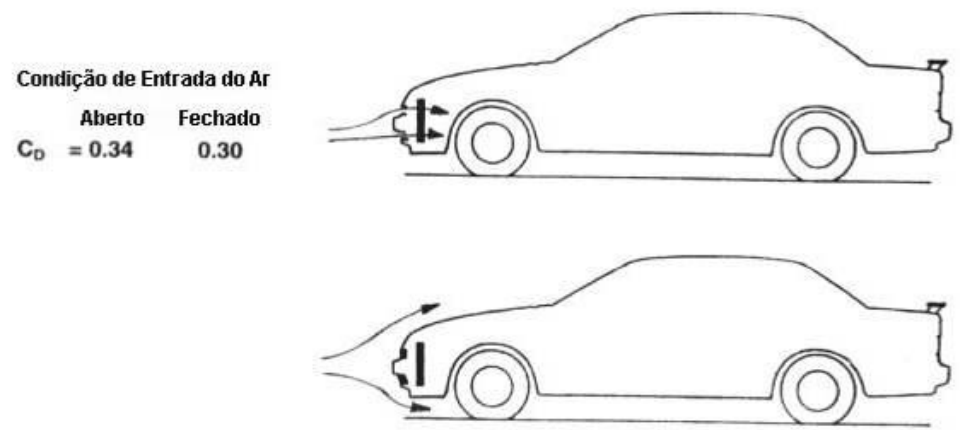

Figura 3.3 - Coeficiente de arrasto $(C d)$ de um carro sedan esporte com e sem aberturas frontais (RENN. E GILHAUS, 1986.).

\subsubsection{Tipos e classificações de túneis de vento}

Os túneis são construídos com muitas formas e para diferentes propósitos. Alguns têm dimensões que permitem testar aviões em tamanho real, sendo que outros permitem testar apenas modelos em escala. Os tipos de túneis de vento podem ser classificados segundo o valor da velocidade do ar que ocorre na seção de testes, suas condições de temperatura ou pelo caminho percorrido pelo ar. 
Segundo o valor da velocidade, os túneis de vento são denominados de subsônico quando a velocidade do ar é menor que a velocidade do som e de supersônico quando esta velocidade é superior a do som. Além desses, também existem os túneis hipersônicos nos quais o número de Mach atinge valores maiores ou iguais a cinco, calculado com a velocidade do escoamento na seção de testes.

Em alguns túneis são adotados ensaios com variação da temperatura do ar, gerando temperaturas muito baixas a fim de simular condições típicas de grande altitude ou temperaturas muito elevadas para simular condições severas suportadas por sistemas de arrefecimentos.

Segundo Hucho (1998) existem dois tipos de túneis de vento, diferenciados em função do caminho percorrido pelo ar.

No túnel do tipo Eiffel, ou de circuito aberto, o ar é retirado do meio externo ao túnel e o mesmo é devolvido a este meio, caracterizando um circuito aberto. Na figura 3.4 pode ser visto um projeto de um túnel de vento deste tipo, e na figura 3.5 pode ser observada a seção de testes do túnel do Forschungsinstitut für Kraftfahrwesen und Fahrzeugmotoren Stuttgart (FKFS), localizado na Alemanha, considerado um dos mais modernos do mundo, com um sistema de esteira rolante de alta eficiência que pode atingir velocidade de até $250 \mathrm{~km} / \mathrm{h}$.

No túnel tipo Göttingen, ou circuito fechado, o ventilador recircula o ar dentro de um circuito fechado, não havendo entrada de ar do ambiente exterior ao circuito. Dois exemplos destes túneis estão nas figuras 3.6 e 3.7. 


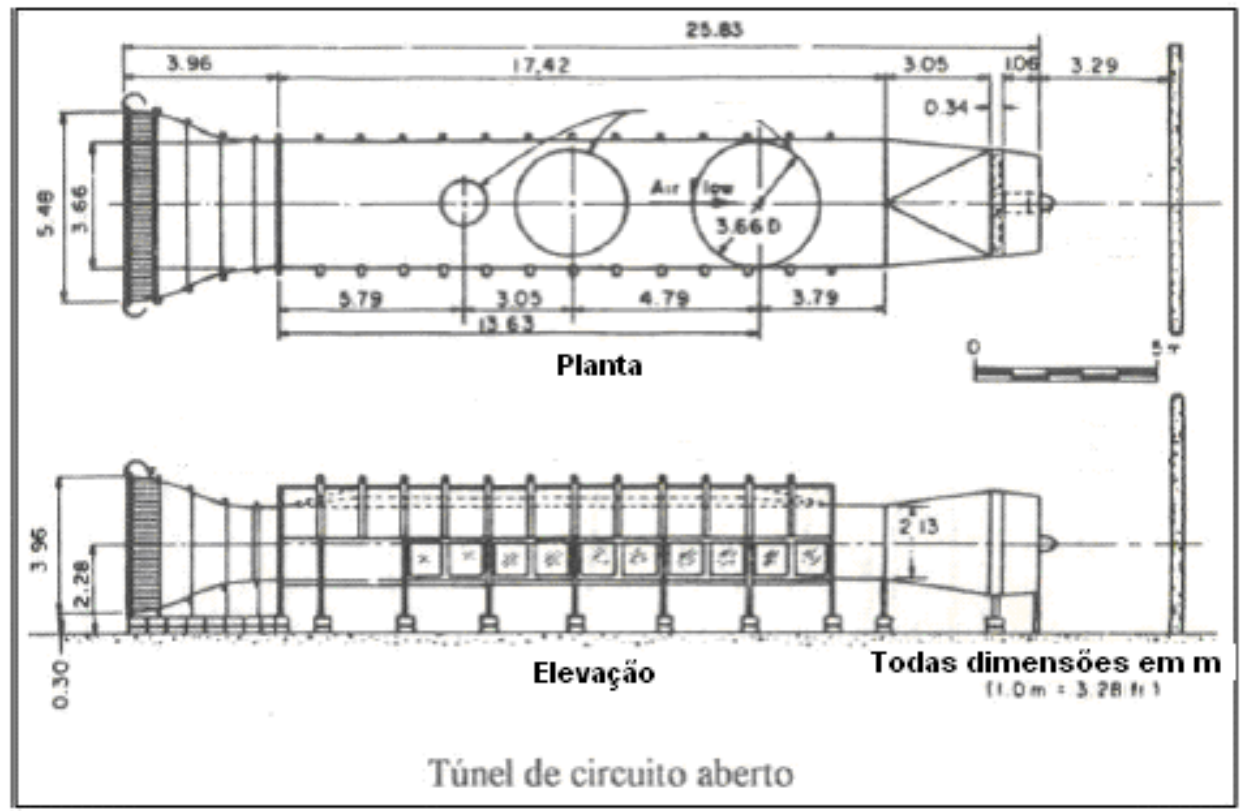

Figura 3.4 - Túnel de vento de circuito aberto. (SACOMANO FILHO, 2008)

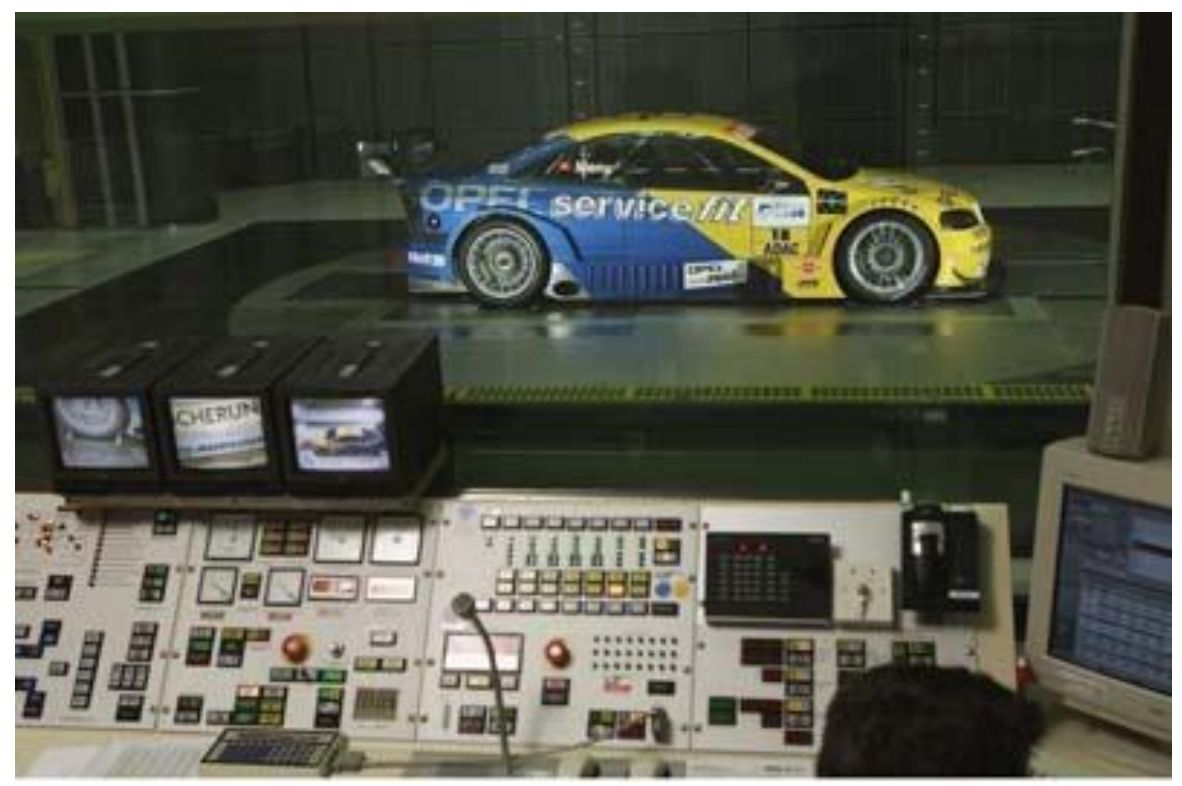

Figura 3.5 - Túnel de vento FKFS (Forschungsinstitut für Kraftfahrwesen und

Fahrzeugmotoren Stuttgart), na Alemanha, de circuito aberto.(FKFS, 2009). 


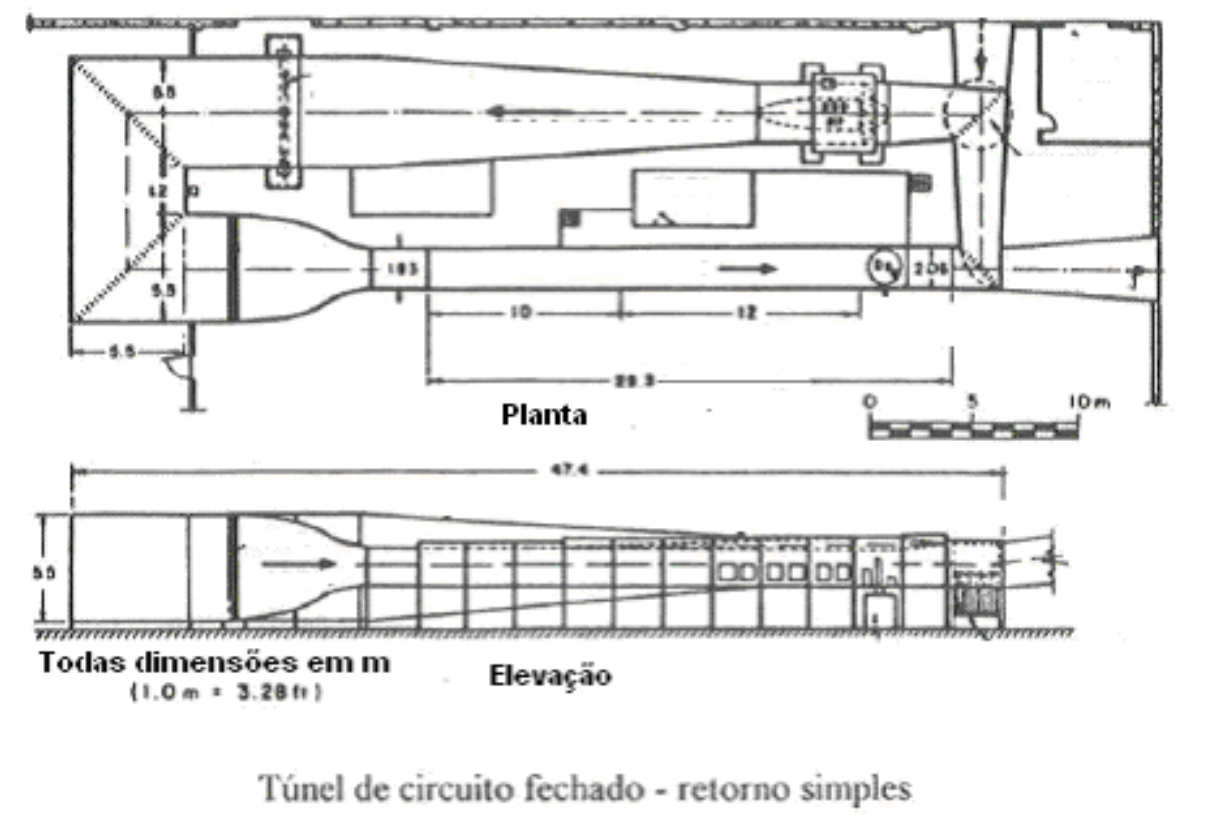

Figura 3.6 - Túnel de vento de circuito fechado. (SACOMANO FILHO, 2008)

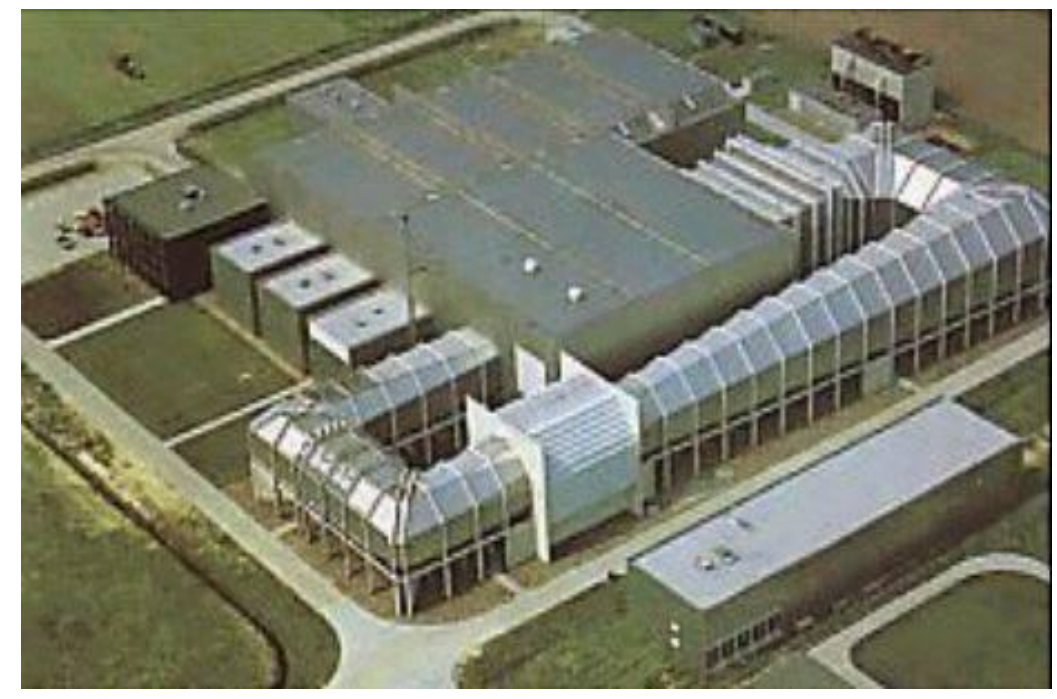

Figura 3.7 - Túnel de vento DNW (Deutsch-Niederisch Windkanal) de circuito fechado, localizado na Holanda.(DNW, 2009)

Os túneis do tipo Göttingen têm a vantagem de, em geral, consumir menos energia em sua operação, comparado aos túneis do tipo Eiffel. O equipamento que faz a movimentação do ar, também é de menor custo, comparado ao custo do duto do sistema Eiffel, aberto. 
Nos túneis do tipo Eiffel, existe a desvantagem do mesmo só poder operar em condições climáticas adequadas, ou seja, sem presença de neve ou chuva, devido ao seu sistema que é aberto. Além disso, a principal vantagem desse tipo de túnel é o custo de fabricação do mesmo, contando com uma estrutura mais simples comparada á estrutura de um túnel com sistema fechado.

A figura 3.8 ilustra o esquema de um túnel de circuito fechado, similar ao utilizado neste trabalho.

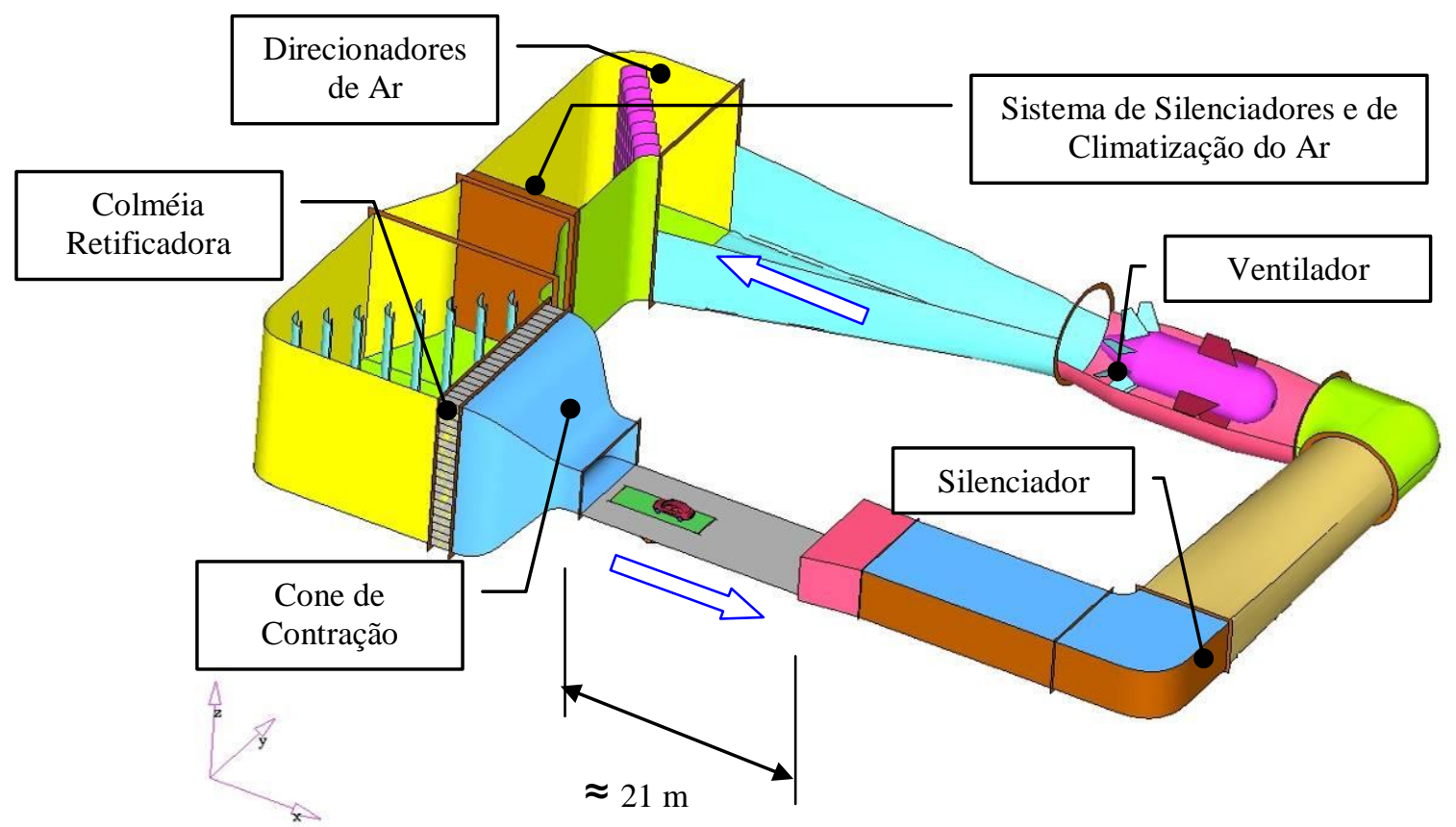

Figura 3.8 - Figura ilustrativa dos componentes internos do túnel de vento de circuito fechado para ensaio aerodinâmico em veículos automotivos.

Wiedemann (1996), afirma que os túneis também podem ser classificados quanto ao sistema de simulação de solo que apresentam em sua seção de teste. Esta é uma classificação importante, pois a utilização de diferentes tipos de solo pode causar influências nos parâmetros aerodinâmicos obtidos em ensaios. Ele afirma que há uma constante busca de um tipo de representação de solo que consiga reproduzir com exatidão o movimento de um veículo em condição real de operação. Os tipos estudados neste trabalho, piso fixo, plataforma elevada e esteira rolante, além de outras configurações, são detalhados nos próximos itens. 


\subsubsection{Configurações de solo}

A presença do solo pode gerar características importantes no escoamento que percorre o objeto, especialmente na região que fica estabelecida entre o objeto e o solo, e estas estão relacionadas com a distância do objeto ao solo e com a geometria das superfícies. Segundo Katz (1995), em uma situação real, o objeto se move em relação ao ar e ao solo, em um túnel de vento, o ar que se move em relação ao objeto e ao solo, desenvolvendo padrões de escoamento de camada limite nas paredes e principalmente no solo do túnel. A influência desse padrão de escoamento em camada limite causado pelas paredes do túnel e pelo solo interfere na tentativa de representar com exatidão a condição real de operação do veículo.

O aprimoramento de ensaios em túneis pretende reduzir a influência da camada limite do solo de modo que não interfira no escoamento ao redor do objeto testado. Esta interferência pode estar relacionada com a espessura da camada limite, que eventualmente varia em função da localização da seção considerada e do número de Reynolds.

Segundo Hucho (1998), uma série de alternativas têm sido utilizadas para simular a condição real da interação veículo-solo nas seções de testes em túneis de vento. A figura 3.9 mostra exemplos de configurações de solo:
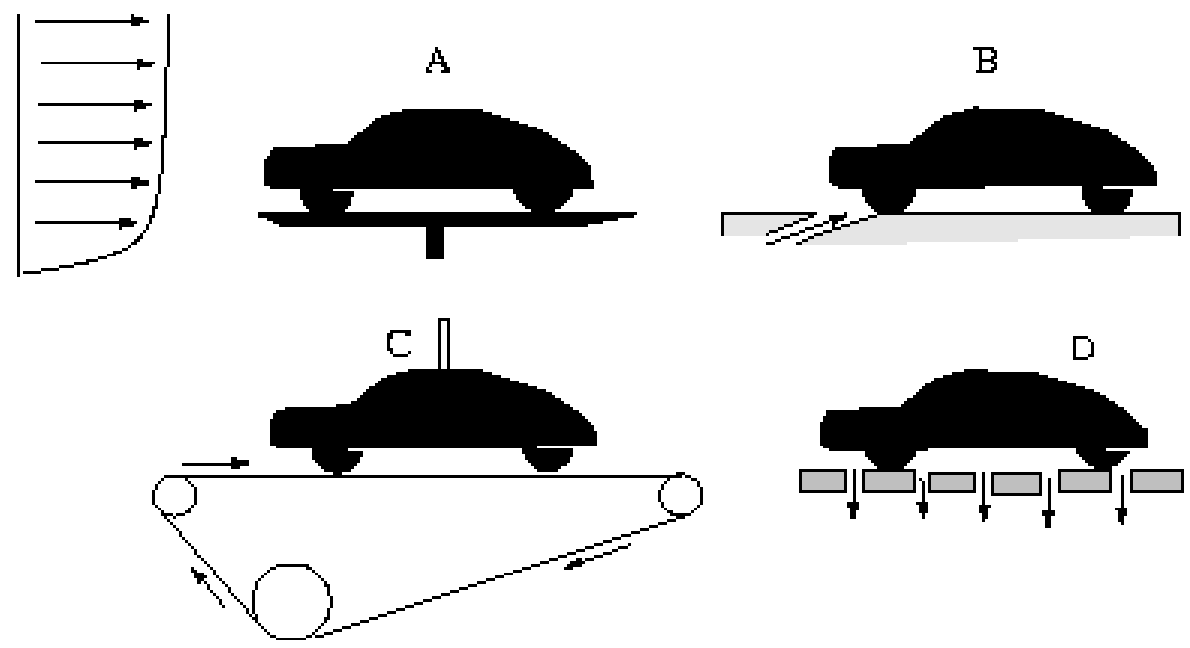

Figura 3.9 - Figura ilustrativa dos tipos de solo em túneis automotivos. (A) - Plataforma Elevada; (B) - Injeção de ar; (C) - Esteira rolante; (D) - Sucção distribuída (HUCHO, 1998) 
Na literatura (HUCHO, 1998 e KATZ, 1995) encontra-se que o método mais adequado para a representação da configuração real do solo é o proporcionado pela solução deste com esteira rolante, pois há movimentação do piso e das rodas. Contudo, também é ressaltado que há exigência de um projeto complexo para sua implantação, com altos custos. Outros métodos para simulação do comportamento do solo foram desenvolvidos como alternativas mais simples e econômicas como plataforma elevada e piso fixo.

\subsubsection{Plataforma elevada}

Um dos métodos utilizados para tentar eliminar a influência da camada limite em um ensaio de veículo é usar uma plataforma que faz com que o objeto ensaiado fique em um plano mais elevado em relação ao solo da seção de testes (figura 3.10).

O principal aspecto dessa alternativa é o de tentar diminuir a influência da camada limite já existente no túnel de vento, embora exista o desenvolvimento de uma nova sobre a placa que irá compor este segundo piso. Para tanto este novo piso deve ser elevado o acima da espessura da camada limite original do túnel. O ângulo de ataque da plataforma elevada deve ser nulo em relação ao escoamento ao longe.

Uma grande desvantagem deste aparato é o de necessitar de uma grande área na seção, uma vez que há a necessidade de incluir um outro solo, a plataforma, sobre o original do túnel.

A plataforma elevada é geralmente combinada com um sistema de sucção, localizado no início do solo da seção de testes. A função desse sistema de sucção de ar é reduzir a espessura da camada limite que se desenvolve no solo do túnel e, em conjunto com a plataforma, atenuar o efeito do solo estático sobre o escoamento na região inferior do veículo. Em termos globais há uma melhora, ainda que haja formação de outra camada limite na própria plataforma, porém com espessura reduzida. 


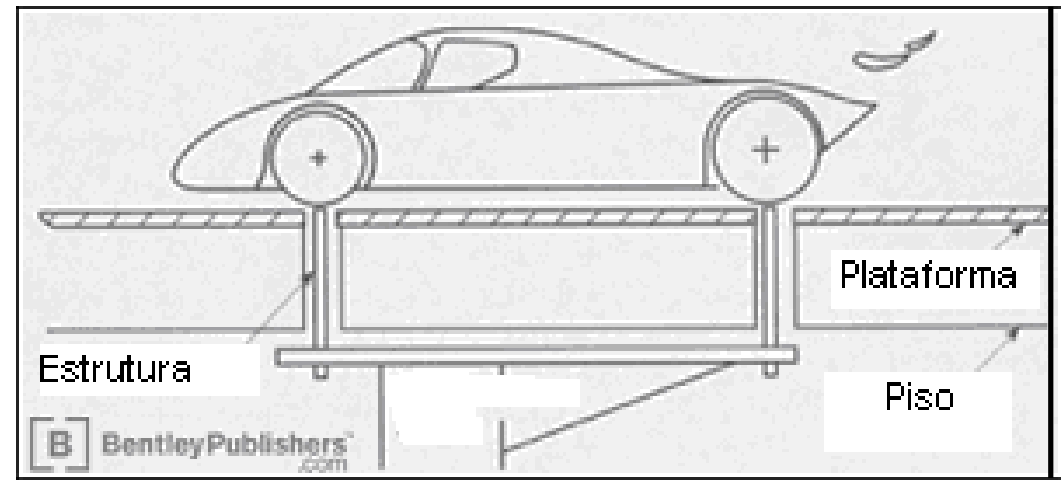

Figura 3.10 - Esquema de uma plataforma elevada montada em um túnel de vento.(KATZ, 1995)

\subsubsection{Piso fixo com sistema de sucção}

Existe uma solução semelhante ao método anterior, a qual conta apenas com o sistema de sucção da camada limite, sem usar a plataforma. Em estudos realizados por Wäschle (2007) e Wiedemann (1996) foi desenvolvida a análise da interferência do piso fixo do túnel de vento, com sucção na seção de testes, sobre o comportamento aerodinâmico de veículos. Estes estudos apresentavam diferenças nos resultados, quando comparados com a solução da esteira rolante no piso. Essas diferenças estão relacionadas com o fato do piso fixo não permitir a representação da rotação das rodas dos veículos, que podem ter influência no escoamento em seu entorno. Um exemplo deste tipo de seção de testes é mostrado na figura 3.11 do túnel A2WT.

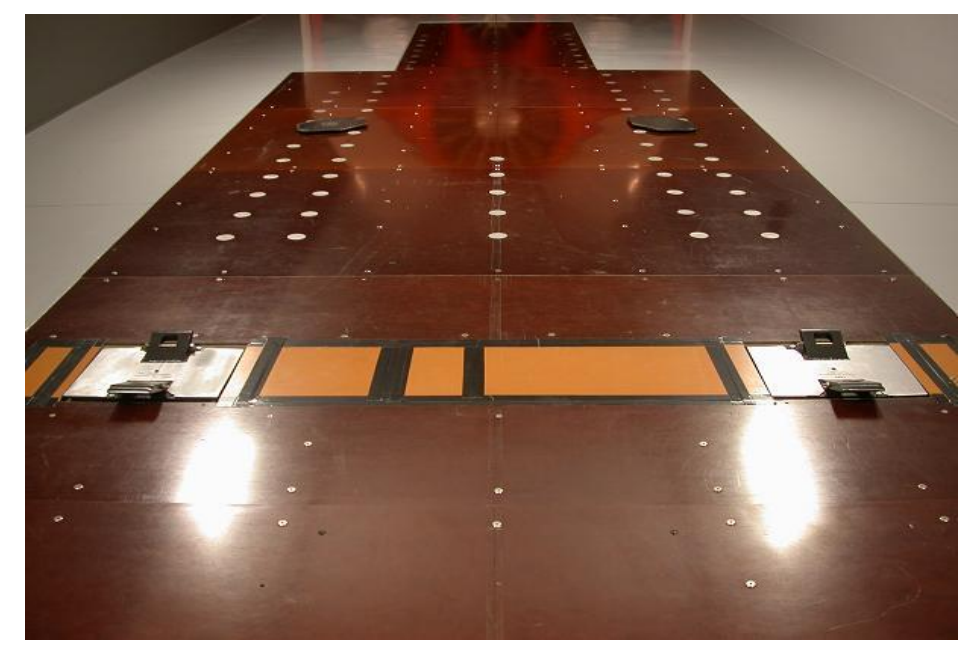

Figura 3.11 - Detalhe do piso fixo de um túnel de vento com sucção. (A2WT, 2009) 


\subsubsection{Esteira rolante}

Segundo Hucho (1998) o método que melhor procura aproximar-se das condições reais de operação de um veículo é aquele que aplica uma esteira rolante na seção de testes do túnel de vento. Nesse método, a idéia é reproduzir a condição de uma via em que o veículo está deslocando-se contra o ar, e o ar está com velocidade nula em relação ao solo. Para reproduzir esta condição no túnel de vento o piso deve movimentar-se com a mesma velocidade do ar. Além disso, as rodas devem estar também em movimento e em contato com essa esteira. Geralmente, a esteira é integrada ao solo do túnel, mantendo-se no mesmo nível, e a montante dela existe um sistema de sucção, com o objetivo de diminuir a influência da camada limite que tenha sido formada em seções anteriores. As figuras 3.12 e 3.13 ilustram exemplos de esteiras rolantes, posicionadas em seções de testes de túneis de vento automotivos.

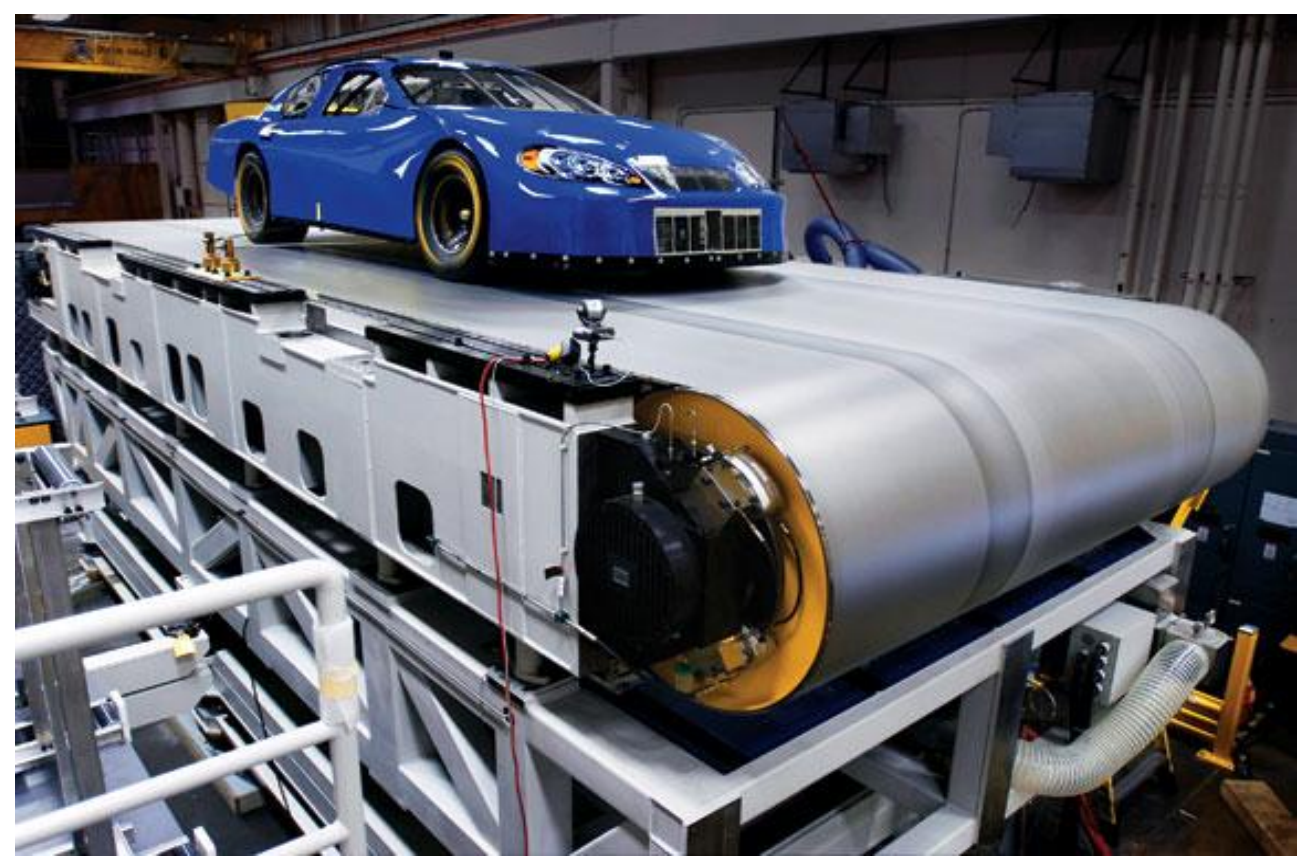

Figura 3.12 - Exemplo de uma esteira rolante, localizada na seção de testes do túnel de vento automotivo Windshear, nos EUA. (WINDSHEAR, 2008) 


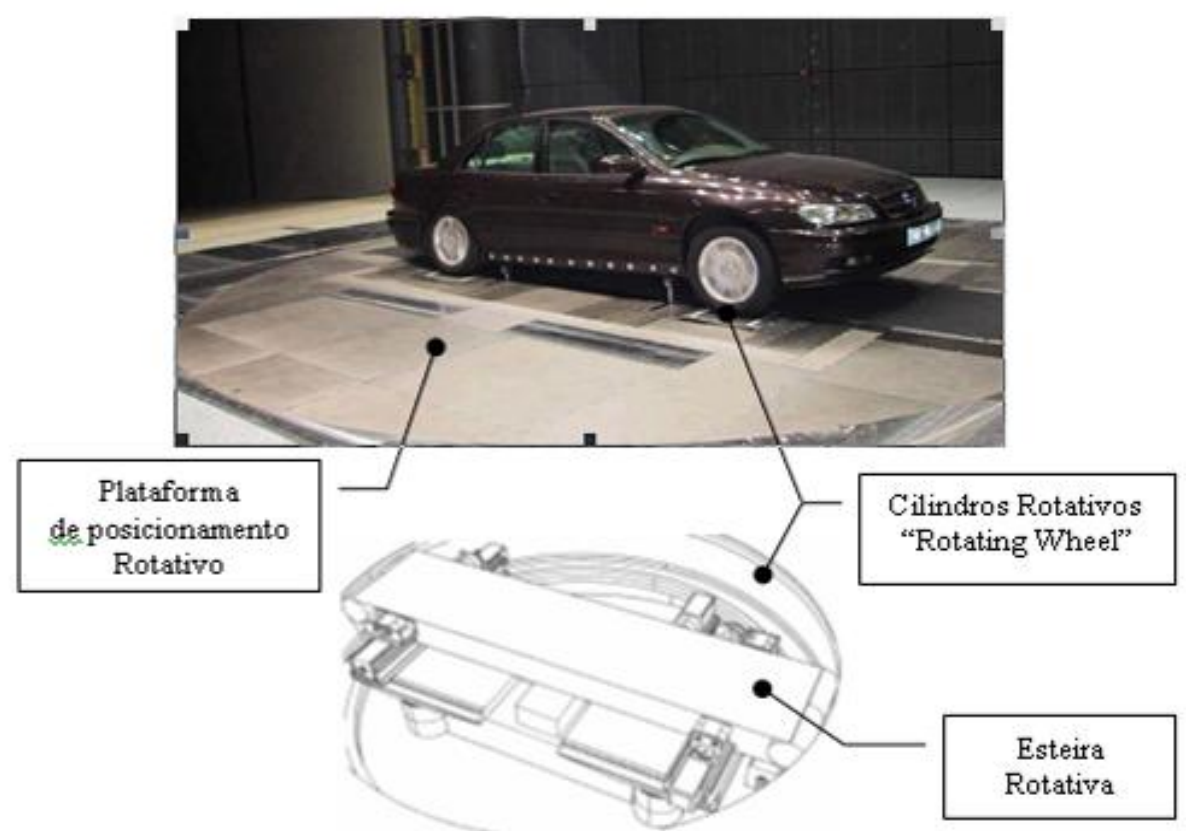

Figura 3.13 - Veículo montado sob sistema de esteira e cilindros rotativos. (QUIM, 2007)

Em sua concepção mais usual, o sistema é composto por um sistema de dois cilindros, os quais são envolvidos por uma esteira feita de borracha ou outro material sintético. Um dos cilindros está associado a um motor que faz com que ele rotacione e movimente a esteira, embora haja casos em que ambos cilindros possuem motores para melhor controlar esse movimento.

No exemplo do túnel da Figura 3.12, as rodas do veículo em teste tocam a própria esteira, e esta interação provoca o movimento de rotação.

Para o caso apresentado na Figura 3.13, as rodas do veículo são posicionadas sobre cilindros rotativos, localizados nos arredores da esteira, sendo que esta possui menores dimensões e fica localizada apenas na região abaixo do veículo. A principal função desses cilindros rotativos é de sustentar o carro, apoiado pelas rodas e fazer com elas rotacionem, nas mesmas condições de movimentação em um deslocamento real. Além disso, os cilindros que ficam em contato com as rodas que estão vinculadas ao motor do veículo, podem ser substituídos por dinamômetros, permitindo a realização de outros tipos de ensaios, como testes dos motores. 
Em 2008, a empresa italiana Pininfarina, (2008) implantou em seu túnel de vento, um novo tipo de esteira rolante para simulação das condições de movimento relativo solo-veículo, chamado T-Belt. Este sistema conta com três esteiras rolantes, montadas na forma de um $\mathrm{T}$ no solo do túnel de vento, conforme mostrado na figura 3.14. O objetivo dessa solução é simular a influência do solo móvel, não só na parte inferior do veículo, mas também próximo às rodas frontais, visando fornecer resultados com maior exatidão para calcular as propriedades aerodinâmicas.

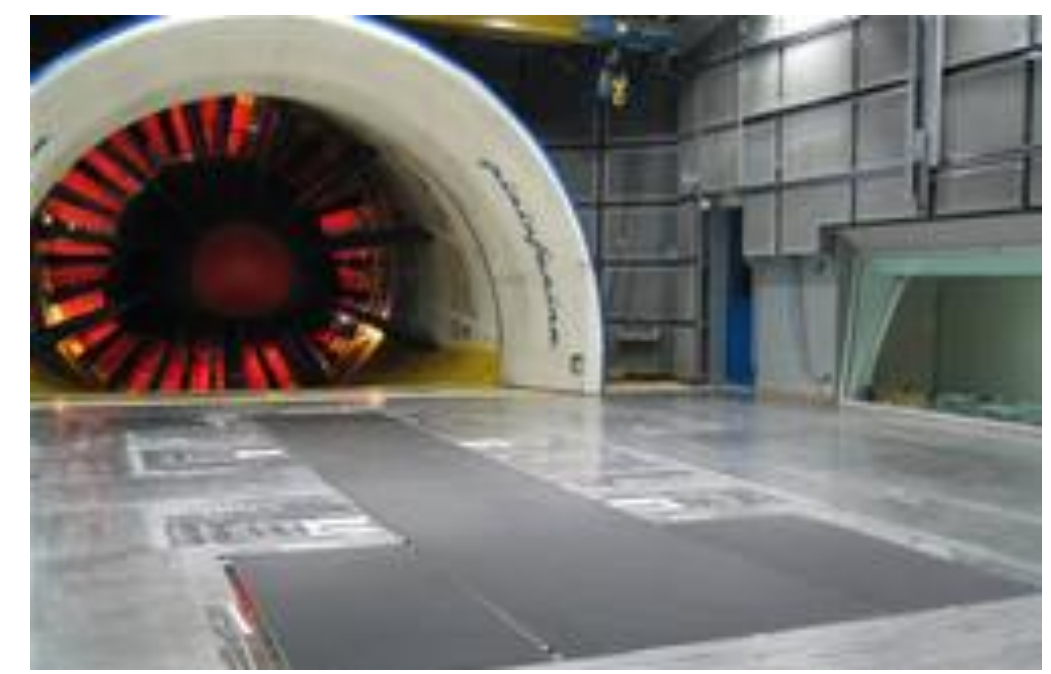

Figura 3.14 - Sistema T-Belt, localizado no túnel de vento da Pininfarina. (PININFARINA, 2008)

\subsubsection{Sistemas de sucção e de injeção de ar}

Segundo Hucho (1998), os métodos de representação do solo em uma seção de testes de um túnel de vento podem ser combinados com sistemas de sucção, que tem como principal função diminuir a espessura da camada limite formada em seções anteriores a esta. A figura 3.15 ilustra um sistema de sucção posicionado no início da seção de testes.

O sistema de sucção é composto por circuitos pneumáticos que aspiram ar na região da camada limite na superfície do piso. Essa aspiração pode ser feita em toda a extensão do solo do túnel, chamada sucção distribuída ou apenas no começo do mesmo, denominada de sucção simples. 


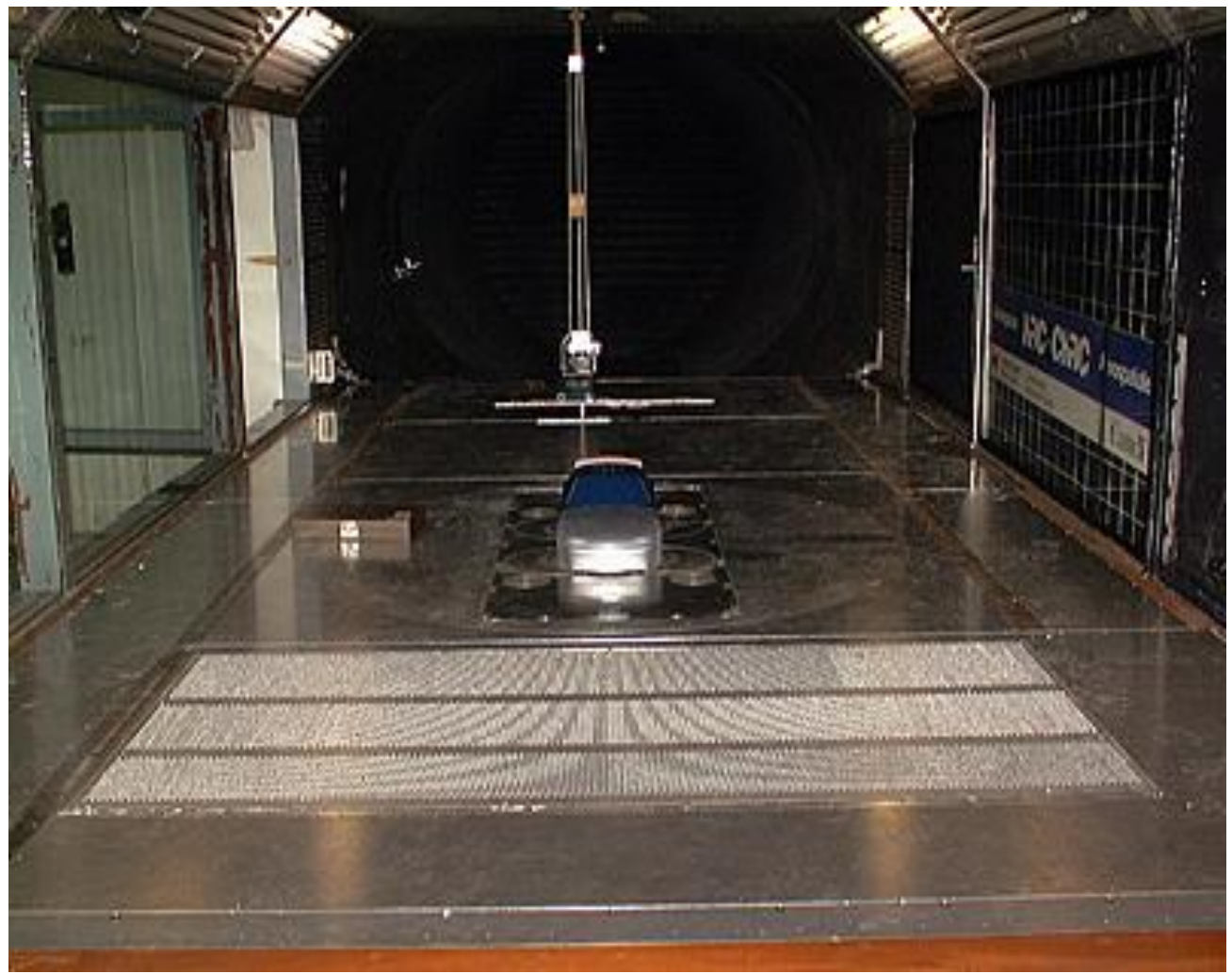

Figura 3.15 - Detalhe do sistema de sucção na entrada da seção de testes do túnel de vento. (DNW, 2009)

Hucho (1998) também apresenta um sistema pneumático que opera com insuflação de jatos de ar tangencialmente ao solo, em uma região imediatamente anterior à seção de testes, e que pode ser utilizado para reduzir a camada limite, como indicado na figura 3.9 B. Isso é feito por jatos de ar em alta pressão, que aumentam a energia cinética do escoamento de fluido na camada limite e reduzem sua espessura.

\subsubsection{Os subsistemas do túnel de vento}

Segundo Sacomano Filho (2008), o túnel de vento é um equipamento que possui subsistemas com funções específicas que serão explicados nos subitens seguintes. A figura 3.16 representa o esquema construtivo de um túnel de vento, circuito fechado, que conta com uma esteira rolante em sua seção de testes. 


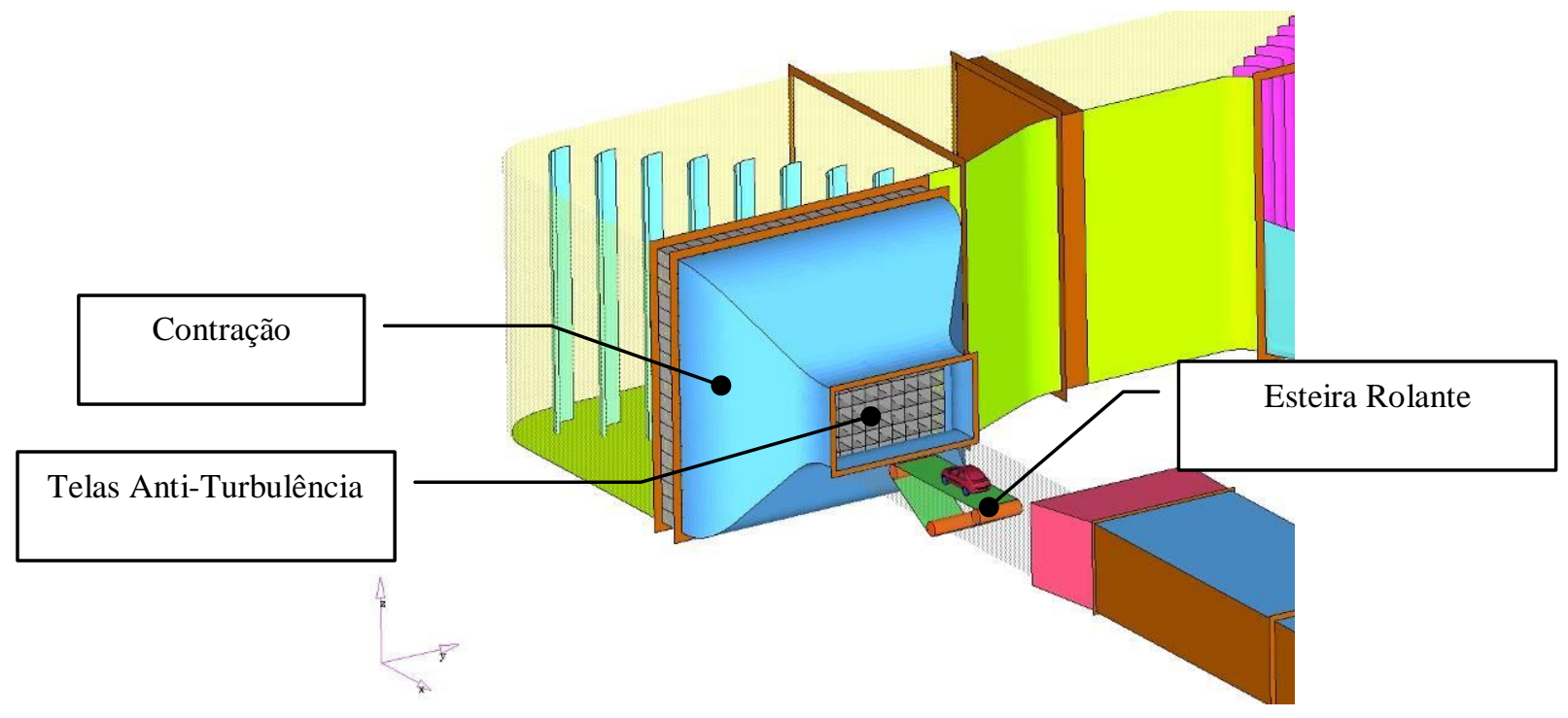

Figura 3.16 - Figura ilustrativa dos principais subsistemas de um túnel de vento nas proximidades da seção de testes.

\subsubsection{Contração}

A contração de um túnel de vento tem por principal objetivo acelerar o escoamento e garantir sua qualidade na seção de testes. A qualidade do escoamento pode ser medida através dos seguintes parâmetros:

- Perfil de velocidades na seção de teste

- Desvios locais da velocidade média

- Intensidade de turbulência do escoamento (I).

Os desvios locais da velocidade média são originados por distorções no escoamento, e são controlados pela razão de contração que também controla o nível de turbulência. Um exemplo disso é o efeito das paredes do túnel que, através do desenvolvimento da camada limite do escoamento sobre sua superfície, pode provocar desvios locais na velocidade média ao longo de uma seção transversal.

A intensidade turbulenta I é definida como a razão da flutuação da velocidade pela velocidade média de entrada.

$$
I=\frac{u^{\prime}}{U}=\frac{(2 / 3 \cdot k)^{1 / 2}}{U}
$$


Onde:
u'
flutuação de velocidade
$\mathrm{k}$ energia cinética
$U$ módulo da velocidade média na entrada

A caracterização da contração é feita através da determinação da geometria de sua seção longitudinal e de sua razão de contração, definida como a razão entre a área de entrada pela área de sua saída.

Para o túnel de vento estudado tem-se que sua razão de contração é igual a 3. De acordo com Hucho (1998), tem-se que para túneis de vento de circuito aberto razões de contração entre 2 e 3 são suficientes para garantir um nível de turbulência aceitável para realização de ensaios.

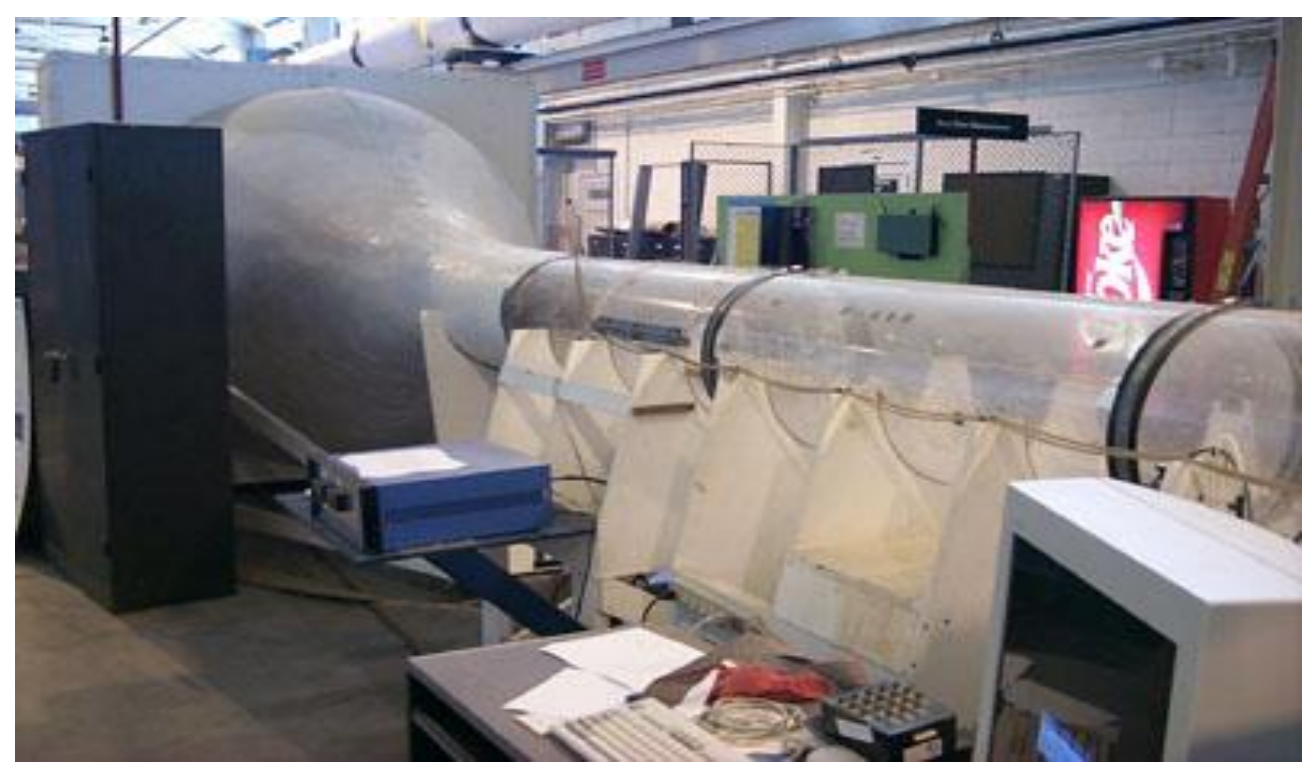

Figura 3.17 - Túnel de vento com alta contração da Universidade Purdue. (PURDUE, 2009) 


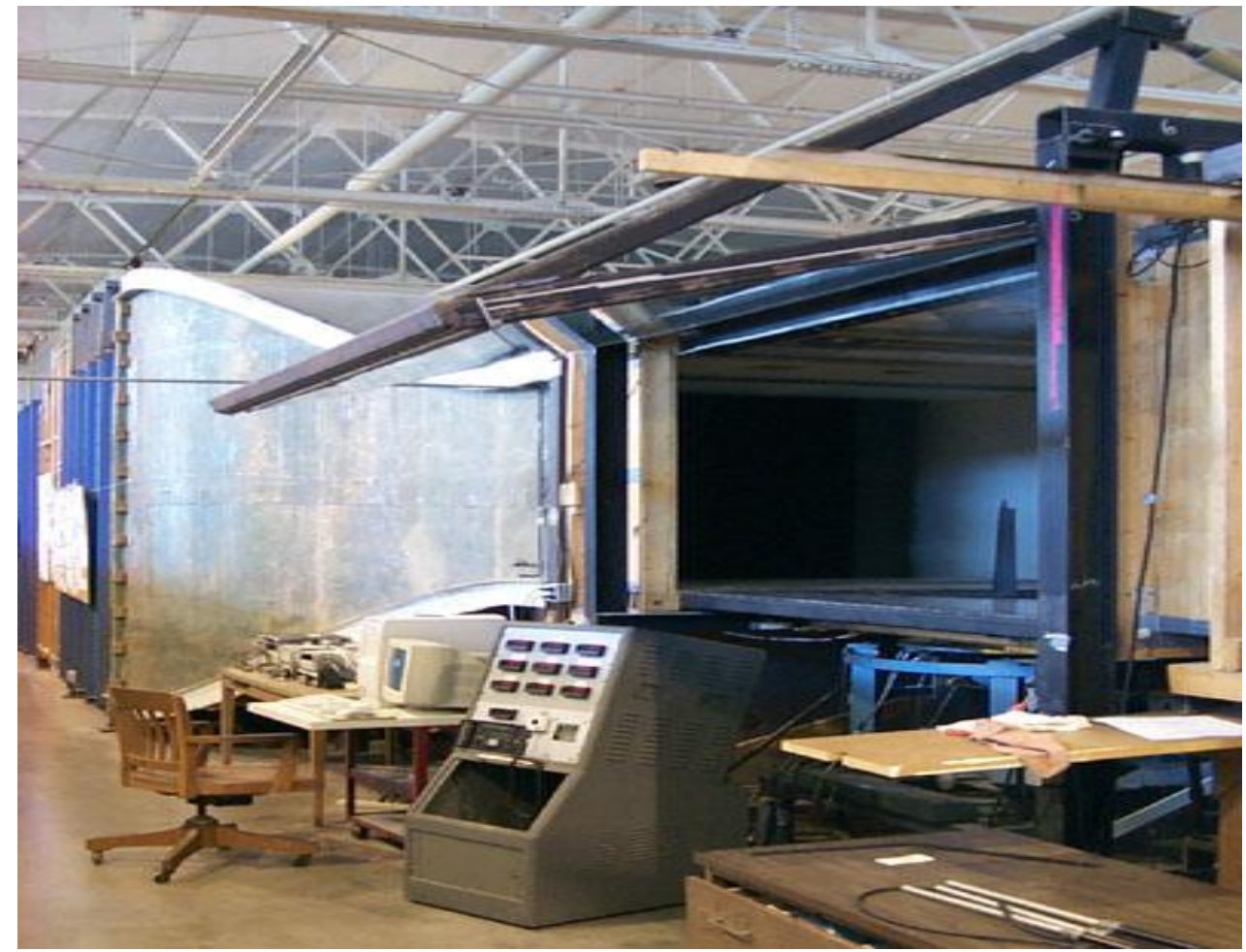

Figura 3.18 - Detalhe da contração de um túnel de vento localizado na Universidade Purdue. (PURDUE, 2009)

\subsubsection{A seção de testes}

Segundo Katz (1995), a seção de testes é a região mais importante do túnel, pois lá são realizados os ensaios e medições aerodinâmicas. Nesta seção diferentes tipos de solo podem ser adotados, conforme já dito neste capítulo. De acordo com Carril Júnior (1995) a definição desta região é o primeiro passo do projeto de um túnel de vento, podendo ter formas retangulares, circulares, ovais ou similares. Além disso, dependendo do tamanho da seção, o corpo ensaiado pode sofrer efeito de blocagem. A figura 3.19 ilustra a seção de teste do túnel de vento da Honda F1, com esteira rolante, destinado a realização de testes em veículo de competição. 


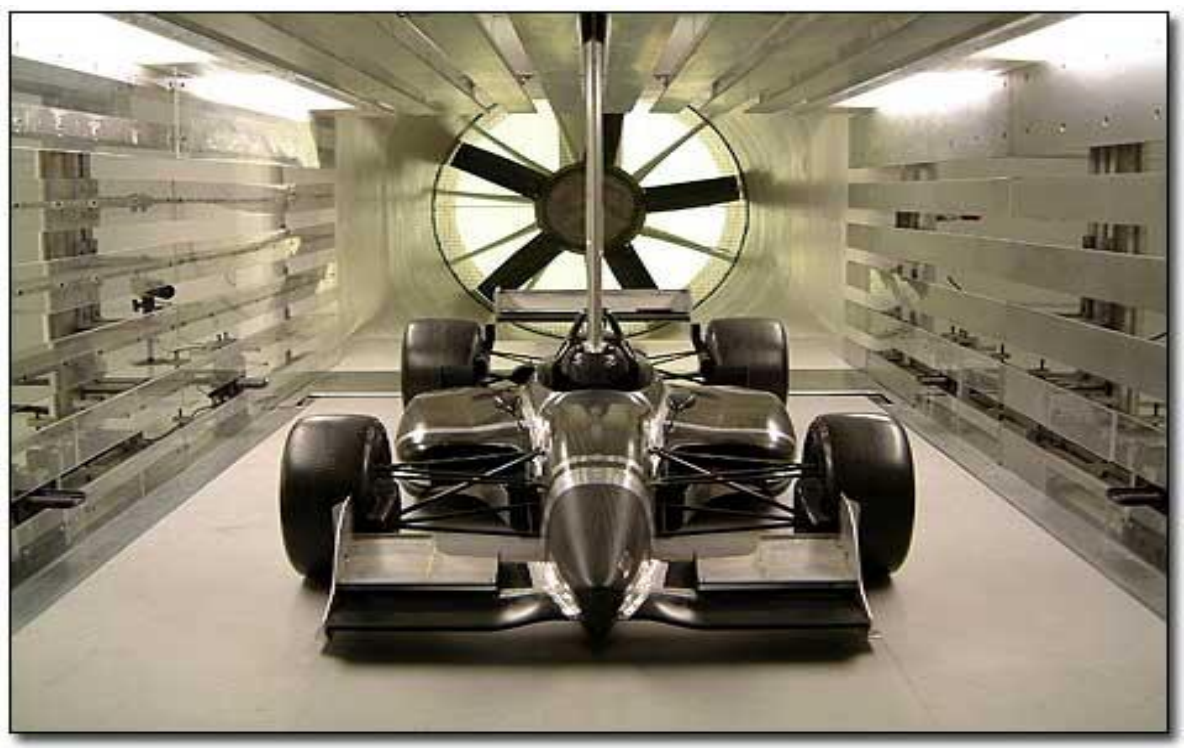

Figura 3.19 - Detalhe da seção de teste de um túnel de vento da Honda F1 (HONDA WIND TUNNEL, 2008)

Uma das características das seções de testes de túneis de vento é a de poderem ser abertas ou fechadas, independentemente do túnel ser de circuito aberto ou fechado. A seção de testes fechada apresenta, em relação à seção de testes aberta, uma maior liberdade quanto à definição de seu comprimento, porém, com certas limitações.

Segundo Sacomano Filho (2008), a dificuldade em aumentar este comprimento é o de ocorrer a ampliação da espessura da camada limite desenvolvida nas fronteiras do túnel de vento com o aumento da distância até a contração. $O$ espessamento dessa camada limite provoca um aumento na velocidade do escoamento na seção média do túnel, reduzindo a seção de testes efetiva, ou seja, menos influenciada por esse efeito. Os túneis de seção aberta possuem a vantagem em relação aos de seção fechada de não sofrer o efeito de blocagem. Exemplos dessas seções são mostrados nas figuras 3.20 , seção aberta e figura 3.21 com seção fechada. 


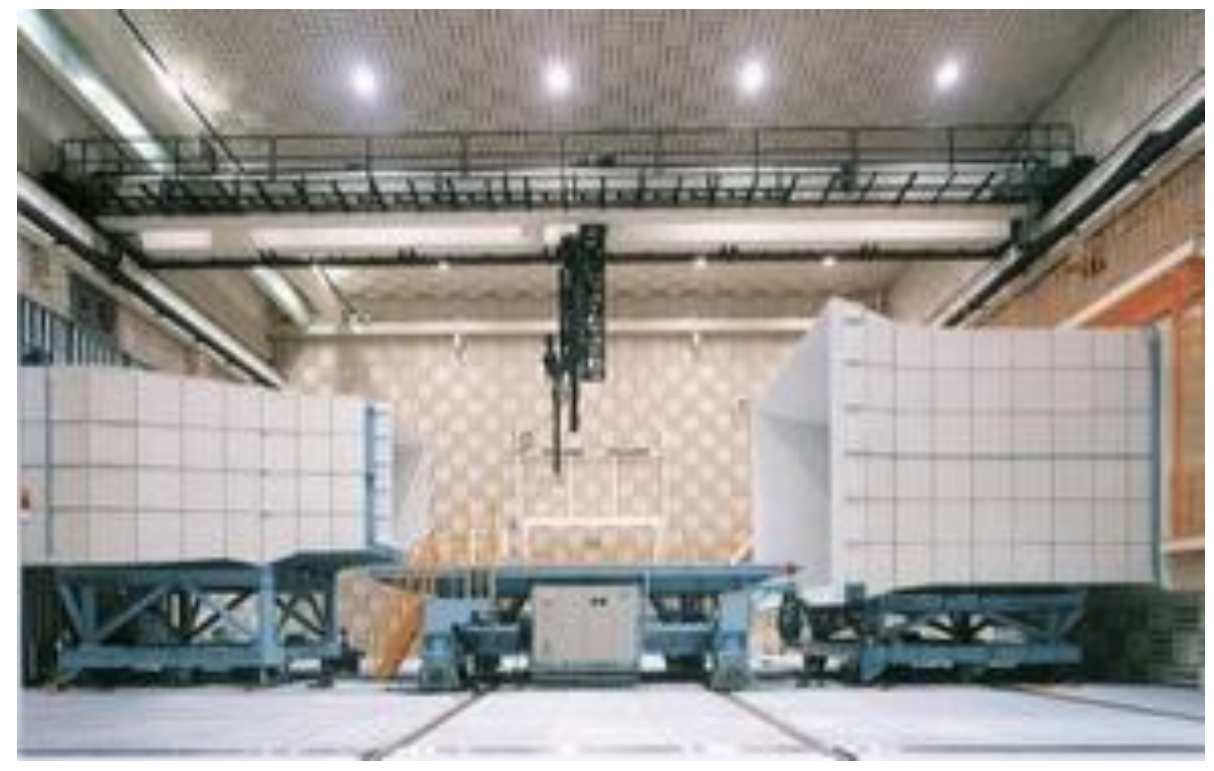

Figura 3.20 - Túnel de vento de seção de testes aberta. (MAIABARA, 2009)

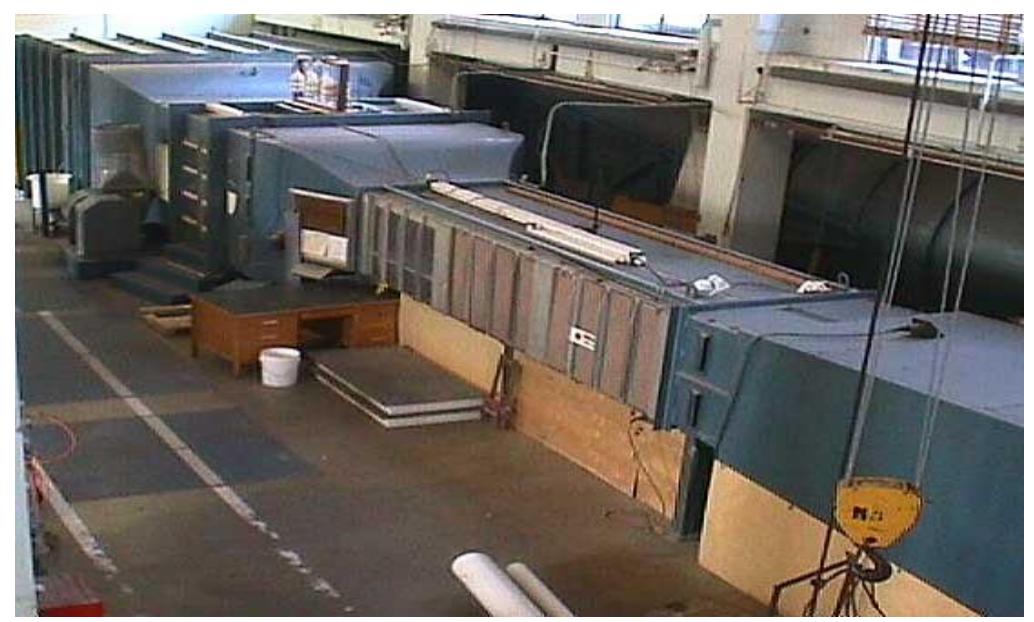

Figura 3.21 - Túnel de vento de seção de testes fechada. (PURDUE, 2009)

Um dos principais fatores que colaboram no projeto e determinação das dimensões da seção de testes e sua geometria é o efeito de blocagem. O efeito de blocagem se relaciona com a limitação geométrica da seção de testes, o que acaba por interferir no escoamento sobre o corpo ensaiado.

Segundo Hucho (1998), túneis de vento com área da seção de testes maior que $30 \mathrm{~m}^{2}$, podem ser usados para estudar a aerodinâmica de carros de passageiros, sem limitações. Até pequenas peruas podem ser testadas em escala real. Para veículos comerciais maiores, o autor recomenda que devem ser adotados modelos reduzidos em uma escala de 1:2,5. para os ensaios. 
Túneis com áreas da seção de teste entre $15 \mathrm{~m}^{2}$ e $25 \mathrm{~m}^{2}$ não são grandes o suficiente para testes aerodinâmicos de carros de passageiro tradicionais ou de pequenas peruas, e há limitações.

A área transversal da seção de testes do túnel de vento $\left(A_{N}\right)$ e a configuração do túnel têm grande influência nos resultados de ensaios. Quanto maior essa área $\left(A_{N}\right)$, maior será a possibilidade de reprodução das condições reais.

O fator de bloqueio $(\varphi)$ é um importante parâmetro para avaliar as possibilidades de ensaio na seção de testes. Ele é definido pela razão:

$$
\varphi=\frac{A}{A_{N}}
$$

Onde:

A é a área projetada do veículo no plano perpendicular ao solo.

O bloqueio ocorre quando as linhas de escoamento sofrem contrações, isto é, ficam mais próximas umas das outras, nas regiões perto das paredes do túnel devido à redução de área transversal livre para a passagem do ar. Esse efeito é mostrado na figura 3.22.

(a)

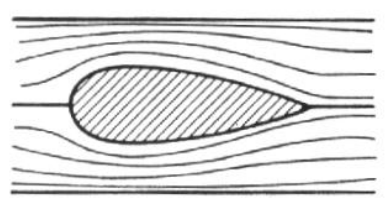

(b)

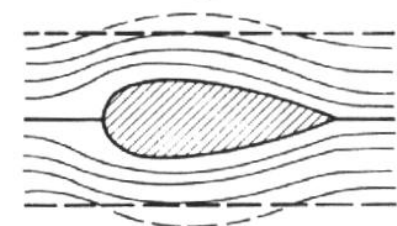

Figura 3.22 - Efeito da fronteira lateral no campo de escoamento: a) efeito de contração em um túnel com seção de testes fechada, b) expansão em um túnel com seção de testes aberta. (HUCHO, 1998)

Segundo Hucho (1998), o limite tolerável para testes em veículo automotivo é de $\varphi=0,10$. Neste trabalho, o túnel de vento adotado como referência para as simulações numéricas apresenta área com seção transversal de aproximadamente $56 \mathrm{~m}^{2}$ e a média de área projetada dos veículos de passeio é da ordem de $2 \mathrm{~m}^{2}$, desta forma, o fator de bloqueio de $\varphi=0,035$ encontra-se dentro dos limites recomendados. 
É na seção de testes onde as forças que o ar exerce sobre o corpo estudado são medidas, na maioria das vezes, por meio de uma balança aerodinâmica. Por meio das forças medidas por essa balança, obtêm-se os valores do arrasto, da sustentação, e de forças laterais. A figura 3.23 ilustra uma balança aerodinâmica montada sob um sistema de esteira rolante, no túnel de vento Windshear.

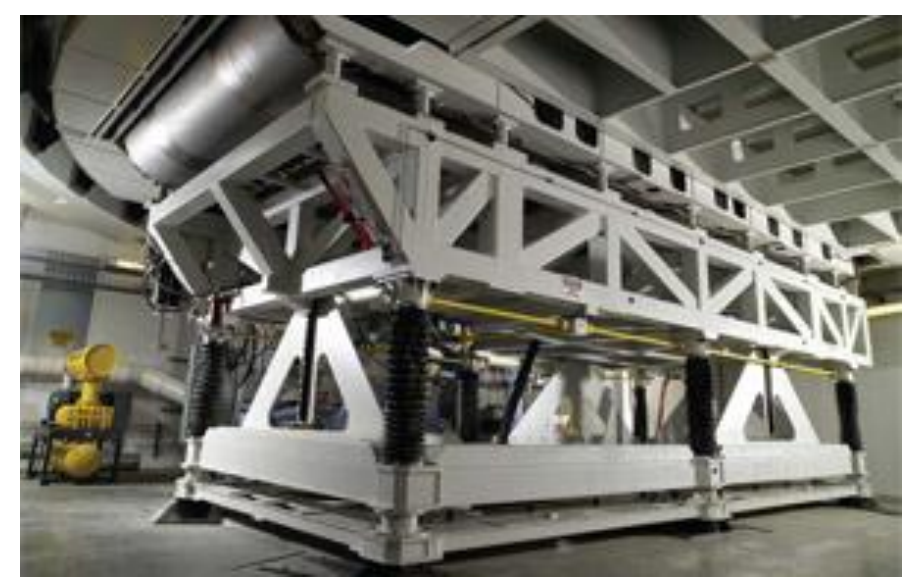

Figura 3.23 - Balança aerodinâmica do túnel de vento Windshear, localizado na Carolina do Norte, EUA.(WINDSHEAR, 2008)

\subsubsection{Telas e colméias retificadoras}

$\mathrm{Na}$ seção de entrada do túnel de vento de circuito aberto são instaladas telas protetoras e estabilizadoras, conhecidas também como colméias retificadoras de fluxo, responsáveis por funções que vão desde uniformizar o escoamento como proteger a seção de testes para que nenhum objeto estranho penetre no fluxo de ar, comprometendo o ensaio realizado. Pode-se ver um exemplo de tela protetora na figura 3.24. 


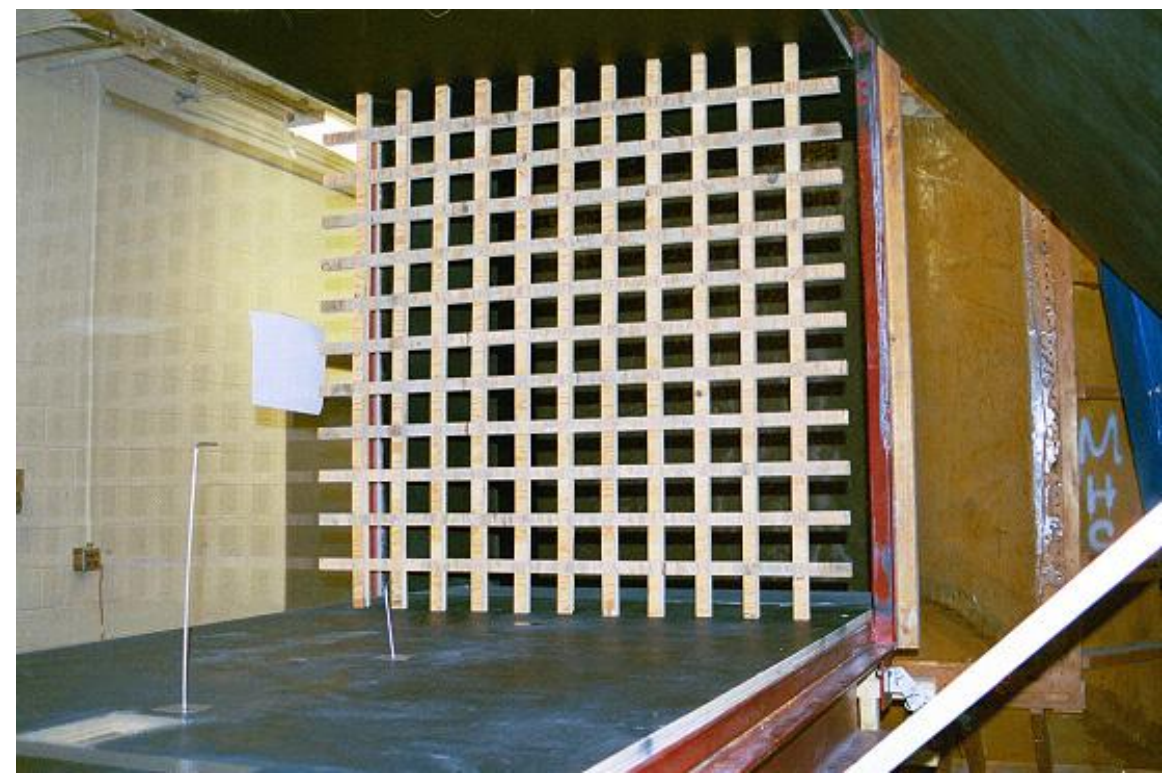

Figura 3.24- Detalhe da tela de proteção de um túnel de vento.(PURDUE, 2009)

Segundo Katz (1995), as grandes telas retificadoras, localizadas na entrada de túneis de vento de circuito aberto, podem ser feitas de pequenos elementos de colméia ou vários elementos simples de tela. Sua função primária é reduzir o efeito de correntes externas, melhorando qualidade do escoamento, pois o fluxo que passa através da tela será estabilizado e chegará até a seção de testes o mais uniforme possível. As telas têm ainda a finalidade de evitar que objetos estranhos sejam sugados pelo túnel e possam danificar o ventilador. Pode ser visto na figura 3.25 um exemplo de uma grande tela retificadora no túnel de vento da NASA (National Aeronautics and Space Agency). 


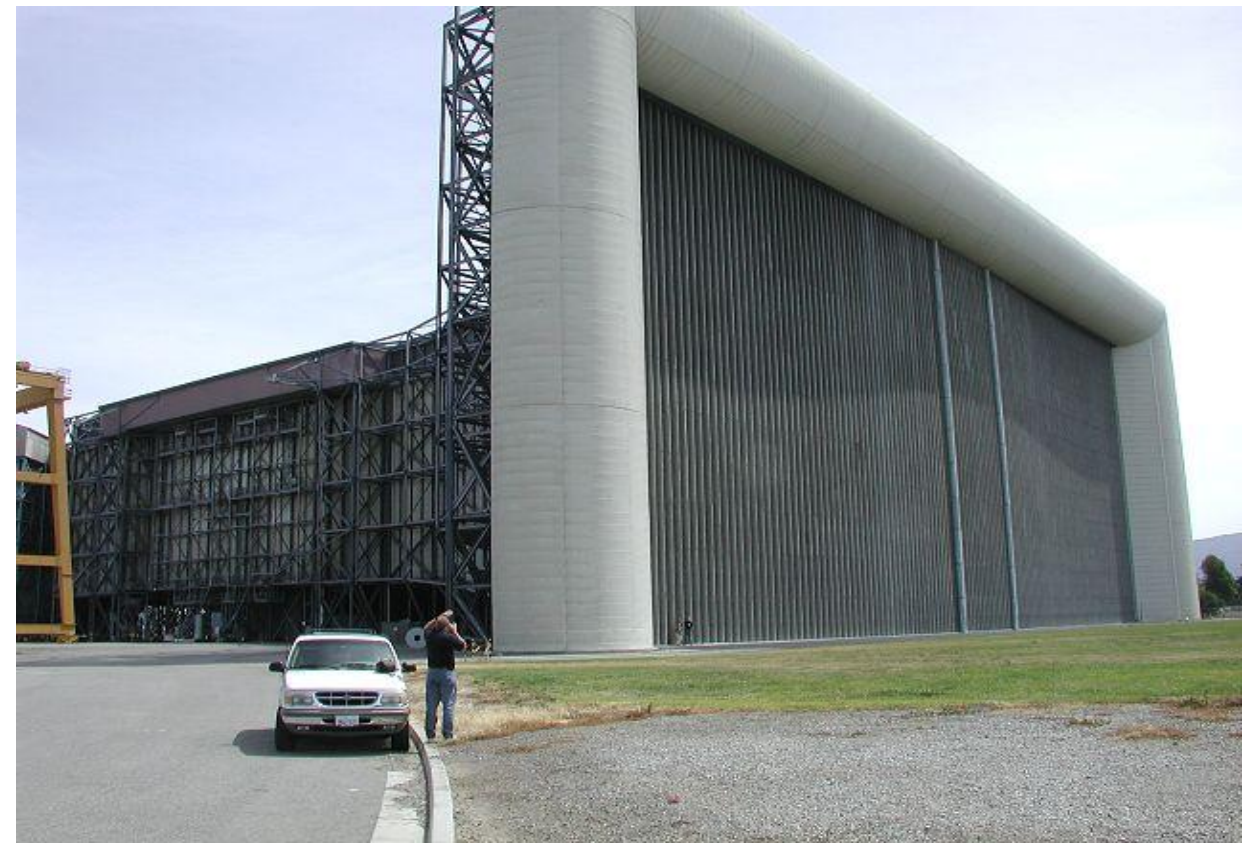

Figura 3.25 - Colméia retificadora na entrada do túnel de vento da NASA (NASA, 2008)

\subsubsection{Ventilador}

O conjunto motor-ventilador faz com que o ar se movimente no interior do túnel de vento e viabilize, na seção de testes, um padrão de escoamento com as velocidades desejadas para os ensaios. Em relação à seção de testes do túnel de vento, os ventiladores podem insuflar ou aspirar o ar, dependendo das definições construtivas do túnel. Caso o ventilador seja montado antes da seção de testes, ele insuflará o ar em direção a ela. Caso seja selecionada a opção de alocar o ventilador depois da seção de testes, ele aspirará o ar para a mesma.

Há túneis de vento que operam com um único ventilador de grandes dimensões e em outros casos, múltiplos ventiladores movimentam o ar em direção da seção de testes. A utilização de um ou múltiplos ventiladores é definida pelas características dimensionais da seção do túnel e também pelo custo. Um exemplo de ventilador de grande porte é o caso do túnel de vento da General Motors, o qual possui 13 metros de diâmetro, e como já dito está sendo adotado como referência para as simulações numéricas deste trabalho. A imagem do ventilador deste túnel é mostrada na figura 3.26. 


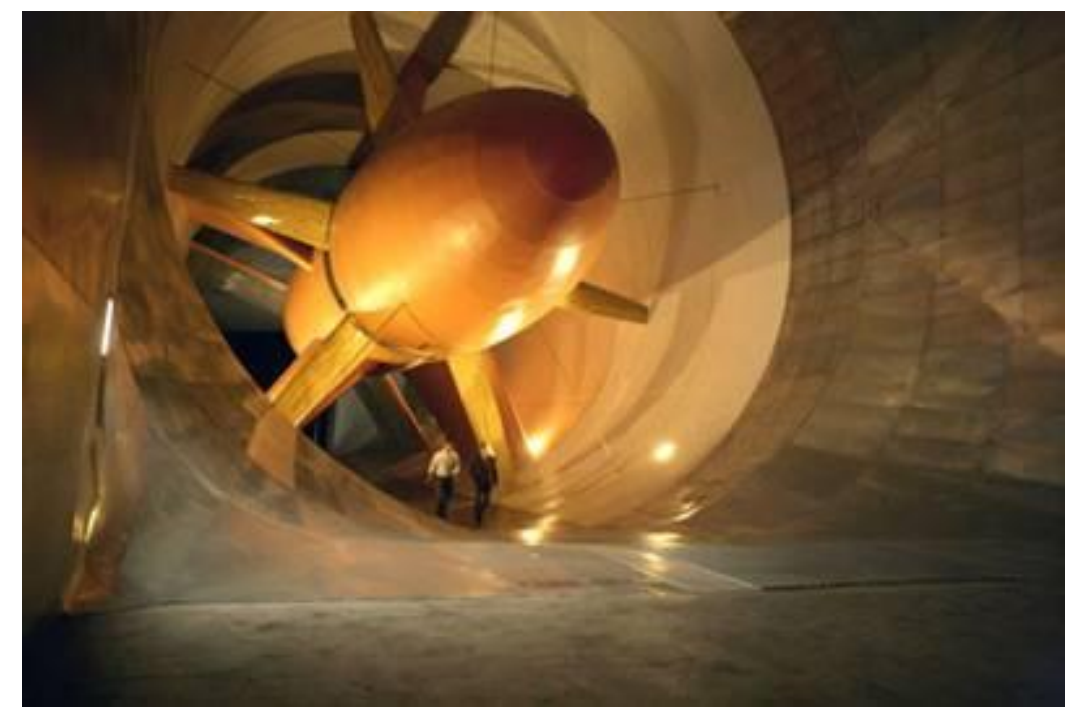

Figura 3.26 - Ventilador do túnel de vento da General Motors, em Warren.(RELATÓRIO DE ENSAIO DA CAMINHONETE, 2007)

Túneis de vento de circuito fechado possuem guias após o ventilador para eliminar a rotacionalidade do escoamento e conseguir fazer curvas dentro do circuito do túnel, mantendo a uniformidade do fluxo e evitando a separação da camada limite. Um exemplo dessas guias são mostrados na figura 3.27.

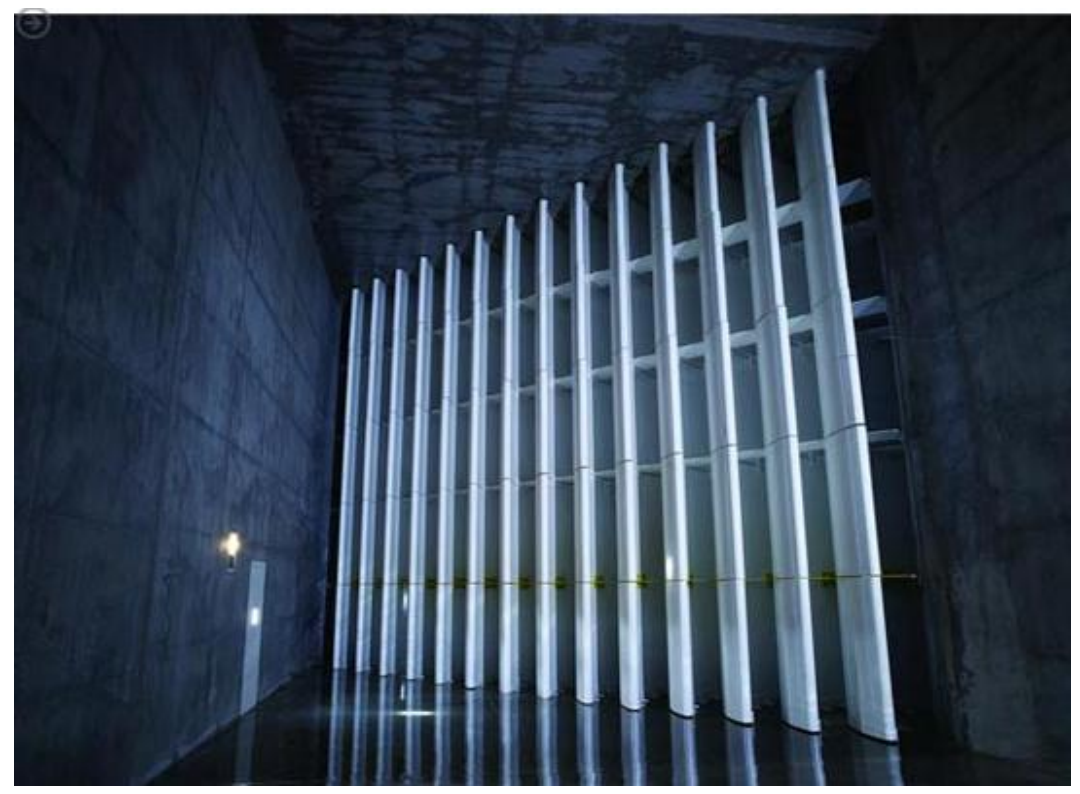

Figura 3.27 - Guias de ar, localizadas após o ventilador do túnel de vento Windshear, na Carolina do Norte, EUA.(WINDSHEAR, 2008) 


\subsection{SIMULAÇÃO NUMÉRICA}

Uma solução para acelerar o desenvolvimento da parte aerodinâmica de um veículo foi a introdução do cálculo por métodos numéricos. A dinâmica dos fluidos computacional, em inglês identificada por Computational Fluid Dynamics (CFD) emprega programas de computador que simulam diversas condições, situações e interações de fluido com outros meios, em geral sólidos, escoamento ao redor de corpos, reação entre fluidos, entre outros.

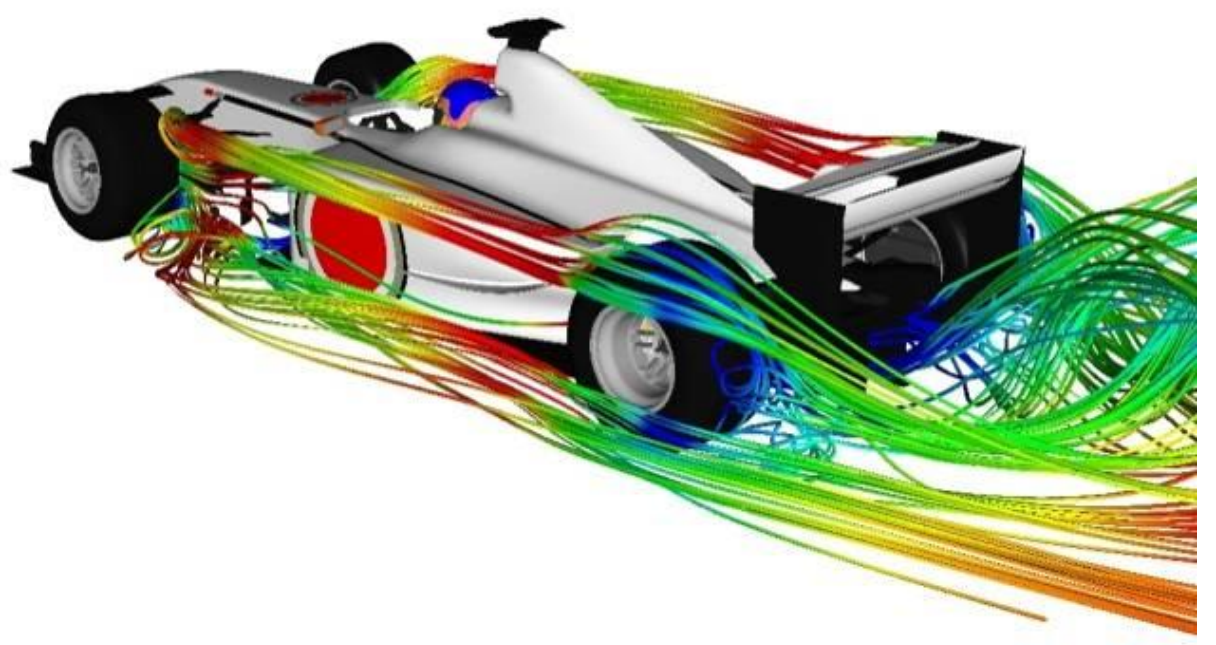

Figura 3.28 - Linha de fluxo, em torno de um carro de Fórmula 1, calculadas por um programa de CFD. (FLUENT, 2003)

\subsubsection{Breve histórico}

Os primeiros códigos de dinâmica dos fluidos computacional apareceram no começo da década de 60, embora apenas na década de 70 que os cálculos realizados por esses softwares apresentaram resultados coerentes.

Na indústria, o CFD foi adotado na década de 80 , para a resolução de pequenos trabalhos, embora a expansão significativa desse tipo de simulação ocorreu na década de 90 , quando os softwares desenvolvidos 
começaram a oferecer conexão com outros programas de engenharia, principalmente CAD e CAE.

Inicialmente, na década de 80, segundo Quim (2007), as empresas automotivas e aeronáuticas, como GM, Mercedes-Benz e Boeing, desenvolveram softwares e metodologias próprias para cálculo computacionais de propriedades aerodinâmicas. Mas eles ficaram obsoletos muito rapidamente e não tinha uma confiabilidade elevada. Além disso, muitas empresas estabeleceram parcerias com companhias que produzem programas comerciais de CFD, tendo como objetivo o desenvolvimento de módulos específicos aplicados a um determinado tipo de simulação.

Dessa forma, os trabalhos recentes sobre simulação utilizando CFD (QUIM e WÄSCHLE, 2007) já utilizam softwares comerciais de grande popularidade, tais como o FLUENT®, StarCD ${ }^{\circledR}, \mathrm{UH}^{\circledR} \mathrm{D}^{\circledR}, \mathrm{CFX}^{\circledR}, \mathrm{PAM}^{\circledR}$ FLOW $^{\circledR}$ e outros.

Para as simulações dos diferentes tipos de configuração de solo deste projeto, os softwares de CFD utilizados são o FLUENT® para os cálculos de mecânica dos fluidos e o software T-GRID® para geração de malha volumétrica, além do Hypermesh® para geração de malha superficial 2D.

\subsubsection{Características dos Softwares de CFD}

Segundo Hucho (1998), simulações numéricas são muito boas para avaliar diversos tipos de formas de carros, numa fase de desenvolvimento de um novo veículo, por exemplo. Além disso, permitem investigar situações que são difíceis de testar em um túnel de vento. Dois veículos em ultrapassagem é um exemplo disso. CFD está evoluindo lentamente como uma nova ferramenta básica em aerodinâmica.

Os métodos numéricos, em geral, para calcular escoamentos são baseados nas equações completas de Navier-Stokes. Elas são equações diferenciais de segunda ordem parciais, não-lineares que descrevem 0 comportamento do escoamento. 
O programa de computador FLUENT® pode ser classificado como um software que resolve as equações de Navier-Stokes pelo método RANS (Reynolds-average Navier Stokes), ou seja, equações de Navier-Stokes com as tensões médias de Reynolds.

Segundo FERZIGER (1999), é um método para descrever o comportamento de um escoamento turbulento, onde suas equações são obtidas pela média das equações de movimento no tempo, em uma coordenada especifica. O conjunto de equações formado pelo método RANS não forma um sistema fechado, necessitado de aproximações, que são realizadas com o auxílio de modelos de turbulência. Estes modelos introduzem novas equações representando a parte da turbulência do escoamento e complementam o sistema de equações.

Existem diversos modelos de turbulência pré-determinados no banco de dados dos programas de CFD, sendo que, para este trabalho, o modelo de turbulência utilizado é o k-E. As dificuldades de modelar turbulência com uma formulação mais geral e a complexidade da malha necessária para descrever escoamentos ao redor de veículos são os principais pontos de pesquisa nessa área.

Com a crescente capacidade de processamento das máquinas, trabalhos recentes de avaliação aerodinâmica já utilizam modelos detalhados de CFD que podem chegar a 25 milhões de elementos, com alto detalhamento de componentes do veículo. Os mesmos utilizam processamentos paralelos com a utilização de supercomputadores, os HPCs.

\subsubsection{Trabalhos envolvendo simulação numérica de escoamentos}

O uso do método computacional vem ganhando cada vez mais campo para o auxilio no desenvolvimento tanto de aerodinâmica, quanto de sistemas de arrefecimento, como linhas de combustível entre outros sistemas que envolvam fluidos. 
Quim (2007) em seu trabalho desenvolve uma metodologia para a correlação de ensaios reais na parte de arrefecimento veicular comparando resultados com valores obtidos em simulações via CFD. Todas as partes e trocadores de calor são representados na simulação numérica e existe uma boa correlação entre os mesmos.

Wäschle, et al (2004) descreve em seu trabalho a influência aerodinâmica de se analisar um modelo de carro com a roda e pneu rotacionando, usando testes e simulações numéricas. Vários tipos de rodas foram testados e pode-se dizer que CFD e ensaios experimentais associaram-se em busca do melhor resultado. Baseado nos resultados de simulação, o escoamento em torno de uma roda rotacionando foi caracterizado.

O resultado obtido mostrou que a diferença no coeficiente de arrasto no caso do túnel com piso fixo comparado com o sistema de esteira rolante, para um mesmo veículo, é de 0,012 tanto para o valor medido experimentalmente quanto para o obtido por simulação numérica, comprovando a capacidade dos novos softwares de dinâmica dos fluídos em predizer as propriedades aerodinâmicas de um corpo testado.

Wäschle (2007) também realiza um trabalho considerando apenas uma roda de carro de competição - Fórmula 1 isolada, simulada usando 3 diferentes programas de CFD e experimentalmente testada em túnel de vento, avaliando seu comportamento parada e em movimento de rotação.

No trabalho, o estudo indica que o resultado do coeficiente de arrasto obtido por simulação se aproxima muito ao obtido em ensaio experimental, com uma diferença de $3 \%$, tanto para o caso de roda parada quanto para o caso de roda em movimento. Há apenas pequenas discrepâncias locais no campo de velocidade e de pressão obtidos pelos cálculos de simulação, comparado com os padrões medidos experimentalmente.

Wiedemann (1996), em seu trabalho, compara os ensaios de túnel de vento com o solo fixo e móvel para um veículo. Analisa os valores de arrasto obtidos em ambos, apresentando também a determinação analítica do 
consumo de combustível desse mesmo veículo, mostrando a influência do tipo de ensaio.

Estudos feitos pelo Elofsson (2002) e Beauvais (1968) mostram que, no ensaio de uma roda isolada, colocada em um túnel de vento com piso fixo, conseguiram identificar a formação de vórtices em forma de ferradura, quando o escoamento passa por ela e mostrado na figura 3.29 a).

Cogotti (1983) realizou um estudo comparativo considerando uma roda em duas condições. Uma mesma condição que Elofsson (2002) e Beauvais (1968) utilizaram em seus estudos, ou seja, fixa. Na segunda condição, essa mesma roda é colocada sobre um piso móvel e rotaciona, simulando a condição real de operação dessa roda. Experimentalmente foi determinado o coeficiente de arrasto para cada uma das condições analisadas e concluiu-se que a roda em movimento possui menor valor, comparado ao estudo com a que está fixa. Essa conclusão está na figura $3.29 \mathrm{c})$.

a)

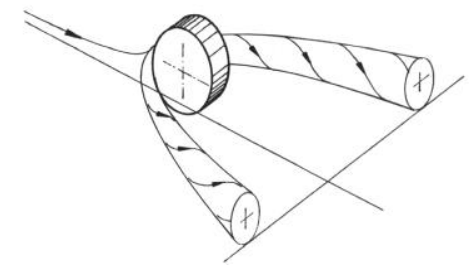

$\omega=0$

$\omega$ - velocidade angular b)

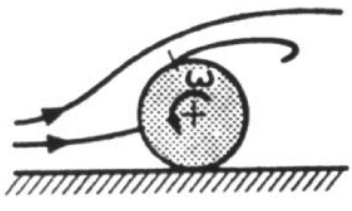

$\omega \neq 0$

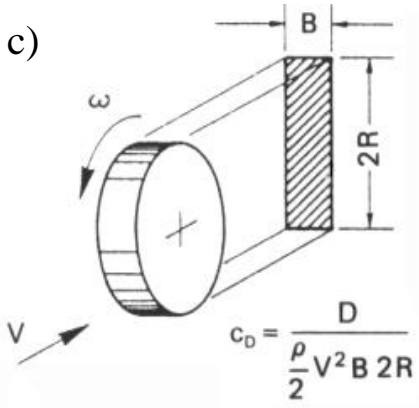

\begin{tabular}{|l|l|l|}
\cline { 2 - 3 } \multicolumn{1}{l|}{} & $\omega=0$ & $\omega=\frac{\mathrm{V}}{\mathrm{R}}$ \\
\hline $\mathrm{c}_{0}$ & 0.593 & 0.579 \\
\hline
\end{tabular}

Figura 3.29 - a) Separação de fluxo e formação do vórtice de ferradura para rodas em condição estacionária Elofsson (2002) b) Deslocamento do ponto de estagnação e alteração da esteira de vórtices devido à rotação da roda Cogotti (1983). c) Redução do coeficiente de arrasto para roda em movimento Cogotti (1983). 
Yang e Schenkel (2004) utilizaram três modelos de carro de passeio SUVs e caminhonetes genéricos, para estudar os efeitos de blocagem em túneis de vento de circuito fechado. Para isso, foi utilizado o CFD comparado com os ensaios em escala real e, a partir da validação da metodologia de cálculo por computador, diferentes túneis de ventos virtuais, com seções de testes diferentes foram analisados, mostrando o efeito de blocagem com a variação da seção de testes.

Boermans e Hemerik (2006) mostram, em seu artigo, que a Universidade de Delft, na Holanda, utilizou CFD e o software FLUENT® no desenvolvimento aerodinâmico de seu terceiro carro solar chamado Nuna 3. O uso de simulações economizou tempo de desenvolvimento e também diminuiu a quantidade de ensaios de túnel de vento neste veículo, onde um baixo coeficiente de arrasto é extremamente necessário para que se economize energia e o rendimento do veículo seja maior. Posteriormente ao desenvolvimento, o Nuna 3 foi campeão da World Solar Challenge de 2007, competição de veículos solares realizada bianualmente na Austrália.

O trabalho de Singh (2008), mostra a análise de um carro de corrida NASCAR quanto suas propriedades aerodinâmicas, utilizando um modelo virtual do veículo e do túnel de vento, com esteira rolante. Através do software FLUENT®, diversas alternativas de formas para melhorar 0 coeficiente de arrasto do veículo foram estudadas, a partir do modelo base desse veículo de corrida. Além disso, o artigo mostra a evolução do veículo quanto a quesitos aerodinâmicos, seguindo as novas regras da competição.

$O$ estudo de validação de um modelo de um sedan da OPEL analisado em túnel de vento com um modelo feito em elementos finitos é o tema do trabalho de Fischer, et al (2008). Nesse trabalho, um modelo extremamente detalhando foi analisado em túnel e posteriormente representado virtualmente. Os resultados de ambas análises foram semelhantes, considerando o valor de arrasto obtido. 
Outra aplicação de CFD no desenvolvimento aerodinâmico de veículos é mostrada no trabalho de Batista (2007), onde é feito o estudo de diversas formas de carenagens a serem adotadas em um veículo de competição de economia de combustível. O estudo visa determinar as propriedades aerodinâmicas, principalmente o coeficiente de arrasto de diversos perfis de carenagem que se adaptem a esse tipo de veículo, ajudando a melhorar seu rendimento e ampliar sua autonomia por litro de combustível. 


\section{DINÂMICA DOS FLUIDOS}

Este capítulo trata fundamentalmente dos conceitos básicos de dinâmica dos fluidos, utilizado neste trabalho. O escoamento de um fluido é causado por meio de forças externas, tais como gradiente de pressão, a efeitos relacionados à gravidade, às tensões de cisalhamento do fluido, à rotação e à tensão superficial. Para que problemas envolvendo escoamento de fluidos sejam solucionados analiticamente, são necessários modelos matemáticos capazes de representá-los. O escoamento ao redor de um veículo, localizado na seção de teste de um túnel de vento é considerado totalmente turbulento, segundo Hucho (1988), ou seja, é necessário utilizar o conceito de turbulência para descrevê-lo com maior exatidão. $\mathrm{Na}$ análise computacional da influência da utilização de diferentes tipos de solo em um túnel de vento, foco deste trabalho, as equações que regem o escoamento e descrevem a turbulência serão resolvidas pelo software FLUENT®.

\subsection{EQUAÇÕES DE NAVIER-STOKES.}

Tomando-se como base uma partícula fluida elementar, onde sua estrutura molecular e o seu movimento molecular são ignorados, conseguese desenvolver as equações de conservação de massa, quantidade de movimento e energia (VERSTEEG E MALALASEKERA, 1995). O comportamento do fluido estudado é descrito com base na velocidade, pressão, densidade e temperatura, além da parte derivativa do espaço e tempo.

As equações que descrevem o escoamento de um fluido provêm das equações de conservação de massa, força, energia e de estado. $\mathrm{Na}$ formulação de conservação geral do transporte, de forma conservativa, é adotada pela expressão:

$$
\frac{\partial \rho \phi}{\partial t}+\operatorname{div}\left(\rho \phi u_{r}\right)=\operatorname{div}(\Gamma \operatorname{grad} \phi)+S_{\phi}
$$


Onde:

$u_{r}$

velocidade relativa entre o fluido e a velocidade do sistema de coordenadas

grandeza escalar $(u, v, w, k, \varepsilon, E)$

$\Gamma$

coeficiente de difusão

$S_{\phi}$

termo fonte

$\mathrm{Na}$ equação 4.1, o termo escalar $\phi$ pode ser representada pela velocidade, temperatura ou mesmo a concentração. O lado esquerdo da equação representa a taxa de variação de $\phi$ no tempo e do termo convectivo, já no lado direito temos o termo difusivo ( $\Gamma$ é o coeficiente de difusão) e o termo fonte $S_{\phi}$.

Para a equação da conservação de massa $\phi=1$ e para conservação de momento $\phi=u, v, w$, representando as equações de Navier-Stokes, as quais descrevem o movimento de um fluido. A tabela 4.1 mostra essas equações, providas da equação 4.1.

Tabela 4.1 - Equações da Conservação para um fluido Newtoniano e compressível (VERSTEEG E MALALASEKERA, 1995).

\begin{tabular}{|c|c|c|}
\hline $\begin{array}{c}\text { Equaça de } \\
\text { Conservação de } \\
\text { Massa }\end{array}$ & $\frac{\partial \rho}{\partial t}+\operatorname{div}\left(\rho u_{y}\right)=0$ & $(4.2)$ \\
\hline $\begin{array}{l}\text { Quantidade de } \\
\text { Movimento em } x\end{array}$ & $\frac{\partial(\rho u)}{\partial t}+d i(u, \rho u)=-\frac{\partial p}{\partial x}+d i v(u \operatorname{grad} u)+S_{M}$ & (4.3) \\
\hline $\begin{array}{l}\text { Quantidade de } \\
\text { Movimento em y }\end{array}$ & $\frac{\partial(\rho v)}{\partial t}+d i v(u, \rho v)=-\frac{\partial p}{\partial x}+d i v(\mu \operatorname{grad} v)+S_{u}$ & (4.4) \\
\hline $\begin{array}{l}\text { Quantidade de } \\
\text { Movimento em z }\end{array}$ & $\frac{\partial(\rho w)}{\partial t}+\operatorname{div}(u, \rho w)=-\frac{\partial p}{\partial x}+\operatorname{div}(\mu g r a d w)+S_{1 L}$ & (4.5) \\
\hline Energia Irterna & $\frac{\partial(\rho E)}{\partial t}+\operatorname{div}\left(u_{r} \rho E\right)=-p \operatorname{div} u_{+}+\operatorname{div}\left(k_{2} g(a d T)+\Phi+S_{z}\right.$ & $(4.6)$ \\
\hline
\end{tabular}

Onde:

$\Phi$ dissipação viscosa

E energia interna 


\subsection{CONCEITO DE TURBULÊNCIA}

O fenômeno da turbulência está associado ao número de Reynolds crítico, que é uma relação de forças inerciais com as forças viscosas. A instabilidade do fluxo observado é originária de forças viscosas e variações de pressões, que resultam em regiões com pequenas perturbações no fluxo laminar. O Reynolds é calculado considerando-se a velocidade ao longe, as propriedades do fluido e a coordenada de posição tomada no inicio do veículo.

Para escoamentos com valores de Reynolds abaixo do Reynolds crítico, o escoamento característico é o laminar $\left(R e<R e_{\text {crit }}\right.$ ). Para números acima do valor crítico, o escoamento se dá de maneira caótica e suas propriedades variam ao longo do tempo e das regiões do escoamento, o que caracteriza um escoamento turbulento ( $R e>R_{\text {ecrit) }}$. A maior parte dos tipos de escoamento encontrado em problemas reais de engenharia são considerados turbulentos, inclusive o escoamento sobre um veículo, segundo Hucho (1998).

A transição de um escoamento laminar para turbulento pode ser explicada considerando a estabilidade laminar para pequenas perturbações. Essa transição ocorre em um intervalo chamado de instabilidade hidrodinâmica. Como essa parte transitória é extremamente difícil de ser representada, equacionada e modelada, em engenharia, é suficiente a análise do escoamento laminar e do escoamento turbulento plenamente desenvolvido.

O outro fator que leva a ignorar essa fase de transição é que não existe uma teoria concreta que a modele de maneira satisfatória. Os códigos CFD disponíveis ignoram esta fase de transição e classificam o escoamento laminar ou turbulento plenamente desenvolvido.

A análise da turbulência pode ser dividida em três categorias:

- Experimental: permite obter informações qualitativas e quantitativas de um determinado fluxo; 
- Modelagem: permite o desenvolvimento e refino dos modelos matemáticos de modo a representar o mais próximo dos efeitos da turbulência;

- Controle: estudos que envolvem tanto a parte experimental quanto a parte matemática de forma a manipular e controlar o fluxo. Por exemplo, alterando as condições geométricas para melhorar uma mistura, ou utilizando um controle ativo para a redução do arrasto.

O método das equações de movimento tem sido analisado extensivamente, porém ainda não é possível predizer com precisão sem recorrer aos resultados empíricos. Os métodos estatísticos das equações de movimento sempre enfrentam situações em que o número de incógnitas são maiores que o número de equações. Este tipo de situação é denominado de problemas de fechamento, a qual necessitam de hipóteses para a obtenção de equações adicionais. A teoria da turbulência está relacionada com o postulado da relação entre tensões e taxa de deformação a qual está associada com o efeito da viscosidade, que supostamente tem o papel similar à da viscosidade molecular no escoamento laminar. A técnica de uso de escala de similaridade (KOLMOGOROV 1941) tem sido amplamente utilizado no estudo da turbulência.

\subsubsection{Equacionamento da turbulência}

A aleatoriedade do escoamento turbulento faz com que suas propriedades possam ser decompostas em um valor médio mais uma flutuação. Essa média é utilizada para a caracterização do escoamento em suas propriedades.

$$
\begin{aligned}
& u_{r}=\bar{u}_{r}+u_{r}^{\prime}, u=\bar{u}+u^{\prime} \quad ; v=\bar{v}+v^{\prime} \text { e } w=\bar{w}+w^{\prime} \\
& p=\bar{p}+p^{\prime} \\
& \phi=\bar{\phi}+\phi^{\prime}
\end{aligned}
$$


A energia cinética turbulenta $k$, associada com turbulência é definida como a soma das flutuações médias elevadas ao quadrado, dividindo o valor obtido por 2, como mostrado na equação 4.10:

$$
k=\frac{1}{2}\left(\overline{u^{\prime 2}}+\overline{v^{\prime 2}}+\overline{w^{\prime 2}}\right)
$$

Para investigar o efeito da turbulência nas equações de NavierStokes, serão substituídas as equações 4.7, 4.8 e 4.9, ou seja, as somas do valor médio com sua flutuação e serão consideradas as regras de comutação das flutuações demonstradas pelo Tennekes and Lumley (1972). O resultado é mostrado na tabela 4.2 .

Tabela 4.2 - Equações de escoamento turbulento para fluido compressível (VERSTEEG E MALALASEKERA, 1995).

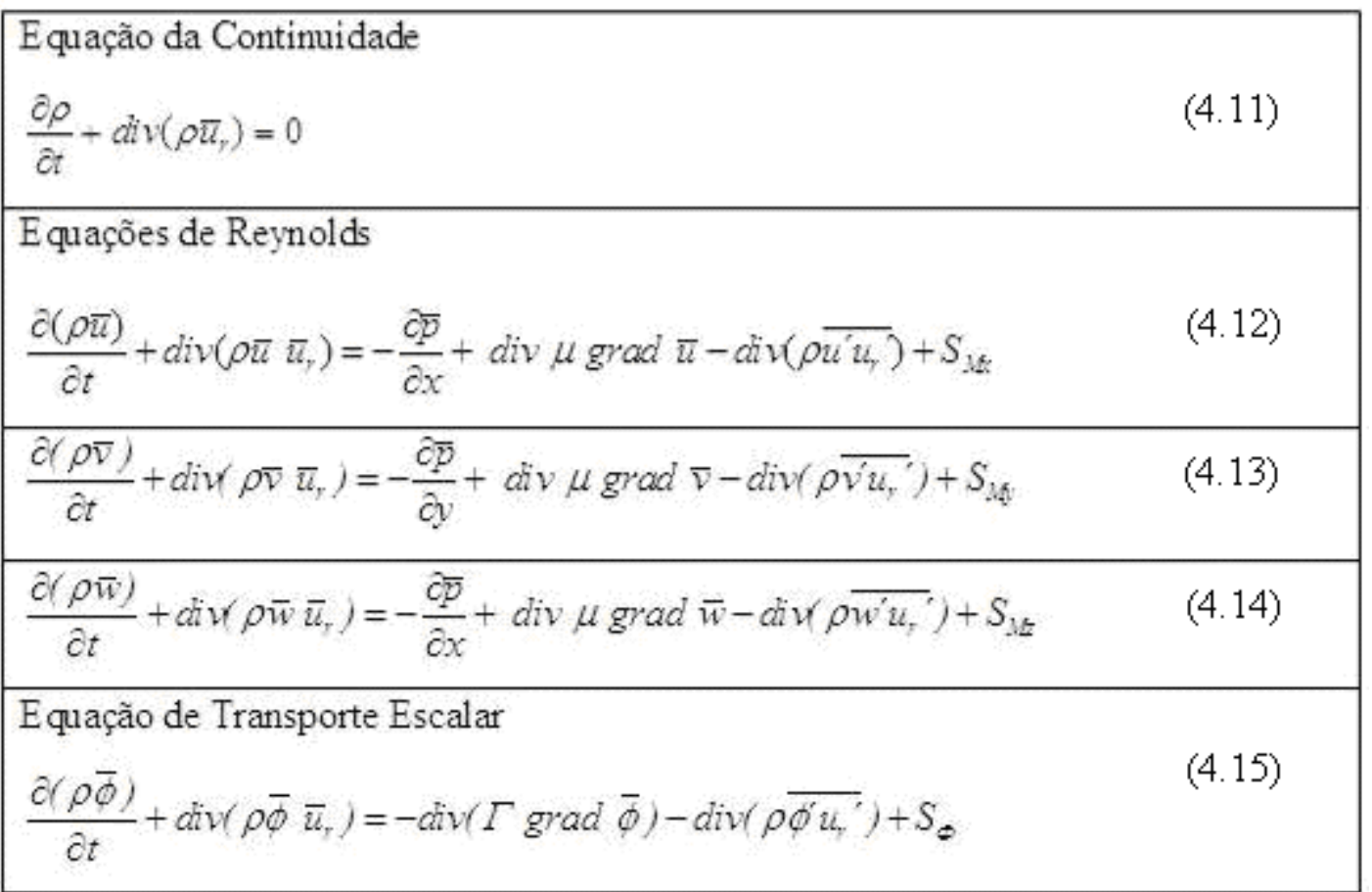

\subsubsection{Modelo de turbulência $\mathrm{k}-\varepsilon$}

A utilização de um modelo de turbulência é um procedimento computacional utilizado para que as equações de Navier-Stokes possam ser resolvidas, uma vez que esses modelos fornecem equações que são usadas 
para solucionar um sistema de equações, compostos por Continuidade, Reynolds e Transporte Escalar (tabela 4.2).

Um dos modelos mais usuais em programas comerciais de CFD é 0 modelo k-E. Este modelo baseia na existência de analogia entre as tensões viscosas e as tensões de Reynolds para o fluxo médio. As tensões viscosas são consideradas como sendo uma proporcionalidade da taxa de deformação do elemento fluido, relação proposta por Boussinesq (1877).

As equações de $k$ e $\varepsilon$ são obtidas pelo produto das equações de Reynolds pelo respectivo termo $\bar{u}, \bar{v}$ e $\bar{w}$ e, posteriormente a sua soma, obtendo-se:

$$
\begin{aligned}
& \frac{\partial(\rho k)}{\partial t}+\operatorname{div}\left(\rho k \bar{u}_{r}\right)=\operatorname{div}\left[\frac{\mu_{\mathrm{t}}}{\sigma_{\mathrm{k}}} \operatorname{grad} k\right]+2 \mu_{\mathrm{t}} E_{i j} \cdot E_{i j}-\rho \varepsilon \\
& \frac{\partial(\rho \varepsilon)}{\partial t}+\operatorname{div}\left(\rho \varepsilon \bar{u}_{r}\right)=\operatorname{div}\left[\frac{\mu_{t}}{\sigma_{\varepsilon}} \operatorname{grad} \varepsilon\right]+C_{1 \varepsilon} \frac{\varepsilon}{k} 2 \mu_{t} E_{i j} \cdot E_{i j}+ \\
& -C_{2 \varepsilon} \rho \frac{\varepsilon^{2}}{k}
\end{aligned}
$$

Para as equações 4.16 e 4.17, os termos no lado esquerdo mostram a taxa de variação e o termo convectivo; no lado direito, existem o transporte por difusão, a taxa de produção e a taxa de dissipação.

As equações de $\boldsymbol{k}-\boldsymbol{\varepsilon}$, utilizadas neste trabalho, apresentam cinco constantes que são obtidas experimentalmente, $C_{\mu}, \sigma_{k}, \sigma_{\varepsilon}, C_{1 \varepsilon}$ e $C_{2 \varepsilon}$ mostrados na tabela 4.3:

Tabela 4.3 - Coeficientes do modelo $k-\varepsilon$ de Turbulência

\begin{tabular}{|c|c|c|c|c|}
\hline$C_{\mu}$ & $\sigma_{k}$ & $\sigma_{\varepsilon}$ & $C_{1 \varepsilon}$ & $C_{2 \varepsilon}$ \\
\hline 0,09 & 1,00 & 1,30 & 1,44 & 1,92 \\
\hline
\end{tabular}

Onde:

$C_{1 \varepsilon}$ coeficiente empírico do modelo $k-\varepsilon$ de turbulência

$C_{2 \varepsilon} \quad$ coeficiente empírico do modelo $k-\varepsilon$ de turbulência

$C_{\mu} \quad$ coeficiente empírico do modelo $k-\varepsilon$ de turbulência 


\subsubsection{Condições de contorno do modelo de turbulência k- $\varepsilon$}

Para que os códigos CFD possam realizar os cálculos das características de um escoamento sobre um corpo, necessita-se das equações que modelam $k-\varepsilon$. Elas necessitam das seguintes condições de contorno, representada na figura 4.2:

- Entrada (1): a distribuição de k e $\varepsilon \square$ e as variáveis $\rho, \mu$ e $U_{e}$ devem ser conhecidas e especificadas;

- Plano de Simetria (2): $\partial k / \partial n=0$ e $\partial \varepsilon / \partial n=0$

- Região de Escoamento Livre (3): $k=0$ e $\varepsilon=0$

- Superfície Sólida (4): depende do número de Reynolds junto com a utilização de função de parede, que será especificado no item seguinte.

- Saída (5): a distribuição de pressão p.

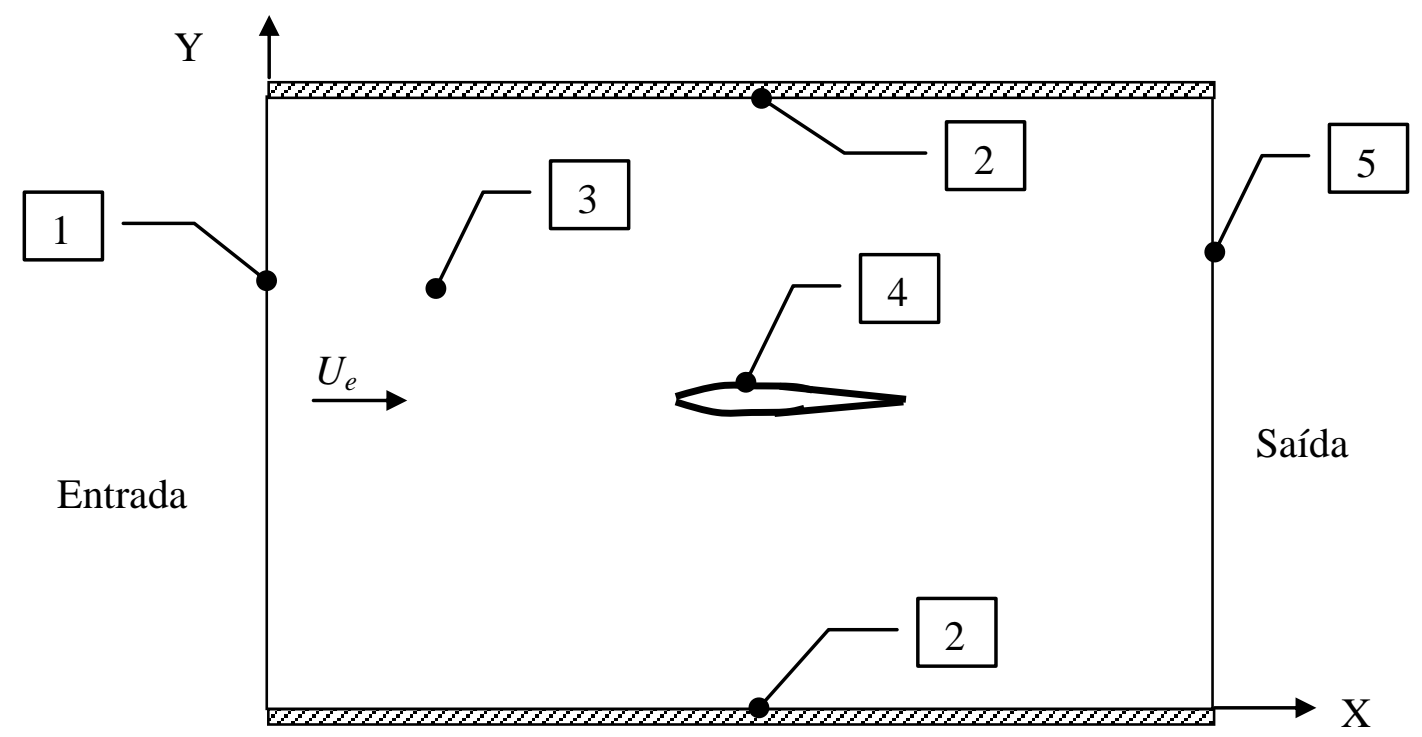

Figura 4.1 - Condições de contornos aplicadas a um perfil de asa em simulação virtual de túnel de vento (QUIM 2007).

Os parâmetros iniciais de $k$ e $\varepsilon$ são importantes na definição da distribuição da turbulência na região de entrada. Uma das dificuldades em modelos de CFD é a obtenção destes valores como parâmetros de entrada, pois dependem de dados empíricos, testes ou de dados de literatura. 


\subsection{DESCRIÇÃO DA FUNÇÃO DE PAREDE}

A estrutura da turbulência possui característica atípica de escoamento próximo a uma parede sólida quando comparada com um escoamento livre. Se analisarmos o número de Reynolds $\left(\operatorname{Re}_{y}=U_{y} / v\right)$ a partir de uma distância $\boldsymbol{y}$ da parede, pode-se verificar que em uma distância y suficientemente longe da parede 0 efeito das forças inerciais é predominante. Enquanto que, para valores de y próximo à parede, o número de Reynolds tende a diminuir de forma a prevalecer as forças viscosas. A velocidade média da região depende além da distância $\boldsymbol{y}$ da parede, da densidade $\rho$, da viscosidade $v$ e da tensão de cisalhamento da parede $T_{w}$. As funções de parede são utilizadas como o termo fonte e, juntamente com as equações de momento e de transporte turbulento modificado, para representar o efeito viscoso da parede.

A análise dimensional demonstrada por Schlichting (1979) resulta na seguinte expressão:

$$
u^{+}=\frac{U}{u_{\tau}}=f\left(\frac{\rho u_{\tau} y}{\mu}\right)=f\left(y^{+}\right)
$$

A equação 4.18 é conhecida como lei de parede, a qual se apresenta a definição de duas adimensionais importantes, a saber, a velocidade $u^{+} \mathrm{e}$ $y^{+}$. 


\section{MODELAGEM NUMÉRICA E ENSAIOS EXPERIMENTAIS DE REFERÊNCIA}

\subsection{CARACTERIZAÇÃO DO TÚNEL DE VENTO}

A modelagem utilizada para realizar as simulações em CFD adota um dos maiores túneis de vento existentes, em que são ensaiados veículos automotivos em escala natural, o da General Motors (GM), situado em Warren, Estados Unidos. Este túnel é dotado de um sistema de circuito fechado e climatizado para avaliação de desempenho aerodinâmico, estabilidade direcional e conforto térmico em veículos de passeio, de médio porte como as "Pick Ups", veículos esportivos e "SUVs" (Sport Utility Vehicle). Na condição real, ele possui o solo da seção de testes fixo, com um sistema de sucção no inicio da seção de testes, visando atenuar o efeito da camada limite do solo do túnel para que não influencie o valor do coeficiente de arrasto medido. Com a ferramenta computacional, é possível, neste mesmo túnel de vento, aplicar a condição de piso móvel e rodas do veículo rotacionando, sem a necessidade de mudar sua configuração original.

Segundo Kelly e Schenkel, (1982), o túnel da GM apresenta uma seção de testes com dimensões $(5,4 \times 10,4 \times 23,0) \mathrm{m}$, construído em metal revestido com uma espessa camada de $600 \mathrm{~mm}$ de concreto para evitar a propagação de ondas sonoras. O fluxo de ar é promovido por um ventilador com hélices de $13 \mathrm{~m}$ de diâmetro e potência de aproximadamente $3000 \mathrm{~kW}$, apto a gerar uma velocidade da ordem de $250 \mathrm{~km} / \mathrm{h}$ por 15 minutos. Um esquema deste túnel de vento está apresentado na figura 5.1. 


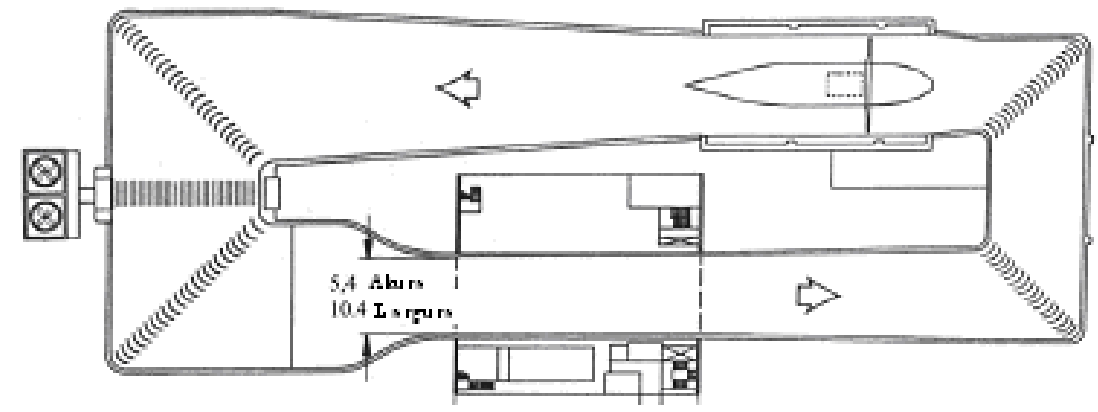

Figura 5.1 - Túnel de Vento da General Motors para testes aerodinâmicos em escala natural de veículos (HUCHO, 1998).

\subsection{CARACTERIZAÇÃO DO VEÍCULO E ENSAIO EXPERIMENTAL DE PROTÓTIPO EM TÚNEL DE VENTO}

No ensaio experimental de referência e na simulação numérica, o carro utilizado é uma caminhonete de pequeno porte, em escala de 1:1, com área frontal de 2,03 $\mathrm{m}^{2}$, colocada na seção de testes do túnel de vento com área de $56,16 \mathrm{~m}^{2}$. As principais dimensões do veículo estão expressas na tabela 5.1 .

Tabela 5.1 - Principais dimensões do veículo estudado

\begin{tabular}{|l|c|}
\hline \multicolumn{1}{|c|}{ DIMENSÕES } & \\
\hline Comprimento Total & $4422 \mathrm{~mm}$ \\
\hline Largura (carroceria) & $1646 \mathrm{~mm}$ \\
\hline Largura Total (espelho a espelho) & $1954 \mathrm{~mm}$ \\
\hline Altura & $1418 \mathrm{~mm}$ \\
\hline Distância do veículo ao solo (referenciada no pára-choque) & $456 \mathrm{~mm}$ \\
\hline Distância entre eixos & $2714 \mathrm{~mm}$ \\
\hline
\end{tabular}

O veículo é mostrado nas figuras 5.2 e 5.3 com o posicionamento do sistema de coordenadas. 


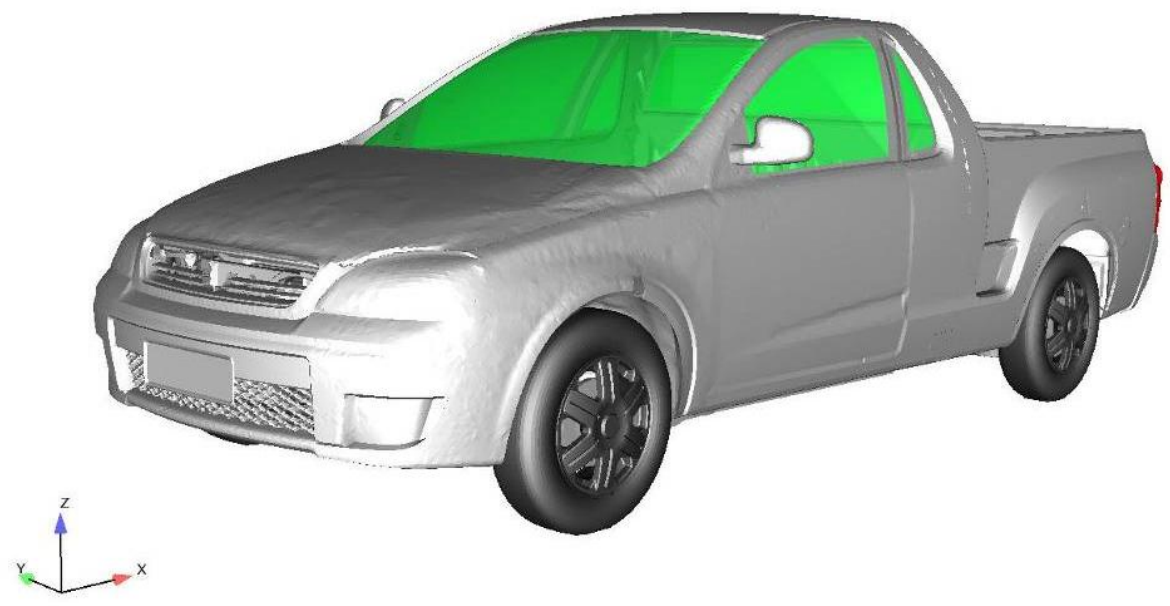

Figura 5.2- Perspectiva do veículo testado e posicionamento do sistema de coordenadas

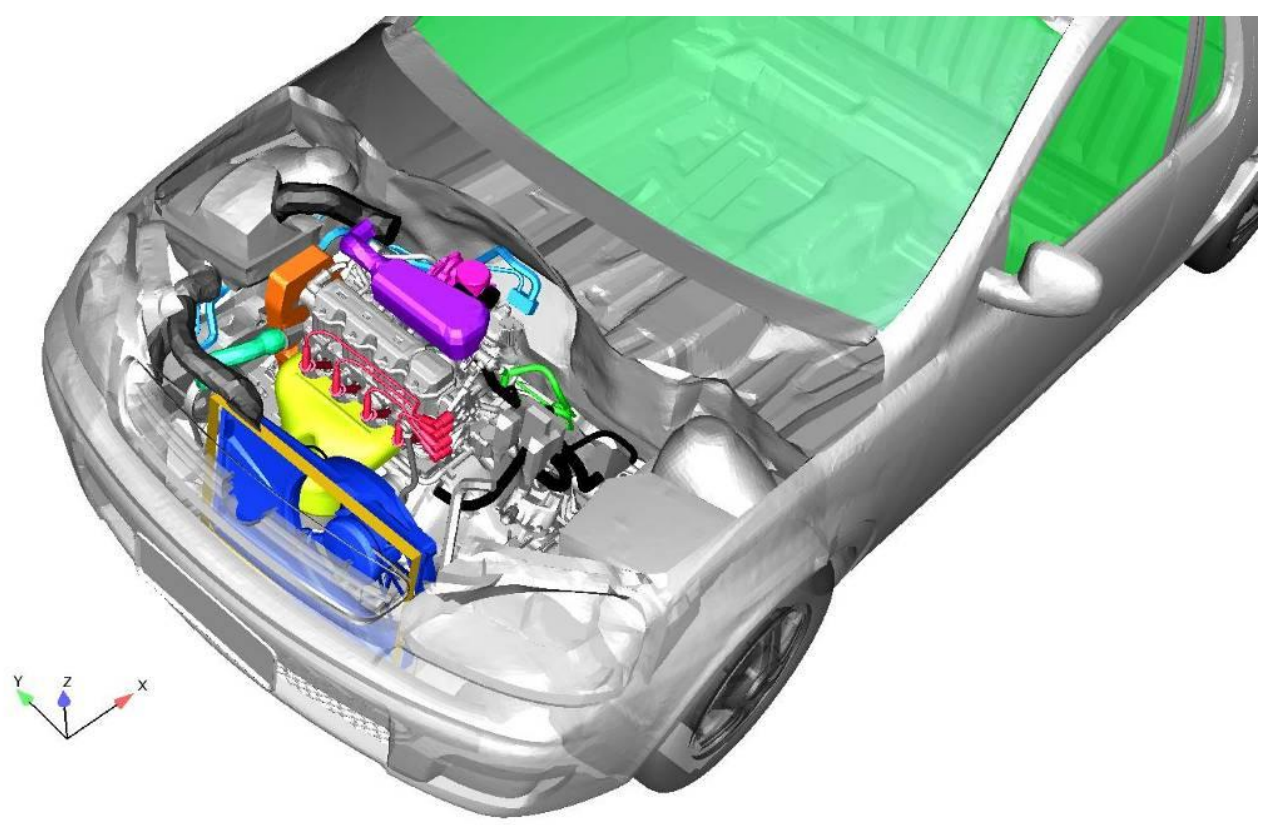

Figura 5.3 - Detalhes internos do motor do veículo.

No ensaio, segundo Relatório de ensaio da caminhonete, (2007), o ar é soprado para a seção de testes com velocidade constante de $110 \mathrm{~km} / \mathrm{h}$, intensidade de turbulência (I) de $0,6 \%$ e medidas de parâmetros aerodinâmicos são feitas por meio de uma balança, montada sob o piso do túnel de vento. 
Segundo este relatório interno, o valor do coeficiente de arrasto obtido no ensaio experimental desta caminhonete, com solo fixo é de 0,430 .

As mesmas condições de teste, citadas neste item, são aplicadas no modelo virtual, adotado na simulação numérica, para a determinação das forças e coeficientes aerodinâmicos. A comparação dos valores obtidos no ensaio experimental com os resultados da simulação, ambos para a condição de solo fixo, tem como objetivo atestar a confiabilidade dos resultados fornecidos pelos softwares de CFD.

\subsection{OS MÉTODOS NUMÉRICOS E SUA APLICAÇÃO}

Para que um objeto possa ser representado virtualmente e sejam aplicados métodos numéricos, sua geometria deve ser discretizada. Estudos envolvendo dinâmica de fluídos são, geralmente, descritos pelas equações diferenciais parciais, que podem ser resolvidas analiticamente, em casos particulares e com simplificações ou numericamente, de acordo com o tipo do problema. Em situações onde as geometrias do problema são complexas, como o deste trabalho, a simulação numérica é mais utilizada. Existem três métodos de simulações numéricas que possibilitam o estudo de um modelo submetido a um escoamento: o método de diferenças finitas, o método de elementos finitos e o método dos volumes finitos, descritos a seguir.

O método de diferenças finitas (MDF) representa as incógnitas do problema de escoamento por meio de valores nos pontos nodais de uma malha estruturada. Expansões em série de Taylor são normalmente usadas para gerar as aproximações de diferenças finitas das derivadas em cada ponto da malha, usando os valores nos pontos vizinhos. Assim, as derivadas que aparecem nas equações de transporte são substituídas pelas diferenças finitas, resultando em uma equação algébrica para os valores das grandezas de interesse em cada ponto da malha.

$O$ método de elementos finitos (MEF) utiliza funções simples (por exemplo, lineares ou quadráticas) para descrever as variações das grandezas a serem calculadas dentro de cada elemento. Estas funções 
simples são nulas fora do elemento considerado. Somando-se os resultados obtidos para todos os elementos têm-se uma aproximação funcional para cada variável, em todo o domínio de cálculo.

Quando as funções obtidas para as variáveis são substituídas nas equações de transporte, elas deixam de ser exatas e cada uma delas tem um resíduo que pode ser usado para medir o erro da simulação. Cada equação aproximada é multiplicada por um conjunto de funções peso e integrada no domínio de cálculo. Como resultado, obtém-se um sistema de equações algébricas para determinar os coeficientes de cada uma das aproximações funcionais.

O método dos volumes finitos (MVF) é a técnica que aplica CFD atualmente mais utilizada, especialmente no estudo de escoamentos ao redor de corpos. Esta técnica adota a integração formal das equações de transporte que regem o escoamento do fluido em todos os volumes de controle obtidos pela discretização do domínio. Nesta integração, a forma conservativa de cada equação é usada para que seja possível transformar as integrais em volume dos divergentes dos fluxos advectivos e difusivos em integrais em área dos fluxos normais à superfície dos volumes de controle, através da aplicação do teorema da divergência Embora esta operação seja exata, a completa discretização destes termos e das outras integrais no volume necessita do uso de técnicas numéricas para aproximar os campos das variáveis conservadas, que utilizam funções de interpolação ou aproximações funcionais. Como os outros métodos, obtem-se um sistema algébrico de equações. A acurácia destas aproximações e da representação obtida para os fluxos através das superfícies dos volumes de controle são os aspectos mais importantes no método de volumes finitos.

O software FLUENT®, utilizado neste trabalho para o estudo do escoamento em torno do veículo e a influência de diferentes tipos de solo, utiliza o método dos volumes finitos para sua formulação, e será detalhado no próximo item. 


\subsection{O MÉTODO DOS VOLUMES FINITOS}

O método de volumes finitos (MVF) visa a solução numérica das equações de Navier-Stokes e de problemas convectivos-difusivos. Esse método mostra-se bastante competitivo em relação aos métodos de diferenças finitas (MDF) e de elementos finitos (MEF). Segundo Ferziger (1999), o MVF pode ser aplicado a qualquer tipo de malha, o que o torna muito utilizado para superfícies complexas. Além disso, é um método simples de programar, o que o torna utilizado na maioria dos programas de CFD.

As soluções numéricas obtidas por meio de técnicas do MVF segundo Patankar (1975) e pelo MDF conforme Cebecci (1981) apresentam problemas de erros numéricos chamados de difusão falsa e dispersão numérica.

A difusão falsa ocorre quando a função de interpolação utilizada na discretização das equações difere da solução exata. Várias funções de interpolação foram desenvolvidas adotando diferentes soluções que visam minimizar os efeitos da difusão falsa, dentre elas o método "Upwind" de segunda ordem, utilizado neste trabalho.

No método dos volumes finitos (MVF), o domínio em estudo é subdividido em volumes elementares ou células computacionais, para as quais as equações escalares de transporte são integradas no espaço e no tempo, e podem ser generalizadas na seguinte forma:

$$
\frac{\partial(\rho \phi)}{\partial t}+\operatorname{div}(\rho \vec{u} \phi-\Gamma \operatorname{grad} \phi)=S_{\phi}
$$

Onde:

$\begin{array}{ll}\rho & \text { massa específica } \\ \vec{u} & \text { velocidade média } \\ \phi & \text { propriedade transportada } \\ \Gamma & \text { coeficiente de difusividade } \\ S_{\phi} & \text { termo fonte }\end{array}$


A integral desta equação escrita para um volume $V$, delimitado por uma superfície e em regime permanente é dada por:

$$
\int_{V C} \operatorname{div}\left(\rho \phi u_{r}\right) d V-\int_{V C} \operatorname{div}(\Gamma \operatorname{grad} \phi) d V=\int_{V C} S_{\phi} d V
$$

Aplicando o teorema do divergente temos:

$$
\oint\left(\rho \phi u_{r}\right) d \vec{A}-\oint(\Gamma g r a d \phi) d \vec{A}=\int_{V C} S_{\phi} d V
$$

Aplicando esta equação para cada volume de controle, ou seja, cada célula volumétrica, obtêm-se:

$$
\sum_{f}^{N_{\text {faces }}}\left(\rho_{f} \vec{u}_{r f} \phi_{f}\right) \vec{A}_{f}=\sum_{f}^{N_{\text {faces }}} \Gamma(\operatorname{grad} \phi)_{n} \cdot \vec{A}_{f}+S_{\phi} V
$$

Onde:

$\begin{array}{ll}N_{\text {faces }} & \text { número de faces de cada célula } \\ \phi_{f} & \text { valor da propriedade } \phi \text { transportada através da face } f \\ S_{\phi} & \text { termo fonte } \\ \rho_{f} \cdot \vec{u}_{r f} \cdot \phi_{f} \cdot \vec{A}_{f}=J_{f} \cdot \vec{A}_{f}: \text { fluxo de massa através da face } f \\ \vec{A}_{f} & \text { área da face } f \\ (\operatorname{grad} \phi)_{n} & \text { grad } \phi \text { normal a face } f \\ V & \text { volume da célula }\end{array}$

Segundo Quim (2007), a equação (5.4) é aplicada em cada célula computacional, onde os valores das propriedades escalares são armazenados no ponto central da célula e interpolados para cada face. $O$ método da diferenças centradas é utilizado na convecção, sendo que este esquema não leva em consideração a direção do escoamento. Para suprir esta deficiência, utiliza-se o método de "Upwind", onde o valor de $\phi_{f}$ é 
tomado na célula a montante, relativa à direção normal da velocidade do escoamento.

O software FLUENT®, usa como padrão o gradiente da propriedade $\bar{\phi}_{f}$ no centro da célula ("Upwind" de primeira ordem) baseando-se na média de valores para as células $C_{0}$ e $C_{1}$, como apresentada na figura 5.4.

$$
\bar{\phi}_{f}=\frac{\phi_{C 0}+\phi_{C 1}}{2}
$$

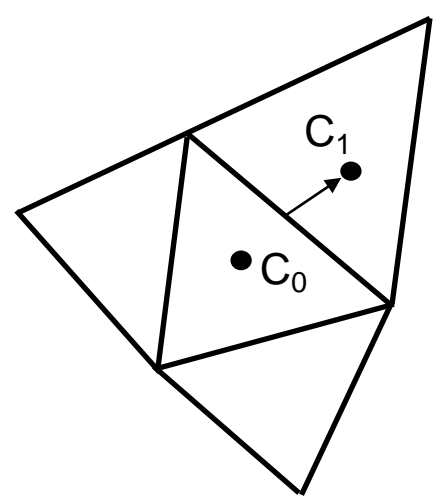

Figura 5.4 - Volume de Controle para ilustrar a discretização das equações de transporte escalar (FLUENT, 2003).

Neste trabalho é usado um método de segunda ordem acoplado, visando obter maior exatidão nos resultados. No método "Upwind" de segunda ordem, as quantidades escalares nas faces da célula são computadas com a utilização do método linear de reconstrução multidimensional, com o qual alta ordem de exatidão é alcançada nas faces através da utilização da expansão das propriedades em série de Taylor. A quantidade escalar é calculada utilizando-se a seguinte expressão:

$$
\phi_{f}=\phi+\operatorname{grad} \phi . \Delta \vec{s}
$$

Onde:

$\phi_{f}$ $\operatorname{grad} \phi$ $\Delta \vec{s}$ valor escalar de f da célula centrada a jusante gradiente da célula centrada a jusante Vetor deslocamento do centróide da célula a jusante em relação ao centróide da face. 
A equação (5.6) necessita do valor do gradiente de $\phi$ em cada célula. Este gradiente é calculado utilizando o teorema da divergência, que, escrito na forma numérica resulta em:

$$
\nabla \phi=\frac{1}{V} \sum_{f}^{N_{\text {faces }}} \bar{\phi}_{f} \vec{A}_{\boldsymbol{f}}
$$

Onde:

$\begin{array}{ll}N_{\text {faces }} & \text { número de faces de cada célula } \\ \bar{\phi}_{f} & \text { valor médio da propriedade } \phi \text { transportada através da } \\ & \text { face } f \\ \vec{A}_{f} & \text { área da face } f \\ V & \text { volume da célula }\end{array}$

Pode-se notar que a equação (5.4) contém a variável escalar $\phi$ como incógnita, localizada no centro da célula, assim como nas células adjacentes. Portanto, essa equação está na forma não-linear, em relação a essas variáveis. Uma forma linear da equação (5.4) de modo a possibilitar os cálculos pelo método numérico, pode ser escrita da seguinte forma:

$$
a_{p} \phi=\sum_{n b} a_{n b} \phi_{n b}+b
$$

Onde os índices " $n b$ ", que se referem às células vizinhas a " $a_{p}$ " e " $a_{n b}$ ", são os coeficientes lineares de " $\phi$ " e " $\phi_{n b}$ ". O número de células vizinhas depende da topologia dos pontos nodais que tipicamente será igual ao número de faces da célula. A equação (5.8) é escrita para cada célula do modelo, formando um sistema de equações algébricas. Na solução desta matriz, utiliza-se o método de sub-relaxação para o controle da variação de $\phi$ durante o processo iterativo. De forma simplificada, o novo valor $\phi_{\text {novo }}$ de uma célula irá depender do seu valor na iteração anterior, $\phi_{\text {anterior }}$ e de um coeficiente de sub-relaxação $\alpha_{r}$ dado na equação (5.9):

$$
\phi_{\text {novo }}=\phi_{\text {antigo }}+\alpha_{r} \cdot\left(\phi_{\text {novo }}-\phi_{\text {antigo }}\right)
$$




\subsubsection{Acoplamento pressão-velocidade}

Diversos métodos de solução são empregados na resolução de problemas envolvendo processamento computacional. O método de solução numérica utilizado é o método segregado, algoritmo no qual as equações são resolvidas seqüencialmente. Devido a não-linearidade das equações que governam o escoamento, diversas iterações devem ser feitas até a convergência da solução, ou seja, uma variação mínima de valores previamente estabelecida, seguindo as etapas mostradas na seqüência e organizada na figura 5.5:

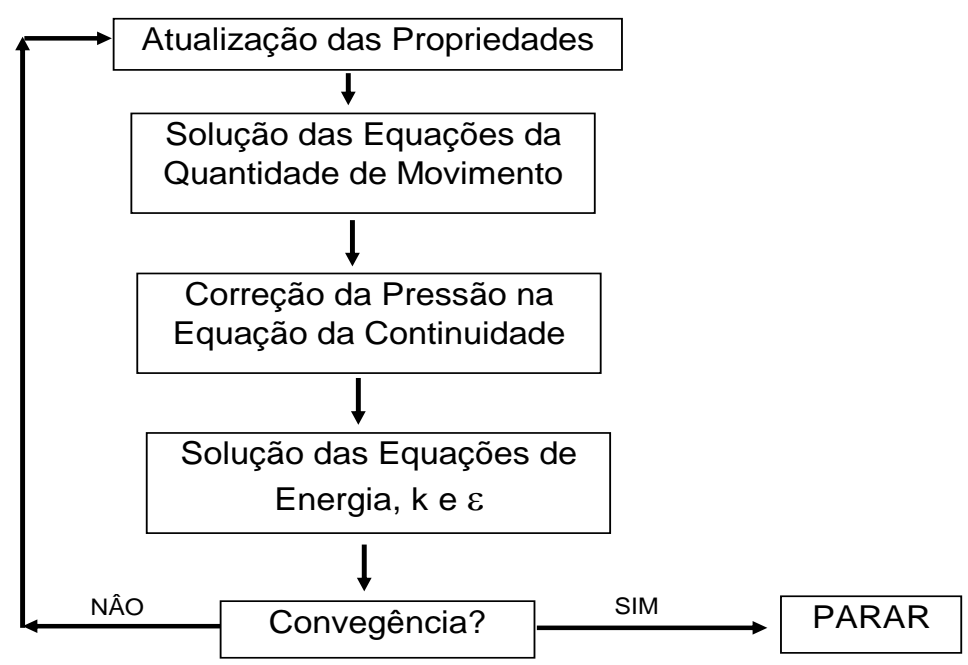

Figura 5.5 - Algoritmo do Método de Solução Segregado.

O algoritmo deste método segue as seguintes etapas:

a) As propriedades do fluido são atualizadas com base na solução anterior.

b) As equações de quantidade de movimento em $\boldsymbol{x}, \boldsymbol{y}$ e $\boldsymbol{z}(\boldsymbol{u}, \boldsymbol{v}$ e $\boldsymbol{w})$ são resolvidas uma de cada vez utilizando-se o valor atual da pressão e fluxo de massa na face, para a atualização do campo de velocidade.

c) Quando a velocidade obtida na etapa b) não satisfaz as condições de continuidade, correções na pressão devem ser feitas de modo a garantir a convergência.

d) Cálculo de quantidades escalares como a energia, $k$, e $\varepsilon$.

e) Verificar a convergência. 
O termo pressão desempenha um papel crucial na equação da continuidade, mesmo que não esteja explícita a sua influência nesta. Este trabalho utiliza o algoritmo SIMPLE (Semi-Implicit Method for Pressure Linked Equations), originalmente desenvolvido por Patankar e Spalding (1972), que é essencialmente um algoritmo de predição e correção para o cálculo da pressão nas células computacionais.

O algoritmo inicia com a utilização do campo de pressão $p^{*}$ para a solução do campo de velocidade $u^{*}$ ou de fluxo dado por apresentados na equação (5.10):

$$
J_{f}^{*}=\hat{J}_{f}^{*}+d_{f} \cdot\left(p_{c 0}^{*}-p_{c 1}^{*}\right)
$$

Onde:

$J_{f}^{*}$

$d_{f}$ função de fluxo de massa $\rho . u^{*}$ através da face $f$ função da razão da área da célula em relação aos coeficientes lineares " $a_{p}$ "

Para satisfazer a condição de continuidade, a função de correção da pressão $J_{f}^{\prime}$ é introduzida na função de fluxo $J_{f}^{*}$ resultando em uma função de fluxo corrigida é dado por:

$$
J_{f}=J_{f}^{*}+J_{f}^{\prime}
$$

Onde função de correção é dada por:

$$
J_{f}^{\prime}=d_{f} \cdot\left(p_{c 0}^{\prime}-p_{c 1}^{\prime}\right)
$$

$p^{\prime} \quad$ pressão de correção

O algoritmo SIMPLE substitui as equações de correções de fluxo, equações (5.11) e (5.12), na equação da continuidade (5.8):

$$
a_{p} \cdot p^{\prime}=\sum_{n b} a_{n b} p_{n b}^{\prime}+b
$$


Onde o termo fonte $\boldsymbol{b}$ é o fluxo de massa através da célula computacional:

$$
b=\sum_{f}^{N_{\text {faces }}} J_{f}^{*} A_{f}
$$

A equação da pressão de correção (5.15) é resolvida através de iterações até a convergência. Neste processo computacional, a equação de correção de pressão está sujeita a divergência no resultado e, portanto, é necessário um processo de sobre-relaxação $\alpha_{p}$ nas correções dos valores de pressão e de fluxo, da seguinte forma:

$$
p=p^{*}+\alpha_{p} \cdot p^{\prime}
$$

\subsubsection{Determinação do Coeficiente de Arrasto}

O cálculo do coeficiente de arrasto aerodinâmico pelo software está ligado ao cálculo da força nas superfícies externas do objeto estudado. Este cálculo é feito seguindo o algoritmo da figura 5.5, Método de Solução Segregado, apenas adicionando uma nova etapa para determinar a força de arrasto.

A força de arrasto é composta pela soma vetorial da componente normal à superfície, devido à pressão, e de uma segunda componente tangencial a esta, a força viscosa, como apresentado na equação (5.16):

$$
\mathrm{Fa}=\mathrm{a} \cdot \mathrm{Fp}+\mathrm{a} \cdot \mathrm{Fv}
$$

Onde:

$\begin{array}{ll}\text { a } & \text { fator de decomposição vetorial } \\ \mathrm{Fa} & \text { força de arrasto } \\ \mathrm{Fp} & \text { força devido à pressão } \\ \mathrm{Fv} & \text { força viscosa }\end{array}$


A equação para a determinação da força de arrasto é:

$$
\mathrm{Fa}=\frac{\mathrm{Cd} \cdot \rho \cdot \overline{\mathrm{V}}^{2} \cdot \mathrm{Af}}{2}
$$

Onde:

$\mathrm{Cd} \quad$ coeficiente de arrasto

$\rho \quad$ massa específica do fluido

$\bar{V} \quad$ velocidade média relativa do fluido ao longe

Af área de referência do objeto

No caso de um ensaio de um veículo em túnel de vento, em geral, a área de referência é dada pela área frontal deste, projetada na direção perpendicular ao escoamento. A velocidade média ao longe, $\overline{\mathrm{V}}$, é similar à utilizada no ensaio real do túnel, para que as mesmas características do escoamento sejam reproduzidas.

Isolando-se $\mathrm{Cd}$, a equação 5.17 é re-escrita, fornecendo o valor do coeficiente de arrasto:

$$
\mathrm{Cd}=\frac{2 \cdot \mathrm{Fa}}{\mathrm{Af} \cdot \mathrm{p} \cdot \overline{\mathrm{V}}^{2}}
$$

\subsection{GERAÇÃO DE MALHA}

O processo de geração de malha é realizado a partir de superfícies produzidas por um software CAD que reproduz a geometria real do veículo sem excluir detalhes, e da seção de testes do túnel de vento representado por um paralelepípedo. A malha $2 \mathrm{D}$ é gerada sobre as superfícies do carro e do túnel pelo software HYPERMESH 7.0. Após a etapa de geração da malha 2D estar concluída, o programa identificado por T-GRID é usado para gerar a malha volumétrica 3D. 


\subsubsection{Geração da malha 2D}

A geração de malha superficial com elementos triangulares é feita no programa HYPERMESH, com o uso do método "Advancing Front", nas superfícies do veículo e do túnel de vento desenhadas pelo software de CAD.

Segundo Quim, (2007) este programa de geração de malha baseia-se no seguinte algoritmo:

a) Discretização da fronteira (perímetro) da superfície em número de partes $\left(N_{s}\right)$ através dos comprimentos mínimos estabelecidos pelo usuário $\left(\delta_{\mathrm{m}}\right)$;

$$
\begin{aligned}
& \Lambda_{s}=\int_{0}^{l} \frac{1}{\delta_{m}} d l \\
& N_{s}=\operatorname{abs}\left(\Lambda_{s}\right)
\end{aligned}
$$

b) Para cada segmento da fronteira, criar elementos triangulares até o fechamento do perímetro.

c) Considerar o novo domínio a fronteira dos elementos anteriores.

d) Proceder as etapas b) e c) até o preenchimento da superfície com todos os elementos.

e) Correção dos elementos com a maximização dos menores ângulos das células triangulares através do algoritmo de suavização "smoothing" onde os nós são reposicionados para uma melhor qualidade. 

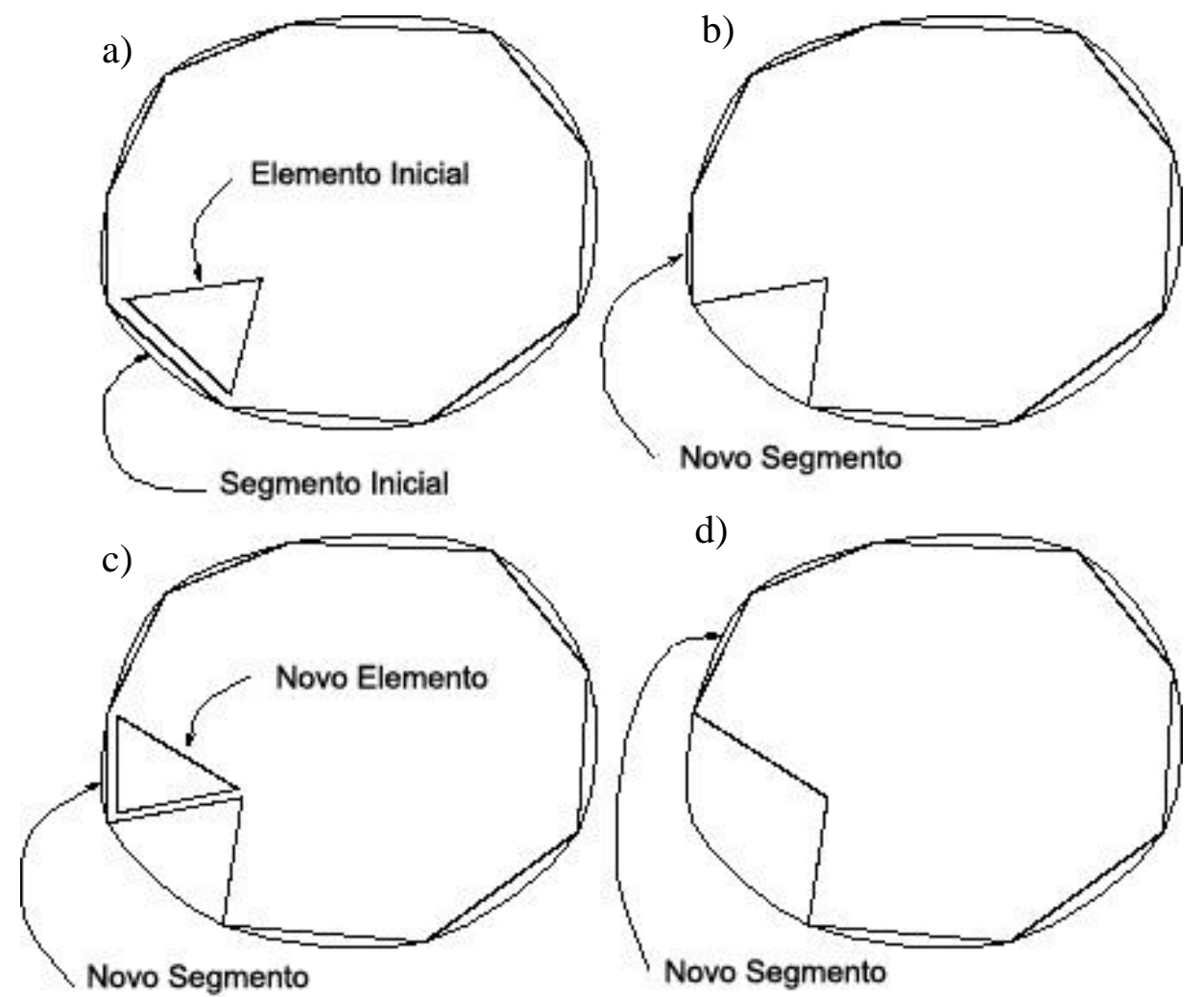

Figura 5.6 - Etapas de geração de malha 2D pelo algoritmo "Advancing Front".

A definição da fronteira é muito importante, especialmente para garantir a geração da malha volumétrica de boa qualidade, pois uma triangularização de baixa qualidade pode resultar em malha volumétrica ruim. Uma forma para garantir a qualidade dos elementos é a utilização das seguintes condições para as arestas adjacentes de modo a encontrar a posição inicial $\mathrm{C} 1$, e não provocar distorções excessivas durante o processo de triangularização (ver Fig. 5.7):

$$
\delta_{1}= \begin{cases}0.55 A B & \delta_{m}<0.55 A B \\ \delta_{m} & 0.55 A B<\delta_{m}<2 A B \\ 2 A B & 2 A B<\delta_{m}\end{cases}
$$

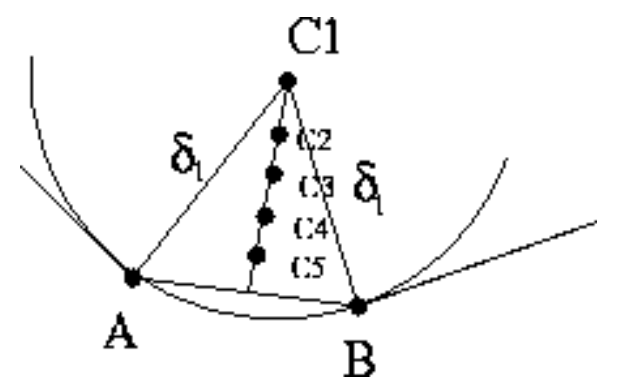

Figura 5.7 - Criação do novo elemento, escolha inicial. 
Uma forma de garantir a qualidade dos elementos 2D é medindo o ângulo de distorção "skew". Este ângulo é calculado da seguinte forma: primeiramente é obtido para cada nó o menor dos ângulos (denominado de $\left.\sigma_{\min }\right)$ entre o vetor que liga o nó ao ponto médio da aresta oposta e o vetor que liga os dois pontos médios adjacentes a este nó. O ângulo de "skew" é a diferença do ângulo de $90^{\circ}$ com o menor ângulo encontrado.

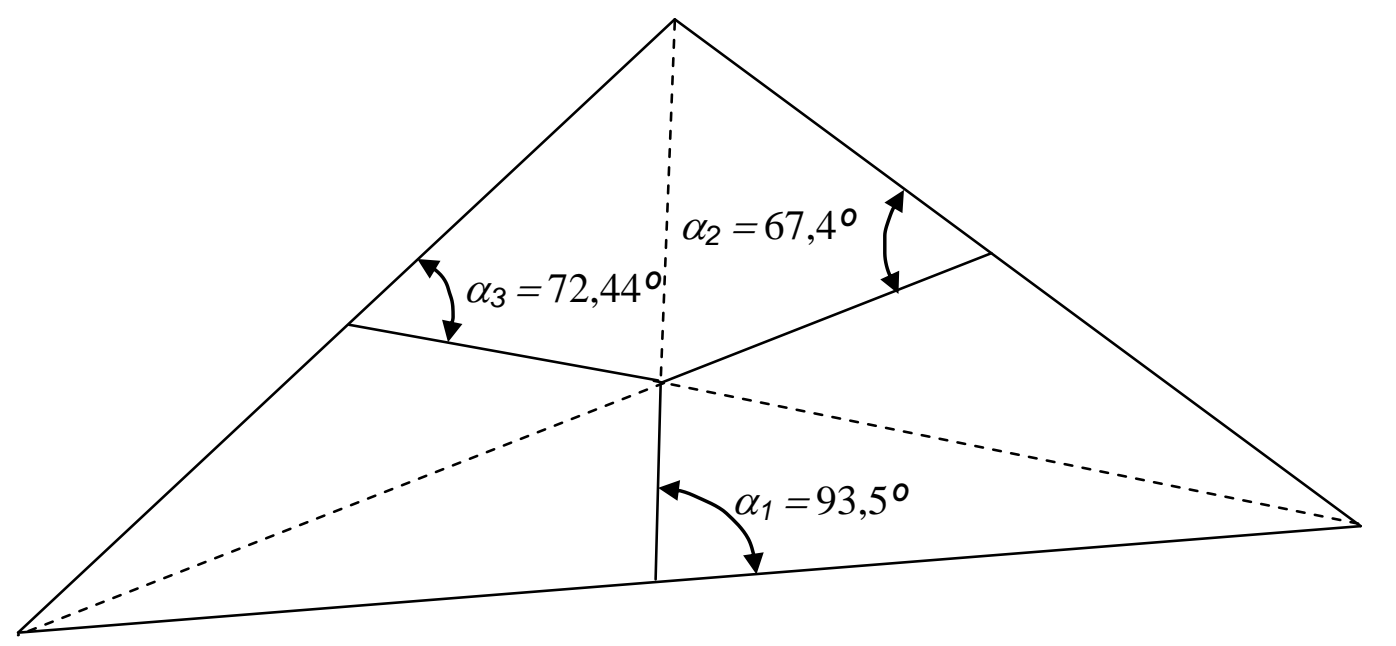

$$
\alpha_{\min }=67,4^{\circ} \quad \text { ângulo de distorção skew }=90^{\circ}-67,4^{\circ}=22,6^{\circ}
$$

Figura 5.8 - Exemplo de um elemento com ângulo de distorção "skew" de 22,6.

O tamanho de elemento utilizado neste trabalho é de $10 \mathrm{~mm}$ como valor máximo do comprimento de cada lado dos triângulos que formam a malha 2D. No capítulo 6 , há um estudo sobre a influência de diferentes tamanhos de elementos de malha, e seus resultados. Representações de malhas aplicadas ao veículo adotado são mostradas nas figuras 5.9, 5.10, $5.11,5.12$ e 5.13 associadas a um sistema de eixos de coordenadas cartesianas. 

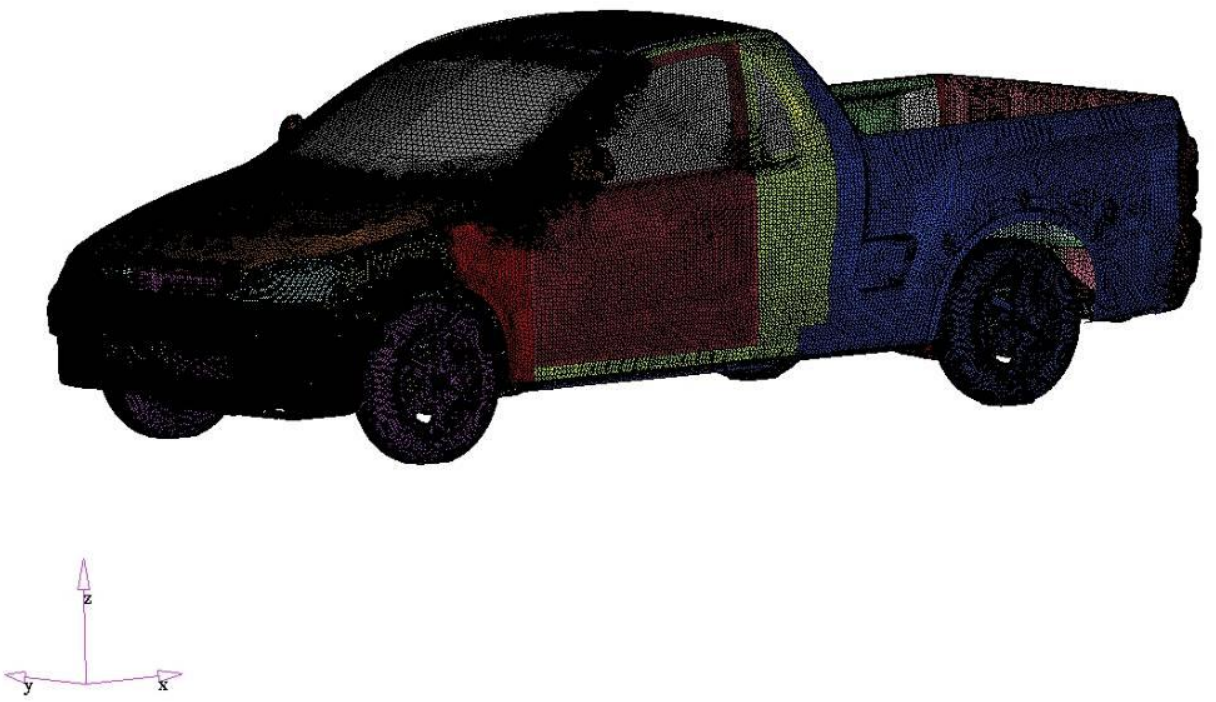

Figura 5.9 - Malha superficial 2D no veículo.

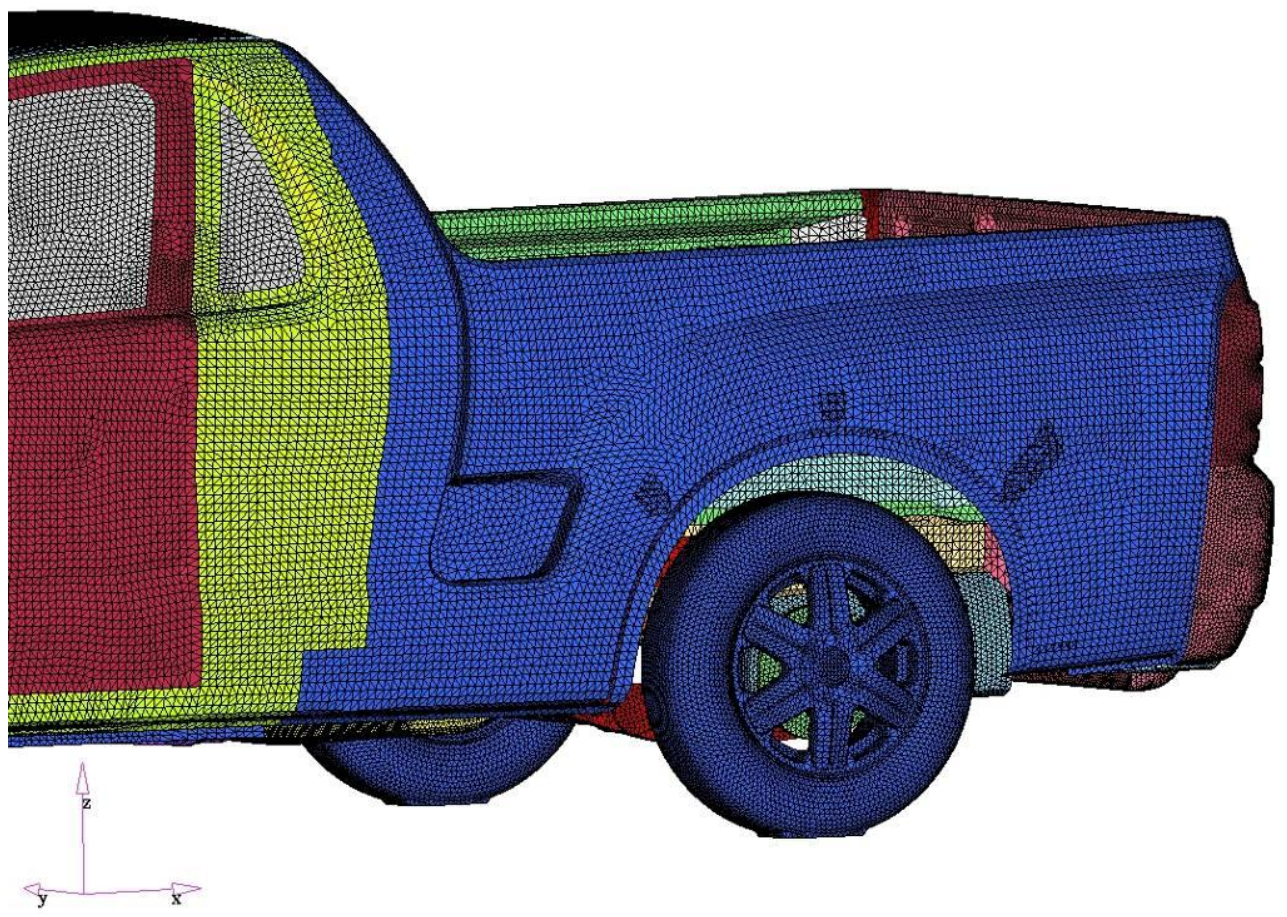

Figura 5.10 - Detalhe da parte traseira do veículo, com malha superficial 2D. 

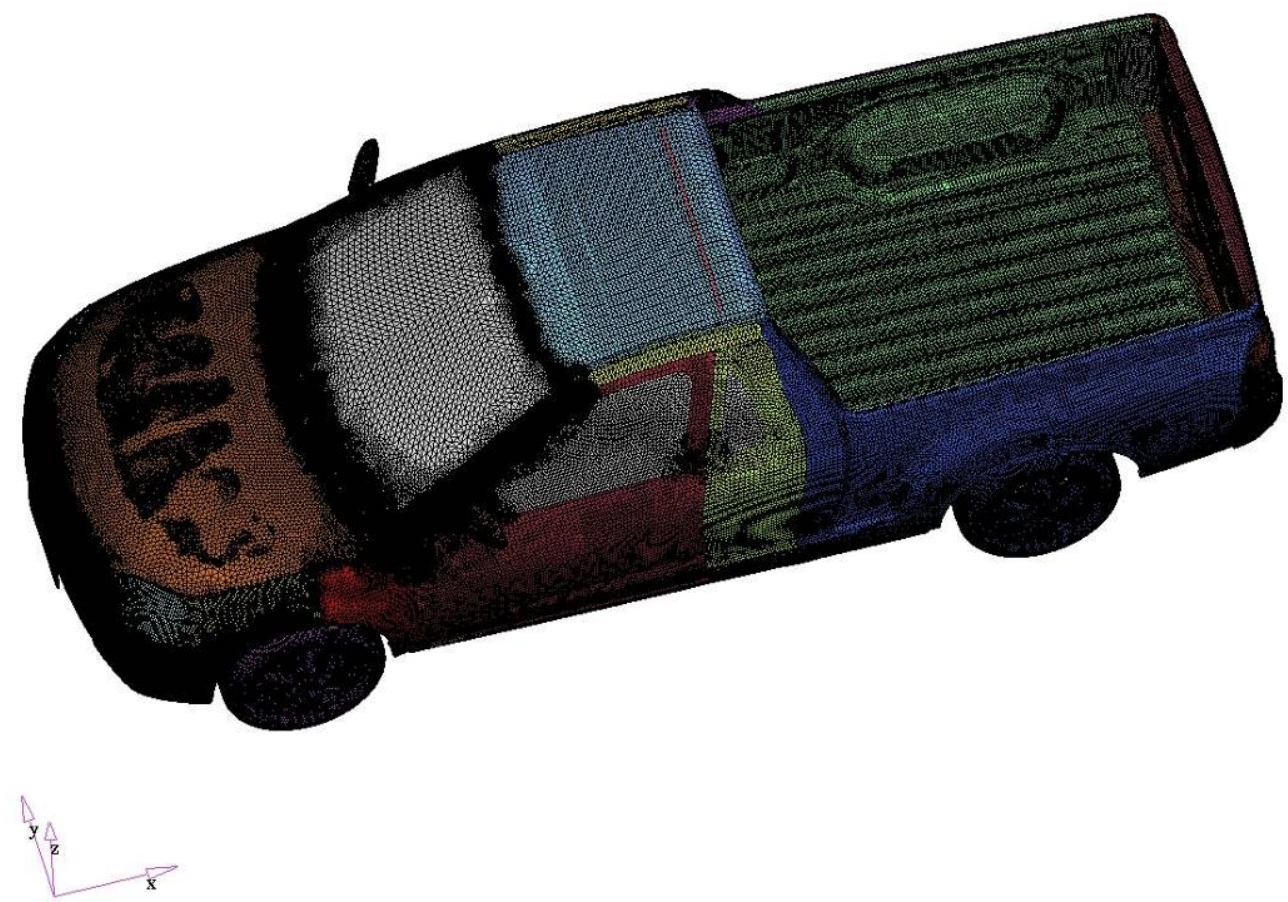

Figura 5.11 - Vista superior da malha superficial 2D no veículo.

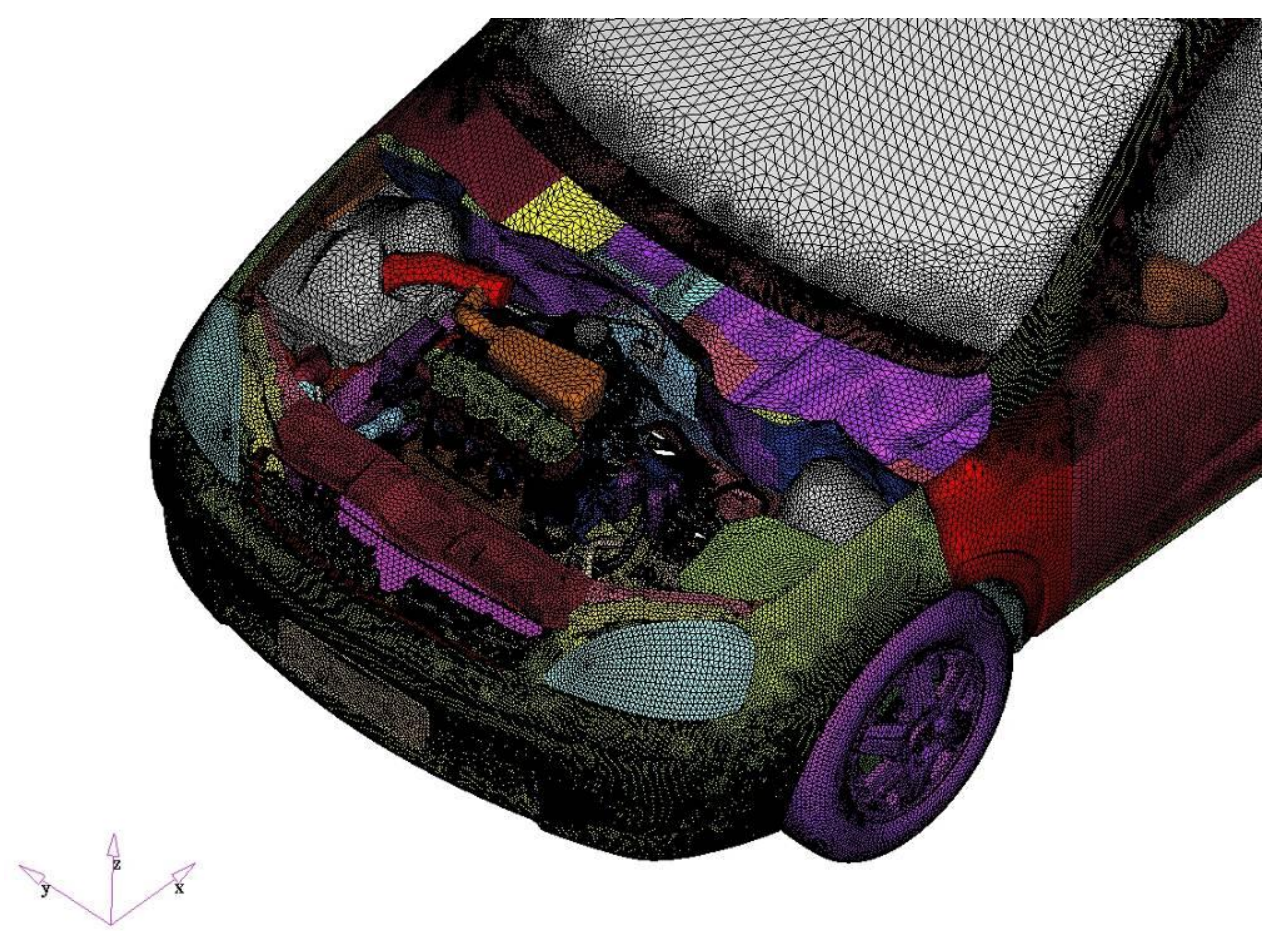

Figura 5.12 - Detalhe do cofre do motor, com detalhamento do motor e seus componentes. 


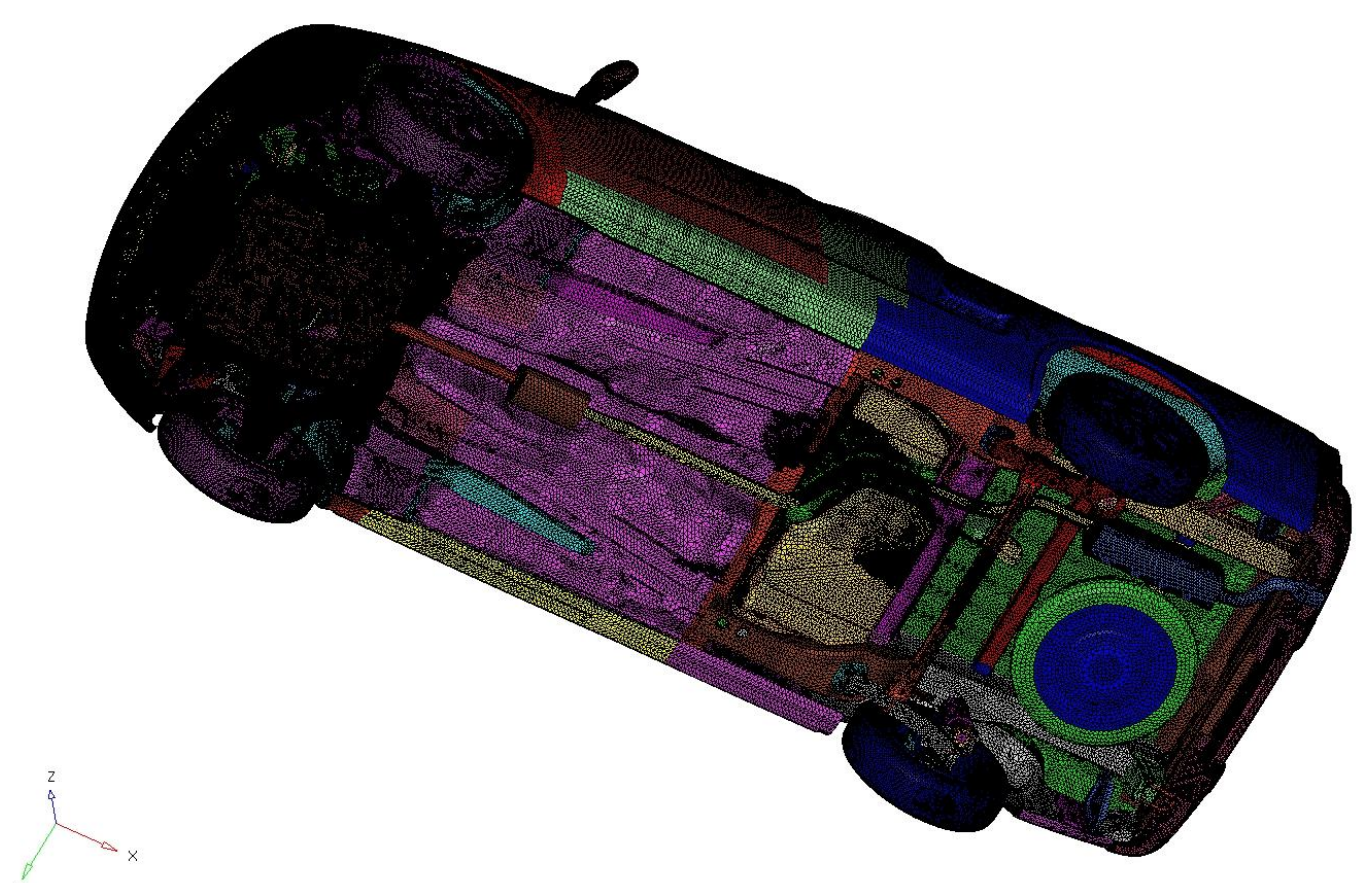

Figura 5.13 - Detalhe da parte inferior do veículo, com detalhamento de seus componentes.

\subsubsection{Geração de malha volumétrica 3D}

O método mais comum de geração de malha tetraédrica, ou 3D, não estruturada a partir de uma superfície triangularizada é o método de "Delaunay". Este método preserva as faces triangulares da superfície até o término do processo de geração de malha. Numa malha Delaunay, para cada célula volumétrica, existe uma esfera que a contém, passando por todos os nós que a definem. Uma malha é Delaunay quando não existe nenhum nó no interior destas esferas.

Em uma malha 2D o algoritmo de "Triangularização de Delaunay" tende a maximizar o mínimo ângulo do triângulo o que é um requisito para uma boa qualidade do elemento. Porém, isto não ocorre para o processo de malha volumétrica diante da complexidade das geometrias e a disposição dos elementos triangulares, de modo que a otimização dos ângulos dos elementos podem resultar em elementos de baixa qualidade. 


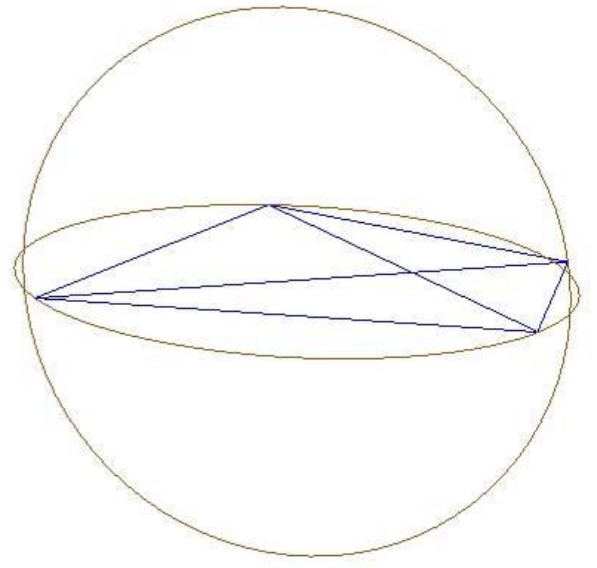

a)

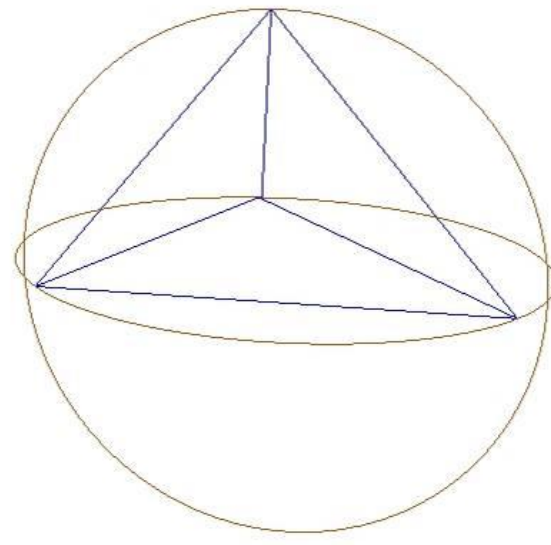

b)

Figura 5.14 - a) Tetraedro de baixa qualidade; b) Tetraedro de ótima qualidade.

A convergência numérica está ligada à qualidade dos elementos, desta forma é necessária uma verificação prévia da qualidade da malha tetraédrica gerada, medida pelo "Skewness". Este parâmetro mostra o ângulo que as faces do tetraedro da malha volumétrica formam entre si, conforme figura 5.14. Verifica-se que quanto maior o ângulo entre elas há uma tendência de se formar uma pirâmide perfeita, circunscrita em uma esfera, indicando melhor qualidade. Este parâmetro é dado por:

$$
\text { skewness }=\frac{\text { tamanho_ótimo }- \text { tamanho_célula }}{\text { tamanho_ótimo }}
$$

Sendo tamanho_ótimo o tamanho do elemento cujas faces são compostos por elementos triangulares eqüiláteros. O valor do "Skewness" varia de 0 a 1 , sendo 0 o valor ótimo. Segundo o manual do software TGRID, recomenda-se a utilização de células com "skewness" de até 0,96.

A escolha de uma malha é fortemente influenciada pelo desempenho e exatidão desejados na simulação. O desempenho, que é medido pelo tempo total exigido nas várias etapas do processamento computacional, depende do número de elementos a serem processados. Assim, quanto maior a área coberta por cada célula da malha, menor será o número de elementos, e conseqüentemente mais rápida será a simulação. 
A exatidão dos resultados da simulação está relacionada tanto com o formato quanto com o tamanho dos elementos. Diferente do desempenho, a exatidão dos resultados será melhor quanto menor forem os elementos. Além disso, os formatos dos elementos também influenciam os resultados, sendo que geralmente, elementos mais próximos dos eqüiláteros são preferidos.

Desempenho e exatidão possuem requisitos conflitantes e geralmente é necessário fazer uma ponderação entre eles. Para um determinado grupo de aplicações, o melhor compromisso entre desempenho e exatidão é obtido com elementos refinados em regiões de separação de vórtices. O refino da malha possibilita assim considerar os vórtices de pequenas escalas.

A representação da camada limite do escoamento na superfície do veículo é feita utilizando a função de refinamento de camadas do software e terá 7 camadas, como mostrado na figura 5.15 abaixo.

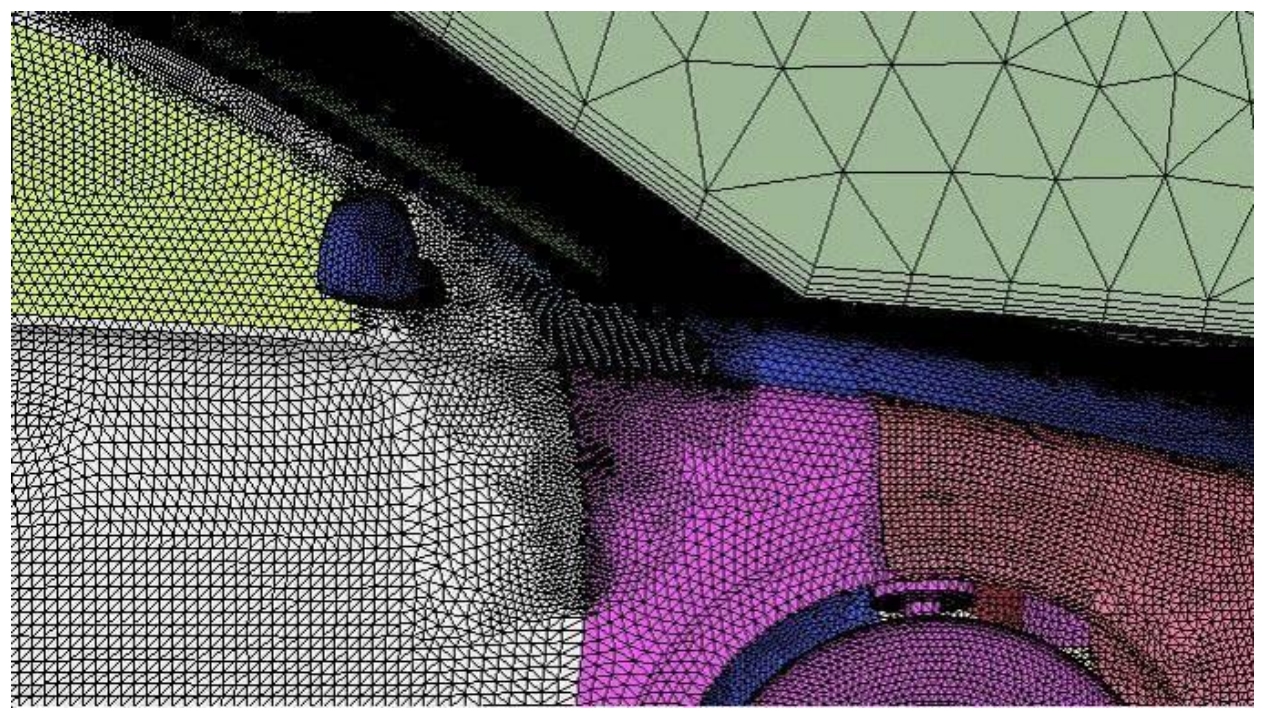

Figura 5.15- Corte em y = $0 \mathrm{~m}$ mostrando a malha volumétrica gerada.

Como resultado final do processo de configuração da malha volumétrica em torno do veículo confinado na seção de testes do túnel de vento, tem-se na figura 5.16 um corte em $y=0 \mathrm{~m}$, do resultado da geração de malha pelo T-GRID. 


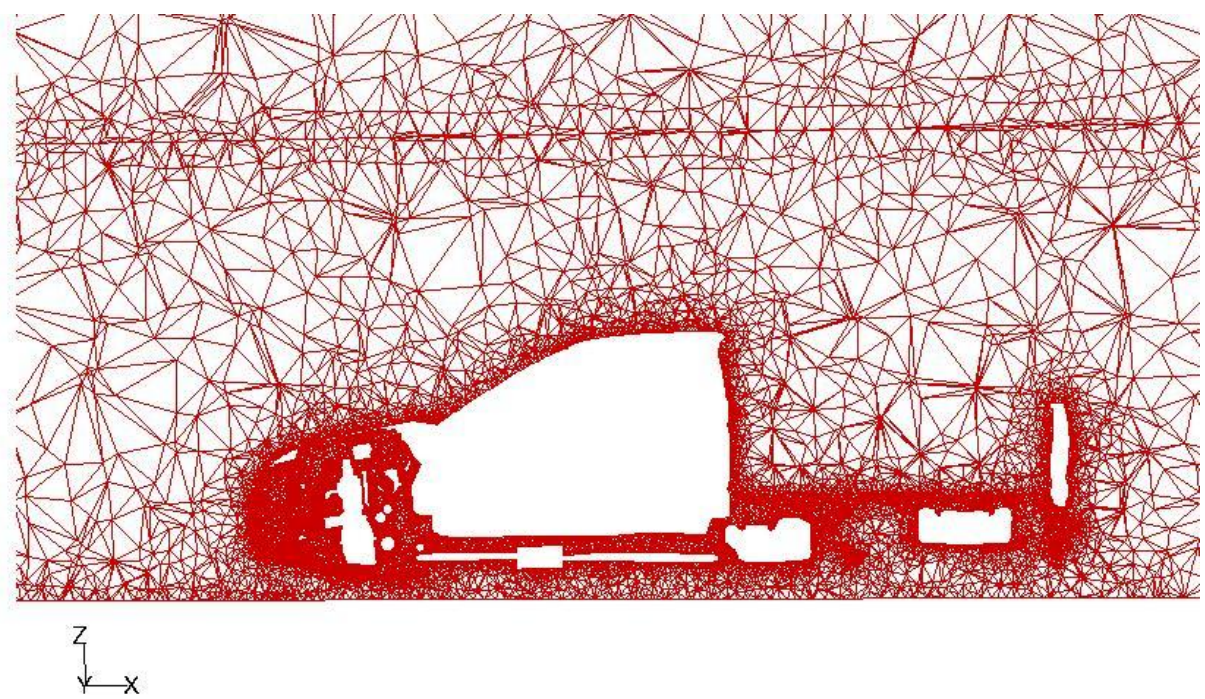

Figura 5.16- Corte em $\mathrm{y}=0 \mathrm{~m}$, mostrando a malha volumétrica gerada.

\subsection{SIMULAÇÃO VIRTUAL DO PROTÓTIPO EM TÚNEL DE VENTO}

Após a geração das malhas, a etapa seguinte consiste em preparar o modelo no software de CFD, sendo escolhido o FLUENT. No Anexo A estão descritos os procedimentos e etapas para configuração do programa de CFD para as condições deste trabalho. Todas as simulações deste trabalho estão em regime permanente.

O ingresso de informações no programa é realizado através de um arquivo contendo as malhas $2 \mathrm{D}$ do veículo e do túnel, e a malha 3D. As condições de contorno inseridas no programa para a seção de testes são as mesmas do ensaio real, conforme valores da tabela 5.2. 
Tabela 5.2 - Parâmetros e configurações para ensaio experimental e simulação numérica

\begin{tabular}{|l|c|}
\hline \multicolumn{2}{|c|}{ Parâmetros comuns ao ensaio experimental e à simulação numérica } \\
\hline Túnel de vento & General Motors, em Warren \\
\hline Velocidade do escoamento & $110 \mathrm{~km} / \mathrm{h}(30,56 \mathrm{~m} / \mathrm{s})$ \\
\hline Pressão na saída da seção de testes & Pressão atmosférica \\
\hline Intensidade de turbulência & $0,60 \%$ \\
\hline Sistema de sucção de camada limite & Montante da seção de teste \\
\hline Dimensões da seção de testes do túnel & $(5,4 \times 10,4 \times 23,0) \mathrm{m}$ \\
\hline \multicolumn{2}{|c|}{ Parâmetros específico da simulação numérica } \\
\hline Tipo de modelo de turbulência & $\mathrm{k}-\varepsilon$ \\
\hline
\end{tabular}

O resultado do arrasto do modelo virtual é comparado com o resultado do arrasto obtido em ensaio experimental, para atestar a confiabilidade do processo de simulação utilizado neste trabalho. $O$ tipo de solo utilizado no ensaio experimental é o piso estático e essa mesma condição é utilizada no modelo simulado para a validação do método. A figura 5.17 apresenta a seção de testes do túnel de vento, com o veículo nela colocado com as mesmas dimensões e condições do ensaio experimental, para a simulação numérica de escoamento utilizado neste trabalho.

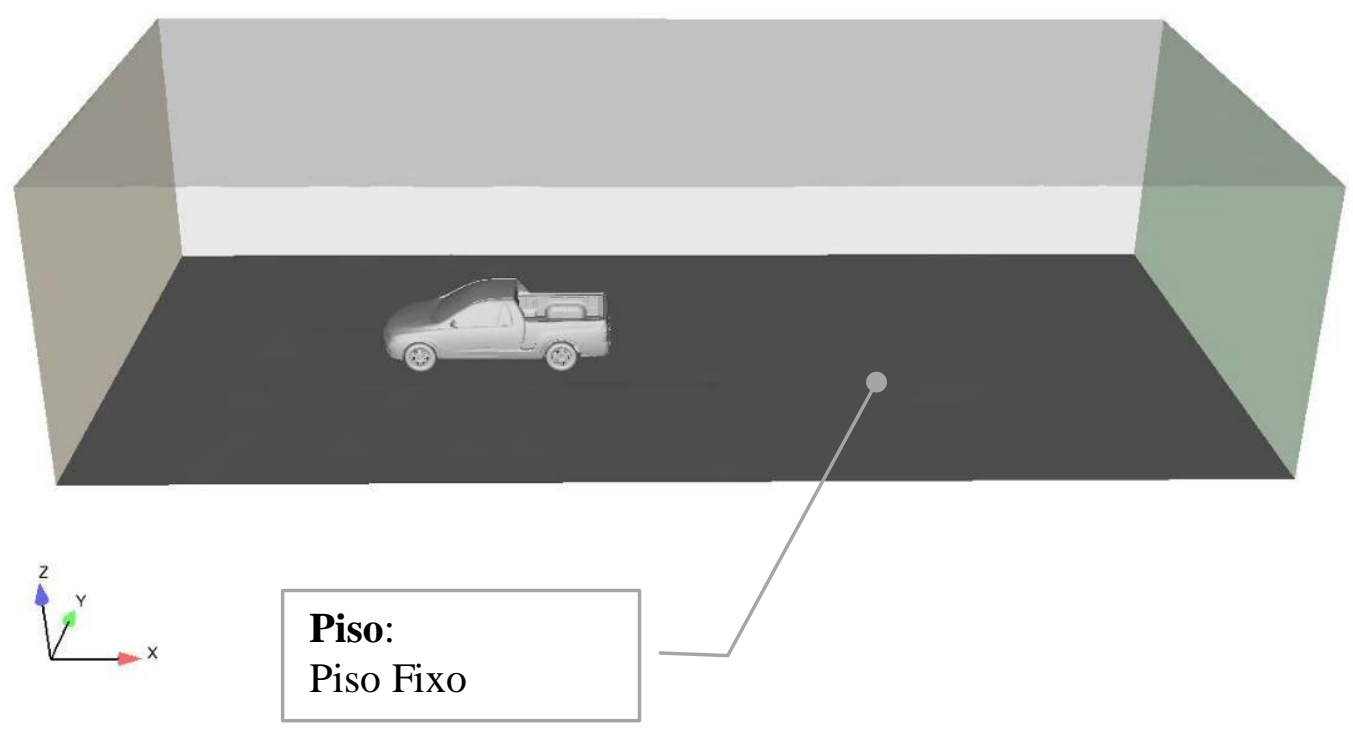

Figura 5.17 - Figura da seção de testes do túnel de vento com piso fixo e veículo colocado sobre ele. 
Os detalhes das configurações e parâmetros de teste e simulação virtual são mostrados na tabela 5.2. Detalhes de configuração no programa de computador FLUENT são mostrados no anexo A.

Após a configuração do modelo, nas mesmas condições do teste real, a simulação que será processada em um cluster com diversos processadores em paralelo, visando resolver todas as equações do fluxo de ar e obter o arrasto do veículo. Neste trabalho, o um cluster com 32 processadores é utilizados para todos os cálculos de simulação presentes neste trabalho. Serão feitas 800 iterações em primeira ordem e 2500 em segunda ordem para garantir uma boa convergência, segundo FLUENT (2003). Essa ordem para o cluster é enviada por meio de um script programado na linguagem de programação $T C L$ apresentado no anexo $B$.

No capítulo seguinte são apresentados os resultados para as simulações numéricas e estudos complementares sobre dimensões dos elementos de malha e simulação de uma roda isolada. 


\section{RESULTADOS}

Neste capítulo são apresentados os resultados obtidos nas simulações numéricas de escoamento em torno de um veículo, comparando três diferentes tipos de piso adotados para seção de teste de um túnel de vento. Estão relatados, também, resultados de análises complementares comparando diferentes tipos de tamanhos de células na definição de malhas e a simulação de uma roda de veículo isolada.

\subsection{ESTUDO SOBRE DIMENSÕES DOS ELEMENTOS DE MALHA}

A análise sobre a variação de dimensões dos elementos da malha superficial adotada para representar um veículo é realizada, com o propósito de mostrar a influência de células de diferentes tamanhos no tempo de processamento e nos valores para o coeficiente de arrasto do veículo.

Este estudo adotou como referências o ensaio de modelo virtual em túnel de vento com piso estático, sua comparação com ensaio experimental do mesmo modelo, e a utilização do coeficiente de arrasto para atestar a confiabilidade da metodologia.

O dimensionamento do elemento superficial 2D adotado para a discretização da superfície do veículo simulado no túnel de vento virtual com piso estático, adota como valor inicial $10 \mathrm{~mm}$. Outros dois valores testados são de $5 \mathrm{~mm}$ e $20 \mathrm{~mm}$.

Estas alternativas de dimensões seguem proposta apresentada por Quim (2007), que, em seu trabalho, fez a discretização apenas da superfície frontal do veículo, como pode ser visto na figura 6.1. No presente estudo, todas as superfícies externas do veículo são consideradas, como indicado na figura 6.2, com detalhes da região traseira do carro. 


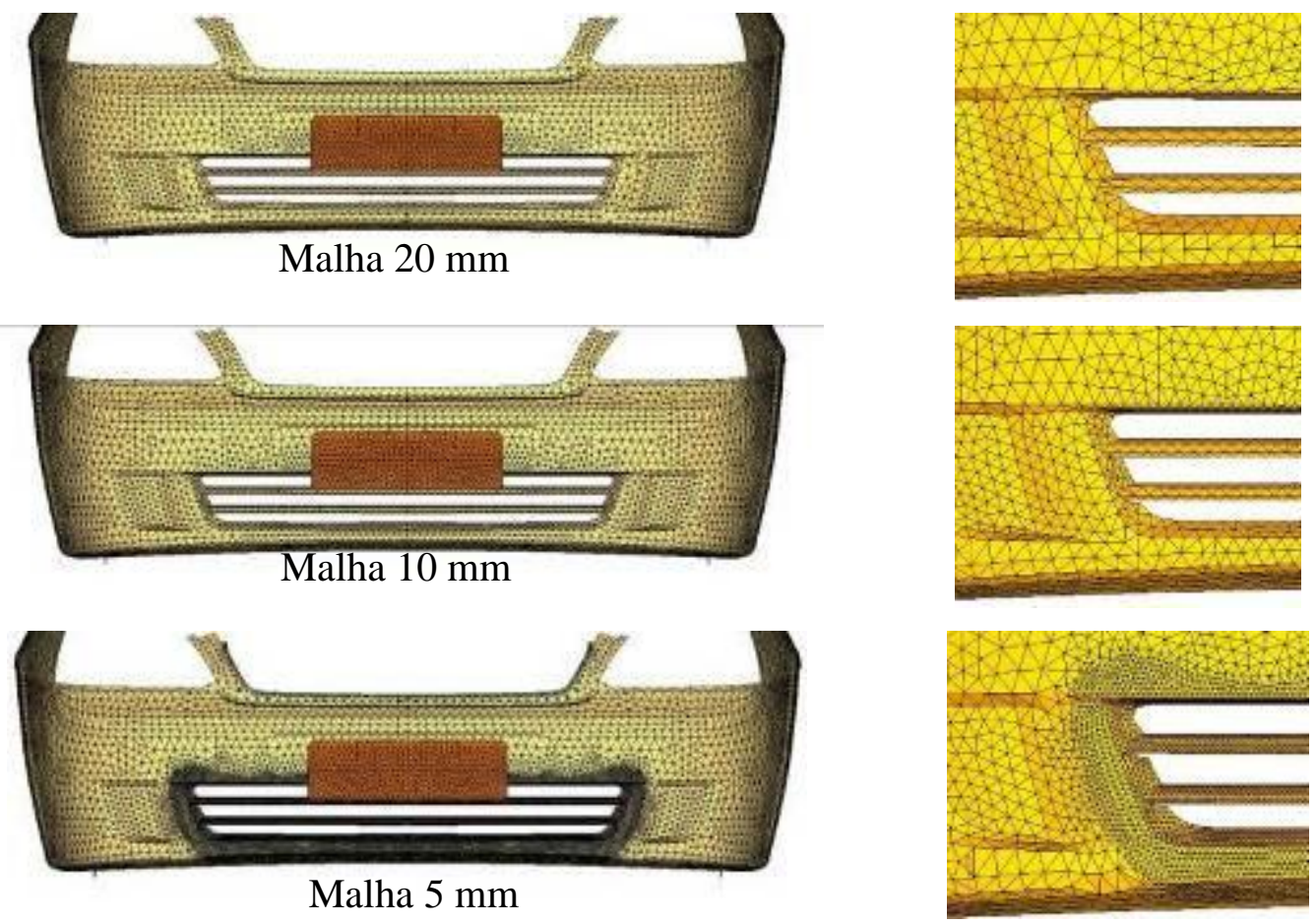

Figura 6.1 - Dimensões dos elementos da malha superficial na grade do pára-choque adotadas no trabalho de Quim (2007).

Nesta análise de diferentes tamanhos de elementos de malha, todas as condições de contorno, citadas no capítulo anterior, são mantidas, ou seja, velocidade do escoamento na seção de testes é de $110 \mathrm{~km} / \mathrm{h}$, piso estático com sucção no início da seção de testes e pressão atmosférica no

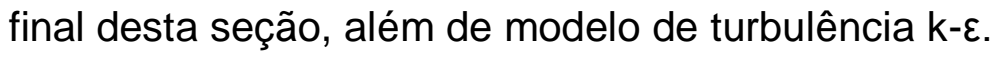



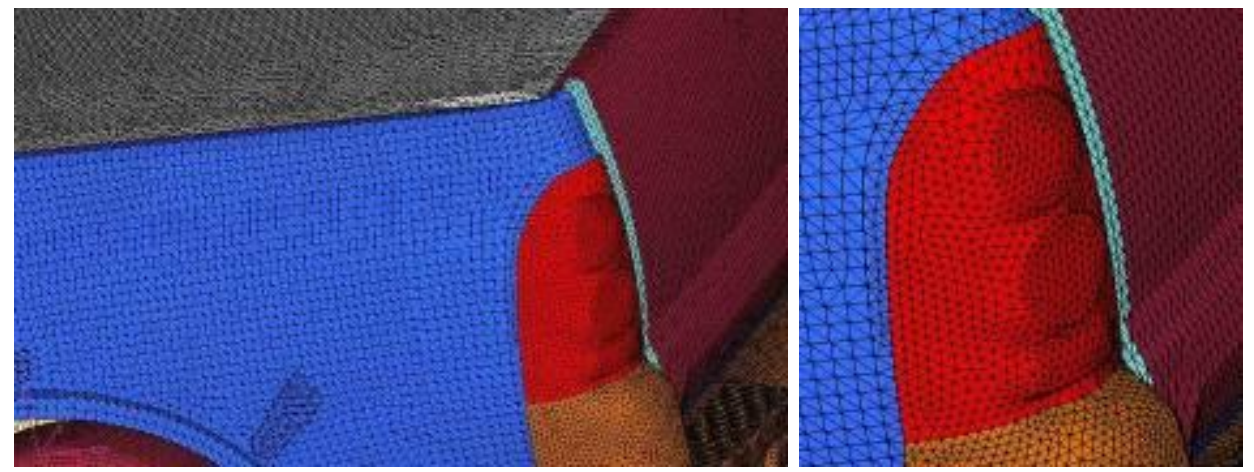

Malha de $20 \mathrm{~mm}$
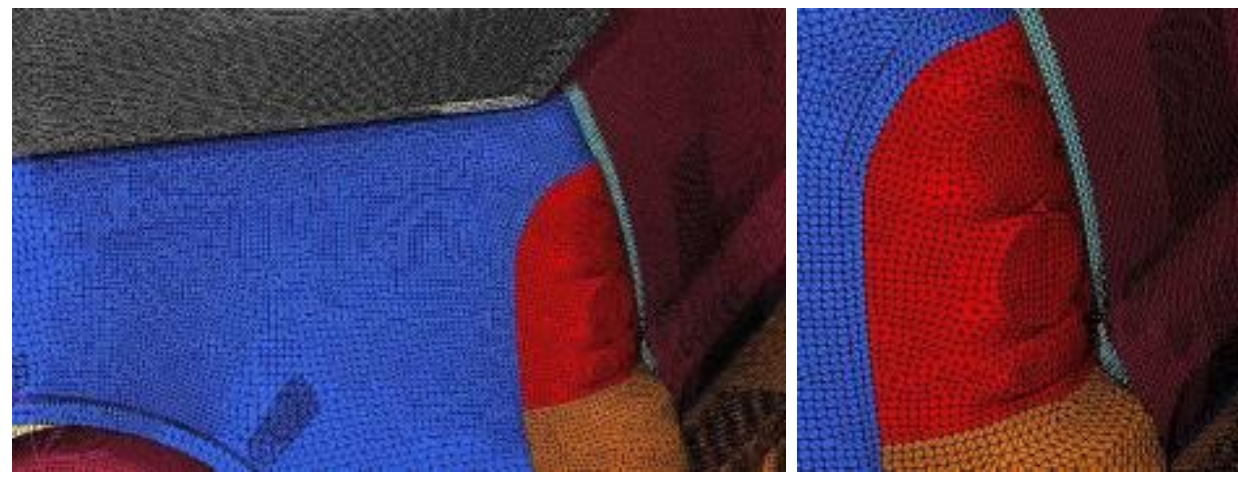

Malha de $10 \mathrm{~mm}$
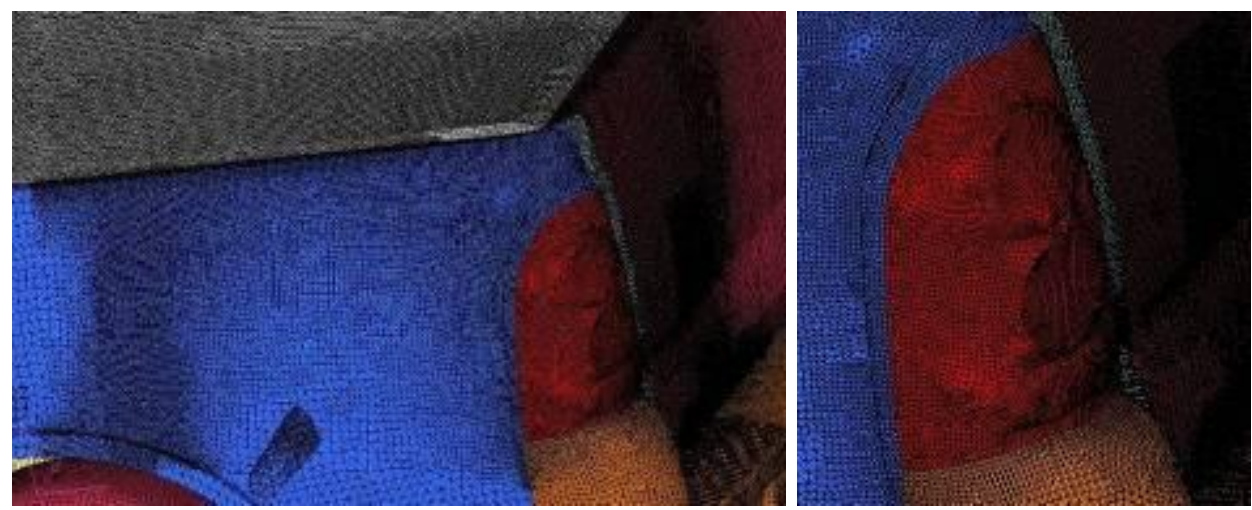

Malha de $5 \mathrm{~mm}$

Figura 6.2 - Dimensões de elementos para a malha superficial, na região traseira da caminhonete utilizada neste trabalho.

O tempo de geração da malha superficial 2D, para as três alternativas é o mesmo, pois o método de triangularização utilizado no HYPERMESH® independe do tamanho selecionado para o elemento, e como já dito, os tamanhos utilizados são: $5 \mathrm{~mm}, 10 \mathrm{~mm}$ e $20 \mathrm{~mm}$. 
$\mathrm{Na}$ geração da malha volumétrica o tempo e a quantidade de elementos tetraédricos criados pelo $T$-GRID® para as diferentes alternativas são inversamente proporcionais ao tamanho das células, ou seja, quanto menor a dimensão do elemento na malha superficial 2D, maior o tempo de geração da malha volumétrica 3D e maior a quantidade de elementos gerados.

No gráfico da figura 6.3 está apresentado o número de elementos volumétricos em função das dimensões das células 2D adotadas para a geração da malha.

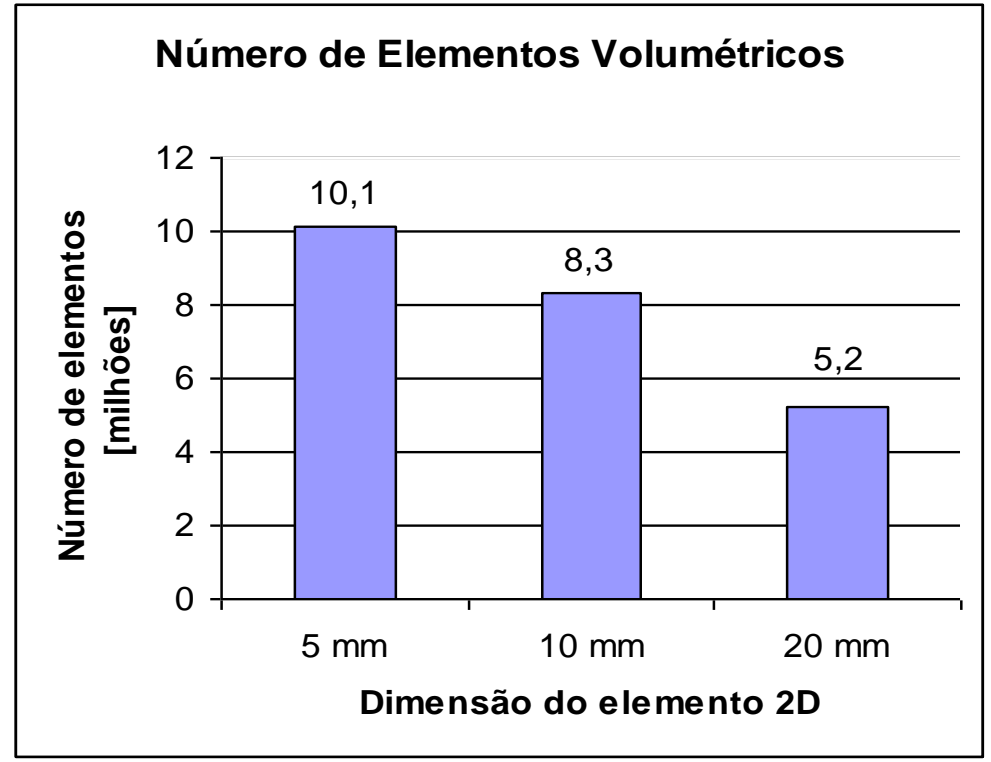

Figura 6.3 - Número de elementos volumétricos gerados em função da dimensão das células 2D.

Foi também determinado o tempo de geração da malha volumétrica para cada uma das alternativas adotadas, conforme mostrado na figura 6.4. Verifica-se que o tempo de processamento para a geração da malha volumétrica correspondente a dimensão de $5 \mathrm{~mm}$, comparada com $10 \mathrm{~mm}$ foi ampliado em $25 \%$. E a diferença porcentual entre os tempos despedidos em função dos elementos 2D de $10 \mathrm{~mm}$ e $20 \mathrm{~mm}$ foi de aproximadamente $33 \%$. 


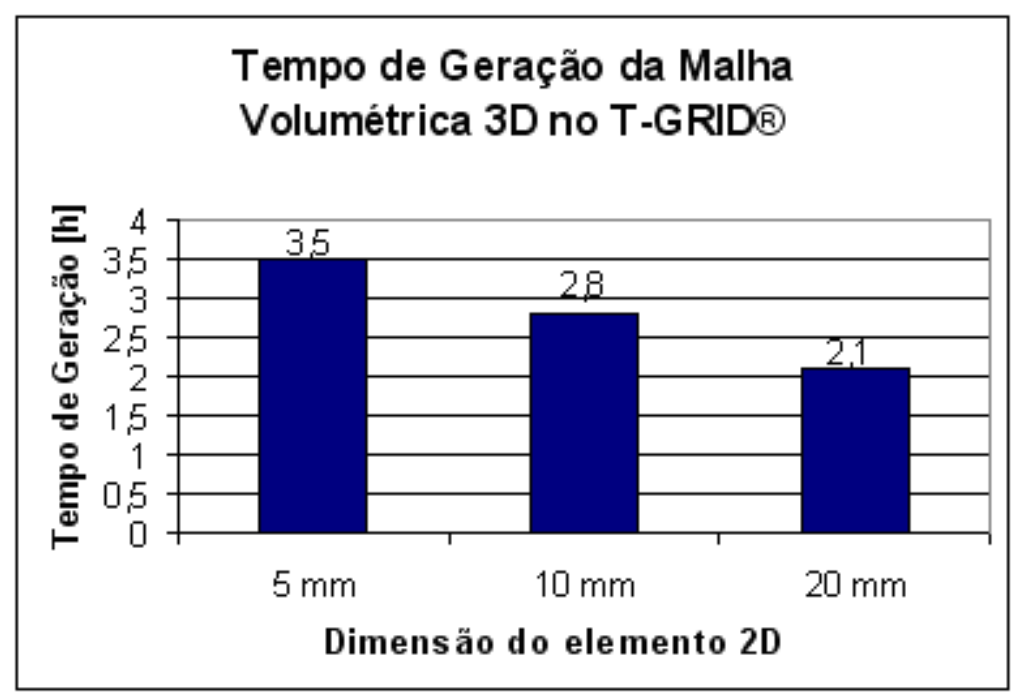

Figura 6.4 - Tempo de processamento para a geração da malha volumétrica 3D em função da dimensão do elemento $2 \mathrm{D}$

A análise do tempo de processamento da simulação do escoamento pelo programa FLUENT® para obtenção do valor do coeficiente de arrasto do veículo é realizada para as três alternativas de dimensões de malha 2D. Nota-se expressiva diferença quanto ao tempo de processamento nos três casos. Os resultados indicam um aumento de 55\% para este tempo com a adoção de dimensões iniciais de $10 \mathrm{~mm}$, em relação à de $20 \mathrm{~mm}$. Comparando-se os elementos de malha de $10 \mathrm{~mm}$ e $5 \mathrm{~mm}$, a diferença encontrada é de $16 \%$, conforme apresentado na figura 6.5 .

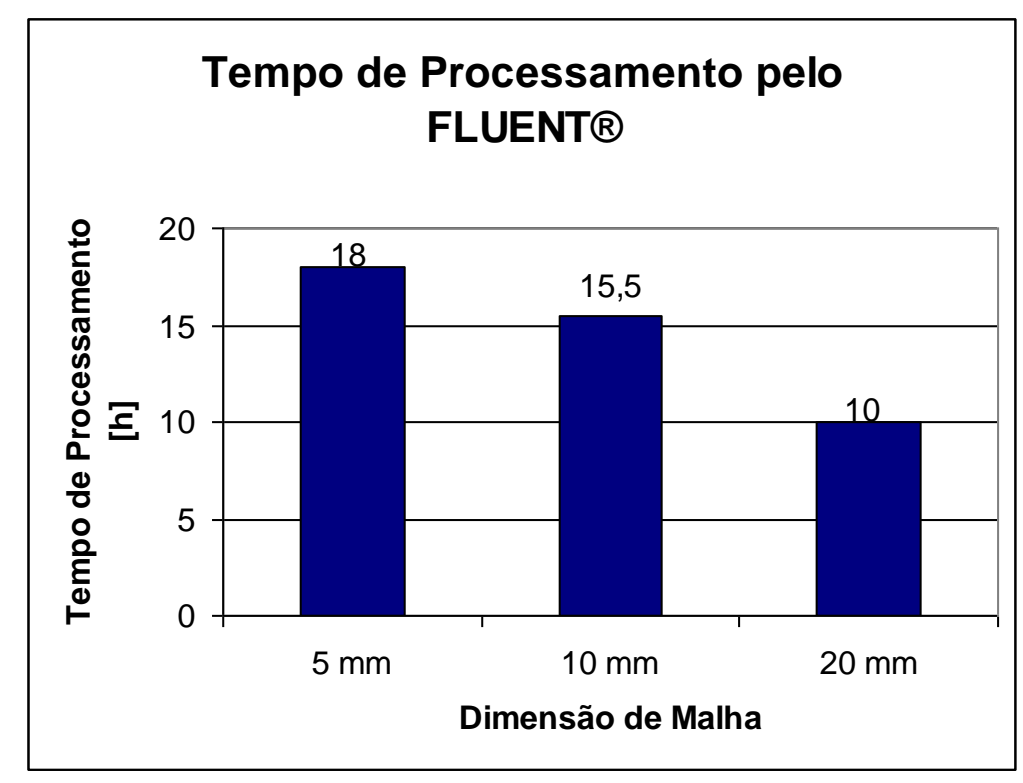

Figura 6.5 - Tempo de processamento da simulação pelo FLUENT® em função da dimensão do elemento 2D. 
Considerando os resultados obtidos para os coeficientes de arrasto nas simulações com elementos de malha de diferentes tamanhos, não houve variação significativa na comparação entre dimensões de $5 \mathrm{~mm}$ e 10 $\mathrm{mm}$. Quando a comparação é feita com elementos de $20 \mathrm{~mm}$ a diferença nos resultados para o coeficiente de arrasto é de $5,1 \%$. Na figura 6.6 , tem-se resultados para Cd nas simulações e o valor experimentalmente medido em um ensaio real em túnel de vento.

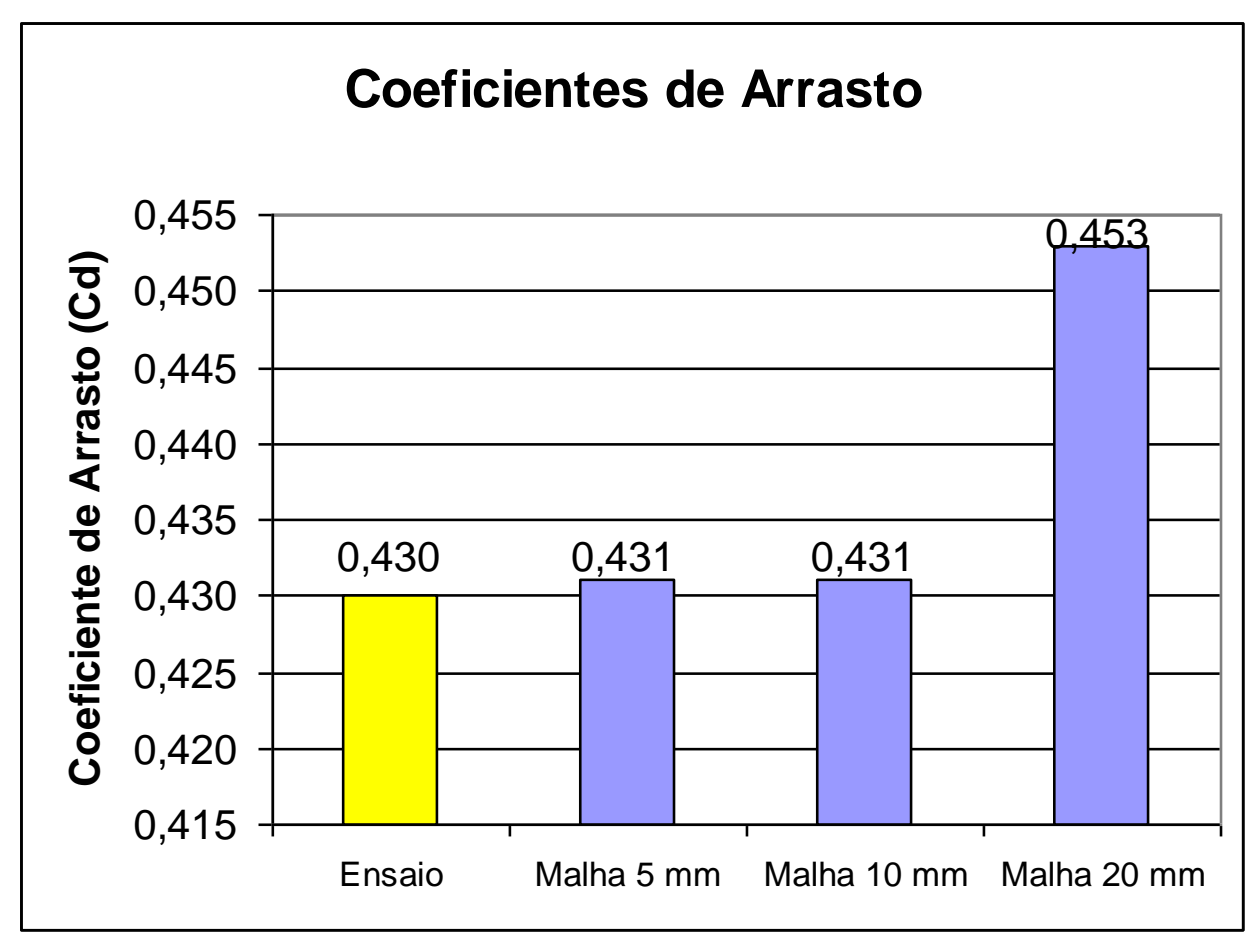

Figura 6.6 - Coeficientes de arrasto para ensaio experimental e simulações numéricas em função da dimensão do elemento 2D

Outro parâmetro avaliado na comparação das dimensões dos elementos de malha foi 0 adimensional $y^{+}$, função de parede, que caracteriza a região da camada limite em que estão posicionados os nós. As propostas de Launder e Spalding (1972) e as recomendações do programa FLUENT® são que o valor de $y^{+}$deve estar entre os seguintes limites: $30<$ $y^{+}<500$, para que a interação fluido-parede no processamento do software possa ser representada adequadamente. $O$ resultados com os valores de $y^{+}$ para as três alternativas de dimensões de células da malha estão apresentados na figura 6.7. A análise deste parâmetro indica que para os 
tamanhos de malha de $5 \mathrm{~mm}$ e de $10 \mathrm{~mm}$, os valores de $y^{+}$estão dentro dos limites do critério adotado. No caso que considera células com dimensões de $20 \mathrm{~mm}$, encontra-se no gráfico determinadas regiões que não atendem a condição limite, com valores de $y^{+}$tendendo a ultrapassar 500.

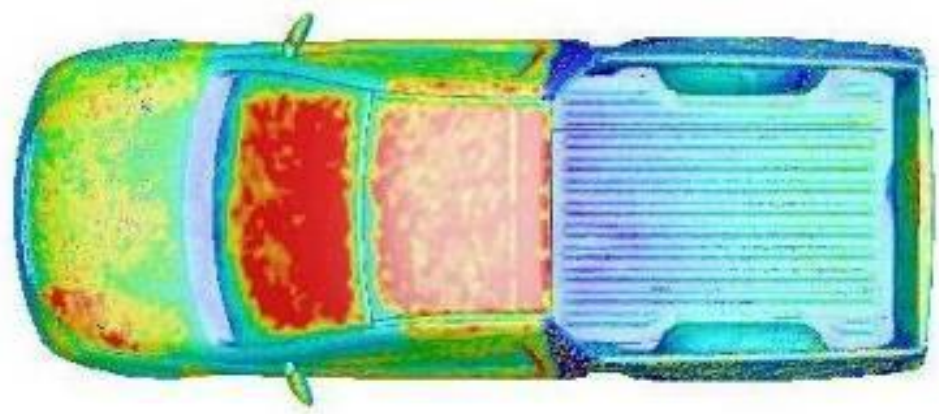

Malha $20 \mathrm{~mm}$

$5.00 \mathrm{e}+02$

$4.76 \mathrm{e}+02$

$4.53 \mathrm{e}+02$

$4.30 \mathrm{e}+02$

$4.06 \mathrm{e}+02$

$3.82 \mathrm{e}+02$

$3.59 \mathrm{e}+02$

$3.36 \mathrm{e}+02$

$3.12 e+02$

$2.86 \mathrm{e}+02$

$2.65 e+02$

$2.42 e+02$

$2.18 \mathrm{e}+02$

$1.94 \mathrm{e}+02$

$1.71 e+02$

$1.48 \mathrm{e}+02$

$1.24 \mathrm{e}+02$

$1.00 \mathrm{e}+02$

$7.70 e+01$

$5.35 e+01$

$3.00 \mathrm{e}+01 \stackrel{\mathrm{Z}}{\longrightarrow} \mathrm{x}$

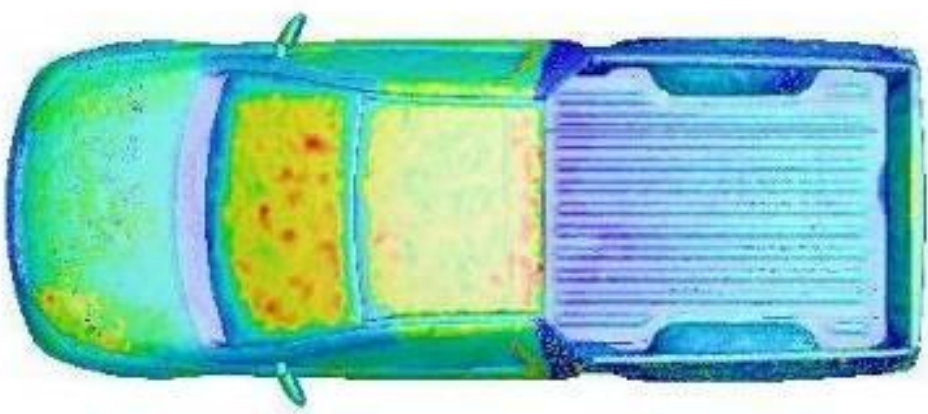

Malha $10 \mathrm{~mm}$

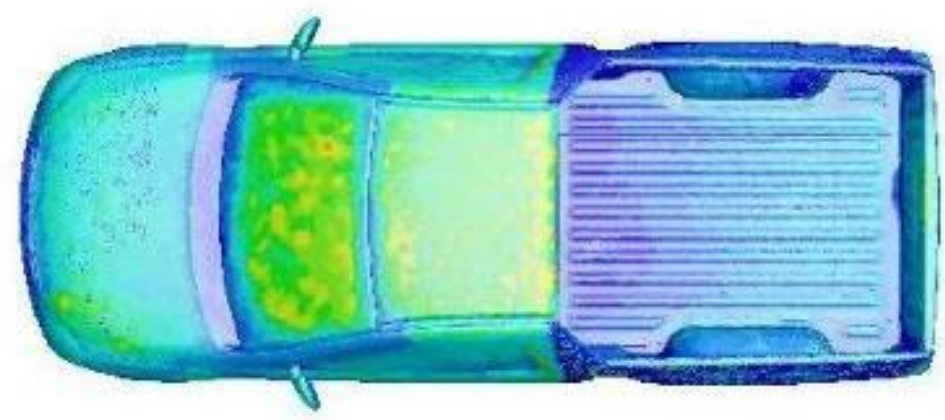

Malha $5 \mathrm{~mm}$

Figura 6.7 - Valores de y+ na malha próxima à superfície do veículo em função das dimensões dos elementos 2D. 
A qualidade da malha 3D, com elementos superficiais de $10 \mathrm{~mm}$, foi também avaliada pela análise do parâmetro "Skewness" após sua geração. Verificou-se que esta segue os requisitos propostos pelo software T-GRID®, em que uma malha volumétrica de boa qualidade deverá ter seus tetraedros com "Skewness" menor que 0,96. Na figura 6.8 está apresentado o histograma da distribuição da quantidade de células por valor do Skewness em cada uma delas. Constata-se que todos os elementos possuem "Skewness" abaixo de 0,80.

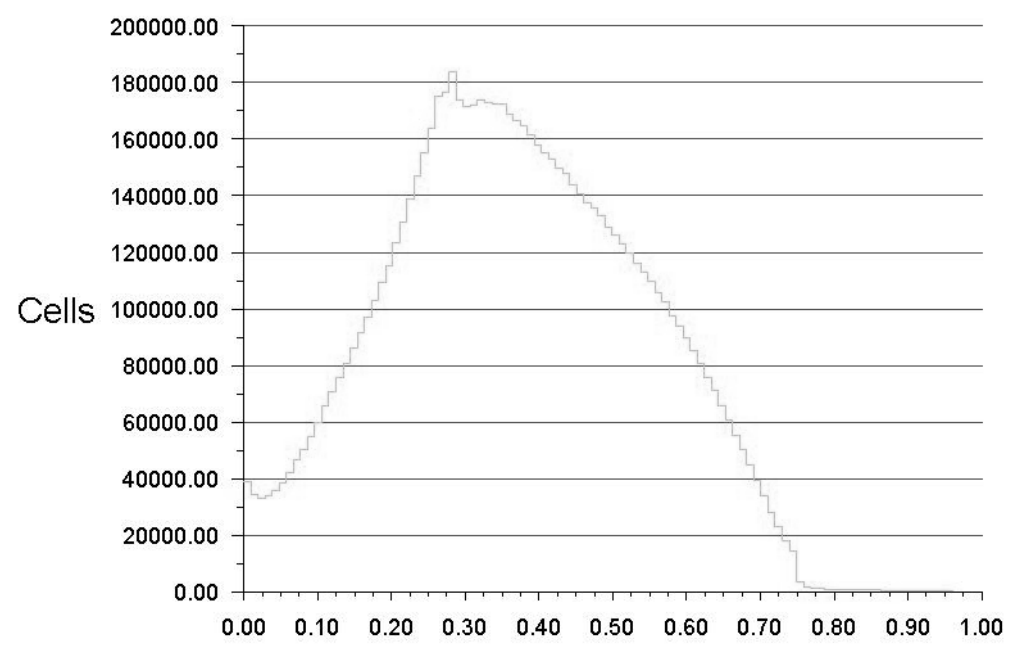

Skewness

Histogram of Cell Quality, Equilateral Volume Deviation Method

Figura 6.8 - Histograma de distribuição de quantidade de células em função do valor do Skewness

Assim foi confirmada a seleção da dimensão de $10 \mathrm{~mm}$ para as células na malha 2D como sendo a melhor opção para discretização das superfícies, considerando os fatores: tempo de geração de malha volumétrica, tempo de processamento da simulação numérica, coeficiente de arrasto e valores para o adimensional $y^{+}$. 


\subsection{ESTUDO AERODINÂMICO DE UMA RODA ISOLADA}

O estudo realizado de forma complementar simulou numericamente 0 escoamento em torno de uma roda com pneu, adotados de forma isolada. Nesta análise duas situações são consideradas: roda parada em solo fixo e em movimento de rotação sobre esteira rolante. A roda utilizada possui 14 polegadas de diâmetro, com pneu de perfil 70 e banda de rodagem de 175 $\mathrm{mm}$, ou seja, ela recebe a denominação técnica 175/70R14. As figuras $6.9 \mathrm{e}$ 6.10 mostram duas vistas do conjunto roda-pneu $e$ indicam $o$ posicionamento dos eixos cartesianos adotados na simulação numérica.

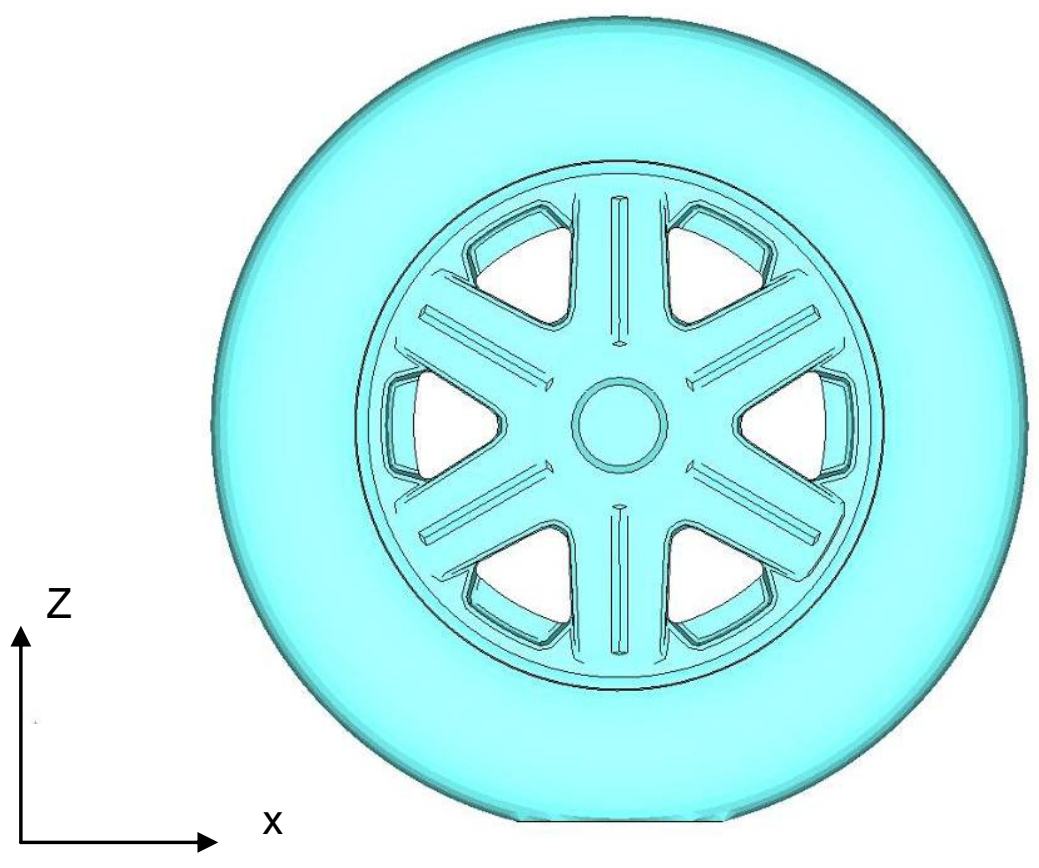

Figura 6.9 - Vista lateral da roda com pneu 175/70R14 e indicação dos eixos adotados 


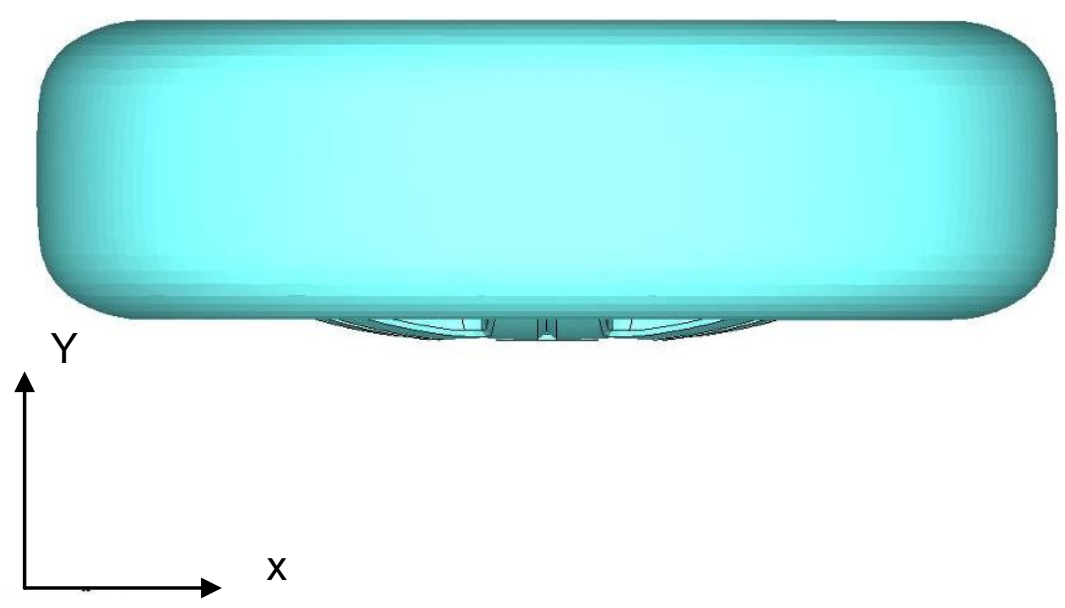

Figura 6.10 - Vista superior da roda com pneu 175/70R14 e indicação dos eixos adotados

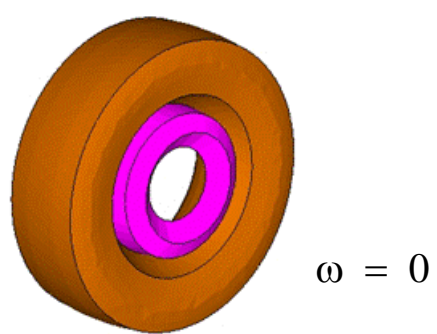

a) Roda parada

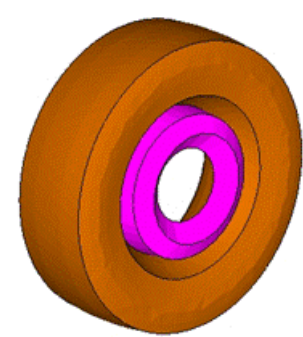

b) Roda em rotação

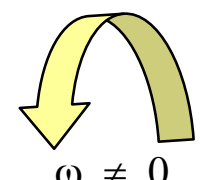

$\omega \neq 0$

Figura 6.11 - Condições analisadas: a) roda fixa b) roda em rotação.

As condições de simulação são mantidas, sendo velocidade do ar de $110 \mathrm{~km} / \mathrm{h}$, ou seja, $30,56 \mathrm{~m} / \mathrm{s}$, e modelo de turbulência $\mathrm{k}-\varepsilon$. No caso com a roda fixa, a velocidade angular da roda permanece zero, ou seja, ela não rotacionará, além do solo permanecer fixo, conforme figura 6.11 a). Já no caso com a roda em rotação, a velocidade angular é de $34 \mathrm{rad} / \mathrm{s}$, o que equivale à velocidade linear de $110 \mathrm{~km} / \mathrm{h}$ do conjunto pneu-roda e da esteira rolante.

Os resultados gráficos apresentando os vetores velocidade para 0 escoamento em torno da roda para os dois casos, fixa e em movimento, estão nas figuras $6.12,6.13$ e 6.14, com vistas em perspectivas. 


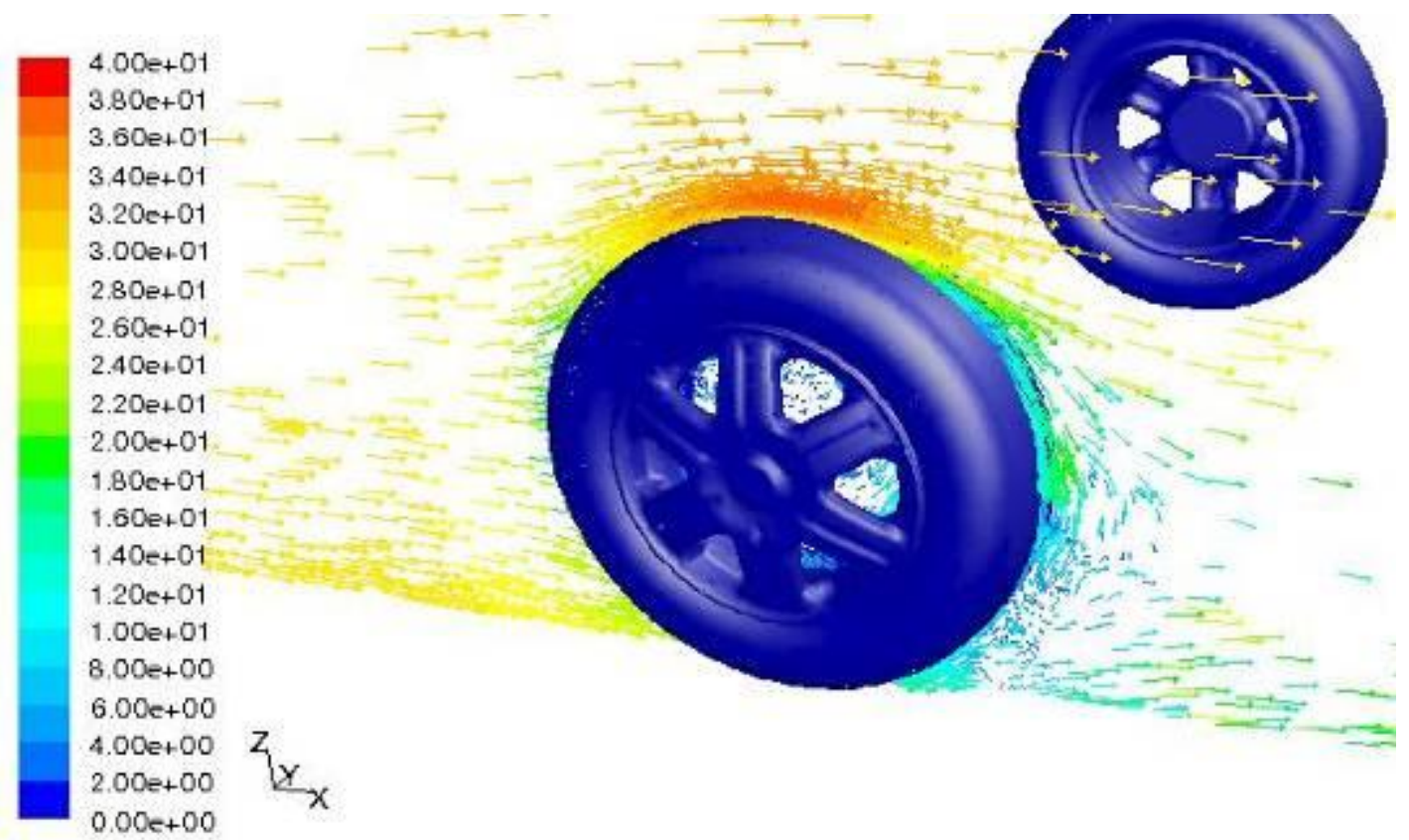

Velocity vectors Colored By Velocity Magnitude ( $\mathrm{m} / \mathrm{s})$

Jul 31, 2008 FLUENT 6.2 (3d, dp, segregated, rke)

Figura 6.12 - Vista em perspectiva da roda com piso fixo e pneu 175/70R14; visualização dos vetores velocidade.

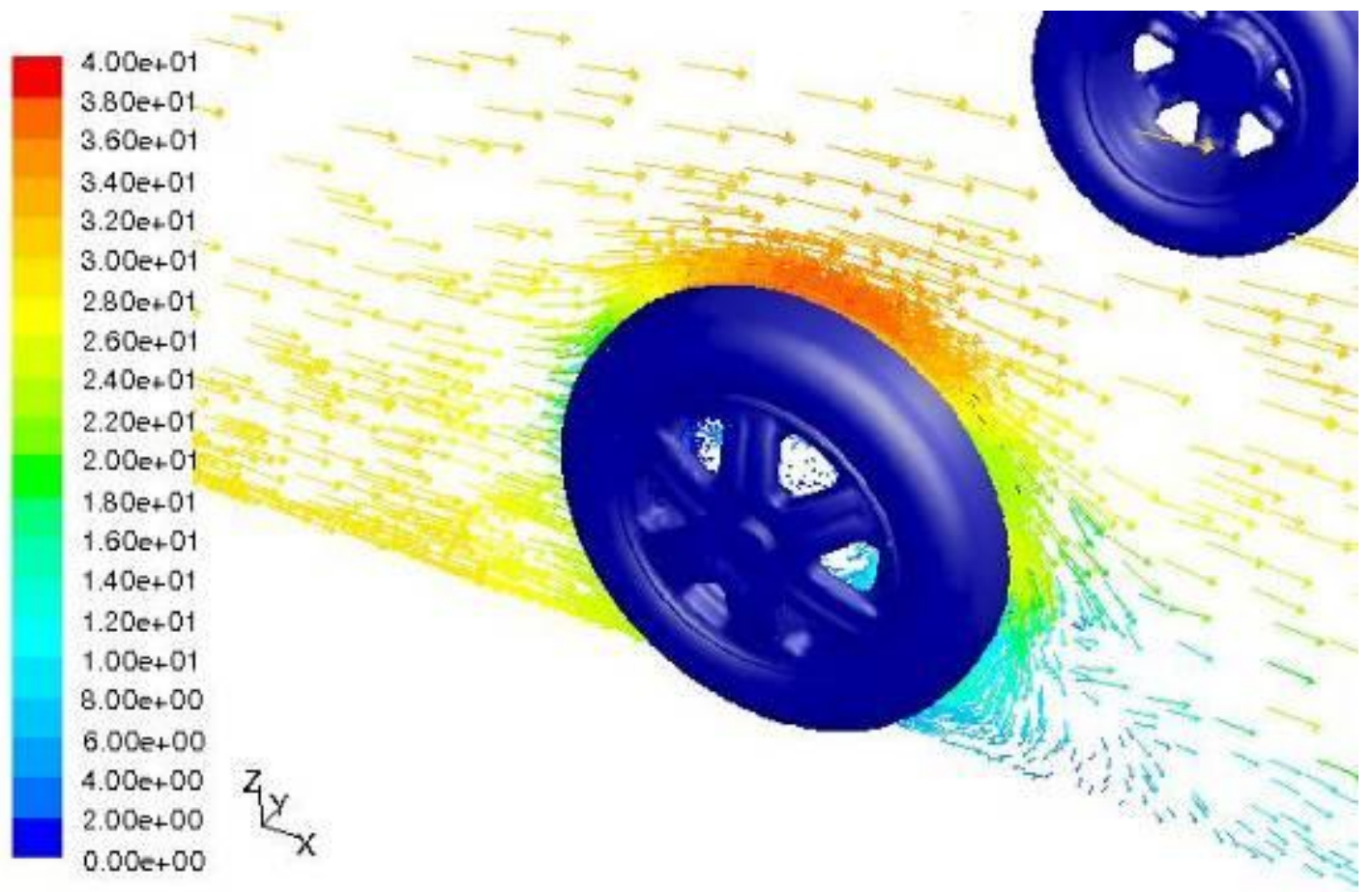

Figura 6.13 - Vista em perspectiva da roda com piso móvel e pneu 175/70R14; visualização dos vetores velocidade. 
A análise dos escoamentos nas regiões próximas à superfície da roda, a partir da representação dos campos de velocidade, e comparando-se as situações de roda fixa e móvel, apresenta as seguintes diferenças:

- No quarto superior da roda voltado para montante do escoamento, a transição de velocidades mais baixas para velocidades maiores foi deslocada no sentido horário para caso de roda móvel;

- No quarto superior da roda orientado para jusante, para o caso de roda fixa, há uma clara redução na velocidade do escoamento, indicando uma tendência de descolamento, com produção de vórtices na região de esteira. Enquanto que para a roda móvel, a influência do movimento de rotação da superfície impede a desaceleração brusca do campo de velocidades na sua proximidade.

- A densidade de vetores velocidade na região próxima à roda, no seu lado voltado para jusante, é maior no caso da roda em rotação. Observa-se também vetores velocidade com valores próximos a zero nesta mesma região para o caso da roda fixa, indicando uma tendência de haver pontos de estagnação do escoamento.

As linhas de corrente, apresentadas a seguir na figura 6.14, auxiliam na visualização do escoamento ao redor das rodas, mostrando um comparativo com estudos experimentais. 


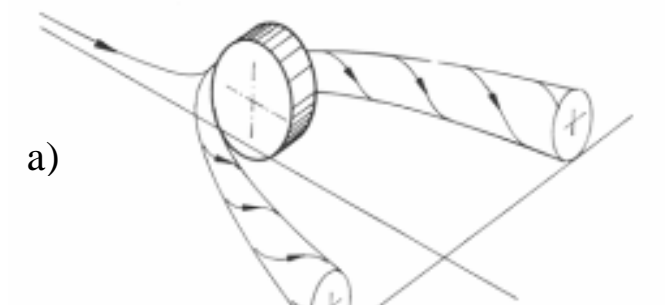

Elofsson (2002) $\omega=0$ b)

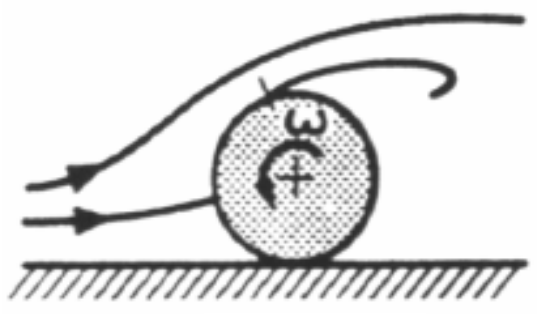

Cogotti (1983)

$\omega \neq 0$ c)

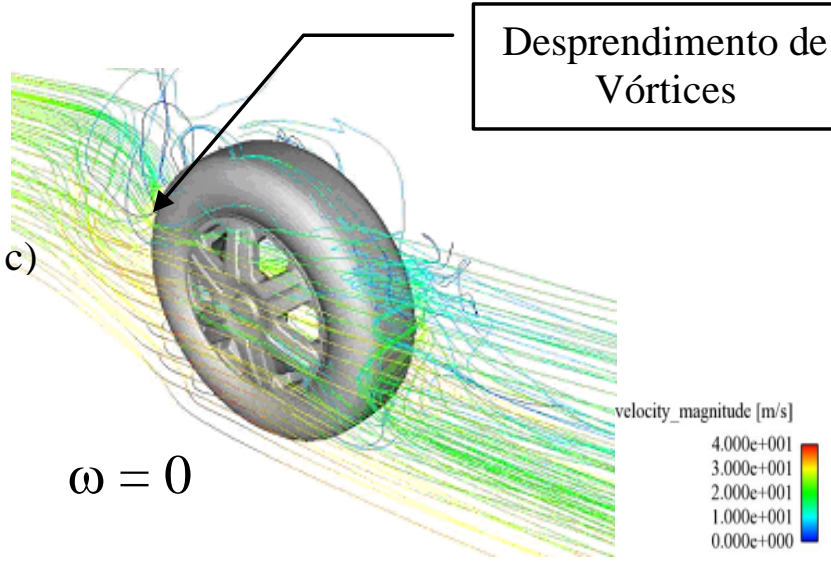

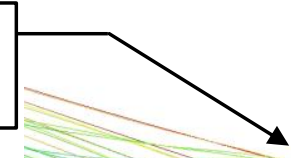

d)

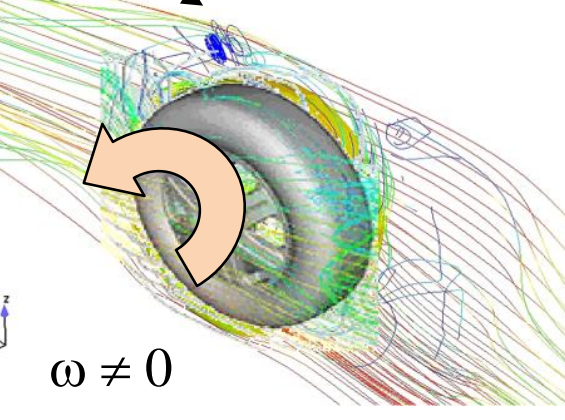

velocity magnitude $[\mathrm{m} / \mathrm{s}]$ $4.000 \mathrm{e}+001$ $3.000 \mathrm{c}+001$ $2.000 \mathrm{e}+00$ $.000 \mathrm{e}+00$ $0.000 \mathrm{c}+000$

Figura 6.14 - a) Estudo de Elofsson (2002) com roda parada b) Estudo de Cogotti (1983) com roda em movimento c) Linha de corrente sob roda estacionária com formação do vórtice ferradura. d) Linha de corrente sob roda em movimento resultando o desprendimento de vórtice na região superior.

Através de visualizações das linhas de corrente na figura 6.14, observa-se a separação do escoamento em uma roda estacionária com a formação de vórtice de ferradura (6.14a e 6.14c), enquanto que para a roda em movimento, a formação do vórtice é localizada predominantemente na região superior (6.14b e 6.14d). Esses estudos experimentais foram feitos por feitos por Elofsson (2002) e Cogotti (1983).

Os valores para o coeficiente de arrasto determinados pela simulação numérica no caso da roda fixa foi de 0,463 contra o valor da roda em rotação de 0,448 .

A diferença de 3,3\% traz similaridade ao trabalho de Wäschle (2007), no qual ele obteve uma diferença de aproximadamente 4,5\%. Esse aumento no coeficiente de arrasto está relacionado à tendência de descolamento indicada pelo comportamento dos vetores velocidade. 


\subsection{SIMULAÇÃO COM PISO FIXO NA SEÇÃO DE TESTES}

Neste caso é realizada a simulação numérica do modelo virtual de uma caminhonete submetida ao escoamento em túnel de vento com piso fixo, seguindo a metodologia apresentada no item 5.6, com sucção de camada limite no solo da seção de testes. As condições de contorno para a simulação são novamente mantidas, sendo velocidade do ar ao longe de $30,56 \mathrm{~m} / \mathrm{s}$ e modelo de turbulência $\mathrm{k}-\varepsilon$.

Uma representação das linhas de fluxo que estão no em torno do veículo inserido na seção de testes é mostrada na figura 6.15, na qual há também indicação do sistema de coordenadas adotadas.

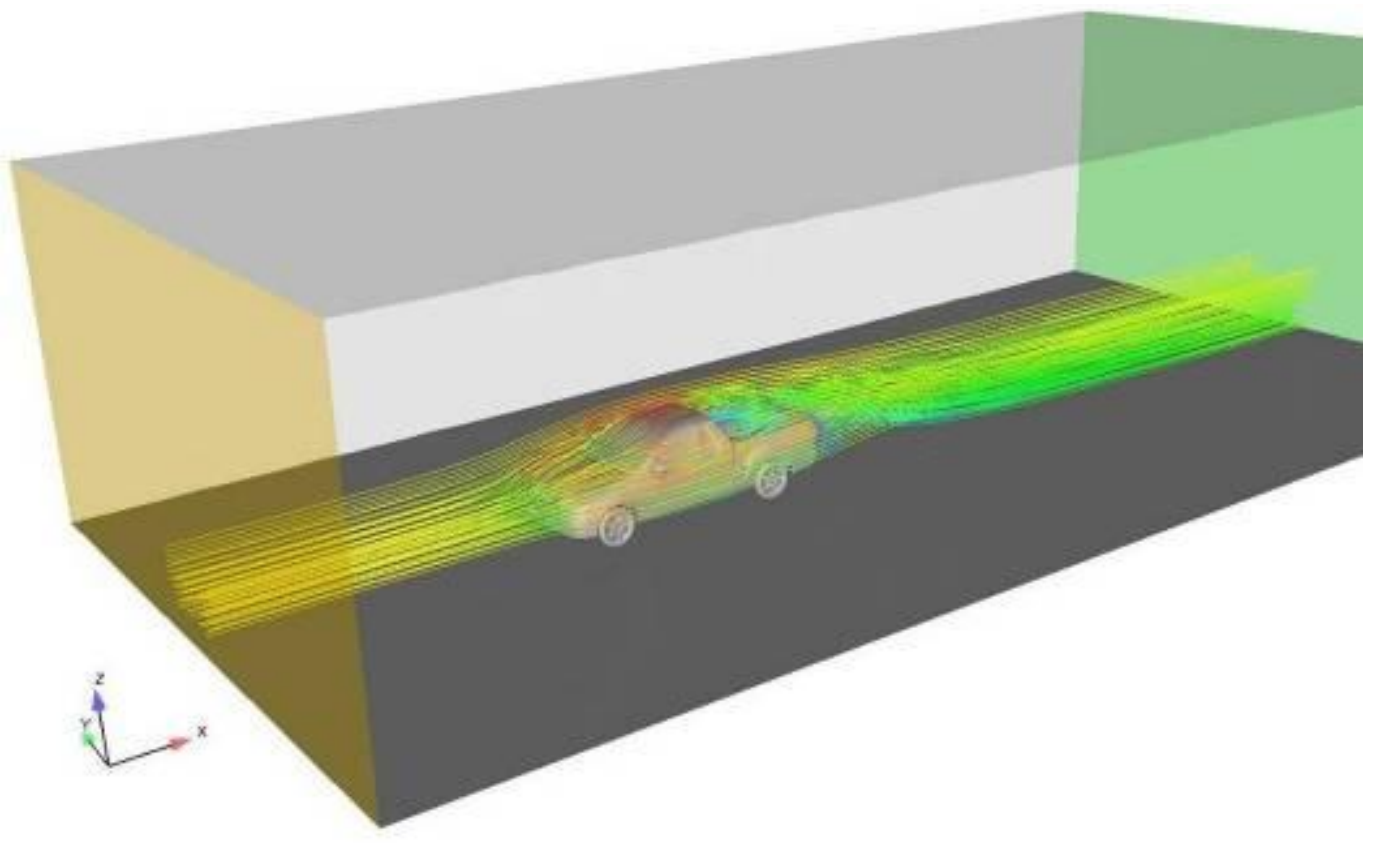

Figura 6.15 - Linhas de corrente no em torno do veículo, na condição de piso fixo.

$\mathrm{Na}$ figura 6.16 têm-se linhas de corrente em planos paralelos à direção longitudinal do veículo. Trata-se de representação ilustrativa, em que há superposição das linhas em diferentes planos, que são visualizados de modo independente nas figuras seguintes. Há indicações de aceleração do ar na região da roda dianteira e redução da velocidade nas linhas de corrente próximas à superfície lateral do automóvel. 


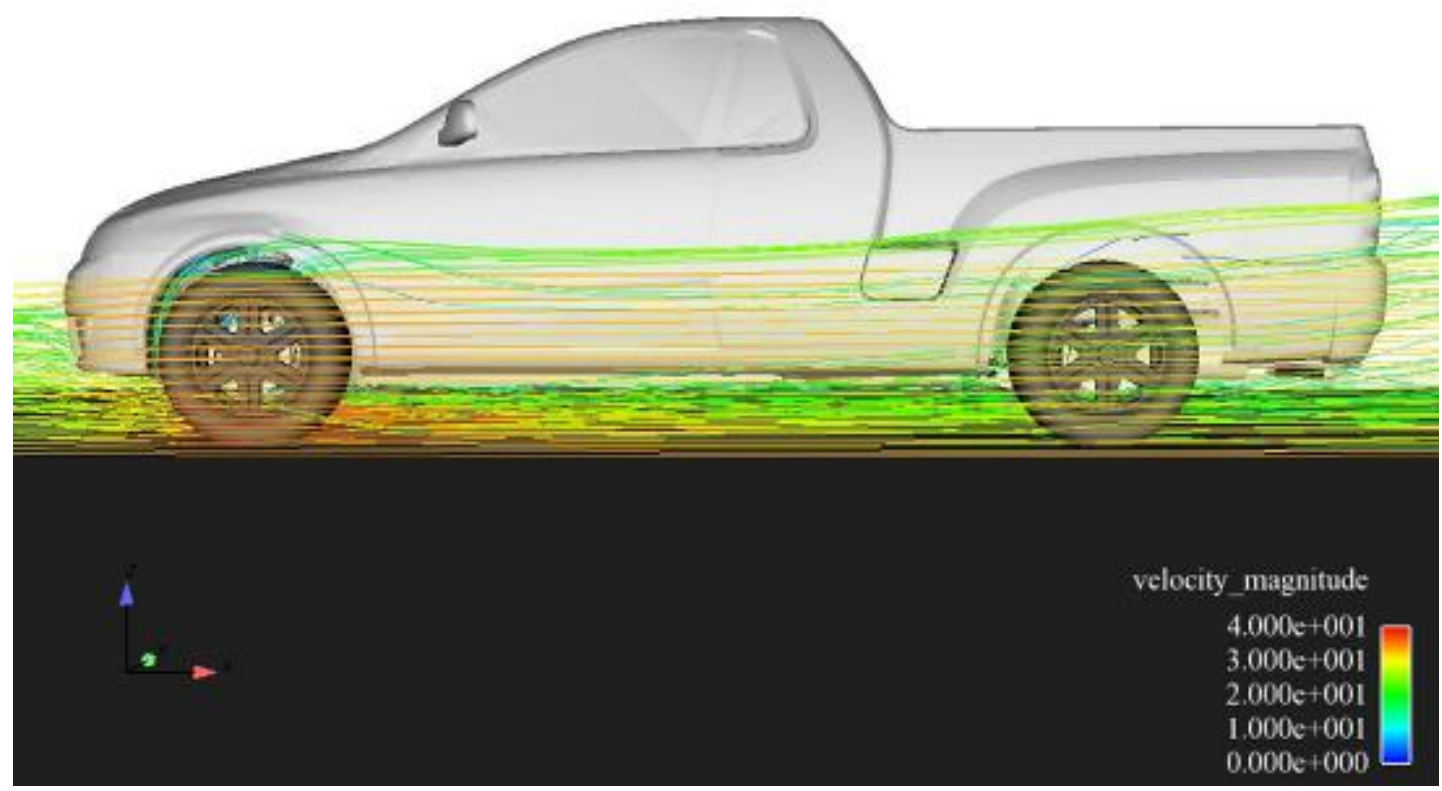

Figura 6.16 - Linhas de corrente em planos longitudinais em relação ao veículo com solo fixo

$\mathrm{Na}$ região próxima ao solo nota-se linhas de velocidade constante indicando eficiência no sistema de sucção na seção de teste do túnel, conforme figura 6.16 .

A visualização dos campos de velocidade no plano longitudinal contendo uma roda dianteira e uma traseira e no plano que corta o veículo pelo centro está apresentada respectivamente nas figuras 6.17 e 6.18 . Considerando que é importante para este trabalho analisar o escoamento na região entre o chassis e o solo, verifica-se nestas figuras que há uma redução de velocidade na parte superior e posterior das rodas principalmente na roda traseira, fato confirmado pelo detalhe com maior ampliação do escoamento na figura 6.21. 


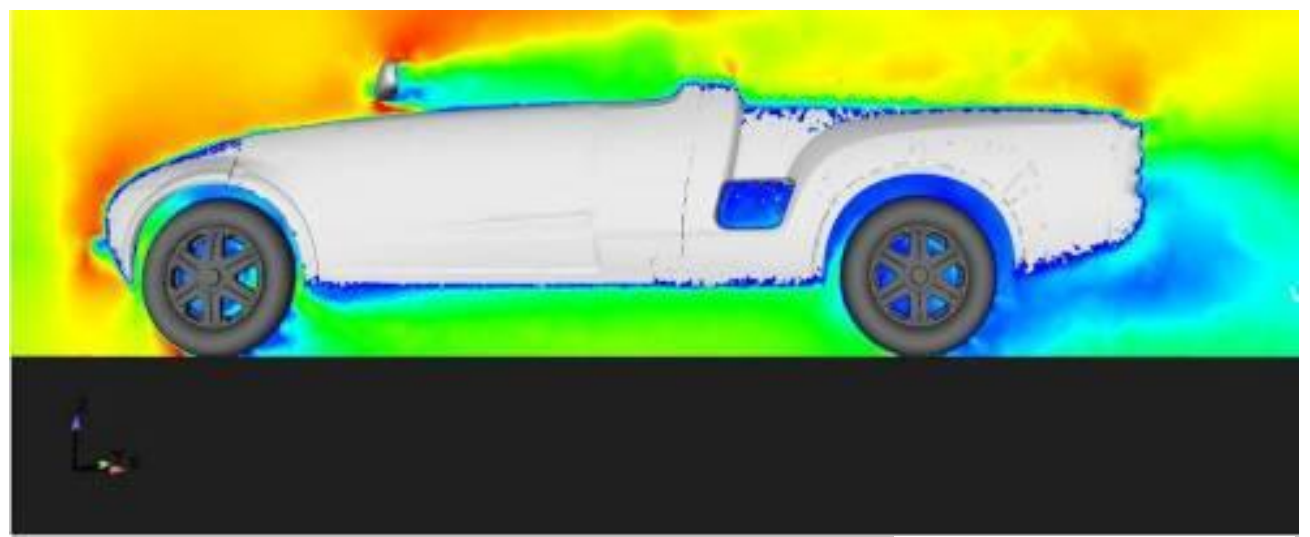

velocity_magnitude $[\mathrm{m} / \mathrm{s}]$

$4.000 \mathrm{e}+001$

$3.000 \mathrm{e}+001$

$2.000 \mathrm{e}+001$

$1.000 \mathrm{e}+001$

$0.000 \mathrm{e}+000$

Figura 6.17 - Distribuição de velocidades no plano longitudinal passando pelo centro da roda.

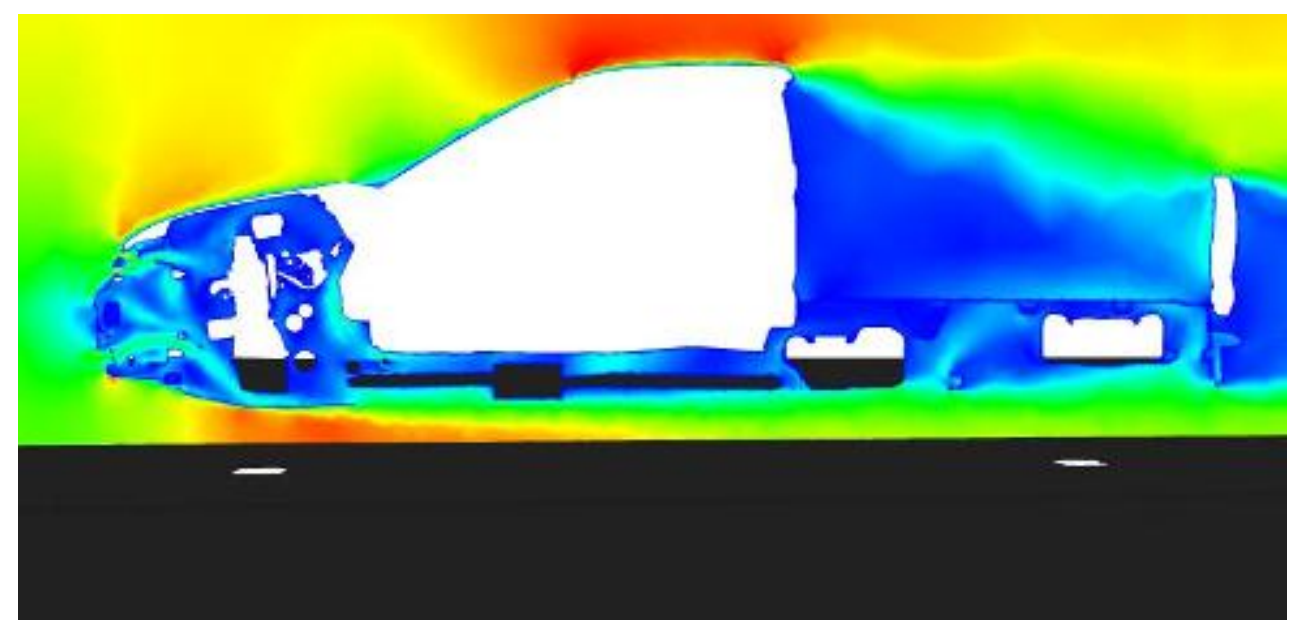

velocity_magnitude $[\mathrm{m} / \mathrm{s}]$

$4.000 \mathrm{e}+001$

$3.000 \mathrm{e}+001$

$2.000 \mathrm{e}+001$

$1.000 \mathrm{e}+001$

$0.000 \mathrm{e}+000$

Figura 6.18 - Distribuição de velocidades em um plano longitudinal passando pelo centro do veículo

O escoamento de ar internamente ao cofre do motor pode ser visualizado na figura 6.18 , apresentando valores com baixa velocidade, sendo que na região entre este cofre e o piso do túnel há uma aceleração do escoamento, associada à redução de área e garantida pelo sistema de 
sucção do piso do túnel de vento. Este movimento de ar, que avança em direção à roda traseira, será desacelerado sem que haja evidência de desenvolvimento da camada limite no solo do túnel.

A distribuição de pressões associada ao fluxo de ar em torno da roda dianteira é apresentada na figura 6.19, e em um plano longitudinal no centro do veículo na figura 6.20. Destaca-se nestas informações gráficas, a área de alta pressão na região frontal da roda e o ponto de baixa pressão na região de contato com o piso.

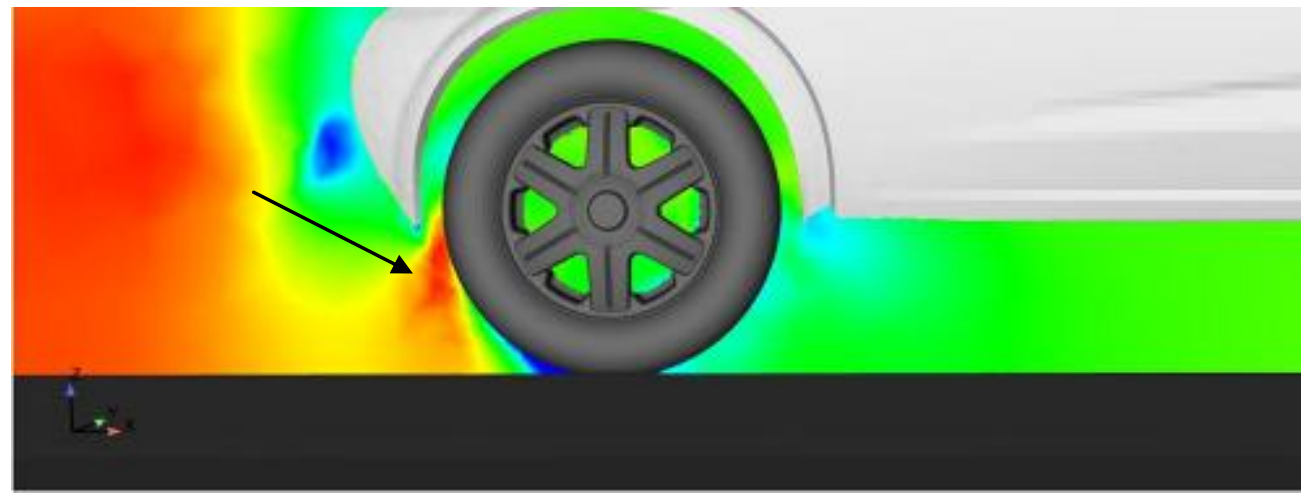

Pressure $[\mathrm{Pa}]$

$2.000 \mathrm{e}+002$

$1.500 \mathrm{e}+001$

$-1.000 \mathrm{e}+001$

$-2.500 \mathrm{e}+002$

$-5.000 \mathrm{e}+002$

Figura 6.19 - Distribuição de pressões no plano próximo à roda dianteira do veículo

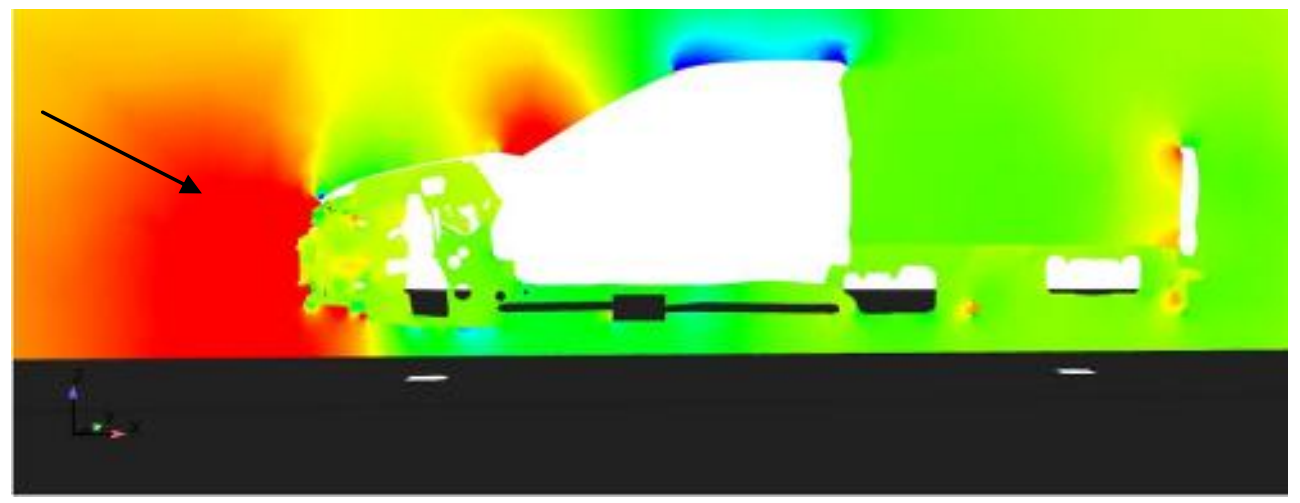

Pressure $[\mathrm{Pa}]$

$2.000 \mathrm{e}+002$

$1.500 \mathrm{e}+001$

$-1.000 \mathrm{e}+001$

$-2.500 \mathrm{e}+002$

$-5.000 \mathrm{e}+002$

Figura 6.20 - Distribuição de pressões em um plano longitudinal passando pelo centro do veículo 
O desenvolvimento de uma camada limite no escoamento de ar em contato com a parte inferior do veículo fica evidenciado pelas figuras $6.17 \mathrm{e}$ 6.21. Esta figura também indica regiões com baixa velocidade, indicando alta vorticidade, especialmente à jusante da roda traseira.

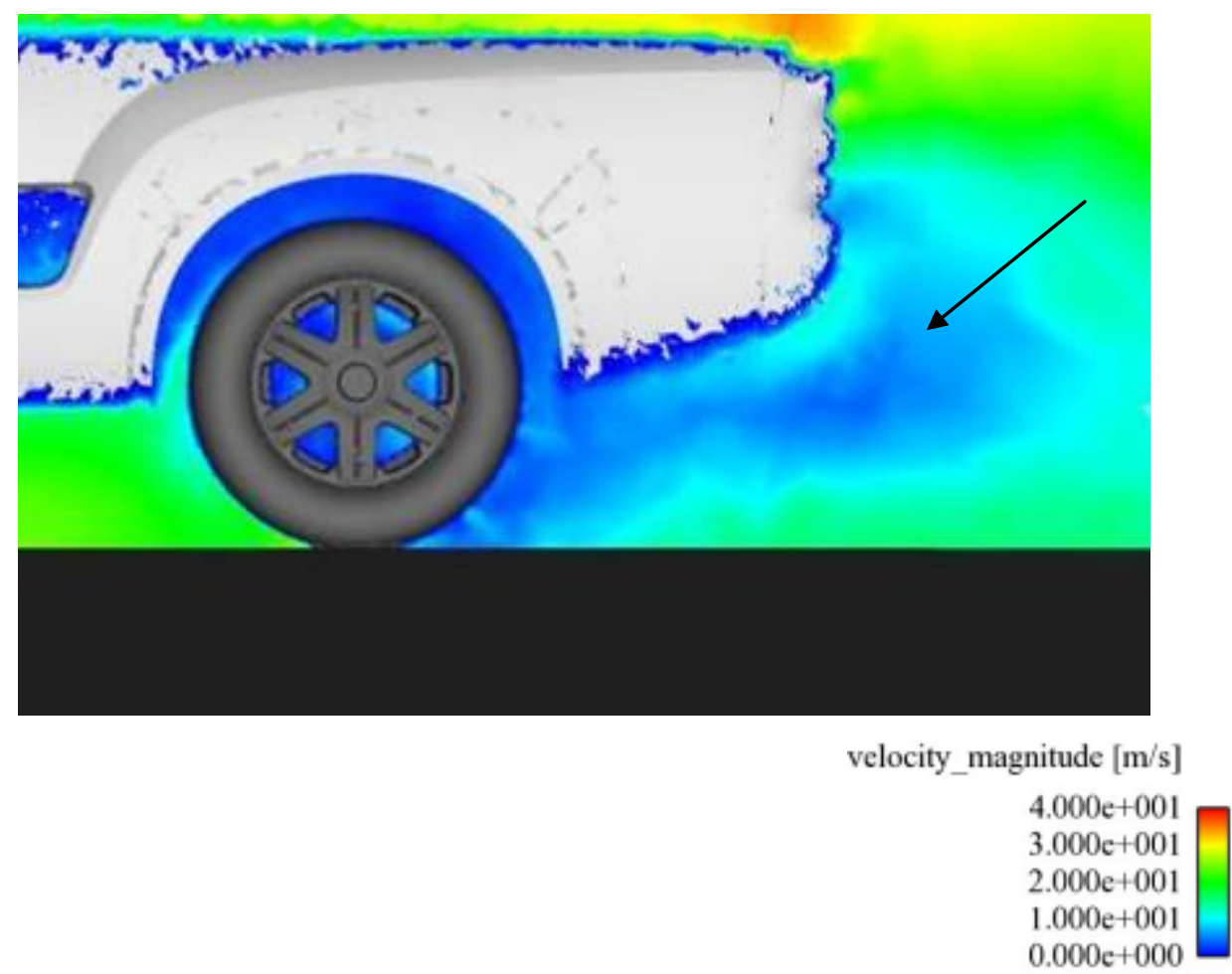

Figura 6.21 - Detalhe da zona turbulenta junto à roda traseira do veículo

O valor do coeficiente de arrasto obtido na simulação é de 0,431 , que comparado com o ensaio experimental, em condições similares, resulta em uma diferença de 0,001 , que representa $0,25 \%$.

\subsection{SIMULAÇÃO COM PLATAFORMA ELEVADA NA SEÇÃO DE TESTES}

A segunda condição de solo para a seção de testes do túnel de vento é avaliada a partir dos resultados de simulação para a determinação do comportamento dos campos de escoamento e do coeficiente de arrasto em um veículo. A simulação adotou as mesmas características e dimensões do túnel de vento e do veículo analisado no caso com o solo fixo. 
O modelo virtual da caminhonete e do túnel de vento, descritos no item 5.6, também são os mesmos utilizados para simular este caso. É utilizada a mesma malha volumétrica $3 \mathrm{D}$ já gerada pelo T-GRID®. As alterações necessárias para as novas configurações de solo foram geradas a partir da malha superficial 2D do piso, possibilitando novas condições, mudando apenas configurações internas do software FLUENT®. Assim, houve economia de tempo de preparação de malhas volumétricas extras.

No presente caso, haverá uma plataforma sob o veículo, que o elevará acima do nível do solo do túnel, com a finalidade de diminuir a influência do desenvolvimento da camada limite na região do piso da seção de testes sobre o escoamento de ar que ocorre entre o veículo e o solo. Neste caso haverá apenas sucção na entrada do túnel, considerando a região no início da plataforma sem sucção.

Nesta simulação, a plataforma tem altura de $150 \mathrm{~mm}$ acima do piso do solo e dimensões de $(3,0 \times 10,0) \mathrm{m}$, localizada na seção de testes com dimensões $(5,4 \times 10,4 \times 23,0) \mathrm{m}$.

As condições e valores para parâmetros de configuração da simulação adotadas no presente caso, como velocidade, intensidade de turbulência, condições de parede, seguem os valores previamente citados na tabela 5.2. As diferenças que são consideradas estão relacionadas à plataforma sob o veículo, como mostrado na figura 6.22.

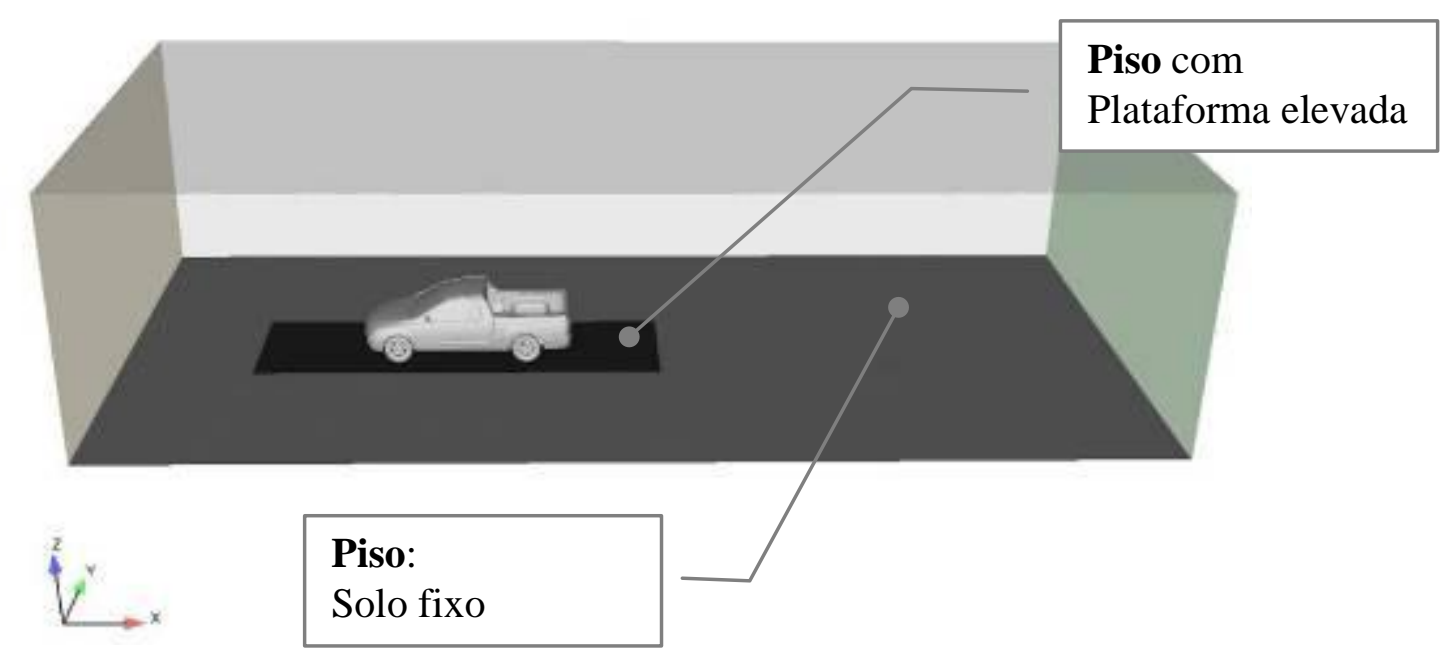

Figura 6.22 - Esquema da seção de testes do túnel de vento com plataforma elevada e veículo sobre ela. 
De modo similar às outras simulações, o caso da plataforma elevada foi processado em um cluster de 32 processadores em paralelo, em um tempo estimado de 16,2 horas.

$\mathrm{Na}$ figura 6.23, que apresenta as linhas de corrente em planos similares aos da figura 6.16. Do mesmo modo que a figura 6.16, trata-se de representação ilustrativa, em que há superposição das linhas em diferentes planos, que são visualizados de modo independente nas figuras seguintes. Há indícios da presença de uma região com escoamento em baixa velocidade próxima à superfície da plataforma, indicando o desenvolvimento de camada limite sobre ela. Nas outras regiões há similaridade de comportamento.

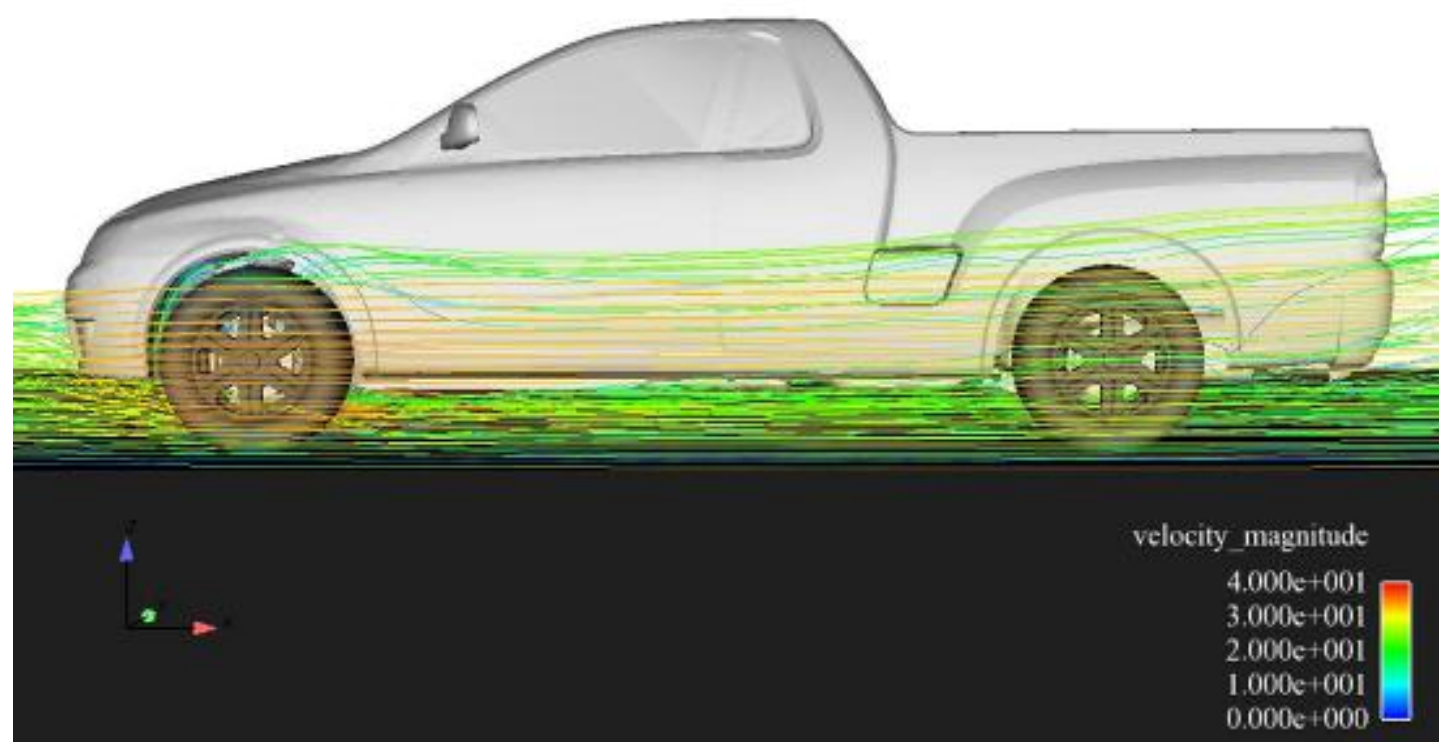

Figura 6.23 - Linhas de corrente em planos longitudinais em relação ao veículo com plataforma elevada

As figuras 6.24 e 6.25 apresentam campos de velocidades nos mesmos planos que as figuras 6.17 e 6.18. A principal diferença é a presença da camada limite na região da plataforma. Esta diferença ocorre por não haver sucção ao longo da plataforma, e apenas no início da seção de testes. 


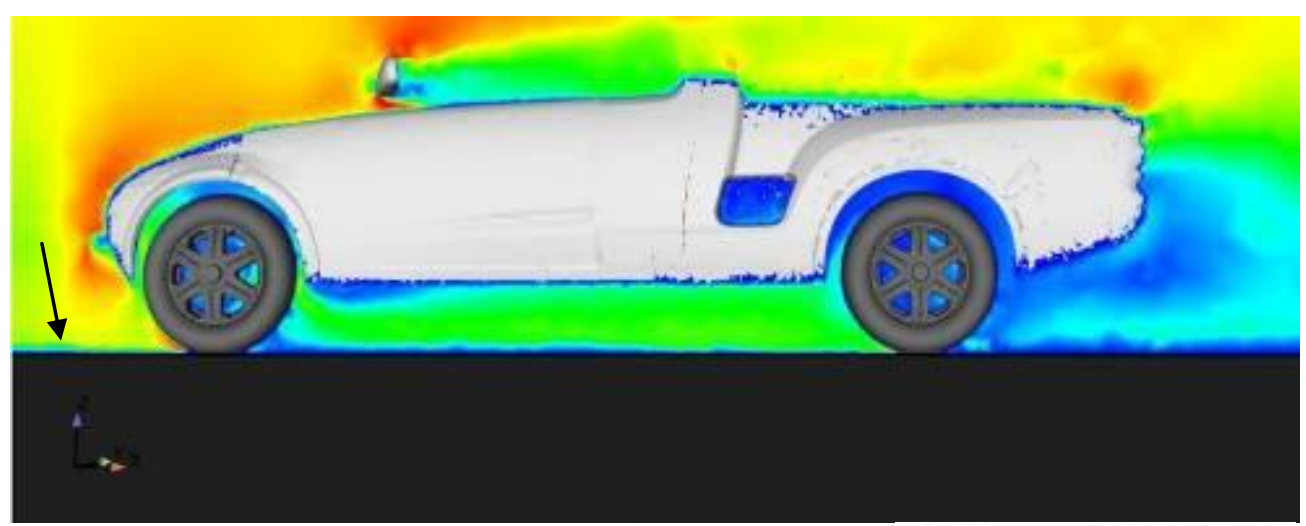

velocity_magnitude $[\mathrm{m} / \mathrm{s}]$

$4.000 \mathrm{e}+001$

$3.000 \mathrm{e}+001$

$2.000 \mathrm{e}+001$

$1.000 \mathrm{e}+001$

$0.000 \mathrm{e}+000$

Figura 6.24 - Distribuição de velocidades no plano central da roda do veículo sobre uma plataforma elevada

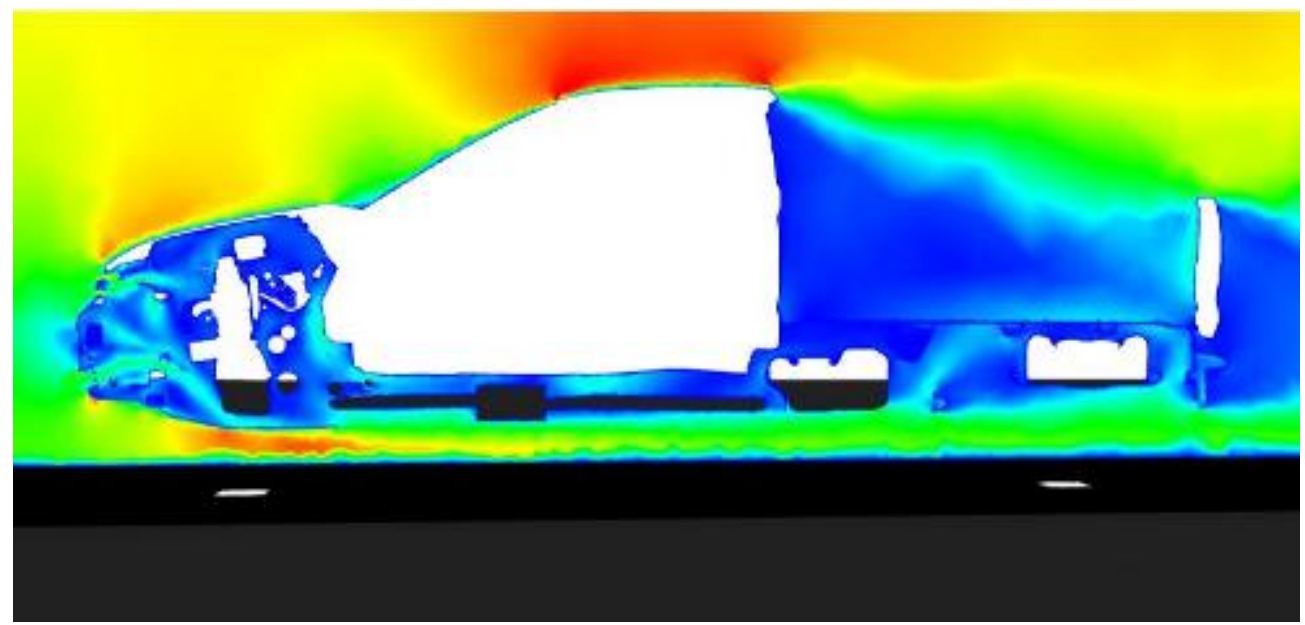

velocity_magnitude $[\mathrm{m} / \mathrm{s}]$

$4.000 \mathrm{e}+001$

$3.000 \mathrm{e}+001$

$2.000 \mathrm{e}+001$

$1.000 \mathrm{e}+001$

$0.000 \mathrm{e}+000$

Figura 6.25 - Distribuição de velocidades em um plano longitudinal passando pelo centro do veículo sobre uma plataforma elevada

A distribuição de pressões associada ao fluxo de ar em torno da roda dianteira é apresentada na figura 6.26, e em um plano longitudinal no centro do veículo na figura 6.27 sem diferenças significativas com os resultados apresentados nas figuras 6.19 e 6.20 . 


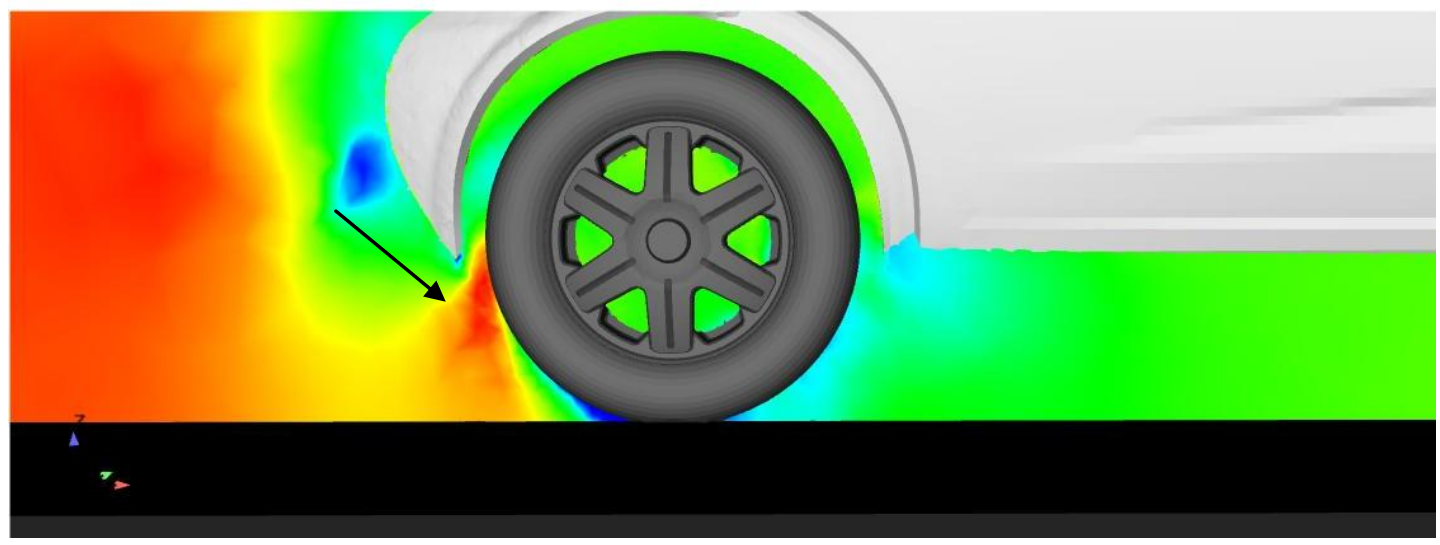

Pressure $[\mathrm{Pa}]$

$2.000 \mathrm{e}+002$

$1.500 \mathrm{e}+001$

$-1.000 \mathrm{e}+001$

$-2.500 \mathrm{e}+002$

$-5.000 \mathrm{e}+002$

Figura 6.26 - Distribuição de pressões no plano próximo à roda dianteira do veículo sobre uma plataforma elevada

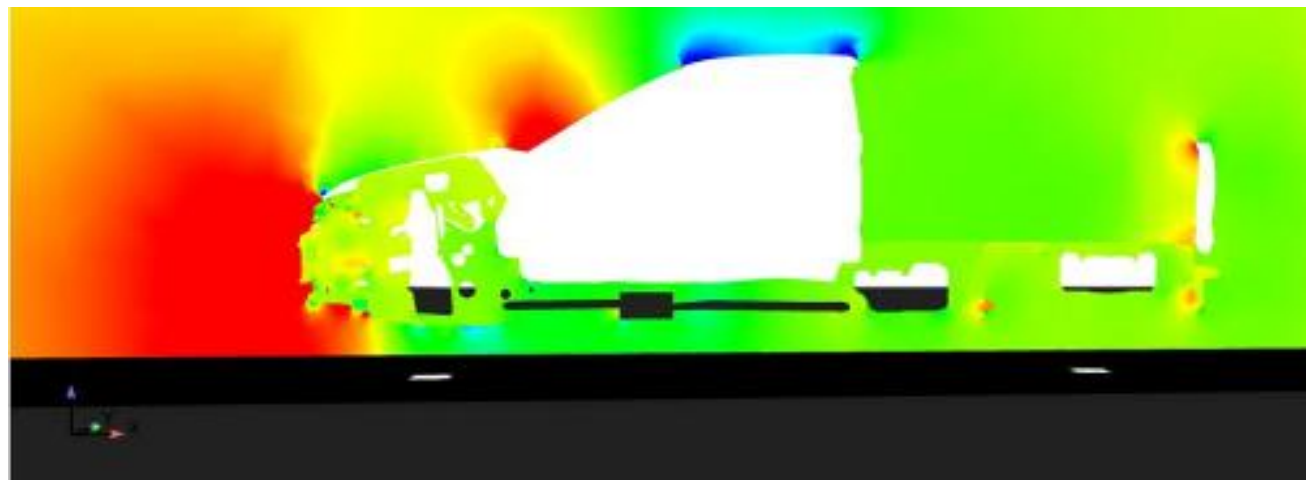

Pressure $[\mathrm{Pa}]$

$2.000 \mathrm{e}+002$

$1.500 \mathrm{e}+001$

$-1.000 \mathrm{e}+001$

$-2.500 \mathrm{e}+002$

$-5.000 \mathrm{e}+002$

Figura 6.27 - Distribuição de pressões em um plano longitudinal passando pelo centro do veículo sobre uma plataforma elevada

A focalização do detalhe do campo de velocidades dado na figura 6.28 indica resultado similar à figura 6.21 , a menos da presença da camada limite no solo da seção de testes verificado quando utilizada plataforma elevada. 


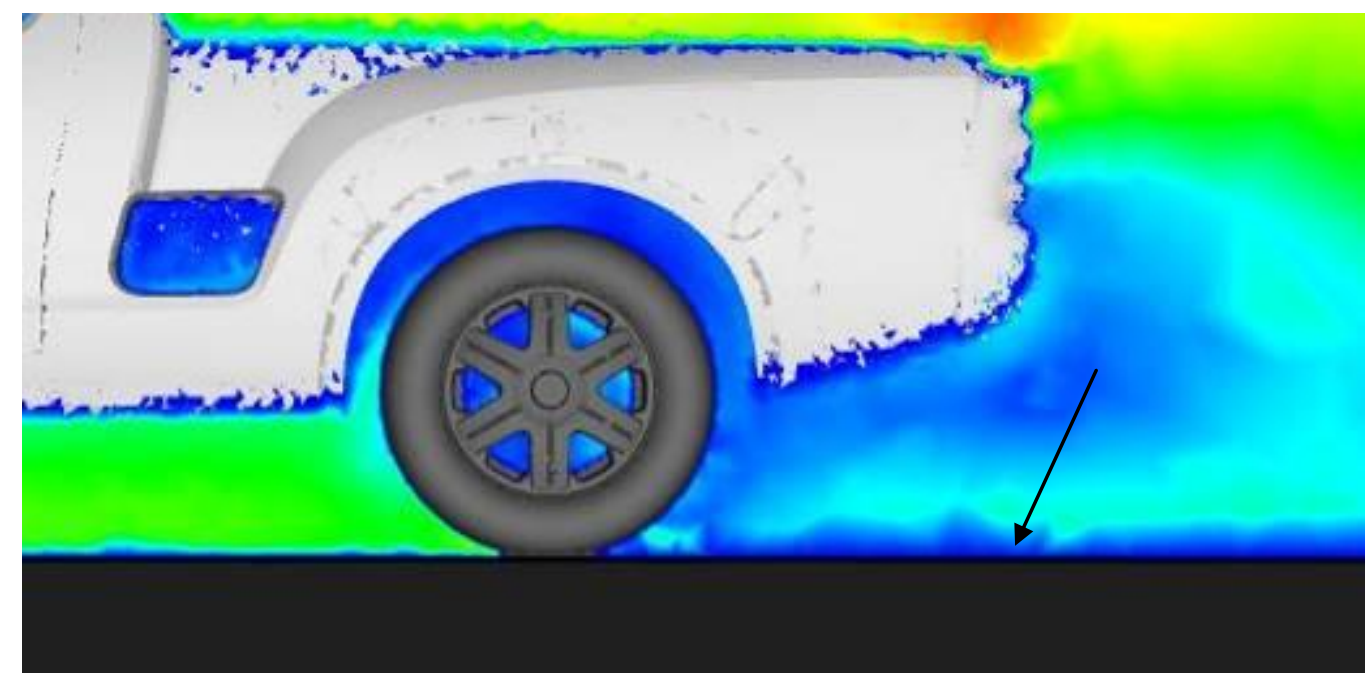

velocity_magnitude $[\mathrm{m} / \mathrm{s}]$

$4.000 \mathrm{e}+001$

$3.000 \mathrm{e}+001$

$2.000 \mathrm{e}+001$

$1.000 \mathrm{e}+001$

$0.000 \mathrm{c}+000$

Figura 6.28 - Detalhe da zona turbulenta junto a roda traseira do veículo sobre uma plataforma elevada

O valor do coeficiente de arrasto obtido na simulação deste caso foi de 0,429 , valor muito próximo ao do determinado no caso do piso fixo com uma diferença de apenas 0,002 .

\subsection{SIMULAÇÃO COM ESTEIRA ROLANTE NA SEÇÃO DE TESTES}

O terceiro caso estudado é o uso de esteira rolante no piso da seção de testes. A esteira estudada tem dimensões do piso da seção de testes do túnel, ou seja, 10,4 m de largura e 23,0 m de comprimento, com suç̧ão a montante da esteira, anulando o efeito da camada limite no escoamento junto ao piso. O carro é montado sobre a esteira, com as rodas rotacionando, simulando a condição real de operação. Esse esquema é mostrado na figura 6.29. 


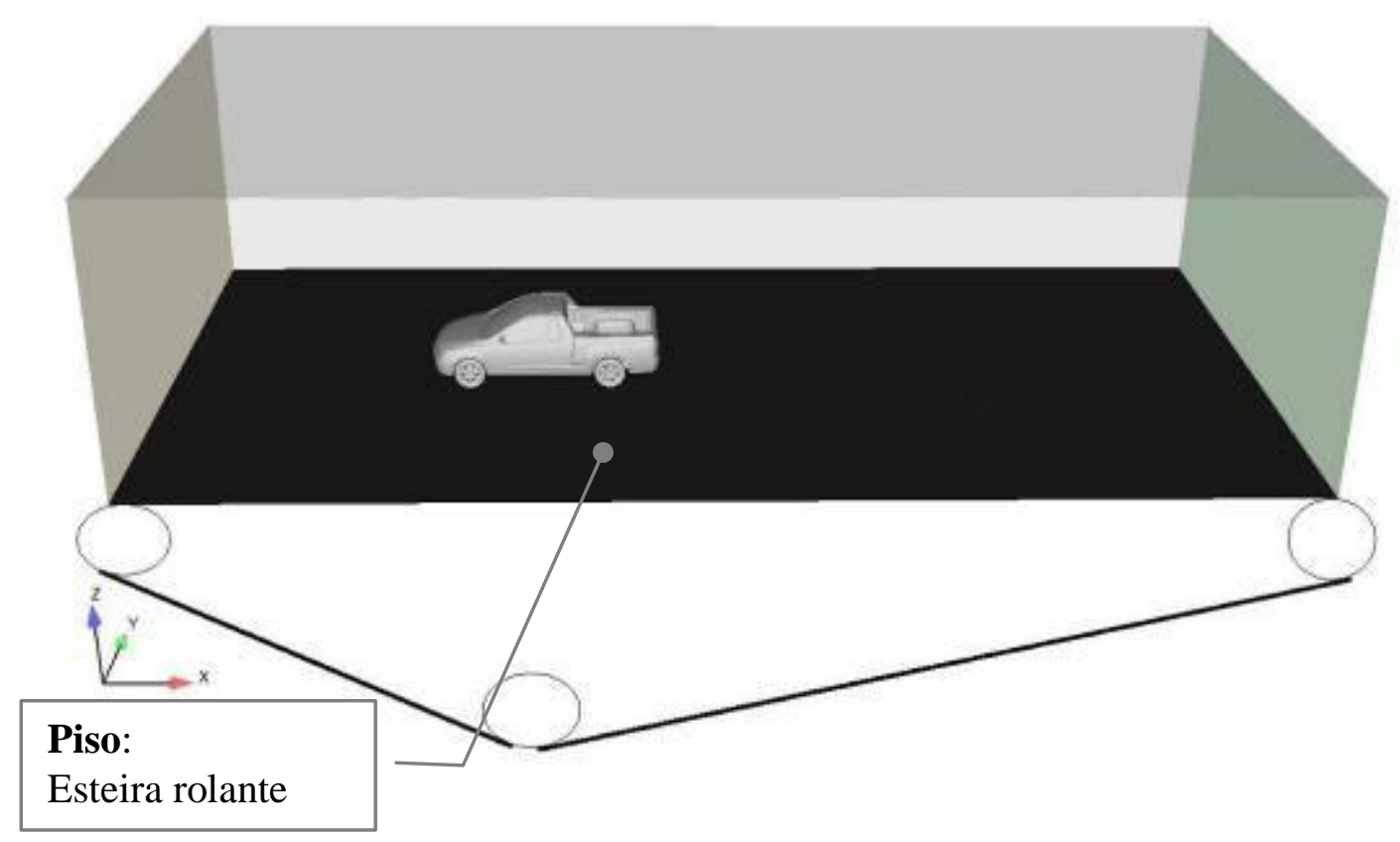

Figura 6.29 - Esquema da seção de testes do túnel de vento com a representação da esteira rolante e veículo colocado sobre ela.

A modelagem que simula o veículo em túnel de vento virtual adota parâmetros similares aos empregados nos casos anteriores naquilo que têm em comum, conforme apresentado na tabela 5.2, novamente reduzindo o tempo de preparação de uma nova malha volumétrica 3D.

Após as etapas de configuração e entrada de dados, o modelo é enviado para processamento no mesmo cluster de 32 processadores. $\mathrm{O}$ tempo de processamento foi de 18 horas.

$\mathrm{Na}$ figura 6.30, tem-se de modo semelhante, às figuras 6.23 e 6.16 representação ilustrativa de linhas de escoamento. Há indicações que principal diferença com a figura 6.23 é que no presente caso, não há camada limite no escoamento na região próxima ao solo. Nas outras regiões há similaridade de comportamento, especialmente com a figura 6.16 . 


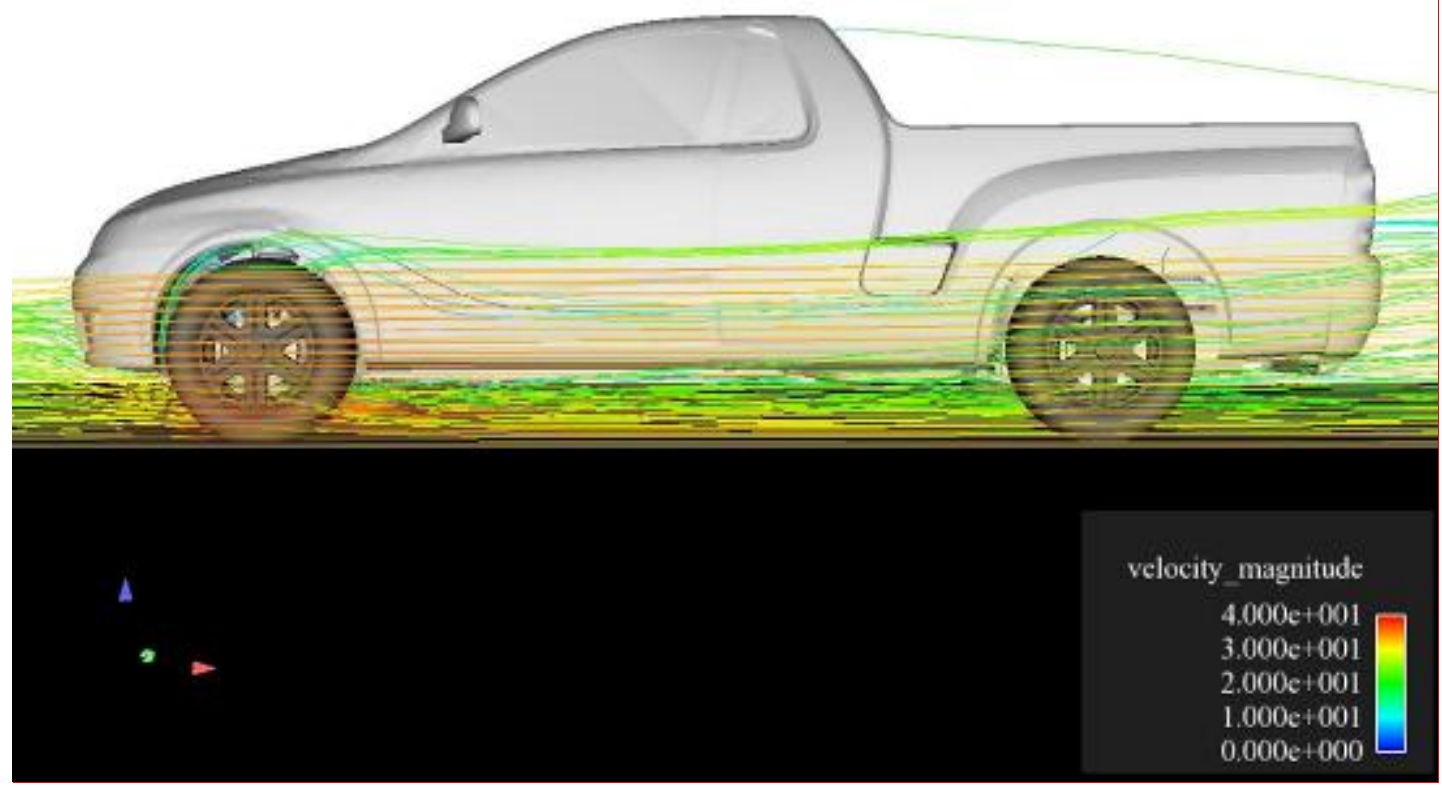

Figura 6.30 - Linhas de corrente em planos longitudinais em relação ao veículo com esteira rolante

As figuras 6.31 e 6.32 também apresentam campos de velocidades nos mesmos planos que as figuras $6.17,6.18,6.24$ e 6.25 . A diferença que distingue o comportamento do escoamento na região entre a parte inferior do veículo e o solo é que com o movimento do piso ocorre aceleração do ar próximo à esteira, com velocidade acima dos valores verificados nas outras camadas.

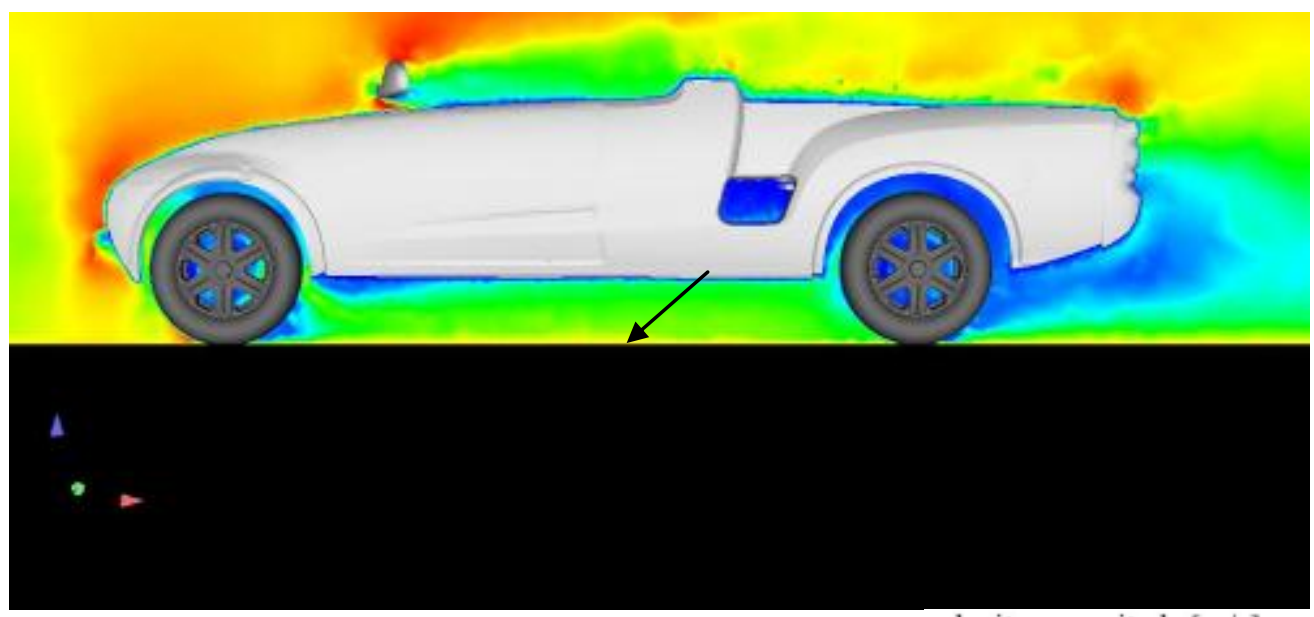

velocity_magnitude $[\mathrm{m} / \mathrm{s}]$

$4.000 \mathrm{e}+001$

$3.000 \mathrm{e}+001$

$2.000 \mathrm{e}+001$

$1.000 \mathrm{e}+001$

$0.000 \mathrm{e}+000$ 
Figura 6.31 - Distribuição de velocidades no plano central da roda do veículo com esteira rolante

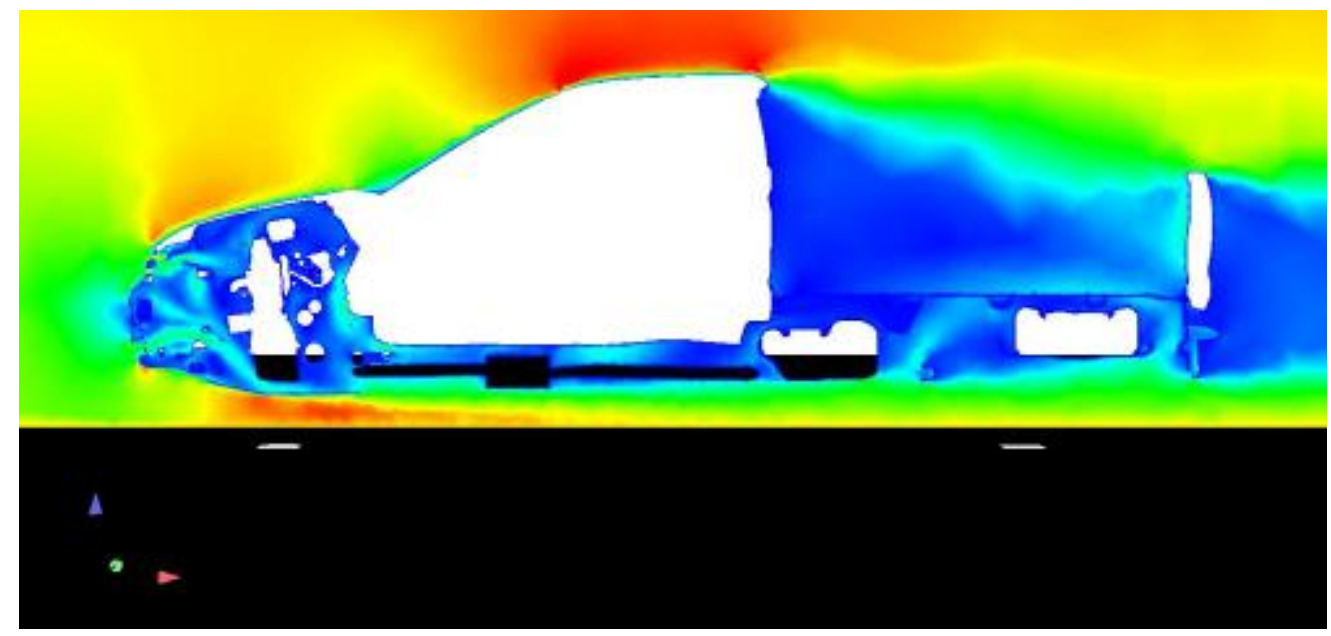

velocity_magnitude $[\mathrm{m} / \mathrm{s}]$

$4.000 \mathrm{e}+001$

$3.000 \mathrm{c}+001$

$2.000 \mathrm{e}+001$

$1.000 \mathrm{e}+001$

$0.000 \mathrm{c}+000$

Figura 6.32 - Distribuição de velocidades em um plano longitudinal passando pelo centro do veículo com esteira rolante

A distribuição de pressões também foi obtida para este caso, em duas posições: associada ao fluxo de ar em torno da roda dianteira, que está apresentada na figura 6.33, e em um plano longitudinal no centro do veículo na figura 6.34. A alteração mais significativa foi a mudança da região de alta pressão, que ocorreu nos casos anteriores conforme as figuras 6.19 e 6.26 , do meio da roda para as proximidades do ponto de contato entre a roda e a esteira. 


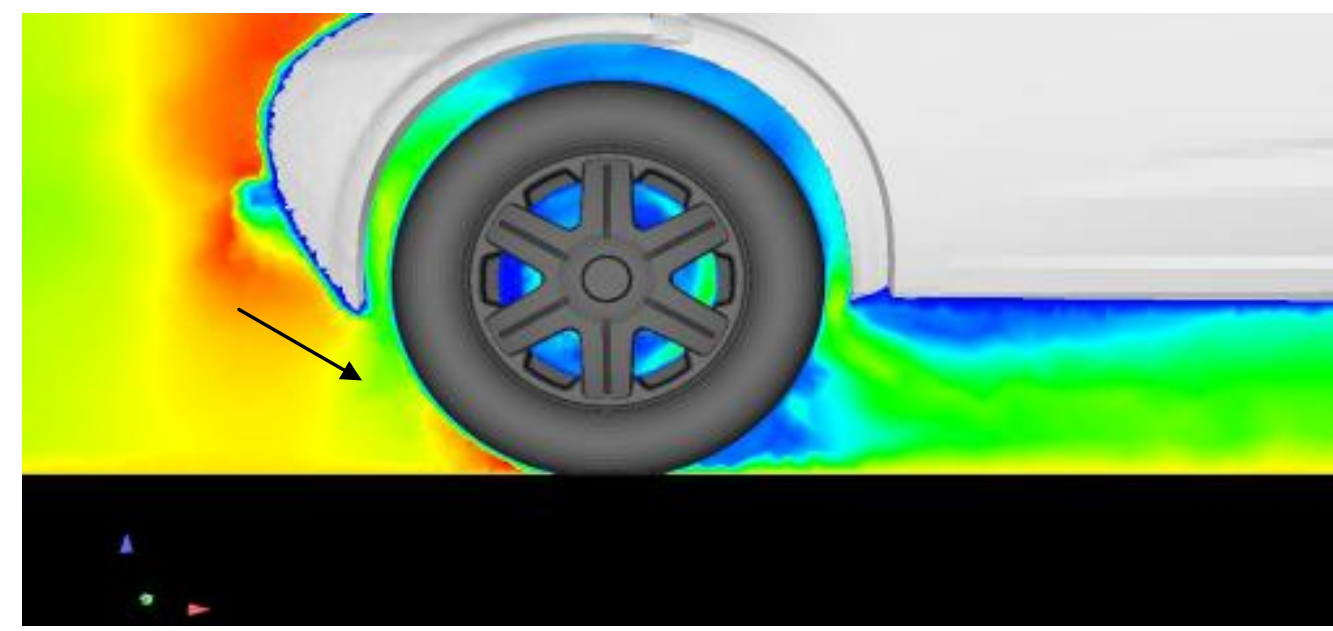

Pressure $[\mathrm{Pa}]$

$2.000 \mathrm{e}+002$

$1.500 \mathrm{e}+001$

$-1.000 \mathrm{e}+001$

$-2.500 \mathrm{e}+002$

$-5.000 \mathrm{e}+002$

Figura 6.33 - Distribuição de pressões no plano próximo à roda do veículo com esteira rolante

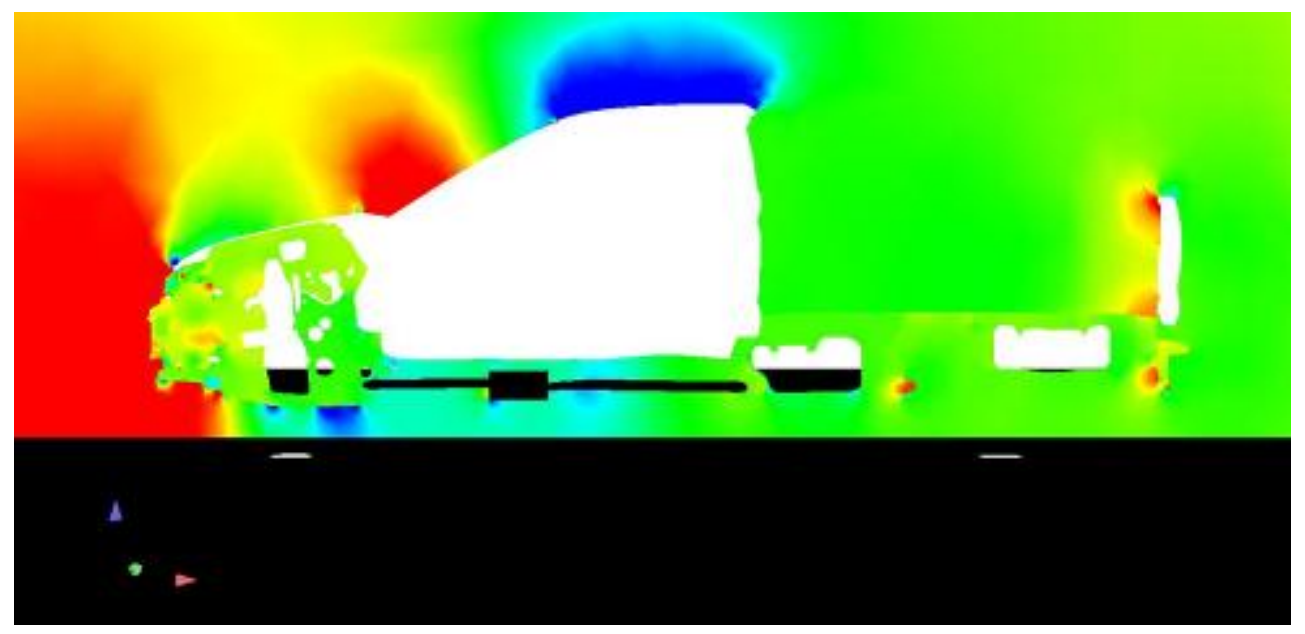

Pressure $[\mathrm{Pa}]$

$2.000 \mathrm{e}+002$

$1.500 \mathrm{e}+001$

$-1.000 \mathrm{e}+001$

$-2.500 \mathrm{e}+002$

$-5.000 \mathrm{e}+002$

Figura 6.34 - Distribuição de pressões em um plano longitudinal passando pelo centro do veículo com esteira rolante 
$\mathrm{Na}$ figura 6.35, é possível visualizar que a movimentação da esteira provoca alterações no escoamento de ar, oferecendo para a camada deste fluido que está próxima ao piso móvel a mesma velocidade de $30,56 \mathrm{~m} / \mathrm{s}$. Assim, ocorre uma modificação do padrão de escoamento entre o veículo e o solo, quando esta alternativa é comparada às anteriores, conforme pode ser verificado nas figuras 6.21 e 6.28 .

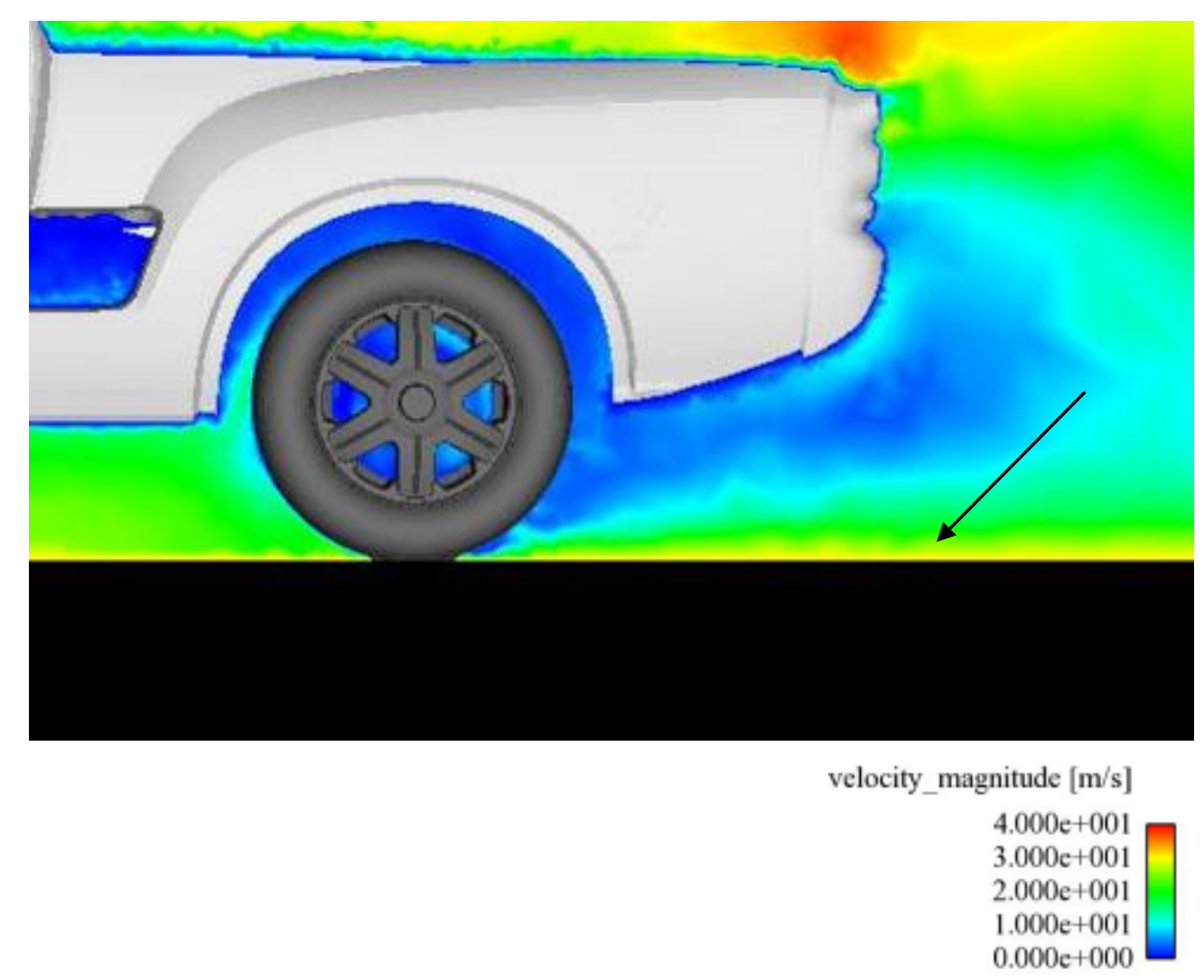

Figura 6.35 - Detalhe da zona turbulenta junto a roda traseira do veículo com esteira rolante

Concluindo esta análise comparativa, obtém-se o resultado para 0 coeficiente de arrasto, que assume valor igual a 0,419 para o mesmo veículo, agora avaliado em piso móvel e rodas rotacionando. Este valor é inferior aos resultados obtidos nas simulações de solo fixo, com 0,012 de diferença. Também difere do resultado com a plataforma elevada, sendo 0,010 a diferença. Confrontando estes valores com os obtidos por Wäschle, em 2007, a diferença entre os coeficientes possui a mesma ordem de grandeza, aproximadamente 0,010 . 


\section{CONCLUSÕES}

O principal tipo de experimento para determinar as características aerodinâmicas de um veículo é o ensaio em túnel de vento, onde é possível obter-se valores para parâmetros e conhecer propriedades relacionadas à forma geométrica deste corpo em condições controladas. O objetivo central deste trabalho foi atendido comparando três tipos de alternativas de solo que podem ser aplicados à seção de testes de um túnel de vento, procurando avaliar a influência de cada uma delas nos resultados de ensaios, a partir da análise de padrões de escoamento que ocorrem nas proximidades da região inferior do veículo e o solo, e da determinação do coeficiente de arrasto aerodinâmico para o automóvel.

Foram realizadas simulações numéricas com o uso de programas de computador que aplicam recursos da dinâmica dos fluidos computacional (CFD) para prever o comportamento das grandezas associadas ao escoamento. As três configurações estudadas foram piso fixo, plataforma elevada e esteira rolante, sendo que a alternativa de piso fixo é a solução adotada na seção de testes do túnel de vento da General Motors, usado como referência para as simulações realizadas.

O trabalho adotou em seus testes uma caminhonete de pequeno porte, similar a um veículo regular produzido. Este modelo e sua interação com o piso do túnel de vento são estudados em escala real, no túnel de vento citado, e foram determinadas características do escoamento e parâmetros aerodinâmicos.

\subsection{ANÁLISE DE PARÂMETROS E CONDIÇÕES DE CONTORNO NA SIMULAÇÃO NUMÉRICA}

Seguindo a metodologia proposta, foram cumpridas etapas preparatórias para a aplicação dos métodos de simulação do escoamento, com destaque para o processo de geração de malhas que discretizam as 
superfícies e regiões onde o escoamento acontece, testes de configuração do programa, avaliação de parâmetros de entrada e as condições de contorno necessárias para obtenção de resultados coerentes.

A etapa de geração de malhas avaliou o dimensionamento dos elementos que as compõe. Nesta fase foram analisadas três alternativas de tamanhos para os elementos 2D capazes de discretizar a superfície total do veículo: 5, 10 e $20 \mathrm{~mm}$. Foram avaliados os resultados de sua influência nos valores de coeficiente de arrasto obtidos e no tempo total da simulação.

Considerando o critério de tempo de processamento, a malha com elementos de $20 \mathrm{~mm}$ é a mais vantajosa, pois o tempo de processamento é menor, comparado aos casos de $10 \mathrm{~mm}$ e $5 \mathrm{~mm}$, respectivamente. Baseado no critério de exatidão do resultado da simulação para parâmetro aerodinâmico, no caso coeficiente de arrasto, comparado com valores conhecidos, as malhas com elementos de menores dimensões, 5 e $10 \mathrm{~mm}$, possibilitam obter resultados mais próximos do ensaio experimental. Como ambos critérios devem ser levados em consideração, conclui-se que a melhor malha é a de $10 \mathrm{~mm}$, uma vez que possui um bom grau de exatidão, semelhante ao da malha de $5 \mathrm{~mm}$, mas exige um tempo de simulação menor.

As definições das condições de contorno para todas as simulações adotaram os mesmos parâmetros do ensaio experimental de referência, para permitir correlações entre as simulações estudadas. Em todos os casos existe sucção de camada limite através do piso, no início da seção de testes do túnel, visando reduzir efeitos da mesma no escoamento entre o solo e o veículo naquela região.

Também foi realizado estudo de escoamento interagindo com uma roda isolada através de simulação numérica, nas condições fixa e rotacionando, e feitas comparações com valores encontrados na literatura. Este estudo, com objeto de geometria mais simples que a de um automóvel completo, ofereceu uma avaliação preliminar sobre as hipóteses adotadas, condições de contorno, parâmetros de entrada no programa. Foram analisadas as linhas de corrente do escoamento e a influência no coeficiente de arrasto da roda do movimento de rotação. 
Foi concluído que a consideração do piso móvel e da rotação, reduz o valor do coeficiente de arrasto em relação à condição estacionária e piso fixo.

\subsection{ANÁLISE COMPARATIVA PARA ALTERNATIVAS DE PISO NA SEÇÃO DE TESTES}

Estabelecidas as condições de contorno, selecionados parâmetros de entrada para a simulação numérica, o primeiro caso estudado foi piso estático na seção de testes, com sistema de sucção no início da seção de testes. A simulação realizada obteve resultados para as linhas de escoamento na região entre o veículo e o solo e valores numéricos do coeficiente de arrasto aerodinâmico. A análise da coerência para a representação do escoamento interagindo com as superfícies foi verificada e o resultado para o coeficiente de arrasto do veículo adotado no estudo de caso foi comparado com resultado de ensaios experimentais em túnel de vento real.

Na comparação do valor obtido no ensaio experimental real com o modelo virtual avaliado por simulação numérica, para solo do túnel fixo, a diferença de valores é de $0,25 \%$. Esta proximidade de valores confirma que a metodologia, e parâmetros de simulação utilizados conseguem reproduzir um ensaio real com uma considerável exatidão. $O$ gráfico desta comparação pode ser visto na figura 7.1 . 


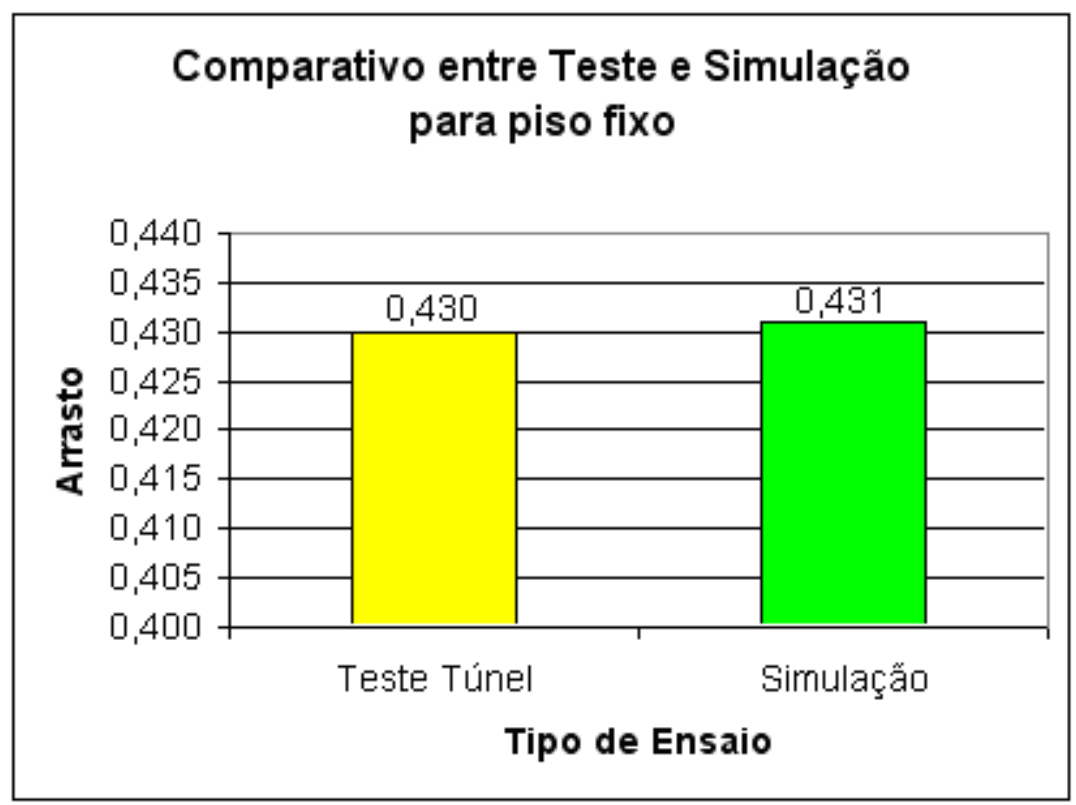

Figura 7.1 - Gráfico comparativo do arrasto do veículo ensaiado, obtido em teste e simulação virtual.

A diferença encontrada entre o resultado de simulação e ensaio real é pequena, e um dos fatores decisivos para tanto está relacionado com o modelo de elementos finitos, e com alto grau de detalhamento de malha adotada.

Foi possível, também, comparar outros tipos de configuração de solo virtualmente, com alto grau de representatividade, sendo testadas as alternativas de piso com plataforma elevada e com esteira rolante.

Os valores para o coeficiente de arrasto do veículo obtidos com os ensaios virtuais destes dois outros tipos de solo foram para plataforma elevada, 0,429 e para uso de esteira rolante 0,419 , conforme pode ser visto na figura 7.2 . 


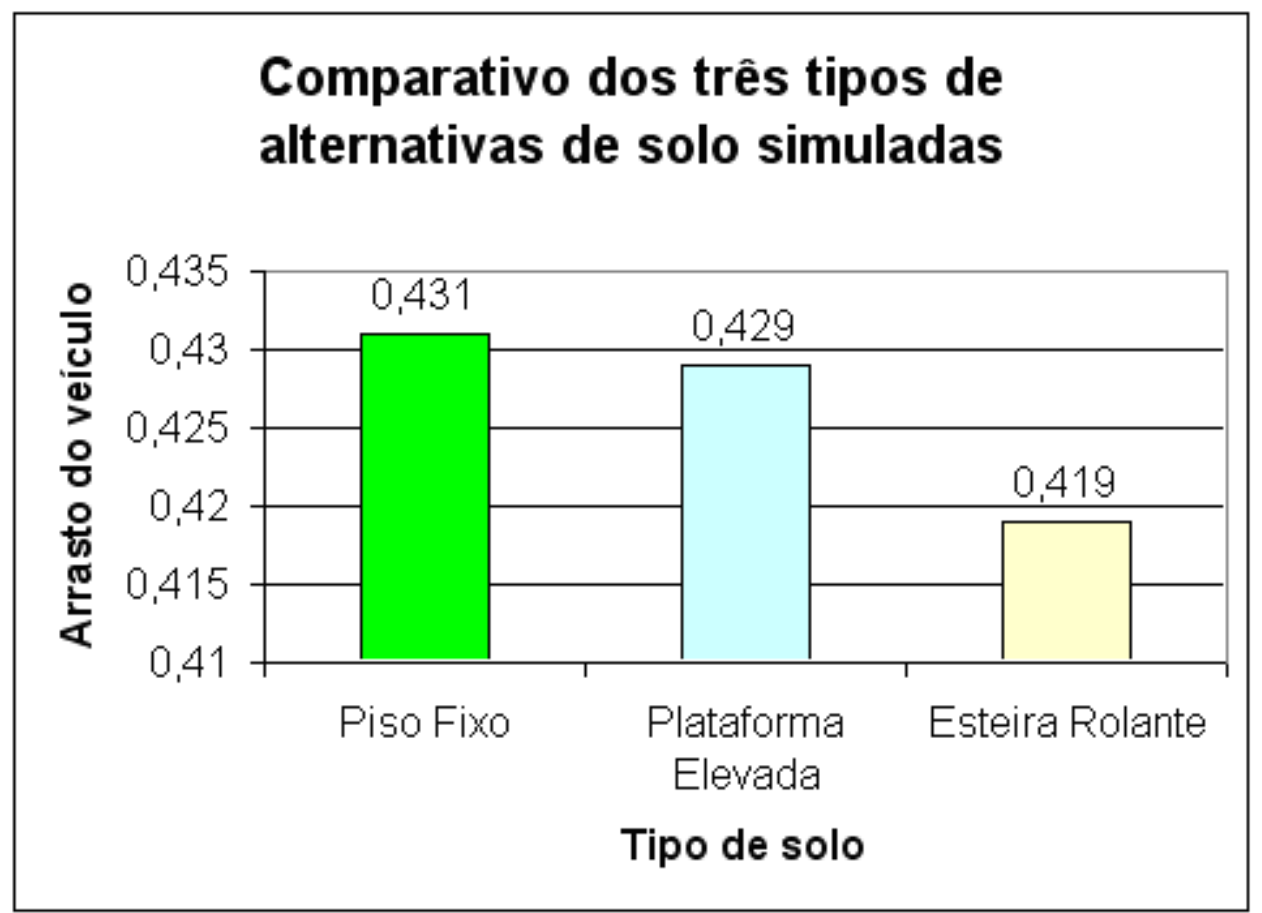

Figura 7.2 - Gráfico comparativo do arrasto do veículo, obtido nos três tipo de solo ensaiados virtualmente.

Foi realizada a análise comparativa dos campos de velocidade, próximos à roda dianteira, considerando todos os casos de pisos, conforme estão apresentados na figura 7.3.

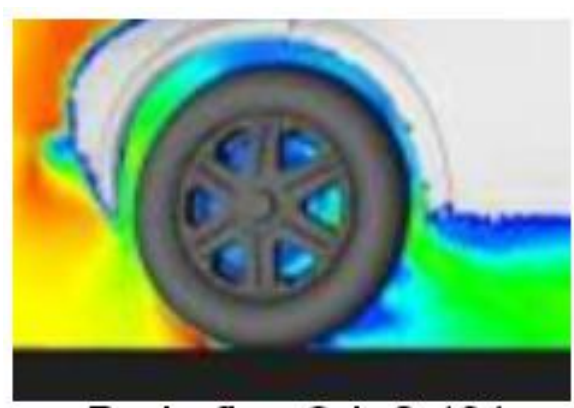

Roda fixa $\mathrm{Cd}=0,431$

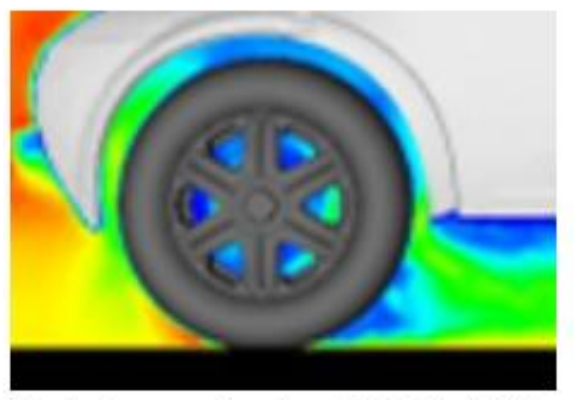

Esteira rolante $\mathrm{Cd}=0,419$

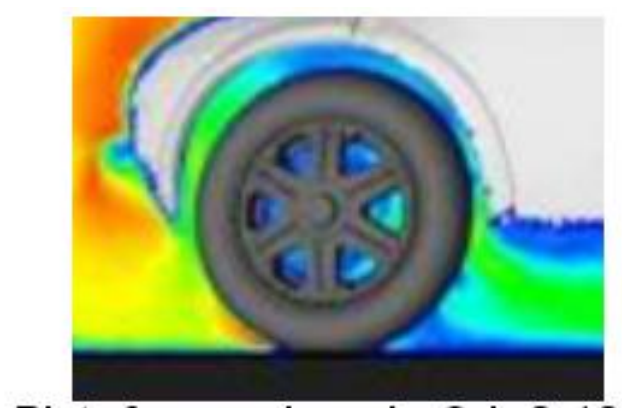

Plataforma elevada $\mathrm{Cd}=0,429$

velocity_magnitude $[\mathrm{m} / \mathrm{s}]$

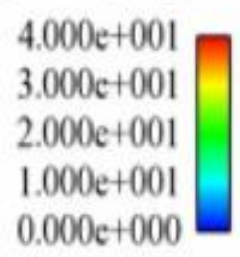

Figura 7.3 - Campos de velocidade no plano central à roda dianteira. 
Em relação aos campos de velocidade, verifica-se que todos os casos possuem uma região com velocidade próxima de zero na região posterior da roda dianteira. No caso da roda fixa não há presença de camada limite no solo, devido ao efeito da sucção, diferente do caso da plataforma, onde a sucção se dá apenas no solo e não na plataforma, onde há formação da camada na região próxima ao solo. No caso da esteira rolante, a região próxima ao solo possui velocidade em torno de $30 \mathrm{~m} / \mathrm{s}$, semelhante a do escoamento, indicando o movimento da esteira.

A figura 7.4 apresenta condensa a análise comparativa realizada dos campos de pressão, próximo à roda dianteira, para os mesmo casos.
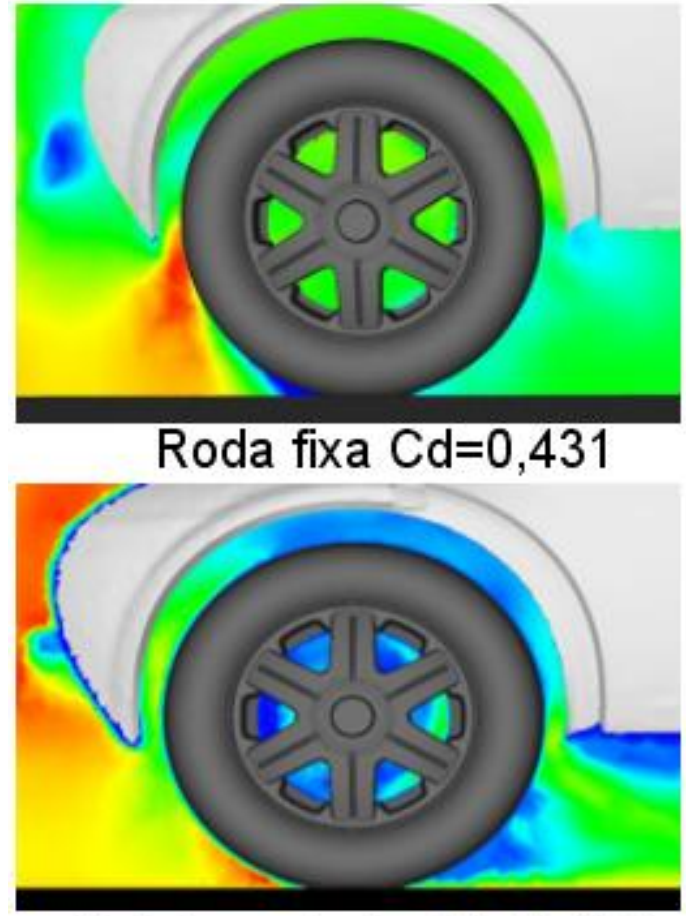

Esteira rolante $\mathrm{Cd}=0,419$

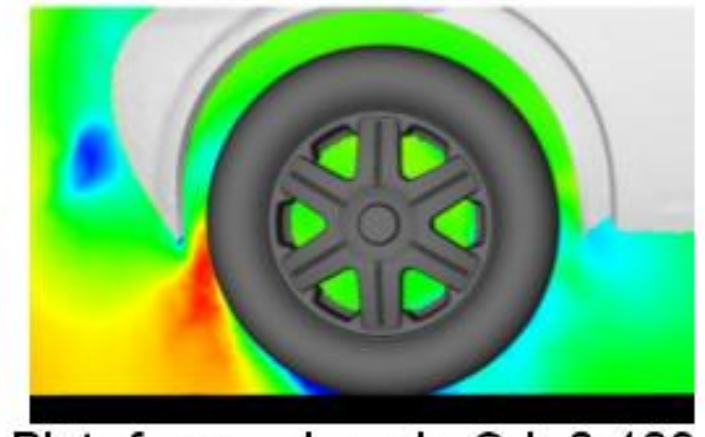

Plataforma elevada $\mathrm{Cd}=0,429$

Pressure [Pa]

$2.000 \mathrm{e}+002$

$1.500 \mathrm{e}+001$

$-1.000 \mathrm{e}+001$

$-2.500 \mathrm{e}+002$

$-5.000 \mathrm{e}+002$

Figura 7.4 - Campos de pressão no plano central à roda dianteira.

Conclui-se que os campos de pressão são semelhantes no caso de piso fixo e plataforma elevada, pois, em ambos os casos, piso e rodas se encontram fixos, diferente do caso da esteira, onde a roda e piso se movimentam e alteram o campo de pressões. 
Os campos de velocidade na região da roda traseira estão retratados de modo aclopado na figura 7.5.

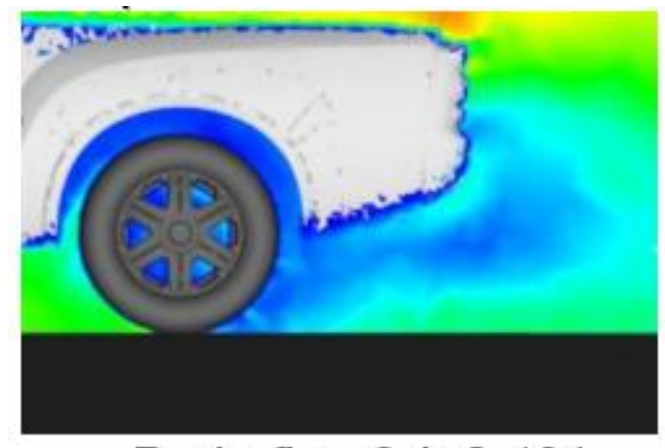

Roda fixa $\mathrm{Cd}=0,431$

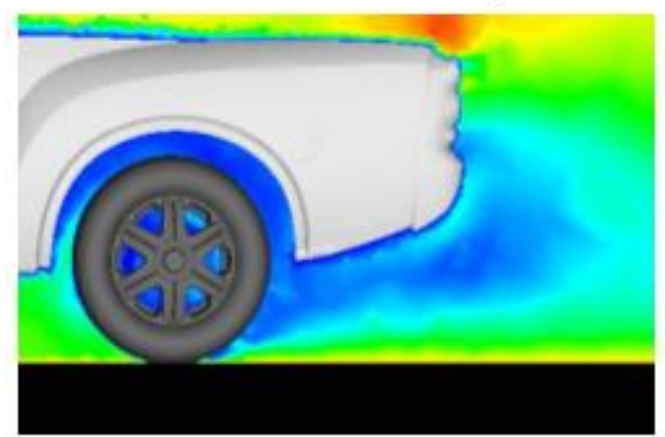

Esteira rolante $\mathrm{Cd}=0,419$

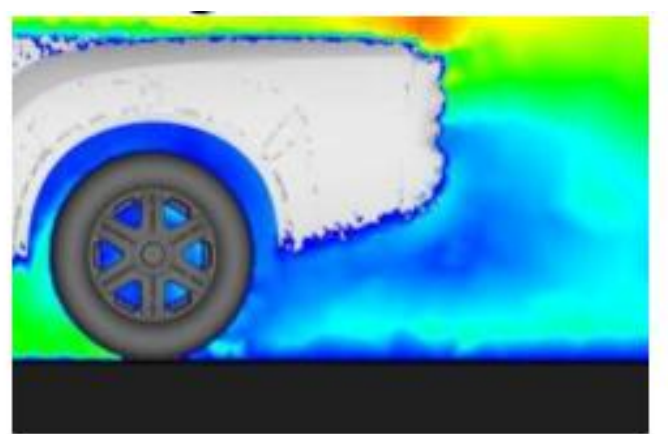

Plataforma elevada $\mathrm{Cd}=0,429$

velocity_magnitude $[\mathrm{m} / \mathrm{s}]$

$4.000 \mathrm{e}+001$

$3.000 \mathrm{e}+001$

$2.000 \mathrm{e}+001$

$1.000 \mathrm{e}+001$

$0.000 \mathrm{e}+000$

Figura 7.5 - Campos de velocidade no plano central à roda traseira.

Pode-se concluir que na região traseira há a maior diferença entre os casos, novamente destacando-se a inexistência de camada limite no solo o caso de roda fixa e evidente formação da mesma, no caso da plataforma elevada, tornando a região de velocidade próxima de zero maior que no primeiro caso e que no caso da esteira rolante. Neste último caso, a região é a menor, comparada com os casos anteriores e há uma região de velocidade de $30 \mathrm{~m} / \mathrm{s}$ próxima ao solo causada pelo movimento do solo e que é responsável por diminuir a região de baixa velocidade na região traseira do veículo.

Conclui-se portanto que o tipo de solo existente na seção de testes do túnel de vento exerce influência no coeficiente de arrasto para o veículo, e este efeito é causado principalmente pela influência do comportamento da 
camada limite desenvolvida no solo, na região das rodas sobre 0 escoamento na região entre o veículo e o piso.

Comparado com o modelo base, o qual possui solo fixo, a plataforma elevada consegue desenvolver uma nova camada limite mais próxima ao veículo, reduzindo o coeficiente de arrasto em 0,002, com as mesmas condições de teste, para o mesmo veículo, diferença pouco significativa.

Já a utilização de um mecanismo de esteira rolante no túnel virtual, representando a condição mais próxima da real para operação do veículo, considerando o movimento do solo relativo ao carro e as suas rodas girando, representou uma redução do arrasto em 0,012 para o valor do modelo com piso fixo e de 0,010 para o modelo com a plataforma elevada do solo do túnel. Essa diminuição do valor do coeficiente de arrasto pela mudança do tipo de solo do túnel possibilita aproximar o valor real do arrasto de um veículo.

Embora existam diversas soluções para a representação do solo em um túnel de vento, as que visam representar com maior exatidão a realidade, são as que possuem um elevado custo de implantação. A solução do solo fixo é a solução mais simples, que pode ser combinado com um sistema de sucção, além de apresentar menor custo de implantação e manutenção. A alternativa da plataforma elevada necessita de uma plataforma, localizada acima do nível do solo da seção de teste do túnel, atuando de maneira similar ao piso fixo, com a diferença de ter uma influência menor da camada limite do solo estático. O conjunto que contempla um sistema de solo móvel, com conjuntos de esteiras, é o sistema que apresenta o maior custo de implantação e operação, devido a quantidade de sistemas envolvidos, mas é a solução que mais se aproxima a condição real de operação de um veículo. Por esse motivo, essa seria a condição mais favorável para a utilização em túneis de vento automotivos. 


\subsection{SUGESTÃO PARA NOVOS TRABALHOS}

É crescente uso de simulação para ajudar e dar suporte ao desenvolvimento em diversas áreas sejam elas em engenharia ou em variados outros campos, com o desenvolvimento de novos campos de atuação e pesquisa.

A área de aerodinâmica veicular vem utilizando cada vez mais as simulações tanto para redução de custos quanto para o desenvolvimento mais rápido de novos projetos, uma vez que, com o aprimoramento dos softwares de CFD comerciais, a confiabilidade se torna maior e a correlação com ensaios reais também.

Existem poucos trabalhos na área de verificação de coeficiente de sustentação em veículos por meio de simulações, sendo esta uma sugestão para próximos trabalhos. Além disso, outras alternativas de solo em túnel de vento podem ser estudadas usando simulação.

Há também a possibilidade de análise de ruído, medido os níveis que chegam até os passageiros do veículo utilizando tanto simulação quanto ensaios reais, em túnel de vento.

Uma outra possibilidade seria o ensaio de um modelo reduzido desse veículo no túnel de vento do IPT, visando comparação com os resultados de coeficiente de arrasto obtidos entre ensaio com escala reduzida, escala real e simulação. 


\section{REFERÊNCIAS BIBLIOGRÁFICAS}

A2WT . Mooresville (EUA). Apresenta recursos e atividades desenvolvidas. Disponível em: < http://www.a2wt.com>. Acesso em: 24 de janeiro de 2009.

BATISTA, M. R., Estudo Aerodinâmico do Carro de Economia de Combustível ECO-MACK, Trabalho de conclusão de curso em Engenharia Mecânica, Escola de Engenharia da Universidade Presbiteriana Mackenzie, São Paulo, 2007.

BEAUVIS, F. N.; TIGNOR, S. C.; TURnER, T. R., Problems of Ground Simulation in Automotive Aerodynamics, SAE Paper, 680121, Society of Automotive Engineers, Warrendale, Pa., 1968.

BOERMANS, L. L. M.; HEMERIK, J. P., CFD Analysis of a Solar Powered Car, Focalpoint, Vol. 10, Texas, EUA, 2006.

BRADSHAW, P.; MEHTA, R. D., Design Rules for Small Low-Speed Wind Tunnels, Aero Journal Royal Aeronautical Society, Vol. 73, p. 443, 1979.

CARRIL JÚNIOR, C. F., Projeto, Construção e Calibração de um Túnel de Vento, Dissertação de mestrado em Engenharia Mecânica, Escola Politécnica da Universidade de São Paulo, São Paulo, 1995.

CEBECCI, T.; Hirsh, R.S.; Keller, H. B.; Williams, P. G., Studies of Numerical Methods for the Plane Navier-Stokes Equations, Comp. Meth. in App. Mech and Eng., Vol. 27, 1981.

COGOTTI, A., Aerodynamic Characteristics of Car Wheels - Impacts of Aerodynamics on Vehicle Design, International Journal of Vehicle Design, SP3, 1983. 
DEFESABR. (Brasil). Apresenta recursos e atividades desenvolvidas. Disponível em: < http://www.defesabr.com/Tecno/tecno_simuladores.htm> Acesso em: 10 de janeiro de 2008.

DNW (Deutsch-Niederisch Windkanal). Noordoostpolder (Holanda). Apresenta recursos e atividades desenvolvidas. Disponível em: < http://www.dnw.aero/home.aspx>. Acesso em: 23 de janeiro de 2009.

ELOFSSON, J. H..; BANNISTER, M., Drag Reduction Mechanisms Due to Moving Ground and Wheel Rotation in the Passenger Cars, SAE Paper, № 2002-01-0531, Society of Automotive Engineers, 2002.

FERZIGER, P.; PERIC, M., Computational Methods for Fluid Dynamics, $2^{\text {nd }}$ Edition, Springer-Verland, Germany 1999.

FISCHER, O.; KUTHADA, T.; WIEDEMANN, J.; DETHIOUX, P.; MANN, R.; DUNCAN, B., CFD Validation Study for a Sedan Scale Model in an Open Jet Wind Tunnel, SAE Paper, № 2008-01-0325, Society of Automotive Engineers, 2008.

FKFS (Forschungsinstitut für Kraftfahrwesen und Fahrzeugmotoren Stuttgart). Stuttgart (Alemanha). Apresenta recursos e atividades desenvolvidas. Disponível em: <http://www.fkfs.de>. Acesso em: 30 de janeiro de 2009.

FLUENT 6.2., User's Guide, Fluent Inc., 2003.

HONDA WIND TUNNEL. Londres (Inglaterra). Apresenta recursos e atividades desenvolvidas. Disponível em: < http://www3.imperial.ac.uk/hondawindtunnel > Acesso em:17 de abril de 2008. 
HUCHO, W. H., Aerodynamics of Road Vehicles, From Fluid Mechanics of Vehicle Engineering, $4^{\text {th }}$ Edition, SAE International, 1998.

HYPERMESH 7.0 User's manual Altair Computing, Inc., 2004.

KATZ, J., Race Car Aerodynamics: Designing for Speed, Bentley Publishers, 1995.

KELLY, K. B.; PROVENCHER, L. G.; SCHENKEL, F. K., The General Motors Engineering Staff Aerodynamics Laboratory - A full Scale Automotive Wind Tunnel, SAE Paper, № 820371, Society of Automotive Engineers, 1982.

KUZMANOV, T.; HARRIS, C. R., Hot Wire Velocity and Turbulence Data Acquisition at General Motors Aerodynamics Laboratory, GM Internal Report, 1993.

LAUNDER, B. E.; SPALDING, D. B., Lectures in Mathematical Models of Turbulence, Academic Press, London, England, 1972.

MAIABARA (Japão). Apresenta recursos e atividades desenvolvidas. Disponível em: <http://www.rtri.or.jp>. Acesso em: 30 de abril de 2009.

MUNSON, B. R.; YOUNG, D. F.; OKIISHI T. H., Fundamentos da Mecânica dos Fluidos, Editora Edgard Blücher, São Paulo, 2004.

NASA (National Aero and Space Agency) (EUA). Apresenta recursos e atividades desenvolvidas. Disponível em: <http://www.nasa.gov>. Acesso em: 3 de abril de 2008. 
QUIM, N., Desenvolvimento de uma Metodologia de Simulação Aplicada ao Sistema de Arrefecimento Veicular, Dissertação de Mestrado em Engenharia Mecânica, Escola Politécnica da Universidade de São Paulo, São Paulo, 2007.

PATANKAR, S. V., Numerical Prediction of Tree-Dimensional Flows, in Studies in Convection: Theory Measurement and Applications. Academic Press, London, Vol.1, 1975.

PEREIRA, M. T., Túnel de Vento de Camada Limite Atmosférica Relatório Final, Projeto FAPESP, São Paulo, 2002.

PININFARINA. Torino (Itália). Apresenta recursos e atividades desenvolvidas. Disponível em: <http://arc.pininfarina.com/english.html>. Acesso em: 16 de abril de 2008.

PURDUE (Universidade Purdue). (EUA). Apresenta recursos e atividades desenvolvidas. Disponível em: <http://engineering.purdue.edu>. Acesso em: 30 de janeiro de 2009.

Relatório de Ensaio da caminhonete, Internal Report of Aerodynamic Test. Warren, 2007

RENN, V., GILHAUS, A., Aerodynamics of Vehicle Cooling Systems, Journal of Wind Engineering and Industrial Aerodynamics, Vol. 22, 1986.

SACOMANO FILHO, F. L., Projeto Básico de Aparato Experimental para a Simulação do Movimento Relativo Veículo-Solo em Túnel de Vento, Trabalho de conclusão de curso em Engenharia Mecânica, Escola Politécnica da Universidade de São Paulo, São Paulo, 2008. 
SCHLICHTING, H., Boundary Layer Theory, $7^{\text {th }}$ ed., McGraw-Hill, New York.,1979.

SINGH, R., CFD Simulation of NASCAR Racing Car Aerodynamics, SAE Paper, № 2008-01-0659, Society of Automotive Engineers, 2008.

SUMANTRAN, V.; SOVRAN, G., Vehicle Aerodynamics, SAE International, PT-49, 1996.

TENNEKES, H.; LUMLEY, J. L., A First Course in Turbulence, MIT Press, Cambridge, MA , 1972.

TGrid 3.6, User's Guide, Fluent Inc., 2004.

VERTEEG, H. K.; MALALASEKERA, W., An Introduction to Computational Fluid Dynamics - The Finite Volume Method, Addison Wesley Longman Ltda, 1995.

WÄSCHLE, A., The Influence of Rotating Wheels on Vehicle Aerodynamics - Numerical and Experimental Investigations, SAE Paper, № 2007-01-0107, Society of Automotive Engineers, 2007.

WÄSCHLE, A.; CYR, S.; KUTHADA, T.; WIEDEMANN, J., Flow around an Isolated Wheel - Experimental and Numerical Comparison of Two CFD Codes, SAE Paper, № 2004-01-0445, Society of Automotive Engineers, 2004.

WHITE, F., Fluid Mechanics - fouth edition, McGraw Hill, 1999

WIEDEMANN, J., The Influence of Ground Simulation and Wheel Rotation on Aerodynamic Drag Optimization - Potential for Reducing Fuel Consumption, SAE Paper, № 960672, Society of Automotive Engineers, 1996. 
WINDSHEAR Carolina do Norte (EUA). Apresenta recursos e atividades desenvolvidas. Disponível em: <http://www.windshear.com>. Acesso em: 30 de novembro de 2008. 
ANEXOS 


\section{ANEXO A - CONFIGURAÇÃO DO SOFTWARE FLUENT®}

O primeiro passo é fazer um upload do modelo gerado no software TGRID® no software FLUENT®, o qual irá resolver o fluxo de ar, mostrado na figura A.1. Uma vez que esse arquivo for carregado, o passo seguinte é colocar o modelo em escala, pois o software FLUENT® processa as dimensões na unidade de metros e nos modelos configurados anteriormente, a unidade utilizada, tanto pelo T-GRID® quanto pelo HYPERMESH®, é o milímetro.Este processo pode ser visto na figura A.2.

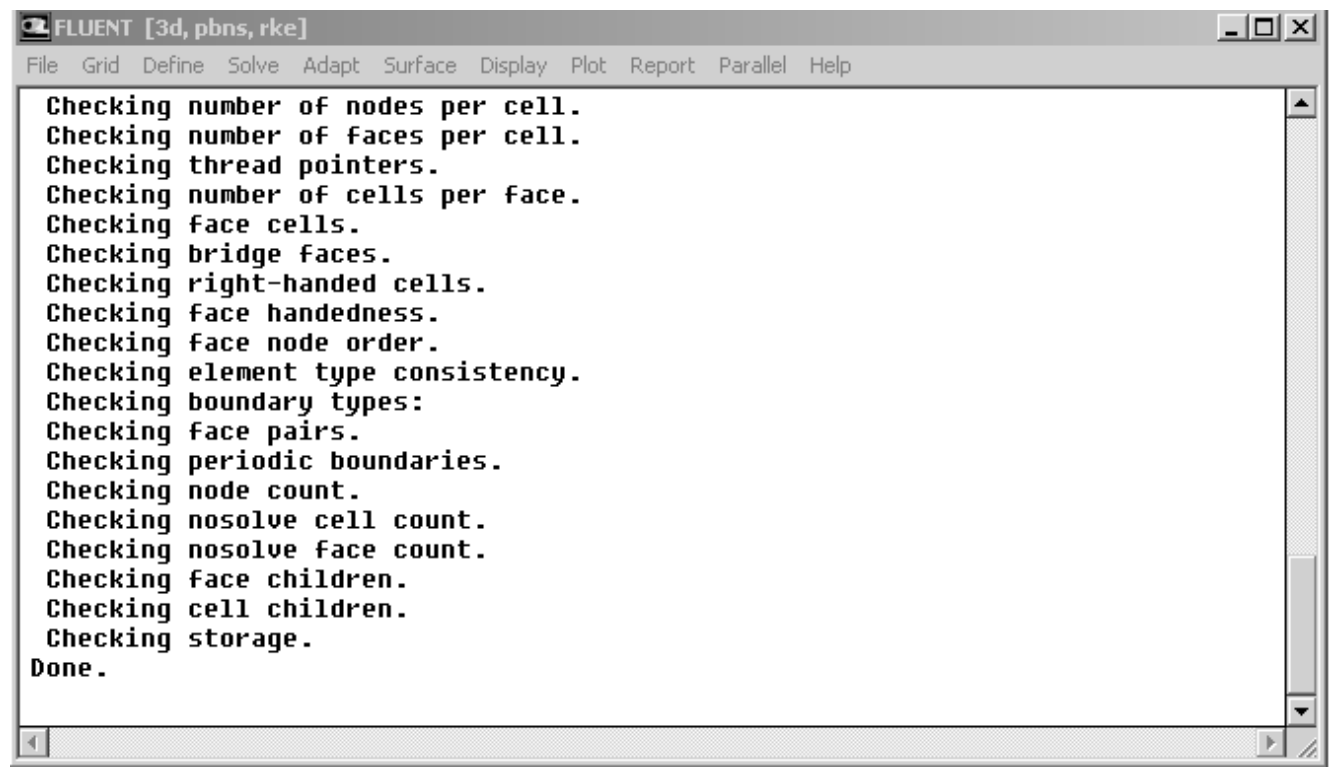

Figura A.1 - Interface do software FLUENT®. 


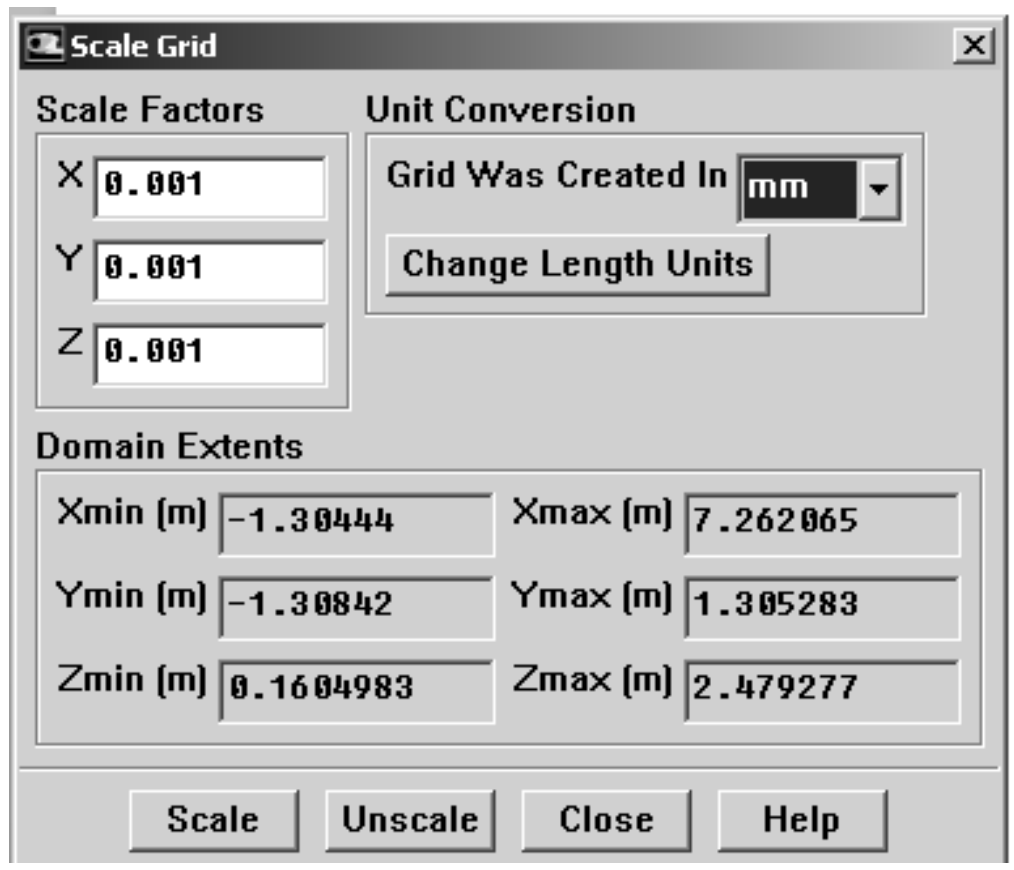

Figura A.2 - Função de escala, dada em milímetros, no menu Grid, do FLUENT®.

O próximo passo é programar o tipo de simulação que será em "Steady State", ou seja, em estado permanente não-transitório, enquanto os demais parâmetros são mantidos padrão do software. Esta função fica no menu Define - Solver, mostrada nas figuras A.3 e A.4.

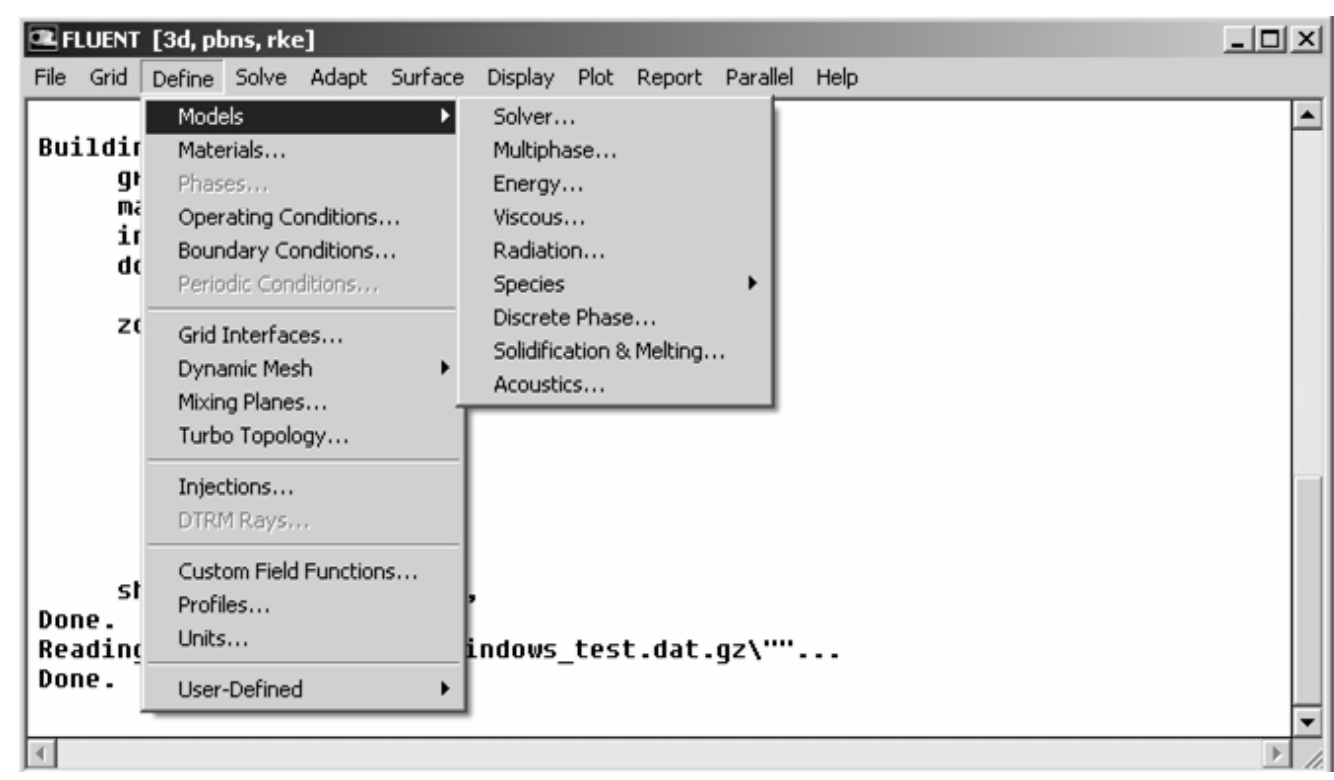

Figura A.3 - Função Define - Models do FLUENT®, onde o tipo de simulação será selecionada. 


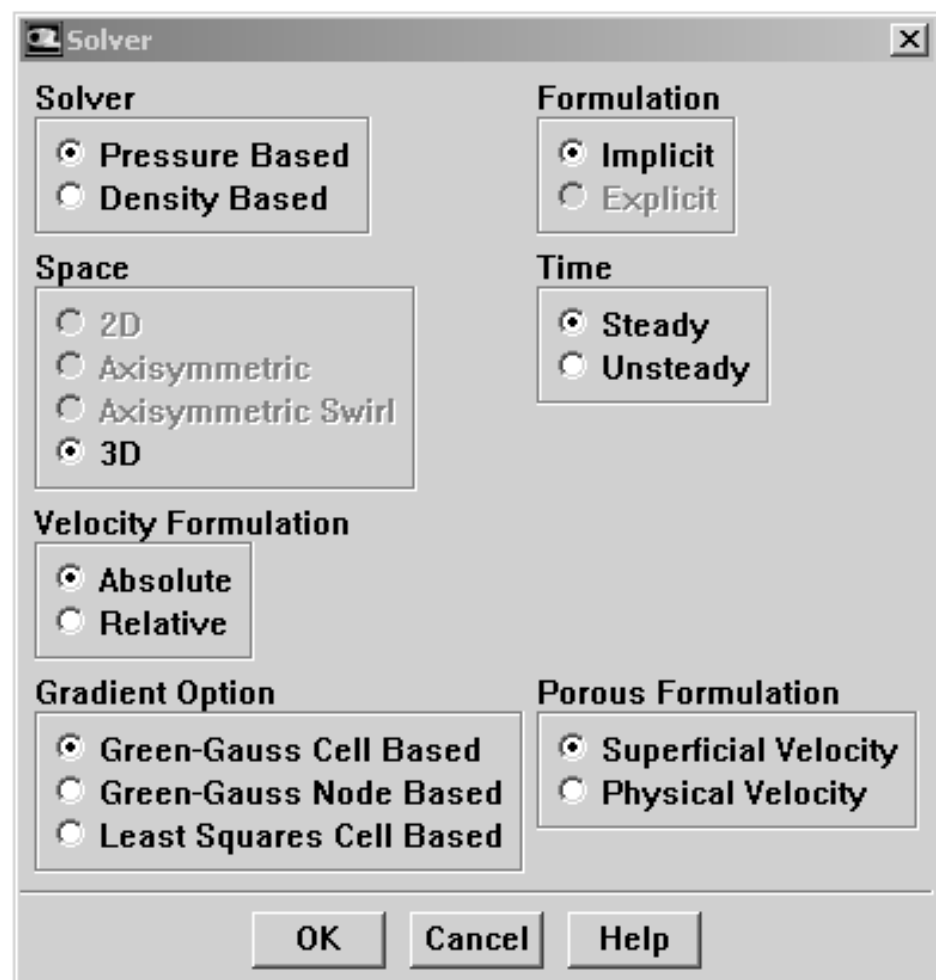

Figura A.4 - Menu Solver, onde os parâmetros são mantidos padrão do software, com solução do tipo Steady State no software FLUENT®.

Em seguida, o modelo para consideração de turbulência deve ser configurado e especificado para que o software consiga calcular todas as equações, mostrado na figura A.5. O software FLUENT possui diversos modelos de turbulência em seu banco de dados, embora o modelo utilizado neste trabalho será o $\mathrm{k}-\varepsilon$, modelo amplamente utilizado em engenharia, previamente detalhado no capítulo 4. 


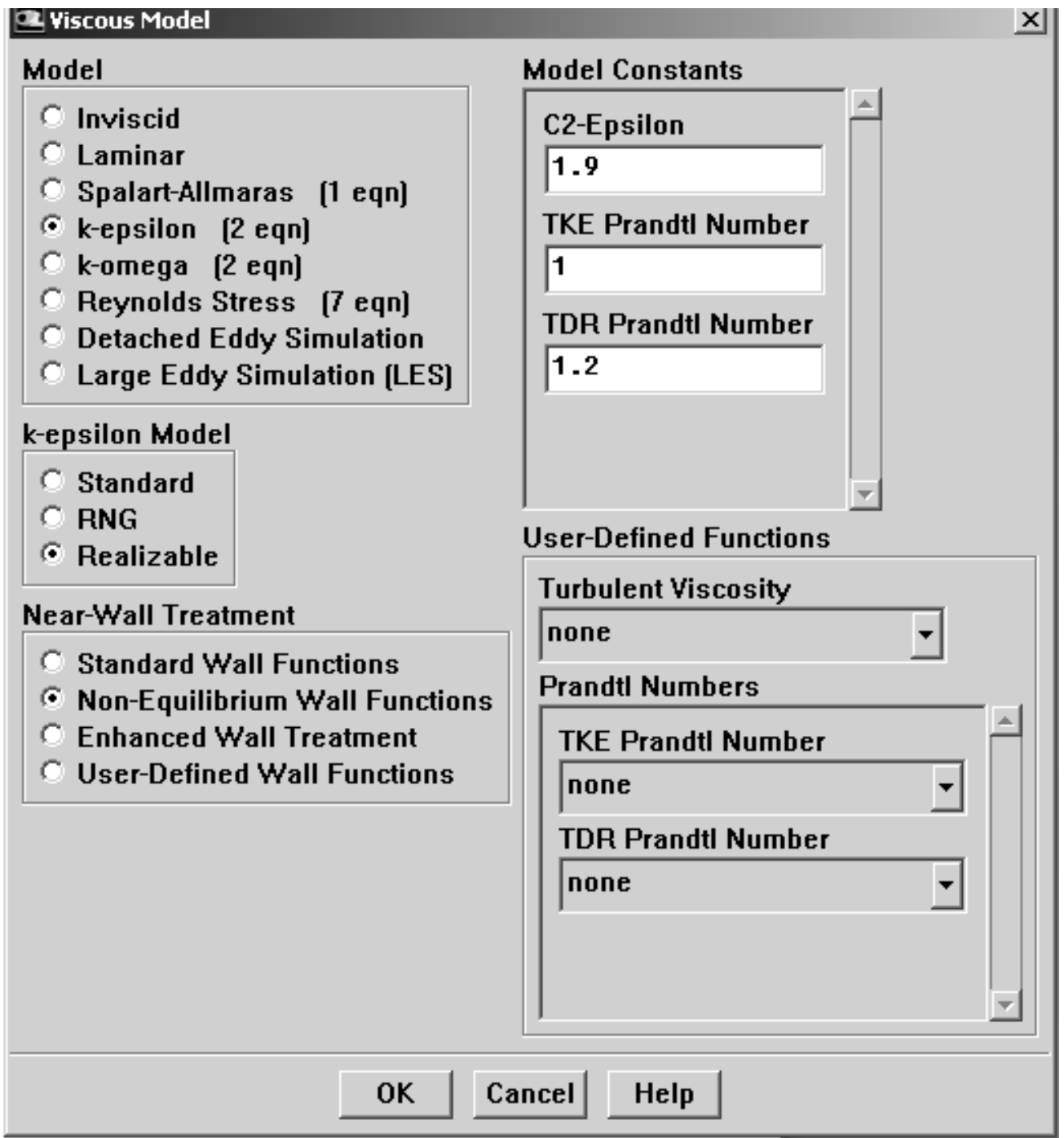

Figura A.5 - Menu Viscous Model, onde os parâmetros de turbulência k-є serão configurados.

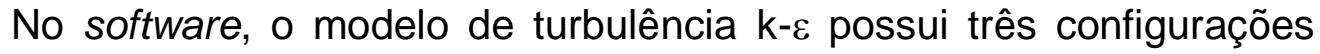
diferentes: Standard, RNG e Realizable. Segundo FLUENT®, o modelo k- $\varepsilon$ Realizable possui a formulação mais nova para cálculo da viscosidade turbulenta, além de conseguir descrever com maior precisão regiões de descolamento, representa com maior exatidão escoamentos com camada limite sujeita a diversos gradientes de pressão diferentes. Essa condição é semelhante ao escoamento ao redor de um automóvel, segundo Hucho (1988). 
Já no caso das paredes do veículo, foram definidas como paredes estacionárias com a condição de aderência, utilizando a função padrão de parede "Non-Equilibrium Wall Function".

O solver utiliza a formulação de Launder e Spalding (1972) para a resolução da turbulência na parede. Além disso, ele consegue determinar as forças reativas nas paredes, gradientes de pressão, além do efeito da camada limite sobre o veículo. Essa formulação é recomendada para escoamentos complexos que envolvam separação e outros efeitos, segundo FLUENT.

O passo seguinte é a configuração do ar como elemento fluido a ser utilizado nessa análise, aplicando suas propriedades nos elementos tetraédricos da malha volumétrica e mostrado na figura A.6.

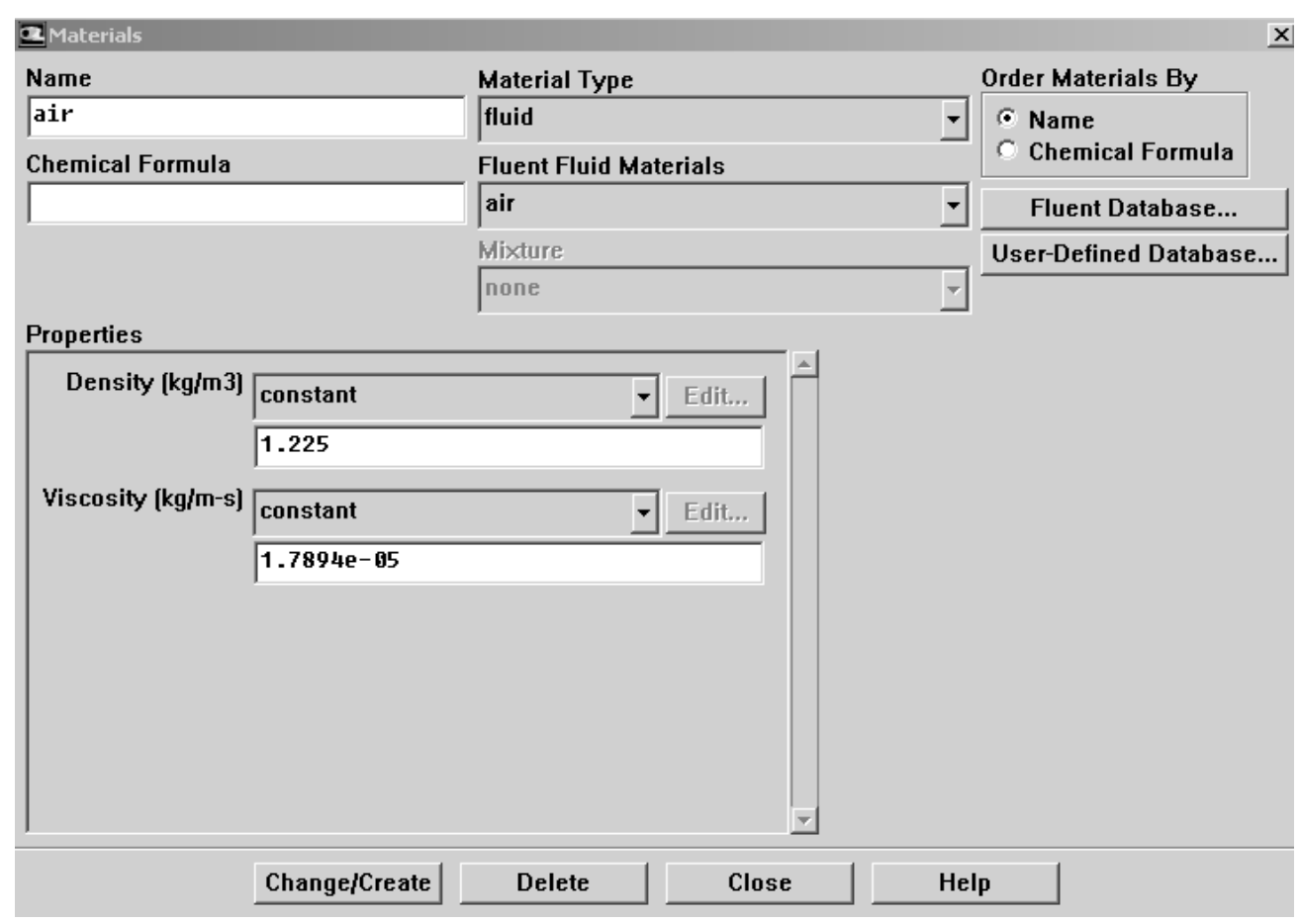

Figura A.6 - Menu Materials, onde o ar é colocado como elemento fluido do sistema a ser resolvido.

Com as condições do escoamento já aplicadas, deve-se configurar as condições de contorno, mostrado na figura A.8, onde devem ser fornecidas as condições de entrada, saída e paredes da seção de testes do túnel. Esses valores são provenientes de ensaios reais e reproduzidos no software, conforme mostrado abaixo na figura A.7. 


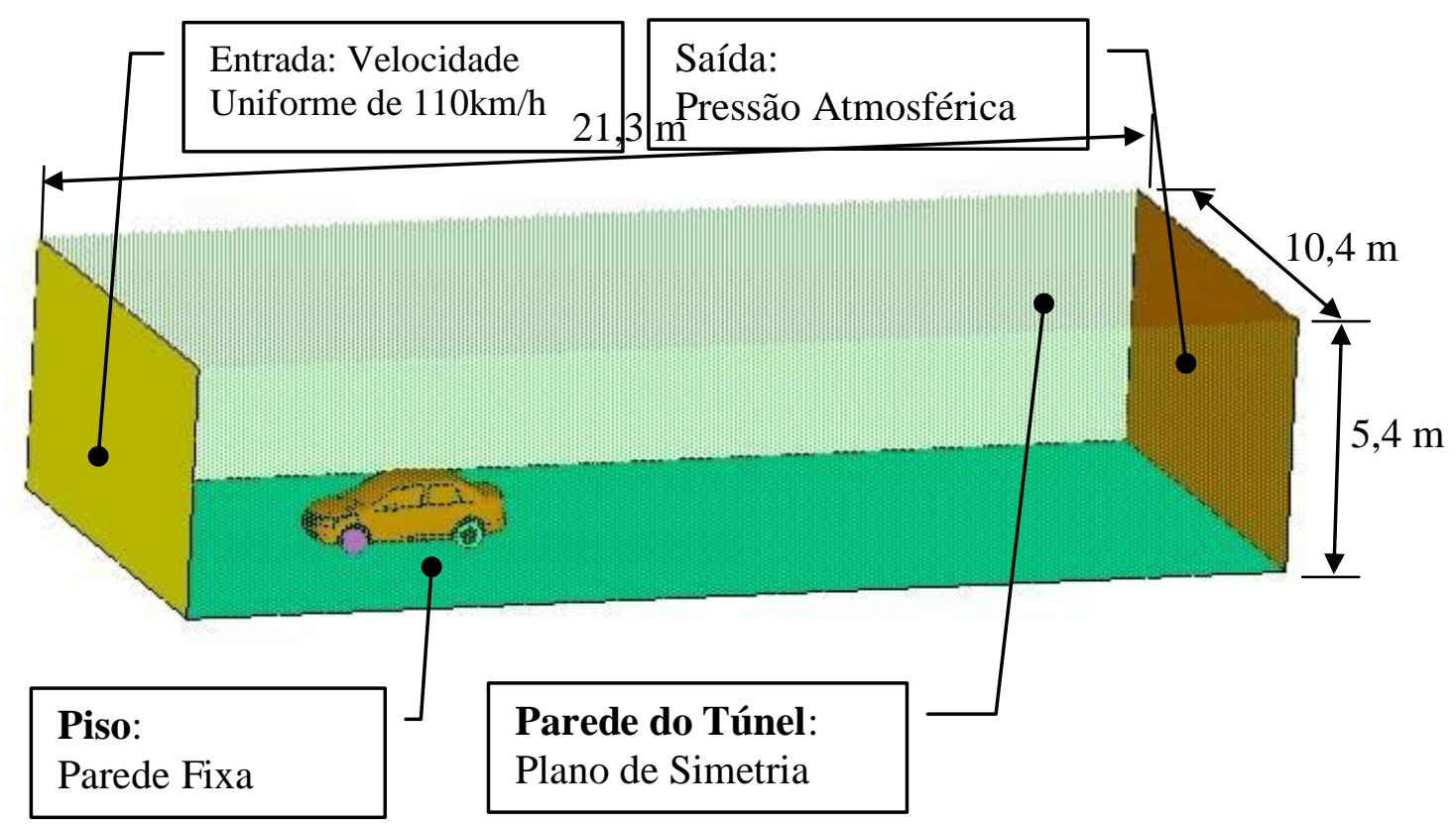

Figura A.7 - Condições de contorno do túnel de vento.

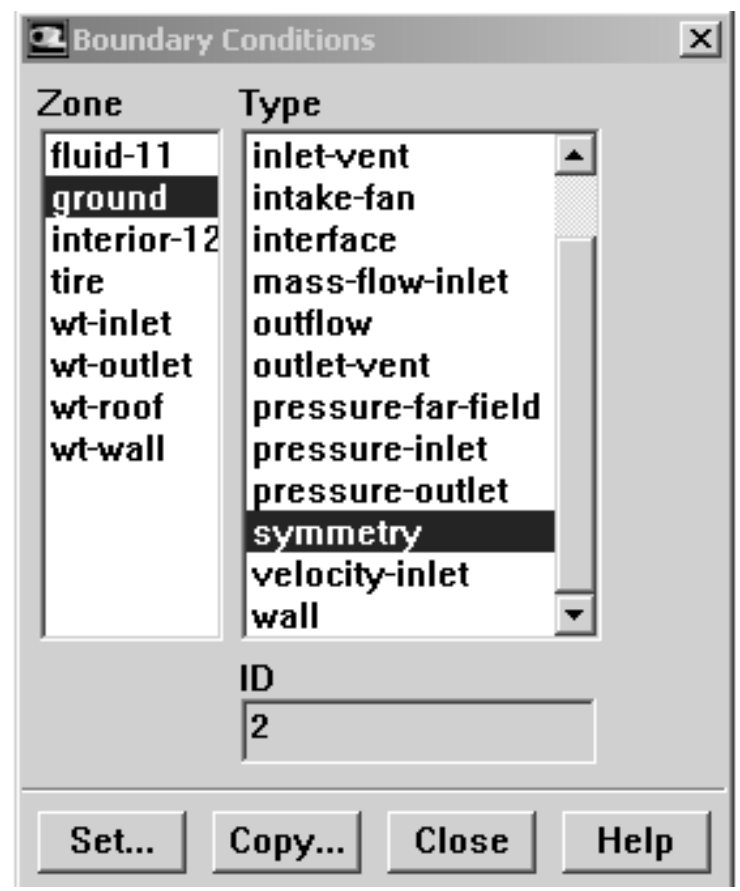

Figura A.8 - Configuração das condições de contorno da simulação no software.

A primeira condição a ser aplicada é a da entrada do escoamento na seção, ou seja, VELOCITY INLET, uma vez que se possui a velocidade na 
entrada, medida em ensaio. O fluxo entra com uma velocidade constante de $110 \mathrm{~km} / \mathrm{h}$ e o menu de configuração é mostrado na figura A.9.

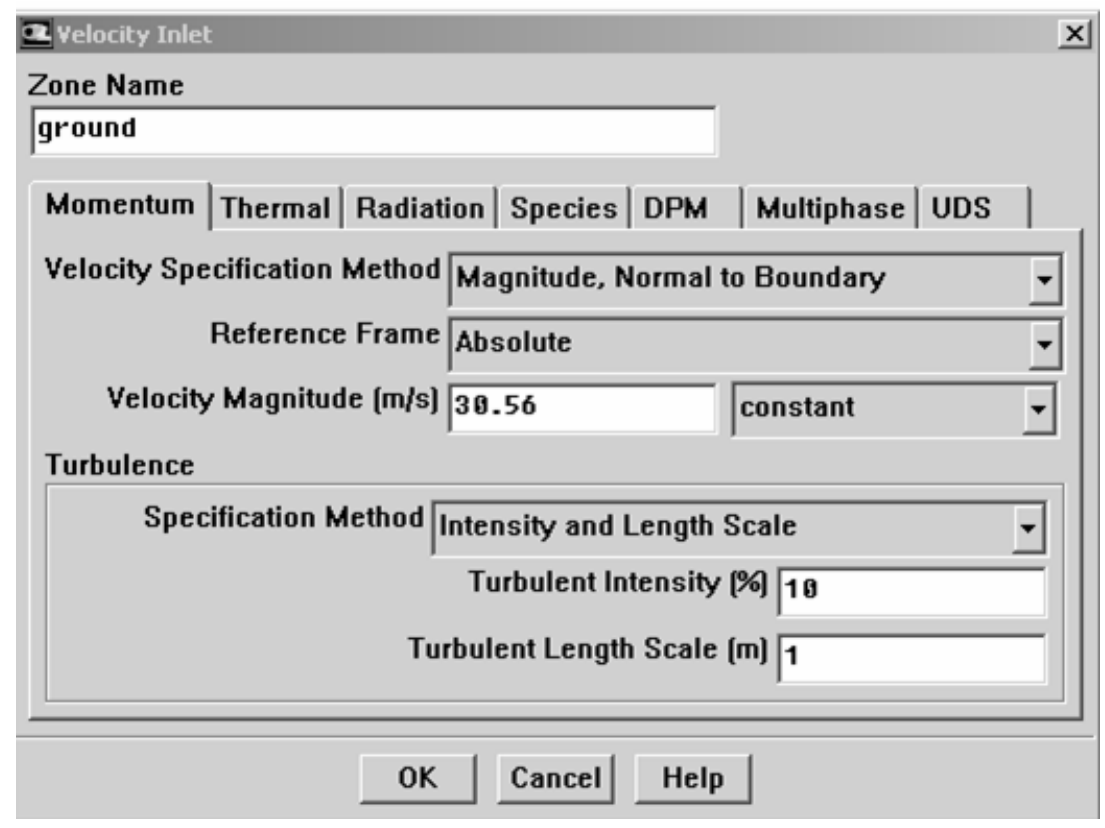

Figura A.9 - Configuração de condições de velocidade na entrada do túnel de vento

De acordo com os resultados de túnel de vento, os valores da intensidade turbulenta utilizada neste trabalho foram: $I=0.6 \%$ e diâmetro hidráulico (Dh) de $7 m$ segundo Kuzmanov (1993).

Para que 0 ar passe pela seção com a velocidade configurada na entrada e crie um fluxo constante, é necessário que a saída seja configurada como uma zona de pressão igual à atmosférica, ou seja, configurar como PRESSURE OUTLET, com pressão zero, simulando a saída de ar da seção de teste do túnel. O menu de configuração é mostrado na figura A.10. 


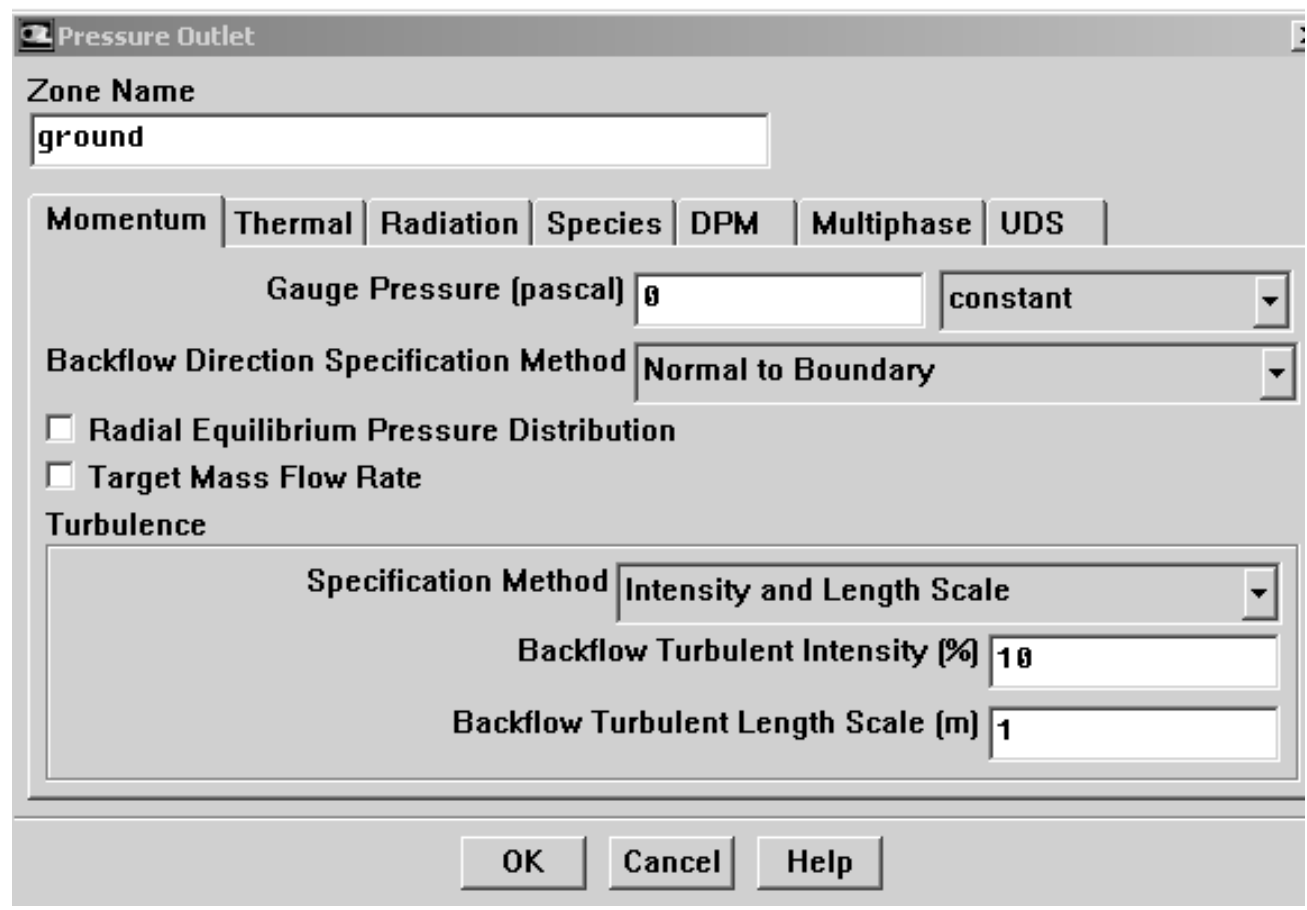

Figura A.10 - Configuração das condições na saída do túnel de vento

Para o piso do túnel, é considerado a condição de parede fixa, de forma a representar o sistema de simulação de solo fixo, semelhante ao encontrado no túnel de vento real.

Quanto às paredes laterais e ao teto do túnel, ambas foram consideradas como sendo planos de simetrias, devido as seguinte razão:

Como a seção transversal do túnel $A_{N}$ é muito maior que a área projetada do veículo $A$, a razão de bloqueio $\varphi$ será menor que 0,05 (HUCHO, 1998), o que significa que o efeito da camada limite na parede do túnel tem pouca influência no escoamento.

$$
\varphi=\frac{A}{A_{N}}=\frac{2,03}{56,16}=0,036
$$

Para o cálculo do arrasto pelo software, dois passos devem ser seguidos. O primeiro é selecionar todas as superfícies do veículo onde o ar tenha contado, para que ele possa calcular a pressão exercida pelo ar nessas partes, fornecendo assim, o valor do arrasto. Essa operação é feita no menu SOLUTION - MONITOR - FORCES, mostrado na figura A.11. Para o cálculo do arrasto, a função "drag" deve ser selecionada. 


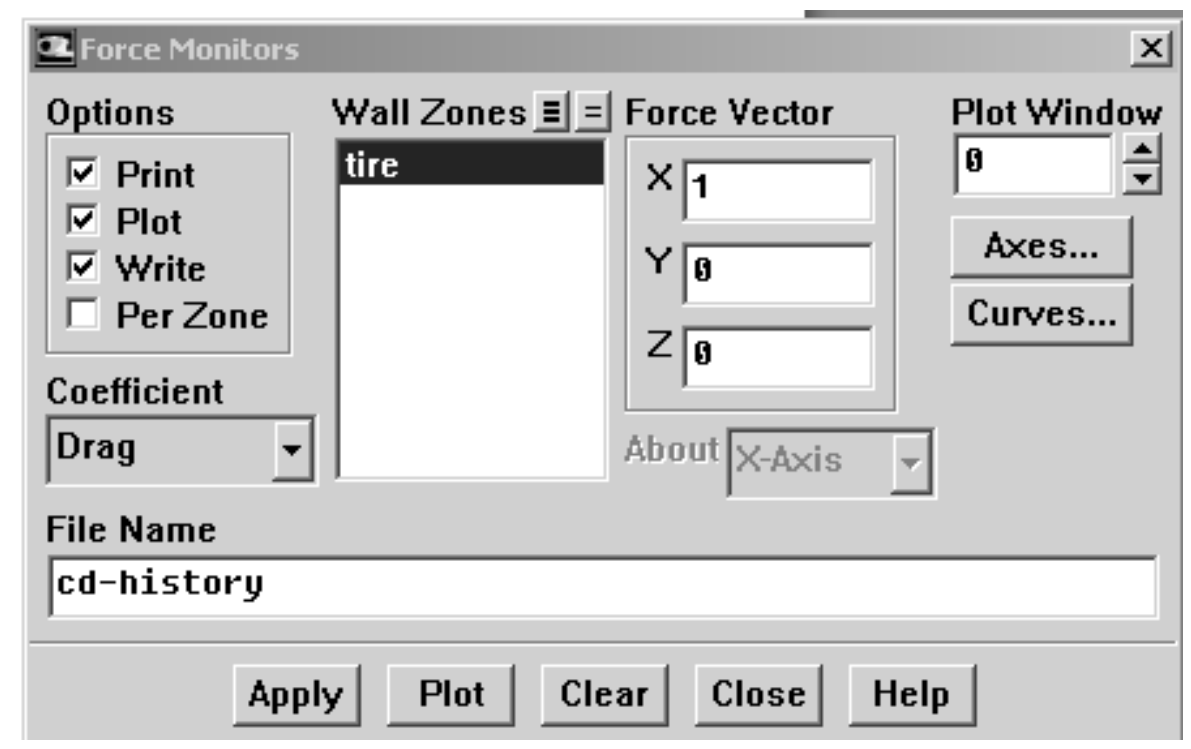

Figura A.11 - Configuração do software para cálculo do arrasto

O segundo passo é a identificação de dois parâmetros, no menu REPORT - REFERENCE VALUES. O valor da velocidade do escoamento, que no caso é $110 \mathrm{~km} / \mathrm{h}$, deve ser expresso em $\mathrm{m} / \mathrm{s}$ e o valor da área frontal do veículo, área projetada no mesmo plano da entrada da seção de teste do túnel, devem ser preenchidos, conforme figura A.12. 


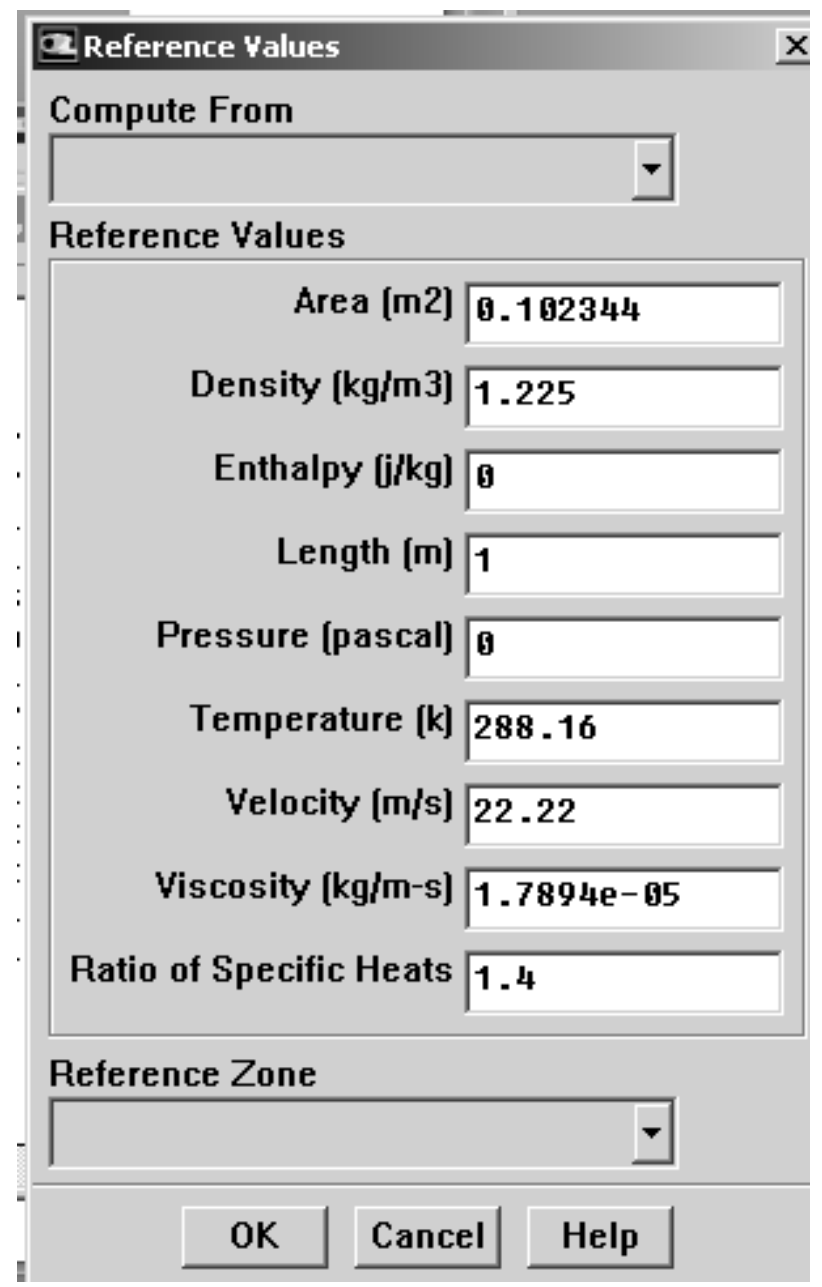

Figura A.12 - Configuração do valores necessário para o cálculo.

O cálculo da área frontal do veículo é feito pelo próprio software FLUENT®, no menu REPORT- PROJECTED AREAS, geralmente com alto grau de precisão, a qual depende do modelo utilizado e mostrado na figura A.13. O veículo utilizado neste trabalho tem área frontal de $2,03 \mathrm{~m}^{2}$, detalhado na figura A.14, calculado tanto por software como em medição real. 


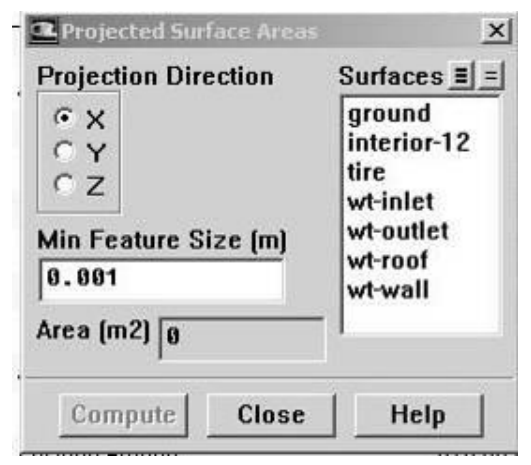

Figura A.13 - Função para cálculo de área projetada, no próprio software FLUENT®.

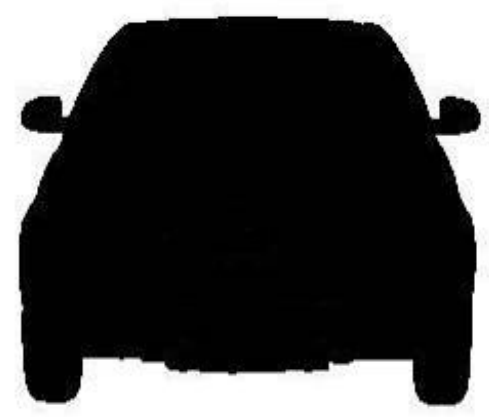

$$
y \rightarrow x
$$

Figura A.14 - Projeção do veículo ensaiado no mesmo plano da entrada da seção de teste do túnel de vento para cálculo de sua área frontal pelo software FLUENT®

Existe ainda uma função para monitorar a convergência da simulação, durante as diversas iterações. Monitora-se quanto a convergência a equação da continuidade, velocidade em X, Y e Z e parâmetros de $k$ e $\varepsilon$. Esta função fica localizada no menu Solver - Monitor Residuals, mostrado na figura A.15. Para a convergência do modelo o critério de convergência é da ordem de 1e-05 para todos os fatores. 


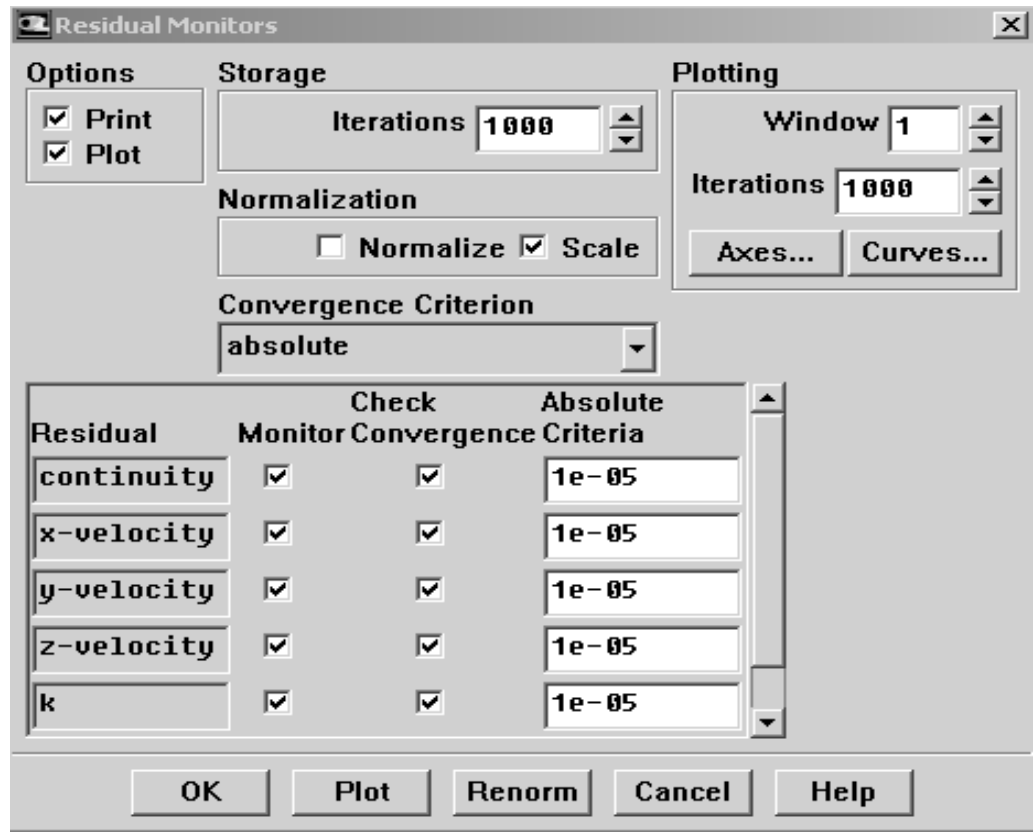

Figura A.15 - Monitoramento dos diversos parâmetros quanto a sua convergência no FLUENT®.

O último passo é configurar o modelo para que o software compreenda que o fluxo de ar inicie a partir da entrada a seção de testes, previamente denominada como VELOCITY INLET, com os parâmetros do ensaio real. Essa função é feita a partir do menu Solve - Initialize, mostrado na figura A.16.

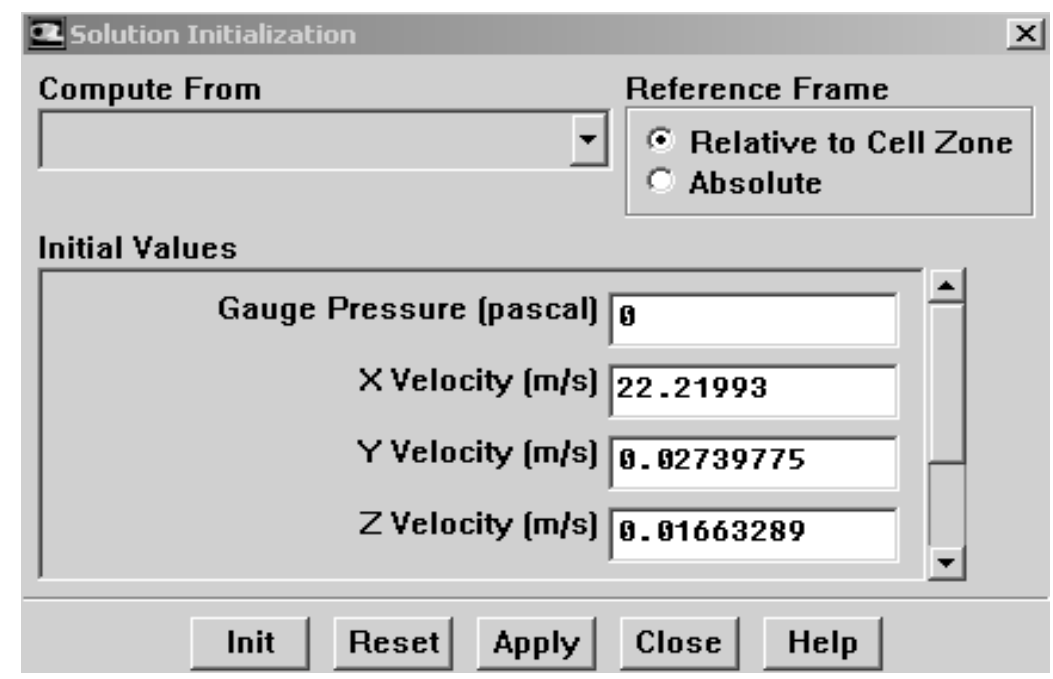

Figura A.16 - Inicialização do fluxo de ar, pela entrada do túnel do FLUENT®

Após esses passos, o modelo está pronto e configurado, para iniciar a simulação que será processada em um cluster com diversos processadores 
em paralelo, visando resolver todas as equações do fluxo de ar e obter o arrasto do veículo. Neste trabalho, o um cluster com 32 processadores é utilizados para todos os cálculos de simulação presentes neste trabalho. Serão feitas 800 iterações em primeira ordem e 2500 em segunda ordem para garantir uma boa convergência, segundo ANSYS. Essa ordem para o cluster é enviada por meio de um script programado na linguagem de programação TCL. (VIDE Anexo B)

As equações continuarão sendo resolvidas por meio de diversas iterações até que ele atinja o critério de convergência, ou seja, uma variação mínima pré-determinada, seja atingida. O gráfico de convergência do modelo analisado se encontra na figura A.17.

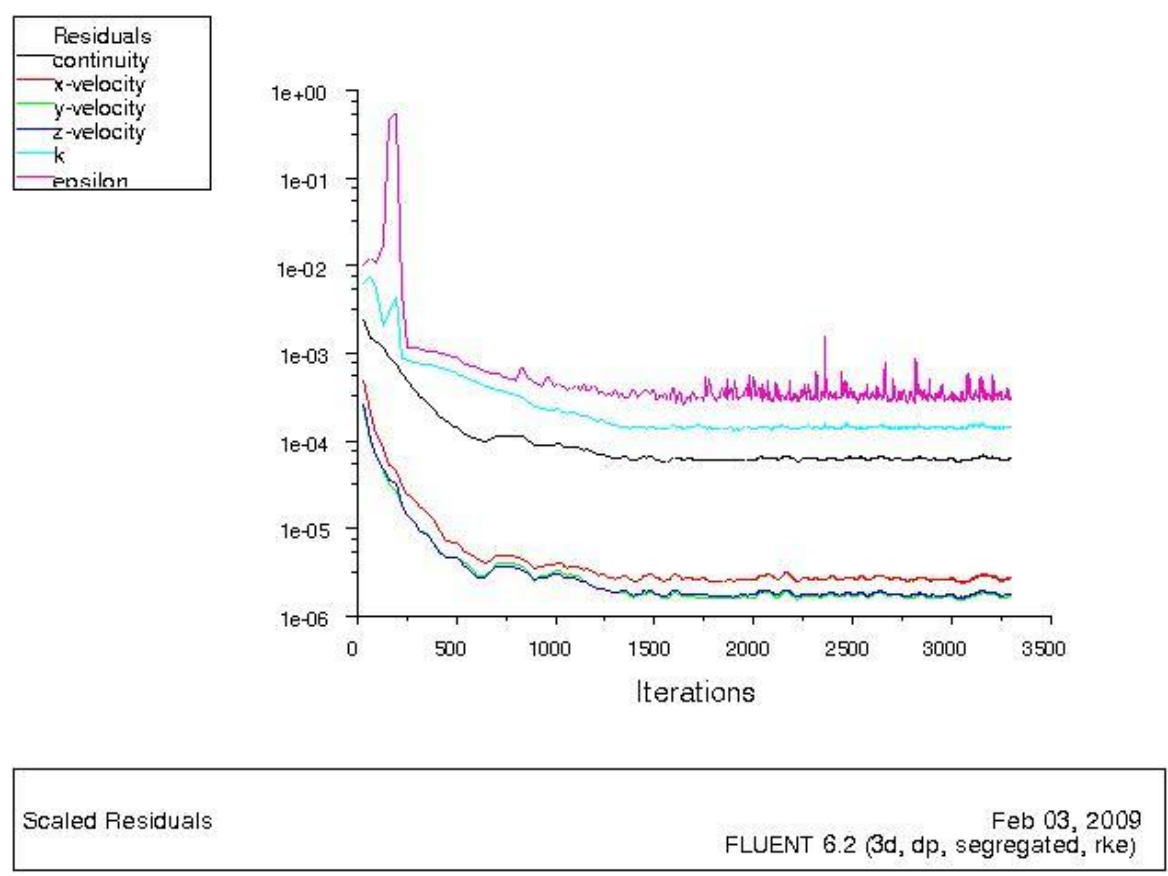

Figura A.17 - Gráfico da convergência da simulação.

Uma vez o modelo tenha estabilizado e convergido, é possível obter, além do valor do arrasto, o contorno de velocidade, pressão, intensidade de turbulência na região da roda do veículo, entre outros parâmetros. Essa etapa de pós-processamento dos resultados é feita no próprio software FLUENT®, utilizado para configuração inicial do modelo. 


\section{ANEXO B - SCRIPT PARA SIMULAÇÃO EM CLUSTER}

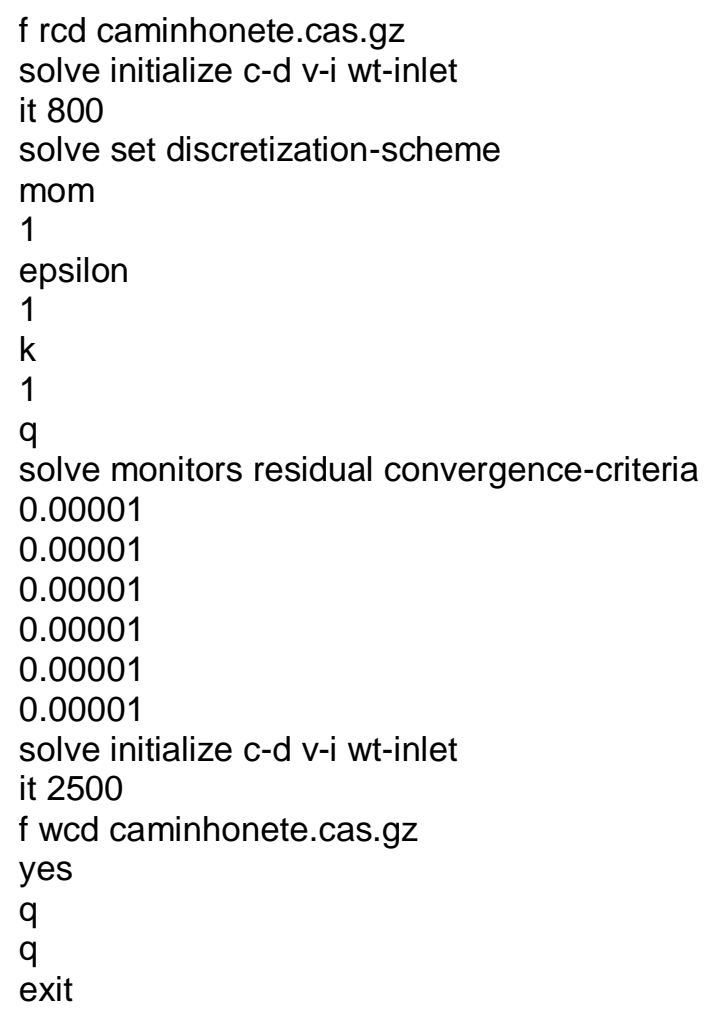

